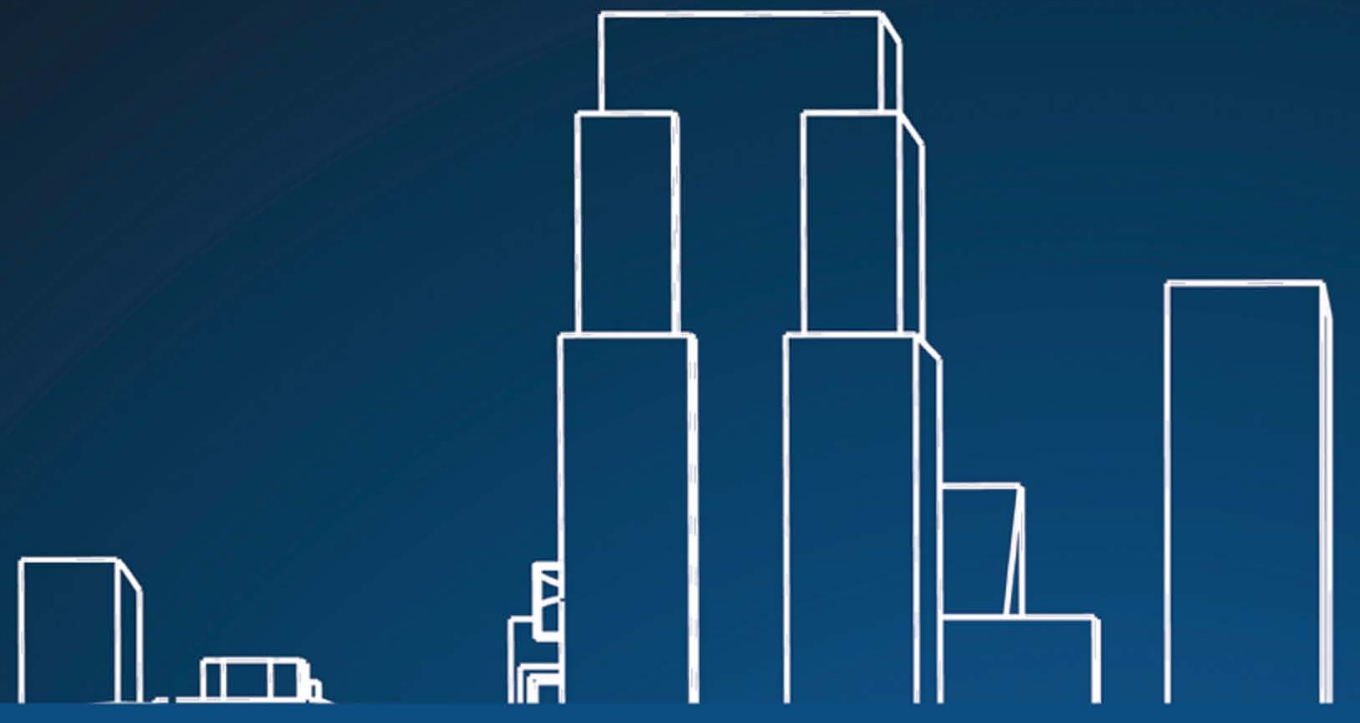

Routledge Studies in Policing and Society

\title{
CRIMINAL FUTURES
}

\section{PREDICTIVE POLICING AND EVERYDAY POLICE WORK}

Simon Egbert and Matthias Leese

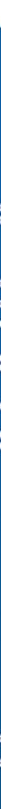


This timely book presents rare ethnographic data within an outstanding analysis of current debates on predictive policing. Conceptualising predictive policing as a sociotechnical system, the book describes various translation processes that lay bare the political, cultural and organizational forces at work. This welcome book sets the standards for future research on data-driven policing.

一Janet Chan, Professor, UNSW Law

Wary of simplistic dystopia/utopia dichotomies, Criminal Futures offers a theoretically sophisticated and empirically rich account of predictive policing as a sociotechnical process. This is a landmark study, providing frameworks and analytical tools for understanding - and responding to - the rapid datafication of security that is unfolding.

—Dean Wilson, Professor of Criminology, University of Sussex 
$\because$ Taylor \& Francis

Taylor \& Francis Group

http://taylorandfrancis.com 


\section{Criminal Futures}

This book explores how predictive policing transforms police work. Police departments around the world have started to use data-driven applications to produce crime forecasts and intervene into the future through targeted prevention measures. Based on three years of field research in Germany and Switzerland, this book provides a theoretically sophisticated and empirically detailed account of how the police produce and act upon criminal futures as part of their everyday work practices.

The authors argue that predictive policing must not be analyzed as an isolated technological artifact, but as part of a larger sociotechnical system that is embedded in organizational structures and occupational cultures. The book highlights how, for crime prediction software to come to matter and play a role in more efficient and targeted police work, several translation processes are needed to align human and nonhuman actors across different divisions of police work.

Police work is a key function for the production and maintenance of public order, but it can also discriminate, exclude, and violate civil liberties and human rights. When criminal futures come into being in the form of algorithmically produced risk estimates, this can have wide-ranging consequences. Building on empirical findings, the book presents a number of practical recommendations for the prudent use of algorithmic analysis tools in police work that will speak to the protection of civil liberties and human rights as much as they will speak to the professional needs of police organizations.

An accessible and compelling read, this book will appeal to students and scholars of criminology, sociology, and cultural studies as well as to police practitioners and civil liberties advocates, in addition to all those who are interested in how to implement reasonable forms of data-driven policing.

Simon Egbert is a postdoc researcher at the Department of Sociology, Technische Universität Berlin. Trained in sociology and criminology, his research interests include science and technology studies, security studies, sociology of prediction, time studies, discourse theory, visual knowledge studies, and sociology of testing. He has published papers on predictive policing, drug testing, lie detection, and ignition interlock devices.

Matthias Leese is Senior Researcher for governance and technology at the Center for Security Studies, ETH Zurich. His research is primarily interested in the social effects produced at the intersections of security and technology. It pays specific attention to the normative repercussions of new security technologies across society, in both intended and unintended forms. His work covers various application contexts of security technologies, including airports, borders, policing, and R\&D activities. 


\section{Routledge Studies in Policing and Society}

Series Editors

Jenny Fleming, University of Southampton, UK

Jennifer Wood, Temple University, USA

Routledge Studies in Policing and Society aims to establish an inter-disciplinary, international intellectual space of original contributions to either classic or emerging debates about the nature and effects of policing in society. The works in this series will advance our theoretical, methodological and/or empirical knowledge of policing in various societies across the world. It is the hope of the series editors that the works in this series will help fill gaps in our global understanding of policing and society.

\section{Criminal Futures}

Predictive Policing and Everyday Police Work

Simon Egbert and Matthias Leese 


\section{Criminal Futures}

Predictive Policing and Everyday Police Work

Simon Egbert and Matthias Leese 
First published 2021

by Routledge

2 Park Square, Milton Park, Abingdon, Oxon OX14 4RN

and by Routledge

52 Vanderbilt Avenue, New York, NY 10017

Routledge is an imprint of the Taylor \& Francis Group, an informa business

(C) 2021 Simon Egbert and Matthias Leese

The right of Simon Egbert and Matthias Leese to be identified as authors of this work has been asserted by them in accordance with sections 77 and 78 of the Copyright, Designs and Patents Act 1988.

The Open Access version of this book, available at www.taylorfrancis. com, has been made available under a Creative Commons Attribution-Non Commercial-No Derivatives 4.0 license.

We acknowledge support by the Open Access Publication Fund of Technische Universität Berlin, as well as by the Center for Security Studies, ETH Zurich.

Trademark notice: Product or corporate names may be trademarks or registered trademarks, and are used only for identification and explanation without intent to infringe.

British Library Cataloguing-in-Publication Data

A catalogue record for this book is available from the British Library

Library of Congress Cataloging-in-Publication Data

A catalog record for this book has been requested

ISBN: 978-0-367-34926-4 (hbk)

ISBN: 978-0-429-32873-2 (ebk)

Typeset in Bembo

by Apex CoVantage, LLC 


\section{Contents}

Preface

List of figures

viii

$\mathrm{x}$

1 Criminal futures 1

2 Predictive policing and its origins 19

3 The police and technology 44

4 Data and the need for speed 69

5 Humans and machines $\quad 94$

6 Putting risk on the map 116

7 Patrolling risk 145

8 Does it work, though? 164

9 “Bad" predictions 186

10 The future of (predictive) policing 206

$\begin{array}{ll}\text { Index } & 226\end{array}$ 


\section{Preface}

This book is the product of a windfall encounter. Each of us individually would have probably written a quite different book - or, even more likely, no book at all. We were lucky enough that our paths crossed at a workshop in Freiburg, Germany, in March of 2017. At the time, both of us had, independent of each other, only recently started to engage with predictive policing. The research outlines that both of us presented at that workshop were remarkably similar, and as it turned out during a couple of longer follow-up conversations, we were in fact interested in almost identical questions surrounding the use of algorithmic crime analysis software. There was a large overlap in the theoretical and conceptual literature that we had been reading. And we had at that point even started to interview some of the same police representatives and software developers.

The decision to join forces and proceed with our research together therefore only felt natural. Admittedly, conducting a multiyear qualitative research and writing project across a physical distance came with a set of challenges. In-person meetings were few and far between, so not only did the weekly coordination of activities have to be done via video-conferencing but also the coding and analysis of our empirical material, the interpretations of interview segments and ethnographic observations, debates about arguments, and so on. Matters were further complicated by the usual struggles of academic precarity: funding ran out, applications were written, and jobs and cities were changed. The book manuscript was finished from the confines of our homes, as the COVID-19 pandemic forced universities to shut down.

Three years after we first met at the said workshop, we are, however, more than happy with how things turned out. Almost needless to say, our professional relationship has turned into a friendship. And this book has offered us the opportunity to work through our empirical material at adequate length and in adequate depth. It will, so at least our modest hope, contribute some nuance to current debates about algorithms, data, and the prediction and prevention of crime.

Obviously, we could not have realized this book without the support of a number of people and institutions. First and foremost, although for reasons of 
anonymization we cannot do so by name, we must thank our research participants for sharing their thoughts, concerns, experiences, and daily work practices with us. We are aware that access to security agencies and their lifeworlds is not always easy. All the more do we appreciate the willingness of police departments and other predictive policing actors to support our research.

Over the years, our work has benefited from countless conversations with colleagues, whose generous engagement with our thoughts has continuously pushed the boundaries of our project. We would like to particularly highlight the support and feedback we received from John Austin, Myriam Dunn Cavelty, Dominik Gerstner, Jens Hälterlein, Lucas Introna, Mareile Kaufmann, Anna Leander, Thomas Linder, Monique Mann, Lars Ostermeier, Bettina Paul, Nikolaus Pöchhacker, Tobias Singelnstein, Dean Wilson, Aleš Završnik, and Nils Zurawski, as well as series editors Jenny Fleming and Jennifer Wood.

Last but not least, our work was to a large extent facilitated by the institutional support from our employers. The Universität Hamburg, the Technische Universität Berlin, and ETH Zurich provided us with the necessary freedom and financial means to finish our manuscript. Our appreciation goes to Susanne Krasmann, Ingo Schulz-Schaeffer, Andi Wenger, and Arnold Windeler. Additionally, Simon Egbert's contribution was partly financed by the Fritz Thyssen Foundation (grant number 10.16.2.005SO).

We would also like to extend our gratitude to Dominika Hadrysiewicz for her relentless assistance in administrative matters. Björn Ewert, Konstantin Gerlach, Sebastian Gülland, Annika Haller, Isabel Kenngott, Karolin Kornehl, Marcus Neuhold, and Anika Redmann have supported our work with research assistance. A special thanks to Gerard Holden for turning our scribbles into something readable and to Jess Phillips and Tom Sutton at Routledge for their guidance and excellent communication throughout the process.

Hamburg/Zurich, May 2020 


\section{Figures}

1.1 Predictive policing as a chain of translation 4

$\begin{array}{lll}5.1 & \text { Operator checklist } & 111\end{array}$

6.1 Different risk maps 118

$\begin{array}{ll}\text { 6.2 PRECOBS operator interface } & 126\end{array}$

6.3 Two PRECOBS memos 127

6.4 PRECOBS patrol handout 132

6.5 Screenshots from the Cantonal Police of Aargau app 136

6.6 Screenshot from the Cantonal Police of Aargau Facebook page 137 


\section{Chapter 1}

\section{Criminal futures}

In a commercial released in 2012, IT giant IBM shows us a criminal and a police officer on their journeys to the same convenience store. ${ }^{1}$ The dramaturgy of the scene leaves little doubt that the criminal's intention is to rob the place. The police officer, however, informed by the high-tech equipment installed in his patrol car, is already fully aware of what the criminal is up to and makes sure to arrive at the soon-to-be crime scene just before the offender. Waiting for him in the parking lot in front of the store with a cup of coffee, the police officer recognizes the criminal and raises his cup to him - and the latter, realizing that his plans have been anticipated before they could materialize, turns around and leaves empty-handed. Has a brave new world of policing arrived? Obviously, the logic of a commercial is to attract attention, and IBM's techno-utopian story of data-driven crime prevention should thus be taken with a grain of salt. Yet it gives us a good impression of the general idea behind predictive policing: to anticipate crime and to be able to implement operational measures that deter offenders and prevent the anticipated crime from happening.

Fast-forward to summer of 2016. It is a quiet Monday morning in a Swiss police station. In a back office next to the control room, a police officer imports citywide data on residential burglaries from the weekend into a notebook computer, runs the crime analysis software PRECOBS (Pre Crime Observation System), and, after a couple of mouse clicks, creates graphically supported insights into areas where increased risk for follow-up incidents is estimated within the next 72 hours. The officer double-checks each of the algorithmically calculated alerts for plausibility by revisiting the underlying data and dismisses one alert that does not seem to meet the criteria: rather than professional offender behavior that could be part of a potential series of burglaries in the neighborhood, this one appears to be related to relationship troubles and is therefore likely a one-off event. He does, however, confirm the rest of the alerts, and for each of them, he produces a short memo that includes a map with a color-coded risk grid and a set of recommended operational measures. Finally, he forwards the memos to central planning and operations, from where they will be further disseminated to local police stations. Based on the algorithmic analysis of burglary data, police patrols will now pay extra 
attention to the areas identified, possibly conduct traffic controls, or check persons - hoping to potentially deter burglars from striking again or even catch them red-handed.

Clearly, there are some major discrepancies between the scenario presented by IBM and the actual practices of algorithmic crime prediction this book investigates. The most striking difference is that one of them targets the behavior of individual persons, and the other identifies specific spaces as particularly susceptible to criminal activity. These are fundamentally different approaches to predictive policing, and they rely on different theories, models, algorithms, and datasets. While it is true that particularly in the US (and other parts of the world with lenient data protection legislation), individual risk profiling is seen as a promising avenue toward the prevention of crime and violence, most currently used approaches to predictive policing are not concerned with persons. Instead, they target the distribution of criminal activity across time and space and seek to identify areas where there is an allegedly higher crime risk during certain periods. This is the type of predictive policing that this book engages with empirically.

A second major difference is the way in which technology is imagined to work. In the first scenario, predictive policing is presented to us as something that miraculously and invisibly operates in the background, thriving on automation and not necessarily requiring human intervention. The officer only needs to look at the screen in his patrol car to get precise information about a crime forecast, after which he can drive to the predicted crime scene where harm can then almost effortlessly be prevented from unfolding. In the real world, however, predictive policing is hard work. It requires coordinated efforts between different specialized police divisions, including the production and consolidation of crime data, the actual analytical process, the dissemination of results, resource management, and the implementation of operational prevention measures. And in the end, patrols might never even see a criminal, as the rationale of crime prevention is largely based on the logic of deterrence that is created by the visibility of the police in public space.

Is predictive policing not as sexy as it is at times presented then? We believe it very much is. Once we strip away any superficial science-fiction layers, predictive policing offers a window into the ongoing transformation of police work along the lines of digitization, data, and algorithms. An analysis of predictive policing allows us to gain insights into larger reconfiguration patterns that concern the relations between society, crime, and the police. Accordingly, this book is interested in practices of crime prediction and the changes in police work that emanate from the use of predictive policing software. It first and foremost provides an academic perspective on knowledge production and social order in a digital age. Just as well, however, it does also offer a civil liberties perspective on the undesirable societal effects that algorithmic analytics in police work can unfold. Last, but not least, from the angle of police professionals, it affords an opportunity to use insights from the study of predictive 
policing as a guide for a responsible implementation of data-driven tools that speaks to the protection of human rights as much as it speaks to the operational needs of police organizations.

Our study will inevitably debunk some of the grand claims with which the theme is associated. Contrary to the techno-utopian narratives that we often find in the statements of police managers, politicians, private companies, and - not least - the media, there is in fact little "Big Data", "artificial intelligence", or "real-time awareness" to be found in everyday crime prediction. Most approaches to predictive policing mobilize well-established criminological theories, are based on rather simple models and a limited amount of data points, and are interested in clear-cut and easily implementable forecasts that need not necessarily be "true" but merely accurate enough to inform operational measures.

Predictive policing is also not "new" in the sense of a disruptive innovation. It builds logically on several larger trajectories within police work, including crime analysis, the turn toward prevention and corresponding patrol strategies, and the mobilization of scientific methods and tools. Notwithstanding these lineages, predictive policing has the potential to reconfigure the ways in which the police constitute knowledge about the intricate relationships between society and deviant behavior. Algorithmic crime analysis tools represent a qualitative leap for the police, as they make it possible to go deeper into data, explore them in more systematic ways, produce situational insights much quicker, and - at least in theory - spark more dynamic and flexible operational measures. Predictive policing in this sense comes with the promise to restructure the use of resources in a more efficient fashion, geared toward targeted interventions in criminal activities as they unfold. And at the same time, it speaks very much to an increasing managerialism that forces public agencies to rationalize and optimize their activities, particularly in times of political and public pressure and budget cuts.

In order to understand the impact of predictive policing, we believe two things are necessary. First of all, we need to study algorithmic crime analysis not as an isolated technological artifact but as a sociotechnical practice. Predictive policing consists not only of software, algorithms, and data sources. While it is important to understand how data are turned into criminal futures, the question if and how predictive policing comes to matter in everyday police work hinges on how police departments incorporate algorithmic crime analyses into their organizational structures and occupational cultures and how they manage to turn them into operational measures. Predictive policing, as we will illustrate throughout this book, involves police officers, morning briefings, patrol cars, election campaigns, data protection, and gut feelings as much as it involves data and algorithms. Studying predictive policing as a sociotechnical system means to pay attention to a multiplicity of technical, human, organizational, cultural, political, ethical, legal, and - not least - economic elements that matter in the production and prevention of criminal futures. 


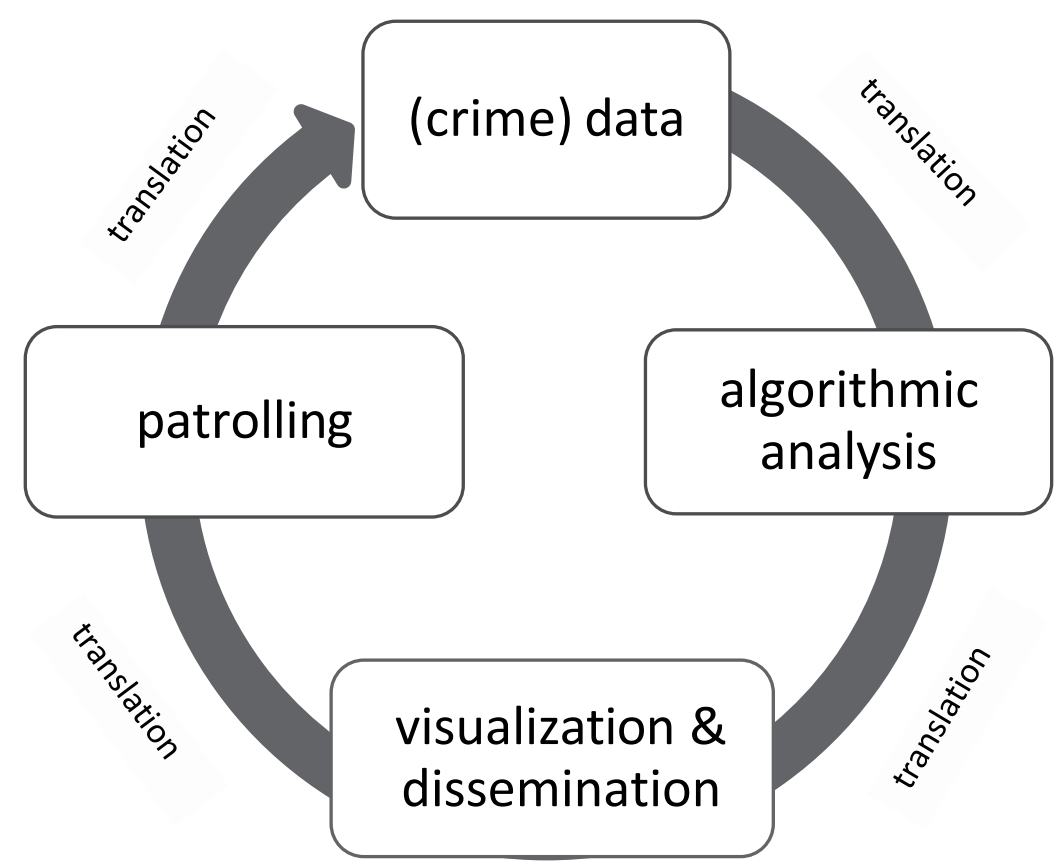

Figure 1.1 Predictive policing as a chain of translation

Predictive policing is, in its essence, about the question of how algorithms can direct the actions of patrol officers in the streets. In order to do so, it needs to align a variety of human and nonhuman elements. As Figure 1.1 illustrates, predictive policing includes a number of interrelated steps. It starts with the occurrence of crime and the data that the police create from and about crime. It continues with the analytical process during which the technical characteristics of predictive policing software come to matter as much as the question of how algorithms and humans work together and split tasks. Insights from the analytical process must subsequently be rendered intelligible and actionable and be disseminated across multiple specialized divisions until they can eventually inform patrol work. Finally, if predictive policing is to have an effect on the occurrence of crime, allegedly criminal futures must be acted upon by street patrols. The result of the predictive policing process is an altered criminal environment that forms the basis for new data creation and sparks the next iteration of the cycle.

Our analysis draws attention not only to these distinct steps, but just as well to what happens in the gaps between them. Predictive policing takes place in patrol cars just as much as it does at crime scenes where data are created, in the 
back office where risk estimates are produced, and in meetings where resources are coordinated and shifts scheduled. These different professional lifeworlds need to be connected, and their actors need to be aligned behind a common cause. Only then can knowledge and power be produced and travel through police organizations in order to inform the work of street patrols. Throughout this book, we will draw particular attention to the translation processes that bridge the gaps between different domains of police work. Translation is what brings criminal futures into being in everyday police work - and understanding translation work will allow us to situate how predictive policing comes to matter not only vis-à-vis the police themselves, but vis-à-vis society.

Second, in order to study how sociotechnical relations come into being and how such translation takes place, an empirical approach is paramount. Looking at policy-making, legal discourses, algorithms, or software interfaces will reveal important insights about some of the imaginaries that underpin predictive policing, but these insights will remain partial accounts if not properly contextualized within actual police practices. Sociotechnical systems, in other words, must be studied "in the wild" in order to account for the frictions, contradictions, appropriations, institutional learning processes, and general change that occurs with and through them. At the time of writing this introduction, few detailed studies that investigate these issues are available. Although predictive policing has more recently been one of the most prevalent topics in research on crime, (domestic) security politics, the police, and criminal justice, the studies by Manning (2008) on digital crime mapping and Brayne (2017, 2021) on policing and surveillance stand out as comprehensive accounts that empirically investigate how the police are attempting to venture into the future in order to tame it.

Other works that have already been published have studied the role of algorithms and data in the constitution of insecure and criminal futures (Amoore and Raley, 2017; Aradau and Blanke, 2017; Kaufmann, 2018, 2019; Kaufmann et al., 2019), often with a critical edge that foregrounds potential issues of discrimination, profiling, and social sorting vis-à-vis digitized and automated modes of policing (van Brakel and de Hert, 2011; Mantello, 2016; McCulloch and Wilson, 2016; van Brakel, 2016; Andrejevic, 2017; Ferguson, 2017; Sanders and Condon, 2017; Sanders and Sheptycki, 2017; Bennett Moses and Chan, 2018; Wilson, 2018; Završnik, 2019). These important literatures shed light on the ways in which data and algorithms can be mobilized in ways that create concerns from ethical and legal perspectives, and their warning calls resonate well within debates about how worrying developments in policing, law enforcement, and criminal justice might be curbed. Despite this, they tend to predominantly approach predictive policing from an exclusively technological vantage point that foregrounds the workings of algorithms while bracketing the "social side" of policing - that is, the organizational structures and everyday occupational practices and routines that shape how predictive policing comes to matter. 
There exists another body of work that foregrounds practical and policyoriented questions around predictive policing, for instance regarding best practices and optimal modes of implementing software tools (Beck and McCue, 2009; Pearsall, 2010; Perry et al., 2013; Babuta, 2017; Hardyns and Rummens, 2018). However, this "applied" literature is in most cases interested in solving taken-for-granted problems rather than in theoretically informed engagement with predictive policing and the wider implications that it holds for the ways in which the police produce and act upon criminal futures. Last, but not least, the current scholarly discourse on predictive policing is very US-centric, leading to an analytic overrepresentation of risk profiling approaches to predictive policing. With this book, we seek to address these gaps in the literature by providing a multiyear empirical case study of predictive policing in two European countries: Germany and Switzerland.

\section{Our study}

Conceptually building on sociological and criminological works that have investigated the implementation and use of information and communication technologies in police work and the frictions and transformations that these new tools undergo as they enter into institutional, organizational, and practical contexts (Marx, 1988; Ackroyd et al., 1992; Ericson and Haggerty, 1997; Chan, 2001; Manning, 2001, 2008), this book presents a detailed account of predictive policing as a sociotechnical practice of constituting and addressing criminal futures. The case selection - Germany and Switzerland - was, to a certain extent, dictated by the locations of our workplaces as well as by the fact that both of us are native German speakers. In Europe, German and Swiss police departments were, however, among the trailblazers that started experimenting with predictive policing early on (particularly the Zurich Municipal Police Department and the State Police Department of Bavaria). They therefore presented suitable research sites within a field that was still very much in its infancy and undergoing continuous changes during the period of our research (2016-2019), with regard to both technological development and organizational and operational implementation (Egbert, 2017; Seidensticker et al., 2018). Finally, a number of German and Swiss police forces (the state police departments of Bavaria and Lower Saxony and the cantonal police departments of Aargau, Basel-Land, and Zurich as well as the Zurich Municipal Police Department) opted to experiment or work with the same software tool (PRECOBS by German manufacturer IfmPt), thus enabling us to compare to a certain extent how predictive policing was beginning to take shape within different organizational contexts.

However, our empirical work should not be mistaken for a comparative investigation in a formalized sense. There was considerable variation in organization, resources, political context, strategic orientation, scope of predictive policing, and software use between the departments we studied. A large degree 
of this variation can be attributed to political structures. Both Switzerland and Germany are federally organized countries, in which the political competencies for domestic security are organized at state level (German Bundesländer, Swiss Kantone). This means that there may be considerable differences between even neighboring jurisdictions not only in terms of the government constellations and corresponding political programs that impact police competencies and budgets but also in terms of larger strategies of patrolling and crime prevention (Wilz, 2012). Against this backdrop, our study should be understood as a multisite perspective on predictive policing practices that provides in-depth empirical insights into the ways in which predictive policing reconfigures localized police practices (Maguire, 2018: 140).

We conducted empirical research with 11 police departments, four of them located in Switzerland (the cantonal police departments of Aargau, Basel-Land, and Zurich as well as the Zurich Municipal Police) and seven in Germany (the state police departments of Bavaria, Berlin, Baden-Württemberg, Hamburg, Lower Saxony, North Rhine-Westphalia, and Brandenburg). All these departments were, during the research period, either already using predictive policing software on a regular basis, running field experiments in order to determine whether to use and/or how to best implement predictive policing, or developing their own predictive policing tools. This fragmentation must be seen as a testament to the novelty of predictive policing at the time, with a lot of uncertainty surrounding key decisions such as whether to purchase off-theshelf commercial software or try to build custom-tailored tools in-house, how to fit algorithmic modes of data analysis into existing IT infrastructures, and how to accommodate special attention to risk areas within patrol practices.

As there is, as of the time of writing, only one commercial German-language predictive policing application available (PRECOBS), those police departments who decided not to develop their own in-house solution inevitably wound up with PRECOBS. In our case, six out of 11 departments used the software at some point between 2016 and 2019. Having been the first ready-to-use predictive policing tool on the market, PRECOBS was also used as a major reference point for the development of in-house software tools by other police departments. Although our empirical material includes several other predictive policing tools (KLB-operativ, KrimPro, PreMAP, SKALA), most technical references throughout this book relate to PRECOBS in either its first version (now called PRECOBS Classic) or the second iteration (PRECOBS Enterprise) that was rolled out in 2019.

PRECOBS primarily specializes in residential burglary prediction. Its theoretical model is predicated upon near-repeat victimization theory (Polvi et al., 1991; Farrell, 1995; Townsley et al., 2003). In simplified terms, PRECOBS computes risk estimates for residential burglaries based on "trigger incidents" that indicate a high likelihood of follow-up crimes in the spatial and temporal vicinity (i.e., "near repeats"). The underlying assumption is that domestic burglaries are mostly committed by professionalized serial offenders who identify 
profitable target neighborhoods, rationally assess the risk of detection and arrest, and in case of a positive cost-benefit ratio, strike multiple times within a short time period and move on to another neighborhood or city before the police can take countermeasures (Johnson et al., 2007; Farrell and Pease, 2014; Sidebottom and Wortley, 2016).

The rationale behind PRECOBS is to put the police in a position where they can identify ongoing burglary series and actively intervene in order to prevent further offences (Schweer, 2015; Balogh, 2016; Schweer, 2016). PRECOBS is thus a highly selective analytical tool, as it not only exclusively focalizes domestic burglary but also primarily targets a specific offender type (the professional serial burglar). The data analysis in the prediction process rests on relatively few data points. Usually these are the time of the incident, modus operandi, haul, type of housing, and street address and GIS coordinates of a burglary (Balogh, 2016: 336). Assuming that these characteristics are sufficient to identify trigger incidents within crime data, the software issues an alert that indicates increased crime risk for specific neighborhoods and time frames as soon as it detects a combination of predefined trigger criteria. What PRECOBS predicts, in a strict sense, is thus the replication of an already recorded criminal activity, which is extended along the dimensions of time and space.

Overall, the model as well as the algorithms applied here are arguably not very complex or advanced. On the contrary, it could be argued that the main contribution of PRECOBS is an automation of previously manually performed crime analysis. However, in doing so, it provides significant increases in speed and scale, enabling timely reactions to ongoing criminal activity that would not have been possible before. Whereas in the past, crime forecasts tended only to become available when they were already outdated, algorithmic crime analysis provides an opportunity to apply prevention strategies while a presumed burglary series is still active and the offender is looking to strike as many times as possible within a short time frame and within a small local radius. This knowledge, so the rationale, can then be used to maximize the effectiveness and efficiency of prevention measures (Okon, 2015; Schweer, 2015). The most important aspect of predictive policing is, in this sense, that it minimizes the time period between data collection, analysis, and the production of actionable intelligence, meaning that operational crime prevention measures can be implemented more quickly and in a more targeted fashion. Knowledge production and action must thereby not be understood as separate domains, but as closely entwined elements of the predictive policing process.

We opted to methodologically triangulate this process in our research through a combination of interviews, ethnography, and document analysis. First of all, we conducted a series of 62 qualitative, semistructured interviews. The majority of our interlocutors were police officers on the analytical, tacti$\mathrm{cal}$, and operational levels, thus covering all practical police levels of relevance for predictive policing (i.e., crime analysis, central planning and resource management, local police chiefs and shift supervisors, patrol forces). This was not 
always possible within each police department, but we were able to assemble cross-cutting perspectives from all relevant levels. Moreover, we spoke with senior officers who were responsible for the integration of predictive policing into their departments, including political, administrative, and managerial aspects. Last, but not least, we engaged with designers and programmers in order to incorporate the imaginaries and decisions that shaped algorithms, user interfaces, and modes of visual representation.

Second, we conducted focused ethnographies in order to understand the concrete ways in which predictive policing becomes a part of everyday police work. We were able to shadow crime analysts during their work with predictive policing software, and this gave us insights into the details of the crime analysis process and the challenges, insecurities, and contingencies that are attached to this process. We also had the opportunity to participate in an end-user meeting that was organized by PRECOBS manufacturer, IfmPt, and facilitated by the Cantonal Police Department of Aargau in 2018. During the meeting, police representatives from Germany, Switzerland, and Austria exchanged practical experiences from their work with PRECOBS and gave feedback to the software manufacturer. Last, but not least, we facilitated a workshop with Swiss police departments at ETH Zurich in 2018. Overall, 40 field protocols were produced.

Finally, we complemented our field research with document analysis. Throughout the research period, we collected a total of 378 relevant documents with reference to predictive policing in Germany and Switzerland, including presentation slides, handbooks, manuals, best practice guidelines, screenshots, photographs, reports, evaluations, parliamentary debates, official statements, and personal correspondence. Some of these documents were for internal use only, and we were not given permission to cite or reference them in our work. They did nonetheless help us to understand organizational challenges and practices with regard to predictive policing. Overall, the inclusion of a wide variation of official and internal documentation amended the subjective perspectives provided by interviews and ethnographic research by adding insights into the specific problem constellations, use cases, and controversies that surrounded the development and implementation of predictive policing in Germany and Switzerland.

All data were analyzed through thematic coding and subsequent qualitative content analysis to further structure the material. For the coding process, we used the qualitative data analysis software MAXQDA (Kuckartz and Rädiker, 2019). In concrete terms, interview transcripts, field protocols, and documents were in an initial round of analysis coded with reference to predefined main categories that had been derived from the literature and from our primary research interests (e.g., "data", "crime prevention", "space"). The code structure was extended throughout subsequent rounds of analysis and refined in an inductive fashion, accommodating thematic complexes that emerged from the data. This combination of deductive and inductive coding was informed by 
grounded theory methodology (Strauss and Corbin, 1990, 1994), speaking to the fact that throughout empirical research processes, mutually constitutive effects between iterative rounds of data collection and analysis are to be expected. Rather than subscribing to a radical form of induction, our analysis was thus epistemically underpinned by a notion of "theoretical empiricism" (Kalthoff et al., 2008) that presupposes an inseparable and fundamentally reciprocal relationship between theory and empirical research.

Per agreement with our research participants, all data have been anonymized to an extent that individual persons, places, and institutions cannot be identified. In cases where information was freely available in the public domain (e.g., which police departments use predictive policing applications, details on software packages, or information publicly communicated by police departments), we have opted not to anonymize. References to our empirical material throughout this book are marked as "I" (interviews), "P" (protocols), or "D" (documents) and numbered according to the production of documentation throughout the research process. In some cases, therefore, numbering is not continuous.

In summary, we believe the multisited, multimethod fieldwork approach that we pursued is well suited to explore how predictive policing transforms the ways in which the police produce knowledge about crime and society and act upon that knowledge. It allowed us to empirically situate algorithmic modes of crime analysis within larger trajectories of police work, technology, and the political rationales that underpin the turn toward data analysis and preventive intervention. And while our findings might not be easily generalizable due to the idiosyncrasy of national, regional, and local models of police organization and policing strategies, they do in fact correspond closely with those of existing works on digitization and security, the transformation of policing, and the societal and ethical challenges that algorithmic means of knowledge production pose.

\section{Our main message}

The first main message that we seek to convey through our empirical analysis is that predictive policing must be understood as a process that is embedded within a set of complex sociotechnical relations. In order to come to matter in everyday police work, crime forecasts must be able to connect various specialized police divisions and their professional lifeworlds. Only when key human and nonhuman elements are properly aligned will knowledge and power be successfully be transmitted from the back office to the street level and be able to inform patrolling and crime prevention strategies. An analytical lens on translation processes allows us to understand the challenges, frictions, and unintended consequences involved in complex sociotechnical systems.

The second main message of this book is that the implementation and use of predictive policing software can in many regards be seen as a blueprint for the 
further digitization of police work. Criminal futures must be understood not only with regard to the spatiotemporal forms of risk that the police create and act upon with predictive policing software but also with regard to the future of policing itself. Even though predictive policing in everyday practice might not always live up to the lofty and futuristic ambitions of some of its advocates, it is safe to say that the police's turn to the future in a systematic and data-driven fashion has significant repercussions for how police work is conducted, how the police shape their relations with the public, how crime is conceptualized as a social phenomenon, what should be done about it, and how it should be done.

Predictive policing might in fact be considered as a first, careful step toward "datafication" and "platformization" of police work. As police departments are starting to scratch the digital surface, it has created the awareness that the police need to reform IT infrastructures, foster data literacy, strengthen crime analysis divisions, and lobby for legal frameworks that enable data sharing across jurisdictions if they want to follow in the footsteps of private industry and systematically exploit the data treasures they have already been creating for a long time. Our research leaves us with little doubt that these larger trajectories will resonate with political priorities and technology development. Even though predictive policing in its current form might appear to be pedestrian and piecemeal, it is in all likelihood here to stay, to be further developed and refined, to be expanded to cover new types of crime, to include more and larger datasets, and to continue transforming the ways in which we are policed.

These tendencies foreground the need to critically accompany how algorithmic tools become part of police work. Advanced data-driven analytical methods change the ways in which the police perceive the world, make sense of it, and act within it. When criminal futures come into being in the form of algorithmically produced risk estimates, this can have wide-ranging consequences for how the police prioritize crime prevention measures differently across neighborhoods, how patrol officers interact with citizens, and it can impinge on the accountability of police organizations for their actions. Police work is a key function for the production and maintenance of public order, but it can also discriminate, exclude, and violate civil liberties and human rights. When algorithms mediate how the police produce power and knowledge, close investigation of these processes is paramount.

Studying how predictive policing comes to matter in everyday police work helps us to understand and situate these challenges. Engaging the sociotechnical practices of algorithmic crime analysis and the operational measures based upon it highlights how predictive policing is a complex, multilevel process that is embedded in organizational structures and occupational cultures. It cannot be understood in an isolated fashion (e.g., as a techno-utopian tool that will revolutionize policing), but needs to be carefully put into context. Such an approach presupposes to take seriously both the social and the technical side of predictive policing and to take into account the contradictions, frictions, 
and adjustments that are produced at their intersections. These insights can be mobilized to identify strategies for how predictive policing can be implemented and used in responsible ways, and we will end the book with some practical recommendations that can help in doing so.

\section{The structure of this book}

The structure of this book is informed by the classical "Coleman boat" (Coleman, 1990). It starts on the macro level with general theoretical and conceptual considerations, then dives into the micro level of empirical study, and finally reaggregates the findings and provides an evaluation and an outlook. This means that readers interested in an overview of predictive policing and its origins and connections to changing models of patrolling and crime prevention as well as its effects on organizational change are invited to focus on Chapters 2 and 3. For those who look for a detailed reconstruction of predictive policing practices and the translation efforts involved in bringing algorithmic crime forecasts to the street level, we can offer a shortcut to Chapters 4-7. And readers with an interest in an evaluation of predictive policing from the perspective of the police as well as from a wider societal angle might want to jump to Chapters 8 and 9. Eventually, Chapter 10 gives an outlook and some practical advice for a responsible use of data-driven tools for crime prevention and wider issues of security and social order. Reading the entire book from start to finish will, of course, make for the best overall experience. In the following paragraphs, we briefly summarize each of the chapters.

Chapter 2 situates predictive policing within larger trajectories of innovations in police work and crime prevention. The emergence of predictive policing, as the chapter illustrates, must be understood in light of general tendencies to render policing more future oriented, scientifically informed, and data driven. Moreover, it must be seen within a lineage of crime prevention strategies since the 1970s, including the likes of community policing, problem-oriented policing, hot-spot policing, and intelligence-led policing. The chapter proceeds to present an overview of different approaches to predictive policing. Differentiating between person-based and place-based approaches, it details different strategies for how data, theories, and models can be mobilized to come up with statements about possible futures. Overall, predictive policing, so we argue, presents yet another step in a rather long history of efforts to render police work more effective and efficient. There is considerable continuity in the ways in which police organizations seek to predict and address the future. Predictive policing should, in summary, be understood as an evolution rather than a revolution - however, as an evolution that nonetheless bears the potential to fundamentally reconfigure organizational routines and policing practices.

Chapter 3 provides an overview of the existing literature on technology and police organizations and develops a conceptual and analytical understanding of technology as embedded within larger sociotechnical systems. From an 
organizational point of view, technological tools are likely to unfold a number of repercussions that go beyond the originally intended scope, including the possibility to cause active resistance as they unsettle long-standing routines and habits. In order to understand how such repercussions come about, we suggest to approach crime prediction technology as interwoven into social and organizational contexts and to highlight the relations that predictive policing forms with its environment. Eventually, the chapter introduces the concept of translation, which allows us to trace the production and transmission of knowledge and power throughout police work. Drawing attention to the coordination and alignment activities between different human and nonhuman elements that are necessary to make predictive policing work, translation addresses the question of how an algorithm eventually manages to move patrol officers through space for the sake of crime prevention.

Chapter 4 explores the relation between data and speed in predictive policing. It starts by examining how the police produce data from crime scenes and illustrates how the representation of criminal activity in datasets is impacted by epistemic uncertainties and the translation of social phenomena into fixed classification systems. Generally speaking, the police usually have to grapple with data that tend to be incoherent, inaccurate, and unreliable - and thus need to be subjected to multiple layers of amendment and quality control before they can be analyzed. This creates considerable tension with regard to predictive policing and the presupposed need to run analyses as quickly as possible in order to be able to intervene in ongoing criminal activity. As the quality of crime data usually only improves over the course of investigations, police departments face a trade-off situation where they have to decide whether to immediately run analyses based on potentially unreliable data or whether to wait for consolidated data but run the risk of receiving already outdated results. This trade-off must, however, also be understood vis-à-vis the daily rhythm of public life and criminal activity within which police work takes place. Overall, the chapter foregrounds the complexity of data and multiple temporalities in predictive policing.

Chapter 5 looks into the relations between algorithms and human analysts. As predictive policing applications aim to facilitate analytical work through the automation of complex tasks, they aim to reduce the workload for humans and accelerate crime analysis. In doing so, they do, however, inevitably remove (parts of) the analytical process from sight. The chapter investigates how predictive policing reconfigures the relationship between humans and machines and discusses some pertinent regulatory and normative questions that come to the fore when analytical tasks are hidden in black-boxed algorithmic systems. Our analysis shows how the police still consider human operators essential in order to review the data basis on which predictive policing software computes outputs. At the same time, from a legal and ethical perspective, police departments are bent on keeping decision-making an exclusively human affair. This is, however, not easy, as arguing against a machine can be quite challenging for 
human operators. Police departments have, therefore, come up with a number of safeguards that are supposed to support humans and keep the algorithm in check.

Chapter 6 engages how crime risk, once computed, is made intelligible and actionable and how it is disseminated throughout various stages of police work: from the analyst's desk to central planning and operations, and from there to local police stations, shift supervisors, and patrol officers. The analysis pays particular attention to two aspects. First, it highlights how the dissemination of results from algorithmic crime analysis must speak to different audiences if it is to successfully bring risk on the street and inform targeted prevention measures. In other words, it needs to enroll different human and nonhuman elements in a common cause and be able to speak to different rationales and logics. Second, our analysis investigates how risk is visualized in order to do so. Specifically, we explore how the use of maps puts risk in relation to space and establishes the existence and coordinates of criminal futures in an intuitive and actionable fashion.

Chapter 7 analyzes how risk estimates become enacted by patrol units in their work practices. It places predictive policing within larger trajectories of patrol techniques and, particularly, within the conflict between an occupational culture of discretion on the one hand and aspirations of managerialism and micromanagement of police work on the other. Vis-à-vis the entrenched conflict between "craft" and "science", the narrow spatial and temporal parameters for targeted patrolling in predictive policing have the potential to favor rationalization over professional experience and intuition. However, as police departments have virtually no possibility to track and monitor patrol units, they need to convince patrol officers of the meaningfulness of algorithmically produced risk. Eventually, the chapter explores how the notion of criminal futures impacts the behavior of patrol officers. While the logic of the patrol is generally geared toward the production of deviance and suspicion as a function of the (mis)fit between persons and their surroundings, there is reason to believe that predictive policing might reinforce already existing concerns in patrolling such as racism, discrimination, or spatial prejudice.

Chapter 8 investigates the question whether predictive policing actually prevents the occurrence of crime. In light of the political prioritization of burglary prevention and the public attention that predictive policing was subjected to, police departments needed to demonstrate that what they were doing was in fact successful. Coming up with proof for the success of targeted crime prevention is, however, not easy. Complex social settings with dynamic interaction effects, as well as numerous possible intervening variables, render it almost impossible to attribute the nonoccurrence of crime to the use of predictive policing software in a causal fashion. When faced with these challenges, evaluation studies of predictive policing thus opted to redefine success criteria instead. Rather than aiming to establish statistical evidence for the assumed relation between algorithmic crime analysis, operational measures, 
and decreasing residential burglary numbers, police departments opted to highlight the long-term organizational benefits of the use of crime prediction software. By foregrounding aspects such as improved data-handling capacities and communication processes, success was framed in a sociotechnical fashion as the capability to produce and transmit knowledge and power across different parts of police work and to bring risk from the analyst's desk to the streets.

Chapter 9 widens the perspective and looks into the societal and ethical ramifications of predictive policing. Against the backdrop that algorithmic crime analysis tools are often used to allegedly rationalize police work and frame its technoscientific character as innovative, impartial, and superior to human behavior, it discusses a number of concerns with regard to the algorithmic production of risk estimates and targeted crime prevention measures. First, the chapter looks into the data basis of predictive policing. For a number of reasons, crime data are likely to be biased. Used as input for algorithmic processing, such bias is likely to persist, although potentially in rationalized and less obvious forms. Second, the chapter engages the behavior of patrol officers within presumed risk spaces. The notion of risky environments can lead to increased suspicion, more aggressive patrolling practices, and aggravate existing racial and/or ethnic prejudice. Third, the chapter explores how predictive policing applications, by design, encourage law enforcement-heavy policing strategies. Predictive policing has been developed on the basis of the same assumptions as situational crime prevention and thus replicates the preference to treat symptoms rather than to address root causes of crime. Finally, the chapter reviews how predictive policing removes analytical processes from sight and, in doing so, potentially undercuts the accountability of police departments for their actions.

Chapter 10 presents a brief summary of the book's main arguments as well as an outlook and some practical advice for the use of predictive policing and other algorithmic crime analysis applications. It discusses how experiences from the implementation and everyday use of predictive policing have revealed a number of technical and organizational shortcomings in police departments and how the political and public exposure of predictive policing was mobilized to put these shortcomings high on the reform agenda. Reviewing a number of legal and technological initiatives for future data-driven policing in Germany and Switzerland, the chapter illustrates how predictive policing is likely to aggravate already existing trends toward "datafication" and "platformization" in police work. We conclude the book with a call to carefully balance predictive policing with civil liberties and human rights and line out seven practical recommendations for a prudent use of algorithmic analysis tools in everyday police work.

\section{Note}

1 www.youtube.com/watch?v $=5 \mathrm{n} 2 \mathrm{UjBO} 22 \mathrm{EI}$ (accessed 30 April 2020). 


\section{References}

Ackroyd S, Harper R, Hughes J A, Shapiro D and Soothill K (1992) New Technology and Practical Police Work. Buckingham/Philadelphia: Open University Press.

Amoore L and Raley R (2017) Securing with Algorithms: Knowledge, Decision, Sovereignty. Security Dialogue 48(1): 3-10.

Andrejevic M (2017) To Preempt a Thief. International Journal of Communication 11: 879-896.

Aradau C and Blanke T (2017) Politics of Prediction: Security and the Time/Space of Governmentality in the Age of Big Data. European Journal of Social Theory 20(3): 373-391.

Babuta A (2017) Big Data and Policing: An Assessment of Law Enforcement Requirements, Expectations and Priorities. London: Royal United Services Institute for Defence and Security Studies.

Balogh D A (2016) Near Repeat-Prediction mit PRECOBS bei der Stadtpolizei Zürich. Kriminalistik 70(5): 335-341.

Beck C and McCue C (2009) Predictive Policing: What Can We Learn from Wal-Mart and Amazon about Fighting Crime in a Recession? The Police Chief 76(11): 18-24.

Bennett Moses L and Chan J (2018) Algorithmic Prediction in Policing: Assumptions, Evaluation, and Accountability. Policing and Society 28(7): 806-822.

Brayne S (2017) Big Data Surveillance: The Case of Policing. American Sociological Review 82(5): 977-1008.

Brayne S (2021) Predict and Surveil: Data, Discretion, and the Future of Policing. Oxford: Oxford University Press.

Chan J (2001) The Technological Game: How Information Technology is Transforming Police Practice. Criminology \& Criminal Justice 1(2): 139-159.

Coleman J S (1990) Foundations of Social Theory. Cambridge/London: Harvard University Press.

Egbert S (2017) Siegeszug der Algorithmen? Predictive Policing im deutschsprachigen Raum. Aus Politik und Zeitgeschichte 67(32-33): 17-23.

Ericson R V and Haggerty K D (1997) Policing the Risk Society. Oxford: Clarendon Press.

Farrell G (1995) Preventing Repeat Victimization. Crime and Justice 19: 469-534.

Farrell G and Pease K (2014) Predictive Policing. In Bruinsma G and Weisburd D (eds.) Encyclopedia of Criminology and Criminal Justice. New York/Heidelberg/Dordrecht/London: Springer, 3862-3871.

Ferguson A G (2017) The Rise of Big Data Policing: Surveillance, Race, and the Future of Law Enforcement. New York: New York University Press.

Hardyns W and Rummens A (2018) Predictive Policing as a New Tool for Law Enforcement? Recent Developments and Challenges. European Journal on Criminal Policy and Research 24(3): 201-218.

Johnson S D, Bernasco W, Bowers K J, Elffers H, Ratcliffe J, Rengert G and Townsley M (2007) Space-Time Patterns of Risk: A Cross National Assessment of Residential Burglary Victimization. Journal of Quantitative Criminology 23(3): 201-219.

Kalthoff H, Hirschauer S and Lindemann G (eds.) (2008) Theoretische Empirie: Zur Relevanz qualitativer Forschung. Frankfurt am Main: Suhrkamp.

Kaufmann M (2018) The Co-Construction of Crime Predictions: Dynamics between Digital Data, Software and Human Beings. In Gundhus H O, Rønn K V and Fyfe N R (eds.) Moral Issues in Intelligence-Led Policing. London: Routledge, 143-160.

Kaufmann M (2019) Who Connects the Dots? Agents and Agency in Predictive Policing. In Hoijtink M and Leese M (eds.) Technology and Agency in International Relations. London/ New York: Routledge, 141-163. 
Kaufmann M, Egbert S and Leese M (2019) Predictive Policing and the Politics of Patterns. British Journal of Criminology 59(3): 674-692.

Kuckartz U and Rädiker S (2019) Analyzing Qualitative Data with MAXQDA: Text, Audio, and Video. Cham: Springer.

Maguire M (2018) Policing Future Crimes. In Maguire M, Rao U and Zurawski N (eds.) Bodies as Evidence: Security, Knowledge, and Power. Durham/London: Duke University Press, 137-158.

Manning P K (2001) Technology's Ways: Information Technology, Crime Analysis and the Rationalizing of Policing. Criminology \& Criminal Justice 1(1): 83-103.

Manning P K (2008) The Technology of Policing: Crime Mapping, Information Technology, and the Rationality of Crime Control. New York/London: New York University Press.

Mantello P (2016) The Machine That Ate Bad People: The Ontopolitics of the Precrime Assemblage. Big Data \& Society (July-December): 1-11.

Marx G T (1988) Undercover: Police Surveillance in America. Berkeley: University of California Press.

McCulloch J and Wilson D (2016) Pre-crime: Pre-emption, Precaution and the Future. London/ New York: Routledge.

Okon G (2015) Vorhersagen von Straftaten - Vision oder Wirklichkeit? arcAKTUELL (4): 22-23.

Pearsall B (2010) Predictive Policing: The Future of Law Enforcement? NIJ Journal (266): $16-19$.

Perry W L, McInnis B, Price C C, Smith S C and Hollywood J S (2013) Predictive Policing: The Role of Crime Forecasting in Law Enforcement Operations. Santa Monica: RAND Corporation.

Polvi N, Looman T, Humphries C and Pease (1991) The Time Course of Repeat Burglary Victimization. British Journal of Criminology 31(4): 411-414.

Sanders C B and Condon C (2017) Crime Analysis and Cognitive Effects: The Practice of Policing through Flows of Data. Global Crime 18(3): 237-255.

Sanders C B and Sheptycki J (2017) Policing, Crime and 'Big Data': Towards a Critique of the Moral Economy of Stochastic Governance. Crime, Law and Social Change 68(1): 1-15.

Schweer T (2015) "Vor dem Täter am Tatort" - Musterbasierte Tatortvorhersagen am Beispiel des Wohnungseinbruchs. Die Kriminalpolizei 32(1): 13-16.

Schweer T (2016) Predictive Policing - Straftaten erkennen und verhindern, bevor sie passieren. Deutsches Polizeiblatt 34(1): 25-27.

Seidensticker K, Bode F and Stoffel F (2018) Predictive Policing in Germany. Available at http://nbn-resolving.de/urn:nbn:de:bsz:352-2-14sbvox1ik0z06 (accessed 30 April 2020).

Sidebottom A and Wortley R (2016) Environmental Criminology. In Piquero A R (ed.) The Handbook of Criminological Theory. Chichester: Wiley Blackwell, 156-181.

Strauss A L and Corbin J (1990) Basics of Qualitative Research: Grounded Theory Procedures and Techniques. Newbury Park/London/New Delhi: Sage.

Strauss A L and Corbin J (1994) Grounded Theory Methodology: An Overview. In Denzin N K and Lincoln Y S (eds.) Strategies of Qualitative Inquiry. Thousand Oaks/London/New Delhi: Sage, 158-183.

Townsley M, Homel R and Chaseling J (2003) Infectious Burglaries: A Test of the Near Repeat Hypothesis. British Journal of Criminology 43(3): 615-633.

van Brakel R (2016) Pre-Emptive Big Data Surveillance and its (Dis)Empowering Consequences: The Case of Predictive Policing. In van der Sloot B, Broeders D and Schrijvers E (eds.) Exploring the Boundaries of Big Data. Amsterdam: Amsterdam University Press, $117-141$. 
van Brakel R and de Hert P (2011) Policing, Surveillance and Law in a Pre-crime Society: Understanding the Consequences of Technology Based Strategies. In De Pauw E, Ponsaers P, Van der Vijver K, Bruggeman W and Deelman P (eds.) Technology-Led Policing. Antwerpen/Apeldoorn/Portland: Maklu, 163-192.

Wilson D (2018) Algorithmic Patrol: The Futures of Predictive Policing. In Završnik A (ed.) Big Data, Crime and Social Control. London/New York: Routledge, 108-127.

Wilz S M (2012) Die Polizei als Organisation. In Apelt M and Tacke V (eds.) Handbuch Organisationstypen. Wiesbaden: VS, 113-131.

Završnik A (2019) Algorithmic Justice: Algorithms and Big Data in Criminal Justice Settings. European Journal of Criminology. Online first. doi:10.1177/1477370819876762. 


\section{Predictive policing and its origins}

Predictive policing did not appear out of the blue. Rather, it is firmly anchored within a long lineage of policing strategies, which have in turn been impacted by technological advancements and political programs. To understand specific forms of predictive policing and their effects on police work, it is important to situate their emergence vis-à-vis larger historical trajectories of how the police produce knowledge and prevent crime. There is in fact little consensus about whether and, if so, how predictive policing can be clearly differentiated from earlier forms of crime analysis, crime mapping, and other computer-supported forms of management, planning, and action. This chapter places predictive policing within multiple overarching trends in policing: digitization, scientification, the turn to future-oriented action, economic and political pressure on police organizations, as well as the policing strategies, patrolling techniques, and crime prevention programs that have emerged vis-à-vis these trends.

Moreover, predictive policing is not a single phenomenon. We might define it as the proactive use of algorithmically mediated data analysis for the purpose of finding patterns in datasets, based on which risk estimates are produced for either individuals or locations and are operationalized in the form of targeted prevention measures. It is, however, not one model, not one process, not one algorithm, and not one software application.

Rather, over the past decade "predictive policing" has emerged as a collective term for a plethora of ways in which the police seek to address the future by using algorithmic data analysis in order to modulate it. It can be based on narrow sets of crime data produced by the police themselves, or it can venture into "Big Data" and integrate heterogeneous data sources. It can be founded on static and rule-based algorithms, or it can incorporate the dynamics of machine learning. It can be used to predict crime in particular places, or it can be used to predict crime by specific persons. It can integrate dynamic environmental information such as weather or traffic data. It can target burglary, car theft, pick-pocketing, or gang violence. It can be developed and designed by the police or by private companies. And these are just some of the possible features that account for variations between different approaches. We thus need to carefully define what we are speaking about when we refer to predictive policing. 
The second part of the chapter provides an overview of person-based and place-based approaches that can currently be encountered.

\section{The police and the future}

The police have by no means only started to look into the future with the advent of predictive policing applications. On the contrary, having always been concerned with the possibility of preventing crime rather than investigating already materialized offenses, police forces have throughout history sought to identify regularities in the occurrence of crime and to estimate possible future trends based on past events (Guerry, 1833; Quetelet, 1842; Burgess, 1928). And yet, with the digital age, the foundations on which the relationship between the police and the future rests are undergoing major changes, as actionable future-related intelligence is now available - intelligence that can, and sometimes must, be put on the street by patrol officers more or less instantly. As Manning (2008: 3) has put it, with regard to the introduction of crime mapping tools that were able to process unprecedented amounts of data and provide hitherto impossible glimpses into possible criminal futures, the police "are being dragged into the information age, an age that imagines the future prior to executing it".

In line with the themes of digitization (i.e., the continuous production of unprecedented amounts of data, almost unlimited storage capacities and processing power, and novel ways of algorithmic knowledge extraction from large and heterogenous datasets), criminological literature has in recent years engaged at length with the police's reinforced, data-driven turn toward the future, the means of bringing possible criminal futures into being, and the operational measures that might be used as ways of intervening in these futures. Ericson and Haggerty (1997) have identified at an early stage the changing role of the police as "knowledge workers" within a society gravitating toward the estimation and prevention of risks. The role of the police throughout the 1990s was, they argued, increasingly seen as a managerial one that was supposed to assemble intelligence in order to administer threat. This tendency was largely supported by the widespread implementation of powerful new IT systems that could store and handle data on an unprecedented scale (Ackroyd et al., 1992; Chan et al., 2001; Cope, 2008; Manning, 2008). This development placed police knowledge on a broader epistemic basis than ever before when it came to quantifying the relation between society and crime and transformed the ways in which the police were able to bring futures into being in order to inform prevention.

The newfound technological ability to create and systematically handle information, in turn, led to what Maguire (2016: 229) has called a "veritable 'data explosion' in the field", and sparked new methodological possibilities of engaging with the future. More data, the underlying assumption ran, could ultimately be turned into more intelligence and thus into more operational capacities to actively shape the future. The thirst for more and more data has 
resonated well with narratives of "Big Data" that thrive on the notion that even unstructured datasets, if properly explored, would almost inevitably yield new insights into the intricate workings of society and the occurrence of crime within it (McCue and Parker, 2003; Beck and McCue, 2009; Babuta, 2017). It has moreover been accompanied by the development of more complex and sophisticated algorithmic means of data analysis that, coupled with increased processing power, allow for novel ways of exploiting large datasets (McCue, 2007; Završnik, 2019).

Larger trajectories of digitization in policing must be contextualized with reference to two more specific developments. First of all, police work has since the 1980s increasingly been undergoing what Ericson and Shearing (1986) have identified as "scientification" - that is, the fact that police work, not unlike scientific practice, is framed as "a form of action with attendant symbolic and rhetorical features, used to discover the truth and settle problems by constructing a view that "satisfies certain criteria of rational acceptability", (Ericson and Shearing, 1986: 132). Reference to academic theories and models, as well as the application of advanced statistical methods, has in this sense played a prominent role in how the police have sought to strengthen their capacities of "truth construction" (Haggerty, 2001). Technological innovations, and particularly the implementation of information and communication technologies, have further helped to put these principles to practice (Ericson and Shearing, 1986).

With the onslaught of digital data and the accompanying possibility of extracting new insights from data that had always been produced on a regular basis, police organizations today show an increased willingness to push the scientific mindset further, in terms of both methods and the epistemic assumptions that underpin them, with paradigms such as "intelligence-led policing" leading the way (Ratcliffe, 2016). Practices of experimenting and tinkering with data in order to explore modes of practical intervention, supported by an empiricist belief in "science as a mechanism that allows us to discover the truth in the world" (Miranda, 2015: 424), have largely contributed to the reinforced role of "intelligence" for all kinds of police and criminal justice activities (Gill, 2000: 18).

Second, the turn toward digital futures has resonated with a political-legal mindset that is increasingly set on preventing undesired events before they materialize. As McCulloch and Wilson (2016: 4) write, what can be witnessed at the intersection of digitization and scientification are "broader sociopolitical transformations in understandings of security and risk [that] have reoriented criminal laws, and criminal law-like processes and practices, towards future threats". Using slightly different terms such as "prediction" (Aradau and Blanke, 2017), "pre-crime” (Zedner, 2007), or "prepression” (Schinkel, 2011), scholars have intensely engaged the wider repercussions of a preoccupation with threat, anticipation, and intervention for policing and the criminal justice system. Data-driven modes of anticipation and prevention have, in this sense, 
been fiercely criticized for their potential to engender practices of surveillance and profiling that aggravate individually targeted modes of knowledge production and interaction (Schauer, 2003; Harcourt, 2007; Gandy, 2009; van Brakel and de Hert, 2011), while operating on the basis of the assumed "predictability, impartiality, and objectivity of technoscientific solutions" (Mantello, 2016: 2). We will pick up some of these questions with particular regard to predictive policing in more depth in Chapter 9.

\section{The evolution of crime prevention}

Predictive policing aims at overhauling the ways in which the police patrol through the dynamic production of crime risk. It implies new strategies of policing and crime prevention, and it has the potential to change parts of the police profession into a more scientific, data-focused way of working. But it did not come out of the blue. Even though algorithmic crime analysis tools are at times presented as a "revolution" in policing (Back, 2016; Thomson, 2018), they should rather be understood as an evolutionary amalgam of different strands of technological, practical, and organizational developments in policing. As Bierschenk (2016: 163) points out, "like all social phenomena, police - whether in the sense of a particular police idea or of a particular institution - are the result of their own history". Exploring how predictive policing picks up on larger trajectories of crime prevention strategies will allow us to better situate it within a changing policing landscape and will also enable us to foreground the unique characteristics that set predictive policing apart from other methods such as crime mapping or hot-spot policing.

Historically, as Jones and Newburn (1998: 18) put it, police tasks have evolved around "organised forms of order-maintenance, peace-keeping, rule or law enforcement, crime investigation and prevention and other forms of investigation and information-brokering". These basic pillars have not changed, yet the particular strategies and methods through which they have been enacted have been subject to ongoing reform. We will limit ourselves to questions related to crime prevention efforts here, as this is the main impetus of predictive policing approaches. Although crime prevention can be traced back to Robert Peel and the invention of the "new police" as an organization that had the explicit task of preventing crime (Jobard, 2014: 520; Mulone, 2019: 215f), the prevention of criminal activity was for quite some time after the Second World War overshadowed by a preference for more repressive forms of law enforcement. Crime prevention only became a higher political priority against the backdrop of rising crime levels in the US in the 1970s and early 1980s. By that time, the standard model of policing that was predicated upon random patrols and responses to calls for service had proved to be little effective in bringing crime levels down (Weisburd and Eck, 2004: 43; Tilley, 2008: 373; Jones et al., 2017: 779), resulting in a penal pessimism that questioned the general possibility 
of effectively controlling or reducing crime (Kelling et al., 1974; Martinson, 1974; Garland, 1995).

New and innovative ways of policing that problematized the standard model of policing were thus politically encouraged, and this agenda sparked the emergence of new, proactive approaches to police work (Tilley, 2008; Willis, 2014). Backed by criminological research, the "preventive turn" (Crawford and Evans, 2012: 798) suggested that the police should attempt to intervene more strongly in the future rather than simply reordering the past (Johnston and Shearing, 2003). The newfound desire to actively shape the future was closely accompanied by political efforts to render the police - and the criminal justice system more generally - more effective and more efficient (Garland, 2001; Savage, 2007; Jones et al., 2017: 779). In fact, all major strategic, tactical, technological, and managerial developments in policing since the 1970 s - i.e. community policing, problem-oriented policing, hot-spot policing, crime mapping, COMPSTAT, intelligence-led policing - are underpinned by a common rationale of streamlining police work and optimizing the use and allocation of resources (Nix, 2015: 276-278; Maguire, 2016: 228; Jones et al., 2017: 780). In the following paragraphs, we will briefly engage with each of these innovations. In doing so, we will show that predictive policing can be understood as yet another step in this quite long lineage of anticipatory and managerial developments.

In the 1970s, community policing approaches were initiated against the backdrop of rising crime levels and increasing frustration about the lack of efficacy of established forms of police work. Community policing programs took the increasingly difficult relations between the police and minority communities in the US as a starting point and made an improvement of these relations a priority (Trojanowicz and Bucqueroux, 1990; Jones et al., 2017: 780). Best understood as a high-level strategy or philosophy rather than a concrete program (Terpstra et al., 2014: 417), community policing aspires to transform the attitudes of local communities toward the police from hostility to productive partnership. One way to achieve such a change would be to have designated "neighborhood cops" who are supposed to regularly engage with communities and build trust in order to produce knowledge about local problems, thus putting the police in a position to devise custom-tailored and cooperative solution strategies (Skogan, 2008). Conceived of as an approach that tackles the roots of crime rather than dealing with its effects, community policing is often presented as an effective means of crime prevention (Tilley, 2008: 376).

A similar approach can be found in models of problem-oriented policing that were first introduced in the late 1970s and got more traction in the early 1990s (Goldstein, 1979, 1990). Starting from the observation that police work was arguably not structured and systematic enough in tackling crime, problemoriented strategies suggest to broaden the scope of policing. Enforcement should not be considered the prime focus, as it would not amount to an end in itself, but merely an alleviation of symptoms (Terpstra et al., 2014: 419). 
Rather, the focus should be on the systematic analysis of the causes and phenomenology of crime, thus aspiring to identify patterns and acquire knowledge about the conditions under which crime occurs - particularly, with regard to place and time (Jones et al., 2017: 781). Notably, the origins of repeat victimization theory can be traced to works on problem-oriented policing (Farrell and Pease, 2001; Laycock and Farrell, 2003). Moreover, problem-oriented policing has paved the way for criminological theories to more strongly enter and inform practical police work - particularly, rational choice theories, routine activity theory, and works on environmental criminology and situational crime prevention (Garland, 2001: 16). Last, but not least, problem-oriented policing incorporated early attempts to detect crime clusters, which would later be taken up and further developed under the label of hot spots (Sherman and Weisburd, 1995; Tilley, 2008: 380).

In the 2000s, hot-spot approaches attempted to combine a focus on the spatial distribution of crime with the analytical scope of problem-oriented policing. Considered a key step toward place-based predictive policing, these approaches could moreover be seen as a tactical incorporation of crime mapping techniques to inform preferred patrol locations (Chainey, 2014: 703f). The concept of the "hot spot" was originally triggered by analyses of police call data and the insight that a large percentage of calls came from the same areas (Sherman et al., 1989). In line with the desire to prevent crime rather than to react to its occurrence, the identification of such pertinent crime clusters was thus seen as an opportunity to render policing more effective and efficient, as patrols could be increased in these areas in a targeted fashion (Bottoms, 2012: 471).

This development tied in closely with technological advances in geographic information systems (GIS). The increased availability of geo-coded information and the possibility of linking police data to GIS data presented new ways to turn crime mapping from a descriptive means into an analytical technique (Chainey and Ratcliffe, 2005). Rooted in environmental criminology (Brantingham and Brantingham, 1981; Wortley and Townsley, 2017), crime mapping picks up on two assumptions: that the occurrence of crime is not a random phenomenon and that the spatial distribution of crime can provide hints about possible future occurrences (Chainey, 2014: 669). Moreover, crime mapping and hot spots both foreground the importance of visual representation in order to make analytical insights tangible and actionable (Bowers and Hirschfeld, 2001: 1) - a theme that is prevalent within predictive policing and that we will analyze in more depth in Chapter 6.

Another key innovation in the lineage of predictive policing was the introduction of COMPSTAT, a software tool for police organizational management that was first used by the New York Police Department in the mid-1990s (Bratton and Knobler, 1998; Eterno and Silverman, 2006). Combining crime mapping techniques with performance measurement and assessment rationales, COMPSTAT was predominantly geared toward the optimization of work 
processes and the targeted allocation of resources so that police departments could maximize their efforts in the fight against crime vis-à-vis shrinking budgets (Walsh, 2001; Bratton and Malinowski, 2008). COMPSTAT signified an important step in the computerization of police work, as it mobilized digital analytical processes to steer police work based on criteria of effectiveness and efficiency (Chainey, 2014: 702). With COMPSTAT, crime mapping and computer-generated knowledge production were established for the first time as standard components in everyday police work.

With its focus on computer-generated information and its drive of consistently drawing on geographical information on crime and on crime statistics in general for the guidance of police work, COMPSTAT can also be understood as a stepping stone for intelligence-led policing approaches that originated in the 1990s and increasingly gained traction throughout the 2000s (Ratcliffe, 2016: 24f). Defined as "a policing business model that incorporates data analysis and criminal intelligence into a strategy that coordinates strategic risk management of threat with a focus on serious, recidivist offenders" (Ratcliffe, 2014: 2573), intelligence-led policing highlights the role of knowledge production in police work through the notion of intelligence, thereby pointing to the work of national security and intelligence services as an inspiration for policing. Intelligence-led policing suggests that knowledge about crime can be obtained from a variety of data sources, ranging from undercover agents and informants to systematic data analysis on a large scale. With intelligence-led policing as a larger paradigm of how the police mobilize a multiplicity of different data sources and modes of knowledge production, some have even argued that predictive policing should be understood as a particular form of such intelligence production rather than a genuinely new approach to policing (Ratcliffe, 2016: 151f; Hardyns and Rummens, 2018: 203).

\section{Predictive policing: doing more with less?}

What exactly sets predictive policing apart from established methods and police strategies, then? Looking at the ways in which practitioners and scholars have attempted to define predictive policing provides some clues. Bratton et al. (2009: 3) suggest we should understand predictive policing as "forwardthinking crime prevention" that "connects technology, management practices, real-time data analysis, problem solving and information-led policing to lead to results - crime reduction, efficient agencies and modern and innovative policing". Quite similarly, Uchida (2009: 1) puts forward a framing of predictive policing as a "multi-disciplinary, law enforcement-based strategy that brings together advanced technologies, criminological theory, predictive analysis, and tactical operations that ultimately lead to results and outcomes - crime reduction, management efficiency, and safer communities".

Both definitions foreground crime reduction as a main goal of predictive policing. While this seems intuitively convincing, such a focus on outcomes 
has sparked some controversy. Demonstrating cause-effect relations between the use of predictive policing software and decreasing crime numbers is in fact not easy, and there is no clear evidence that less crime can be empirically attributed to algorithmic crime forecasts (Bennett Moses and Chan, 2018: 815ff; Benbouzid, 2019; Gerstner, 2019). We will engage with questions of "success" and "proof" in predictive policing in more detail in Chapter 8.

Less goal-driven definitions are provided by Pearsall (2010: 16), who argues that "predictive policing, in essence, is taking data from disparate sources, analyzing them and then using results to anticipate, prevent and respond more effectively to future crime", and Ferguson (2012: 265), who writes that "predictive policing has become a generic term for any crime fighting approach that includes a reliance on information technology (usually crime mapping data and analysis), criminology theory, predictive algorithms, and the use of this data to improve crime suppression on the streets". These views tie in with Perry et al's (2013: 1f) description of predictive policing as "the application of analytical techniques - particularly quantitative techniques - to identify likely targets for police intervention and prevent crime or solve past crimes by making statistical predictions".

Throughout these diverse conceptual takes, a number of cross-cutting themes can be identified. First of all, scholars agree that predictive policing is about estimates of possible futures and about operational policing measures that can be custom tailored on the basis of such estimates. Second, and more importantly, they stress that predictive policing is a data-driven process that is facilitated by technological advances. It builds upon the availability of sophisticated algorithms, unprecedented amounts of data, and rapidly increasing storage capacities and computational power. Third, and not least, authors point to the fact that predictive policing is conceived of as a scientifically informed way of police work that mobilizes criminological theories as much as empirical insights into crime and its occurrence. Taken together, these characteristics are believed to provide the police with the means for better situational awareness, to put them in a situation where they can respond swiftly and flexibly to ongoing criminal activities, and to direct their resources in a more targeted and thus more efficient fashion.

None of these themes are genuinely new, but all of them have a history in the organizational development of the police over recent decades. Their combination did, however, turn out to provide a suitable response strategy to increasing political, public, and economic pressure on the police to find new ways to deal with rising crime levels. In 2012, then LAPD police chief, Charlie Beck (cit. in Orr, 2012) pinpointed the pragmatic appeal of predictive policing as follows: "I'm not going to get more money, I'm not going to get more cops. I have to be better at using what I have. And that's what predictive policing is about." As the aftershocks of the financial crisis of $2008 \mathrm{had}$ put severe budgetary pressure on public agencies, police organizations were forced to find creative ways to maintain their level of service. Beck and McCue 
(2009: 24) had in fact argued early on that new forms of crime analysis and crime prevention would need to be all about "do[ing] more with less". Technological innovation was in this sense widely conceived as a potential way to ramp up the efficiency and effectiveness of police work through more targeted and informed ways of acting (Beck and McCue, 2009; Bratton et al., 2009; Saunders et al., 2016). The rationale of predictive policing was thus, from its early days, to a large extent characterized by business logics.

Some have argued that predictive policing should, in light of these motivations, be primarily understood as an internal management tool that aligns police work with modern business methods in order to increase efficiency and effectiveness (Benbouzid, 2019; Wilson, 2019). Others have foregrounded alleged algorithmic impartiality as a driving force (Miranda, 2015; Shapiro, 2019). As Ferguson (2017: 21ff) notes, the implementation of predictive policing in the US was in fact not least driven by the increasing tension between police forces and ethnic minorities, especially against the backdrop of the Black Lives Matter movement. Predictive policing was in this regard seen as a way to get rid of human bias and let a machine decide where to patrol and who to control. The notion of an impartial algorithm is of course a myth in the first place, and several studies have over the last few years demonstrated how bias enters algorithmic decision-support systems in policing and criminal justice in many different ways (Angwin et al., 2016; Lum and Isaac, 2016; Richardson et al., 2019). We will deal with these issues in more depth in Chapter 9.

The origins of predictive policing can, however, be traced back even further. In the US, police departments started to experiment with technical means for systematic data analysis in the early 2000s. The Richmond Police Department, for example, started using SPSS data mining applications for threat assessment and risk-based deployment of tactical units in 2003 (McCue and Parker, 2003; McCue, 2007), and similar methods spilled over to other departments in the following years (Robinson and Koepke, 2016). Data-driven, risk-oriented approaches to police operations were only explicitly framed as "predictive policing” for the first time in 2008 (Bratton et al., 2009; Perry et al., 2013: 4), and this framing was decisively reinforced by the media attention that accompanied the implementation of the software tool PredPol - short for Predictive Policing - by the police departments of Santa Cruz and Los Angeles in 2011. PredPol was the product of a collaboration between the Los Angeles Police Department and researchers from the University of California, who had aspired to bring together criminological theory and police data in order to come up with an easily usable analytical application for police work (Short et al., 2010; Mohler et al., 2015).

An important role in the advancement of algorithmic crime analysis methods was also played by the US National Institute of Justice (NIJ) and the Bureau of Justice Assistance (BJA), which organized two seminal symposia on predictive policing in order to further explore its potential, its organizational prerequisites, and its possible impacts on policing routines and practices (Pearsall, 2010). 
In doing so, they consulted with William Bratton, a prominent figure in the American police scene and former commissioner of the police departments of Boston and New York as well as former police chief of Los Angeles - thereby making sure to receive plenty of attention from the law enforcement community (Bureau of Justice Assistance, 2009; Perry et al., 2013: 4). In addition, the $\mathrm{NIJ}$ awarded grants to researchers and police departments to conduct basic and applied research on predictive policing. Together, these efforts can be seen as a considerable boost to the development of crime prediction software and its implementation in the US (Nix, 2015: 278; Ferguson, 2017: 32).

In summary, predictive policing takes up and incorporates a number of technical, economic, and political trajectories. The use of algorithmic crime analysis tools is generally presented as an elegant way to resolve organizational shortcomings and external pressures. Not surprisingly, then, predictive policing has over the past decade spread rather quickly into multiple national and local contexts around the globe. In the following sections, we provide a brief overview of current methods and tools. We structure this overview along the lines of person-based approaches (who to police?) and place-based approaches (where and when to police?).

\section{Person-based approaches}

Person-based approaches to predictive policing address the question of who could become a criminal or a victim of a crime at some point in the future. At times also referred to as "predictive profiling" (de Hert and Lammerant, 2016; Sommerer, 2017: 149), "person-based predictive targeting" (Ferguson, 2017: 34), or "individual-based predictive policing" (Brayne et al., 2015: 3), personbased approaches operationalize estimates about individual human behavior based on data about a particular person and/or group. Person-based predictive policing bears a strong resemblance to methods that are applied in violence prevention, extremism prevention, counterterrorism programs, or recidivism prognosis in the criminal justice system (Brayne and Christin, 2020). All these methods are based on the assumption that certain characteristics in past and present behavioral patterns, individual characteristics, and social contacts could be used as indicators to predict future actions of individual persons. Generally speaking, there are two main ways in which person-based approaches to predictive policing can come into being: through risk profiling and through social network analyses (Ferguson, 2017: 34ff).

Risk profiling approaches model the probability that a person could commit a crime or become the victim of a crime on the individual level. They do so by identifying particular personal or group-related characteristics that are considered to be risk factors (Hildebrandt, 2008; Leese, 2014). The idea here is to predict criminal behavior by comparing the individual characteristics of a particular person to the characteristics of known offenders. A significant congruence between the profiles will then be considered as an indication that 
the target person could present a risk or be at risk (de Hert and Lammerant, 2016: 148). Risk profiling approaches can be operationalized in several different ways. For example, they can be based on questionnaires, use clinicalpsychiatric evaluation models, or analyze aggregate data (Kemshall, 2003: 64ff). In practice, different forms of constructing a profile are often combined. In most cases, risk profiles do not directly correspond with police work but rather with the criminal justice system (Ferguson, 2016). They are, in this sense, predominantly mobilized in court proceedings or probation hearings in order to support human review and human expertise (Latessa and Lovins, 2014: 4457f; Hannah-Moffat, 2019).

Social network approaches, on the other hand, assess crime risk through an individual's social contacts, such as friends, relatives, neighbors, or colleagues. As social networks are today to a large extent mirrored in online networks or digital contact data, they can be traced and modeled with increasing accuracy. The idea behind social network analysis is that the number of arrests among a person's social circle can be used as an indicator for this person's future behavior. Analytically, network approaches refer to criminological literature that has examined correlations between victimization and the social connections to persons with gang affiliations or to homicide victims (Papachristos, 2009; Papachristos et al., 2012). These studies suggest that persons whose circle of acquaintances and relatives includes victims or perpetrators of gun-related acts of violence have a high risk of also being involved in such acts in the future. Risk estimates that come into being through social network analysis thus do not focus on individual characteristics, but present a form of collective liability. In other words, "it's not just shooting somebody, or being shot. It has to do with the person's relationships to other violent people" (Wernick, cit. in Stroud, 2014).

The most prominent example of social network analysis is probably the Strategic Subject List (SSL), more widely known as the "heat list", that the Chicago Police Department started using in 2013 (Gorner, 2013). Aiming to reduce gun violence, the SSL targets those individuals who show the highest risk of becoming victims or perpetrators of firearm-related violence (Saunders et al., 2016; Ferguson, 2017: 37ff). Identified "high risk" persons are then subsequently personally addressed by the police to let them know that they are already "on the radar" (McCarthy, 2015), thereby presenting a form of "focused deterrence" that aims at informing and sensitizing high-risk individuals so that they may reconsider any future criminal activities (Ferguson, 2017: 35; Ratcliffe, 2019: 121ff).

Such targeted warnings can already be conceived of as a significant form of discrimination and interference with individual privacy and freedom, and they have been heavily criticized by human rights groups and other civil liberties advocates (Stanley, 2014; Jouvenal, 2016). Intervention strategies based on individual risk estimates do, however, not stop there. Presumed high-risk individuals can be subjected to targeted prevention measures - for instance, 
specialized intervention programs for juveniles or violence prevention programs. Moreover, surveillance measures can be put in place to collect further information and/or enable the police to interfere in case of pending criminal action. Again, the boundaries between policing and national security programs such as extremism prevention and counterterrorism become blurred in such cases. In Germany, in the aftermath of recent terrorist incidents, software tools such as RADAR-iTE or hessenDATA appear to already aspire to bridge the gap between domestic policing and national/international security. We will deal with these trends in some more detail in Chapter 10.

Person-based approaches to predictive policing are also used to provide risk estimates to police patrols when they respond to calls. Applications such as Beware by US technology company Intrado are informed by the rationale that central dispatch can issue warnings to officers in the field when they are on their way to an address presumed to be dangerous or when they are about to interact with a potentially violent person (Jouvenal, 2016; Intrado, no date). Based on such information, police officers could then adapt their behavior and, for example, be extra cautious when entering a building inhabited by known gun owners with a record of violent behavior or when driving through an area that is known as gang territory. Last, but not least, risk profiling techniques are also mobilized retroactively to identify potential suspects in criminal investigations. Automated police database queries, algorithmic analyses of field interview cards, and other digital means of police intelligence are used to tie certain profiles to criminal offenses and narrow down the pool of potential suspects (Perry et al., 2013: 103).

Most critical academic discourse on predictive policing has - for obvious reasons - revolved around the notion of person-based risk profiling approaches (Harcourt, 2007; Mantello, 2016; McCulloch and Wilson, 2016; Andrejevic, 2017; Aradau and Blanke, 2017; Sheehey, 2019). The dangers of risk profiling, even when carefully curated and cautiously implemented, are numerous and range from discrimination (the creation of profiles based on variables such as sex, age, nationality, and religion) and collective liabilities (the creation of risk by association) to the production of false positives (the danger that innocent people will be marked as suspicious). Despite these ethical and legal concerns, risk profiling is an area in which tech companies continue to make strong pushes, mobilizing narratives of "Big Data" and machine learning as promises of better and more efficient law enforcement (Brayne, 2017; Hannah-Moffat, 2019). Future developments in this branch of predictive policing warrant close monitoring and critical evaluation, as they might fundamentally clash with human rights, individual liberties, and societal values.

\section{Place-based approaches}

The majority of predictive policing approaches today are, however, not primarily concerned with individuals. Place-based models of predictive policing have 
proved to offer a comparatively straightforward way to support police work, as they more easily align with established forms of crime analysis and can be integrated more or less seamlessly within existing patrolling and crime prevention strategies. The general idea of place-based approaches is to identify geographic areas that might, within a certain period of time, be more susceptible to crime. Based on the spatiotemporal risk estimates produced, police departments can then devise strategies for preventing or deterring criminal activity within these areas. However, just like with person-based approaches, there is considerable variation between different ways of identifying risky places. Place-based approaches can be differentiated with regard to the data that they use as well as the theories and models they mobilize to generate predictions (Groff and La Vigne, 2002; Perry et al., 2013; Kaufmann et al., 2019).

Arguably, the simplest means of risk production in relation to space is the temporal extrapolation of hot spots. Hot spots are usually small-scale geographic units that have historically shown higher crime rates than their environment. In this approach, crime rates from the past are extrapolated into the future in a linear fashion, meaning that a similar amount of crime is expected to repeat for this area (Groff and La Vigne, 2002: 34ff). This implies that if crime is frequent enough in certain places, it can be rendered manageable - that is, patrols and other crime prevention measures can then be intensified in these areas in order to bring crime figures down (Chainey, 2014; Ratcliffe, 2019: 116). The general assumption that underpins hot-spot methods is that the occurrence of crime is relatively stable over time and that its spatial distribution does not vary significantly. It has been argued that hot-spot methods should explicitly not be understood as predictive policing, as they are not necessarily reliant on algorithmic support and simply reproduce patterns of the past rather than producing estimates about new risk areas (Telep and Weisburd, 2014; Weisburd and Telep, 2014; Braga, 2017).

One approach that promises to do exactly this is the near-repeat approach. Originally referred to as "prospective hot-spotting" (Bowers and Johnson, 2004; Bowers et al., 2004) or "predictive mapping" (Groff and La Vigne, 2002; Johnson et al., 2009), the near-repeat approach is today the one most commonly used in predictive policing. It is based on the observation that certain types of crime are likely to be followed by similar offenses in the immediate vicinity and future (Townsley et al., 2003) as well as the assumption that professional criminals act inherently rationally (Becker, 1968; Cornish and Clarke, 1986). The near-repeat hypothesis has been empirically validated most extensively with reference to domestic burglaries (Johnson et al., 2007; Glasner et al., 2018). A successful burglar, imagined as an "optimal forager" who carefully scouts a neighborhood in order to identify worthwhile targets and potential dangers (Sidebottom and Wortley, 2016: 168), would in this sense be likely to stick to a once-successful formula of action and commit further offenses in the near environment and shortly after the initial deed. In this way, acquired knowledge can be further maximized and risks minimized (Johnson et al., 2007). 
A second important theoretical point of reference for near-repeat approaches is routine activity theory (Cohen and Felson, 1979; Clarke and Felson, 1993). In close correspondence with ideas about rational actor behavior, routine activity theory presupposes that the occurrence of crime is constituted and facilitated by a number of factors including the presence of a motivated perpetrator, the availability of a suitable target, and the absence of sufficient protection measures safeguarding the target. The constellation of these factors changes throughout the day as people move through the city on their way to their daily activities, thereby opening up windows of opportunity for criminals (Felson, 2006). As most people leave their homes in the morning to go to their workplace or pursue other tasks and do not return until early evening, burglars are assumed to make use of the absence of guardians for their activities. Particularly pertinent in this respect is the fall/winter period, when there is a prolonged time frame between dusk and the return of residents, during which professional burglars prefer to operate. We will come back to the temporal aspects and what the rhythm of crime means for predictive policing in Chapter 5.

Assumptions of rational choice and routine activity theory are also closely mirrored in the situational crime prevention models that were first devised in the 1970s and 1980s (Clarke, 1980, 1995). Based on the idea that crime could be prevented if opportunities and facilitating variables could be effectively removed from the environment, situational crime prevention strategies attempt to identify possible targets and deterrents. Increased protection of targets and the establishment of deterrents would then, so the assumption, discourage criminals from carrying out their activities. Situational crime prevention can include a wide variety of different measures and a broad range of different actors. Prominent examples are improved lighting in dark streets and alleys, reinforced locks and doors, gates and fences, surveillance cameras, alarm systems, and neighborhood watches (Ekblom, 1998; Eck and Guerette, 2012; Smith and Clarke, 2012).

Taken together, situational crime prevention strategies aim at increasing the perceived efforts that criminals would need to invest, at increasing the perceived risks that criminals would subject themselves to, and at reducing the anticipated rewards of criminal activities. These principles in fact also form the basis for most operational intervention strategies based on predictive policing. While some situational crime prevention measures such as installing surveillance cameras and alarm systems could be considered to be the responsibility of property owners, and others such as street lighting the responsibility of the municipality, police departments usually operationalize the estimation of risk areas by devising increased patrols to these areas in order to create visibility and possibly deter criminals.

Two major advantages of near-repeat approaches in predictive policing are that they require comparatively few data points as input and that they are mostly predicated upon dedicated crime data that are produced by the police and which are thus already available for analysis right away. Software 
packages such as PredPol or PRECOBS operationalize the near-repeat hypothesis through a two-step process. First, past crime data are analyzed with regard to the identification of specific patterns that could indicate professional offender behavior. In a second step, future criminal activity is estimated on the basis of the occurrence of "trigger" criteria and models relating to where and when they could be followed by further offenses. PredPol, currently being used on a regular basis by major US police departments such as Los Angeles, New Orleans, and Atlanta (Robinson and Koepke, 2016: 14ff; Chan and Bennett Moses, 2019: 45f), as well as currently or previously in London, Kent, and Yorkshire in the UK (Hardyns and Rummens, 2018: 209), does so by taking inspiration from the study of earthquakes. Its algorithm for the prediction of domestic burglaries, car theft, and theft from vehicles is based on a self-exciting point process model that predicts follow-up crimes in the form of aftershocks after an initial earthquake (Mohler et al., 2011).

PRECOBS, on the other hand, uses historical spatiotemporal distributions of crime as the basis for dynamic estimates of future risk. The implementation process of PRECOBS, therefore, starts with a simulation study that retroactively predicts past residential burglary series. The simulation results in the identification of areas that have historically proven to be most vulnerable to near-repeat patterns. These "near-repeat-affine areas" are then used as the baseline for the computation of risk (Balogh, 2016: 336). The assumption here is that once a professional case of residential burglary can be identified in one of these areas, an alert for potential near-repeat offenses will be produced in an automated fashion. Near-repeat-affine areas are updated regularly, and usually there are different seasonal configurations that adjust the analysis for shorter daylight hours in winter and corresponding increases in burglary activities during dusk/darkness (Balogh, 2016; Schweer, 2016).

The criteria for alerts are based on a list of "trigger" and "anti-trigger" criteria that is in turn based on information about modus operandi or haul - with trigger criteria pointing to professional offender behavior and anti-trigger pointing to random, spontaneous, and nonprofessional criminal activity (Schweer, 2015: 14). It is assumed that only professional burglars would commit an entire series of temporally and spatially connected offenses. A second assumption is that professionals would not, for example, smash a window (as this would create noise) or steal large items such as TV sets (as this would pose transportation problems), but that they would silently drill the window and only go for small items that could be easily carried and later sold, such as jewelry.

Finally, a third main approach to place-based predictive policing is risk terrain modeling. Compared to hot spots and near-repeat approaches, risk terrain modeling presents a more complex method in both technical and analytical terms. The general idea here is that risk will not be estimated on the basis of the occurrence of actual crime, but that it can be modeled through a wide range of data points that provide dynamic insights about social and material constellations that can be used to estimate dynamic vulnerabilities of different 
areas (Caplan et al., 2011; Kennedy et al., 2011; Caplan and Kennedy, 2016). Large crowds gathering in particular places would, for example, in this logic present an increased risk of pick-pocketing, whereas congested traffic during rush hour would make a quick getaway more difficult and could thus be seen as decreasing the risk of burglary. Risk terrain approaches provide lots of freedom for modeling assumed causal relations between environmental factors and the occurrence of crime.

What sets the risk terrain approach apart from other forms of place-based predictive policing is the fact that models need not be limited to predefined datasets (i.e., police data). On the contrary, risk terrain modeling opens up the possibility of including almost any conceivable data source as long as it can be logically connected to the occurrence of crime (Kennedy et al., 2018). Data could, for example, refer to the infrastructural characteristics and socioeconomic compositions of specific areas, including the likes of income distribution, household size, building stock, highways, metro stations, or nightlife spots (Perry et al., 2013: 50ff; Caplan and Kennedy, 2016; Kennedy et al., 2018). Over recent years, a diverse and growing (applied) criminological and computer science literature has emerged that attempts to dynamically model crime risks according to movement patterns of people throughout cities based on traffic data and public transport data, weather data, and/or social network data (Wang et al., 2012; Bogomolov et al., 2014; Tayebi and Glässer, 2016; Brüngger et al., 2017; Pelzer, 2018; Kadar et al., 2019).

The implicit notion that underpins many risk terrain modeling approaches is that in order to be as accurate as possible, analyses should integrate as many data sources as possible - which ties in with narratives of "Big Data" that suggest that if only enough data about the world were available, hitherto hidden insights about the mechanisms of the world could be extracted through the data themselves (Anderson, 2008; Beck and McCue, 2009). While most risk terrain modeling applications at least partially refer to criminological theories and empirical studies, some available software packages do in fact embrace a fully data-driven way of creating risk estimates. The most prominent current example of such an approach is arguably HunchLab by US company Azavea (who sold it to ShotSpotter in 2018). HunchLab is presented as a cutting-edge method for crime prediction, as it is predominantly based on the recognition of correlation patterns in heterogeneous data samples (Azavea, 2015: 16f). Its algorithm, building on machine learning techniques, continuously adapts on the basis of the data that it processes, thus allegedly enabling "the software to 'think' like a crime analyst by imitating years of experience drawn from a police department's own data" (Azavea, 2015: 16).

In summary, there is a broad range of ways in which policing can be rendered "predictive", and there is considerable variation when it comes to the theories, models, and datasets that different approaches require. However, no matter whether they are static or dynamic, whether they are based on limited data points or large and heterogeneous datasets, whether they make use of 
police data or mobilize commercial or open data sources, and whether they are based on rule-based or adaptive algorithms, what all place-based approaches to predictive policing have in common is the fact that they need to be translated into operational measures. Crime cannot be prevented on the basis of advanced analytics alone, but insights from crime analysis must be put into action on the street level in order to unfold possible impacts. This is where predictive policing software meets larger trajectories of police strategies and practices.

The central promise of predictive policing is to reconfigure the patrol as one of the central interaction points between the police, society, and crime and tweak it so that it can be rendered more effective and efficient. The patrol is a key element of police work, and it is particularly pertinent for crime prevention, as it creates police visibility as a key deterrent to criminal behavior. However, the ways in which the police patrol have, in conjunction with technological developments and new crime prevention strategies, undergone major changes over the past few decades. In order to understand how predictive policing fits into these trajectories, the next chapter will provide a brief overview of the role of technology in crime prevention and policing.

\section{Conclusion}

In summary, policing innovations going back to the 1970s have produced numerous novel forms of crime prevention that have paved the way for today's predictive policing tools. Many of them were already heavily predicated on the accumulation and analysis of data. Most importantly, they are connected by the desire to render police work more effective and efficient as a response to a number of external pressures. Predictive policing, we might in this sense conclude, is new - but it is not groundbreaking. It should be considered an evolution rather than a revolution. And yet, it comes with a couple of distinct characteristics that set it apart from older ways of knowledge production, crime prevention, and patrol strategies.

There is also considerable analytical continuity in the development of predictive policing tools. Despite often mobilized narratives about data mining, machine learning, and artificial intelligence, most currently used types of predictive policing are built around theory-based models. In other words, the theory defines the pattern that the algorithm looks for in the data, and not the other way around. A similar argument applies to the data basis that predictive policing operates on. Rather than large, unstructured, and heterogeneous datasets from multiple sources (i.e., "Big Data"), most current predictive tools use small and select datasets to model particular assumed relations between variables. These datasets are usually produced by the police themselves, but they can also integrate data from other sources.

Despite these continuities, predictive policing has the potential to fundamentally reconfigure police work. The criminal futures that it creates have repercussions for internal communication processes within police departments, 
for infrastructural and technical reform, for the professional skills required from today's police officers, for career paths, for public relations, and not least for the ways in which new patrol practices change the ways in which the police and society interact. Before we explore these issues empirically, the next chapter is devoted to the development of a theoretical framework that will enable us to study the implementation of predictive policing and the everyday practices of crime prediction and crime prevention that it engenders.

\section{References}

Ackroyd S, Harper R, Hughes J A, Shapiro D and Soothill K (1992) New Technology and Practical Police Work. Buckingham/Philadelphia: Open University Press.

Anderson C (2008) The End of Theory: The Data Deluge Makes the Scientific Method Obsolete. Wired. 16 July. Available at https://www.wired.com/2008/06/pb-theory/ (accessed 30 April 2020).

Andrejevic M (2017) To Preempt a Thief. International Journal of Communication 11: 879-896.

Angwin J, Larson J, Mattu S and Kirchner L (2016) Machine Bias. ProPublica. 23 May. Available at www.propublica.org/article/machine-bias-risk-assessments-in-criminalsentencing (accessed 30 April 2020).

Aradau C and Blanke T (2017) Politics of Prediction: Security and the Time/Space of Governmentality in the Age of Big Data. European Journal of Social Theory 20(3): 373-391.

Azavea (2015) HunchLab: Under the Hood. Available at https://cdn.azavea.com/pdfs/ hunchlab/HunchLab-Under-the-Hood.pdf (accessed 30 April 2020).

Babuta A (2017) Big Data and Policing: An Assessment of Law Enforcement Requirements, Expectations and Priorities. London: Royal United Services Institute for Defence and Security Studies.

Back D (2016) Big Data on the Beat: Predictive Policing Has Arrived. City Journal. 10 February. Available at www.city-journal.org/html/big-data-beat-14125.html (accessed 30 April 2020).

Balogh D A (2016) Near Repeat-Prediction mit PRECOBS bei der Stadtpolizei Zürich. Kriminalistik 70(5): 335-341.

Beck C and McCue C (2009) Predictive Policing: What Can We Learn from Wal-Mart and Amazon about Fighting Crime in a Recession? The Police Chief 76(11): 18-24.

Becker G S (1968) Crime and Punishment: An Economic Approach. Journal of Political Economy 76(2): 169-217.

Benbouzid B (2019) To Predict and to Manage: Predictive Policing in the United States. Big Data \& Society 6(January-June): 1-13.

Bennett Moses L and Chan J (2018) Algorithmic Prediction in Policing: Assumptions, Evaluation, and Accountability. Policing and Society 28(7): 806-822.

Bierschenk T (2016) Police and State. In Bradford B, Jauregui B, Loader I and Steinberg J (eds.) The SAGE Handbook of Global Policing. London/Thousand Oaks/New Delhi/ Singapore: Sage, 155-178.

Biselli A (2014) How-To Analyze Everyone - Teil XI: Predictive Policing oder wenn Vorurteile Algorithmen fuittern. Netzpolitik.org. 29 July. Available at https://netzpolitik. org/2014/how-to-analyze-everyone-teil-ix-predictive-policing-oder-wenn-vorurteilealgorithmen-fuettern/\#spendenleiste (accessed 30 April 2020).

Bogomolov A, Lepri B, Staiano J, Oliver N, Pianesi F and Pentland A (2014) Once Upon a Crime: Towards Crime Prediction from Demographics and Mobile Data. ICMI'14 Proceedings of the 16th International Conference on Multimodal Interaction, Istanbul, 427-434. 
Bottoms A (2012) Developing Socio-Spatial Criminology. In Maguire M, Morgen R and Reiner R (eds.) The Oxford Handbook of Criminology. Oxford: Oxford University Press, 450-489.

Bowers K and Hirschfeld A (2001) Introduction. In Hirschfeld A and Bowers K (eds.) Mapping and Analysing Crime Data. London/New York: Taylor \& Francis, 1-8.

Bowers K and Johnson S D (2004) The Burglary as a Clue to the Future: The Beginnings of Prospective Hot-Spotting. European Journal of Criminology 1(2): 237-255.

Bowers K, Johnson S D and Pease K (2004) Prospective Hot-Spotting: The Future of Crime Mapping? British Journal of Criminology 44(5): 641-658.

Braga A A (2017) Hot Spots Policing: Theoretical Perspectives, Scientific Evidence, and Proper Implementation. In Teasdale B and Bradley M (eds.) Preventing Crime and Violence. Cham: Springer, 269-279.

Brantingham P J and Brantingham P L (1981) Environmental Criminology. New York: Macmillan.

Bratton W and Knobler P (1998) Turnaround. How America's Top Cop Reversed the Crime Epidemic. New York: Random House.

Bratton W, Morgan J and Malinowski S (2009) Fighting Crime in the Information Age: The Promise of Predictive Policing. LAPD Research Paper. Available at https://publicintelligence.net/lapd-research-paper-fighting-crime-in-the-information-age-the-promise-ofpredictive-policing/ (accessed 30 April 2020).

Bratton W J and Malinowski S W (2008) Police Performance Management in Practice: Taking COMPSTAT to the Next Level. Policing: A Journal of Policy and Practice 2(3): 259-265.

Brayne S (2017) Big Data Surveillance: The Case of Policing. American Sociological Review 82(5): 977-1008.

Brayne S and Christin A (2020) Technologies of Crime Prediction: The Reception of Algorithms in Policing and Criminal Courts. Social Problems. Online first. doi:10.1093/ socpro/spaa004.

Brayne S, Rosenblat A and boyd d (2015) Predictive Policing. Available at www.datacivilrights.org/pubs/2015-1027/Predictive_Policing.pdf (accessed 30 April 2020).

Brüngger R R, Bader R, Kadar C and Pletikosa I (2017) Towards Simulating Criminal Offender Movement Based on Insights from Human Dynamics and Location-Based Social Networks. In Ciampaglia G L, Mashhadi A and Yasseri T (eds.) SocInfo 2017: Social Informatics. Cham: Springer, 458-465.

Bureau of Justice Assistance (2009) Transcript: Perspectives in Law Enforcement - The Concept of Predictive Policing: An Interview with Chief William Bratton. Available at https://bja.ojp.gov/sites/g/files/xyckuh186/files/publications/podcasts/multimedia/ transcript/Transcripts_Predictive_508.pdf (accessed 30 April 2020).

Burgess E W (1928) Factors Determining Success or Failure on Parole. In Bruce A A, Hamo A J, Burgess E W and Landesco J (eds.) The Workings of the Indeterminate Sentence Law and the Parole System in Illinois. Springfield: State of Illinois, 205-249.

Caplan J M and Kennedy L W (2016) Risk Terrain Modeling: Crime Prediction and Risk Reduction. Oakland: University of California Press.

Caplan J M, Kennedy L W and Miller J (2011) Risk Terrain Modeling: Brokering Criminological Theory and GIS Methods for Crime Forecasting. Justice Quarterly 28(2): 360-381.

Chainey S (2014) Crime Mapping. In Bruinsma G and Weisburd D (eds.) Encyclopedia of Criminology and Criminal Justice. New York/Heidelberg/Dordrecht/London: Springer, 416-426.

Chainey S and Ratcliffe J (2005) GIS and Crime Mapping. Chichester: John Wiley \& Sons. 
Chan J and Bennett Moses L (2019) Can "Big Data" Analytics Predict Policing Practice? In Hannem S, Sanders C B, Schneider C J, Doyle A and Christensen T (eds.) Security and Risk Technologies in Criminal Justice. Toronto: Canadian Scholars, 41-82.

Chan J, Brereton D, Legosz M and Doran S (2001) E-Policing: The Impact of Information Technology on Police Practices. Brisbane: Criminal Justice Commission.

Clarke R V (1980) "Situational" Crime Prevention: Theory and Practice. British Journal of Criminology 20(2): 136-147.

Clarke R V (1995) Situational Crime Prevention. In Tonry M and Farrington D P (eds.) Building a Safer Society: Strategic Approaches to Crime Prevention. Chicago: University of Chicago Press, 91-150.

Clarke R V and Felson M S (eds.) (1993) Routine Activity and Rational Choice. New Brunswick: Transaction Publishers.

Cohen L E and Felson M (1979) Social Change and Crime Rate Trends: A Routine Activity Approach. American Sociological Review 44(4): 588-608.

Cope N (2008) 'Interpretation for Action?' Definitions and Potential of Crime Analysis for Policing. In Newburn T (ed.) Handbook of Policing. Cullompton/Portland: Willan Publishing, 404-429.

Cornish D B and Clarke R V (eds.) (1986) The Reasoning Criminal: Rational Choice Perspectives on Offending. New York: Springer.

Crawford A and Evans K (2012) Crime Prevention and Community Safety. In Maguire M, Morgen R and Reiner R (eds.) The Oxford Handbook of Criminology. Oxford: Oxford University Press, 769-805.

de Hert P and Lammerant H (2016) Predictive Profiling and Its Legal Limits. In van der Sloot B, Broeders D and Schrijvers E (eds.) Exploring the Boundaries of Big Data. Amsterdam: Amsterdam University Press, 145-172.

Eck J E and Guerette R T (2012) Place-Based Crime Prevention: Theory, Evidence, and Policy. In Welsh B C and Farrington D P (eds.) The Oxford Handbook of Crime Prevention. Oxford: Oxford University Press, 354-383.

Ekblom P (1998) Situational Crime Prevention: Effectiveness of Local Initiatives. In Goldblatt P and Lewis C (eds.) Reducing Offending: An Assessment of Research Evidence on Ways of Dealing with Offending Behaviour. London: Home Office, 23-38.

Ericson R V and Haggerty K D (1997) Policing the Risk Society. Oxford: Clarendon Press.

Ericson R V and Shearing C (1986) The Scientification of Police Work. In Böhme G and Stehr N (eds.) The Knowledge Society: The Growing Impact of Scientific Knowledge on Social Relations. Dordrecht: Reidel, 129-159.

Eterno J A and Silverman E B (2006) The New York City Police Department's Compstat: Dream or Nightmare? International Journal of Police Science \& Management 8(3): 218-231.

Farrell G and Pease K (eds.) (2001) Repeat Victimization. Monsey: Criminal Justice Press.

Felson M (2006) Crime and Nature. Thousand Oaks/London/New Delhi: Sage.

Ferguson A G (2012) Predictive Policing and Reasonable Suspicion. Emory Law Journal 62(2): 261-325.

Ferguson A G (2016) Predictive Prosecution. Wake Forest Law Review 51(3): 705-744.

Ferguson A G (2017) The Rise of Big Data Policing: Surveillance, Race, and the Future of Law Enforcement. New York: New York University Press.

Gandy O H (2009) Coming to Terms with Chance: Engaging Rational Discrimination and Cumulative Disadvantage. Farnham: Ashgate.

Garland D (1995) Penal Modernism and Postmodernism. In Blomberg T G and Cohen S (eds.) Punishment and Social Control. New York: Aldine de Gruyter, 181-209. 
Garland D (2001) The Culture of Control: Crime and Social Order in Contemporary Society. Oxford: Oxford University Press.

Gerstner D (2019) Using Predictive Policing to Prevent Residential Burglary: Findings from the Pilot Project P4 in Baden-Württemberg, Germany. European Law Enforcement Research Bulletin 10(4): 113-123.

Gill P (2000) Rounding Up the Usual Suspects? Developments in Contemporary Law Enforcement Intelligence. Aldershot: Ashgate.

Glasner P, Johnson S D and Leitner M (2018) A Comparative Analysis to Forecast Apartment Burglaries in Vienna, Austria, Based on Repeat and Near Repeat Victimization. Crime Science 7(9): 1-13.

Goldstein H (1979) Improving Policing: A Problem-Oriented Approach. Crime and Delinquency 25(2): 236-258.

Goldstein H (1990) Problem-Oriented Policing. New York: McGraw Hill.

Gorner J (2013) Chicago Police Use 'Heat List' as Strategy to Prevent Violence. Chicago Tribune. 21 August. Available at http://articles.chicagotribune.com/2013-08-21/news/ ct-met-heat-list-20130821_1_chicago-police-commander-andrew-papachristos-heat-list (accessed 30 April 2020).

Groff E R and La Vigne N G (2002) Forecasting the Future of Predictive Crime Mapping. Crime Prevention Studies 13: 29-57.

Guerry A-M (1833) Essai sur la statistique morale de la France: précédé d'un rapport à l'Académie des Sciences. Paris: Chez Crochard.

Haggerty K D (2001) Making Crime Count. Toronto: University of Toronto Press.

Hannah-Moffat K (2019) Algorithmic Risk Governance: Big Data Analytics, Race and Information Activism in Criminal Justice Debates. Theoretical Criminology 23(4): 453-470.

Harcourt B E (2007) Against Prediction: Profiling, Policing, and Punishing in an Actuarial Age. Chicago/London: The University of Chicago Press.

Hardyns W and Rummens A (2018) Predictive Policing as a New Tool for Law Enforcement? Recent Developments and Challenges. European Journal on Criminal Policy and Research 24(3): 201-218.

Hildebrandt M (2008) Defining Profiling: A New Type of Knowledge? In Hildebrandt $\mathrm{M}$ and Gutwirth S (eds.) Profiling the European Citizen. Cross-Disciplinary Perspectives. Dordrecht/London: Springer, 17-46.

Intrado (no date) Beware Incident Intelligence. Available at www.guidestartech.com/products/downloads/government/Beware\%20Brochure.pdf (accessed 30 April 2020).

Jobard F (2014) Conceptualizing Police. In Bruinsma G and Weisburd D (eds.) Encyclopedia of Criminology and Criminal Justice. New York/Heidelberg/Dordrecht/London: Springer, $515-524$.

Johnson S D, Bernasco W, Bowers K J, Elffers H, Ratcliffe J, Rengert G and Townsley M (2007) Space-Time Patterns of Risk: A Cross National Assessment of Residential Burglary Victimization. Journal of Quantitative Criminology 23(3): 201-219.

Johnson S D, Bowers K, Birks D J and Pease K (2009) Predictive Mapping of Crime by ProMap: Accuracy, Unit of Analysis, and the Environmental Backcloth. In Weisburd D, Bernasco W and Bruinsma G (eds.) Putting Crime in its Place: Units of Analysis in Geographic Criminology. Dordrecht/Heidelberg/London/New York: Springer, 171-198.

Johnston L and Shearing C D (2003) Governing Security: Explorations in Policing and Justice. London/New York: Routledge.

Jones T and Newburn T (1998) Private Security and Public Policing. Oxford: Oxford University Press. 
Jones T, Newburn T and Reiner R (2017) Policing and the Police. In Liebling A, Maruna S and McAra L (eds.) The Oxford Handbook of Criminology. 6th Edition. Oxford: Oxford University Press, 769-796.

Jouvenal J (2016) The New Way Police Are Surveilling You: Calculating Your Threat Score. Washington Post. 10 January. Available at www.washingtonpost.com/local/public-safety/ the-new-way-police-are-surveilling-you-calculating-your-threat-score/2016/01/10/ e42bccac-8e15-11e5-baf4-bdf37355da0c_story.html (accessed 30 April 2020).

Kadar C, Maculan R and Feuerriegel S (2019) Public Decision Support for Low Population Density Areas: An Imbalance-Aware Hyper-Ensemble for Spatio-Temporal Crime Prediction. Decision Support Systems 119: 107-117.

Kaufmann M, Egbert S and Leese M (2019) Predictive Policing and the Politics of Patterns. British Journal of Criminology 59(3): 674-692.

Kelling G L, Pate T, Dieckman D and Brown C E (1974) The Kansas City Preventive Patrol Experiment: A Summary Report. Washington, DC: Police Foundation.

Kemshall H (2003) Understanding Risk in Criminal Justice. Philadelphia: Open University Press.

Kennedy L W, Caplan J M and Piza E L (2011) Risk Clusters, Hotspots, and Spatial Intelligence: Risk Terrain Modeling as an Algorithm for Police Resource Allocation Strategies. Journal of Quantitative Criminology 27(3): 339-362.

Kennedy L W, Caplan J M and Piza E L (2018) Risk-Based Policing. Evidence-Based Crime Prevention with Big Data and Spatial Analytics. Oakland: University of California Press.

Latessa E J and Lovins B (2014) Risk Assessment, Classification, and Prediction. In Bruinsma G and Weisburd D (eds.) Encyclopedia of Criminology and Criminal Justice. New York/ Heidelberg/Dordrecht/London: Springer, 4457-4466.

Laycock G and Farrell G (2003) Repeat Victimization: Lessons for Implementing ProblemOriented Policing. In Knutsson J (ed.) Problem-Oriented Policing: From Innovation to Mainstream. Monsey: Criminal Justice Press, 213-237.

Leese M (2014) The New Profiling: Algorithms, Black Boxes, and the Failure of Antidiscriminatory Safeguards in the European Union. Security Dialogue 45(5): 494-511.

Lum K and Isaac W (2016) To Predict and Serve? Significance 13(5): 14-19.

Maguire M (2016) Criminal Statistics and the Construction of Crime. In Bradford B, Jauregui B, Loader I and Steinberg J (eds.) The Sage Handbook of Global Policing. London/ Thousand Oaks/New Delhi/Singapore: Sage, 206-244.

Manning P K (2008) The Technology of Policing: Crime Mapping, Information Technology, and the Rationality of Crime Control. New York/London: New York University Press.

Mantello P (2016) The Machine That Ate Bad People: The Ontopolitics of the Precrime Assemblage. Big Data \& Society (July-December): 1-11.

Martinson R (1974) What Works? Questions and Answers about Prison Reform. The Public Interest 35: 22-54.

McCarthy G F (2015) Custom Notifications in Chicago: Special Order S10-05. Chicago: Chicago Police Department. Available at http://directives.chicagopolice.org/directives/data/ a7a57bf0-1456faf9-bfa14-570a-a2deebf33c56ae59.html (accessed 30 April 2020).

McCue C (2007) Data Mining and Predictive Analysis: Intelligence Gathering and Crime Analysis. Burlington/Oxford: Elsevier.

McCue C and Parker A (2003) Connecting the Dots: Data Mining and Predictive Analytics in Law Enforcement and Intelligence Analysis. The Police Chief 70(10): 115-122.

McCulloch J and Wilson D (2016) Pre-crime: Pre-emption, Precaution and the Future. London/ New York: Routledge. 
Miranda D (2015) Criminal Investigation through the Eye of the Detective: Technological Innovation and Tradition. Surveillance \& Society 13(3/4): 422-436.

Mohler G O, Short M B, Brantingham P J, Schoenberg F P and Tita G E (2011) SelfExciting Point Process Modeling of Crime. Journal of the American Statistical Association 106(493): 100-108.

Mohler G O, Short M B, Malinowski S, Johnson M, Tita G E, Bertozzi A L and Brantingham P J (2015) Randomized Controlled Field Trials of Predictive Policing. Journal of the American Statistical Association 110(512): 1399-1411.

Mulone M (2019) History of Policing. In Deflem M (ed.) The Handbook of Social Control. Hoboken/Chichester: John Wiley \& Sons, 209-220.

Nix J (2015) Predictive Policing. In Dunham R G and Alpert G P (eds.) Critical Issues in Policing: Contemporary Readings. 7th Edition. Long Grove: Waveland Press, 275-288.

Orr B (2012) LAPD Computer Program Prevents Crime by Predicting it. CBS News. 11 April. Available at www.cbsnews.com/news/lapd-computer-program-prevents-crimeby-predicting-it/ (accessed 30 April 2020).

Papachristos A V (2009) Murder by Structure: Dominance Relations and the Social Structure of Gang Homicide. American Journal of Sociology 115(1): 74-128.

Papachristos A V, Braga A A and Hureau D M (2012) Social Networks and the Risk of Gunshot Injury. Journal of Urban Health 89(6): 992-1003.

Pearsall B (2010) Predictive Policing: The Future of Law Enforcement? NIJ Journal (266): 16-19.

Pelzer R (2018) Policing of Terrorism Using Data from Social Media. European Journal for Security Research 3(2): 163-179.

Perry W L, McInnis B, Price C C, Smith S C and Hollywood J S (2013) Predictive Policing: The Role of Crime Forecasting in Law Enforcement Operations. Santa Monica: RAND Corporation.

Quetelet L A J (1842) A Treatise on Man and the Development of His Faculties. Edinburgh: W. and R. Chambers.

Ratcliffe J (2014) Intelligence-Led Policing. In Bruinsma G and Weisburd D (eds.) Encyclopedia of Criminology and Criminal Justice. New York/Heidelberg/Dordrecht/London: Springer, 2573-2579.

Ratcliffe J (2016) Intelligence-Led Policing. 2nd Edition. London/New York: Routledge.

Ratcliffe J (2019) Reducing Crime: A Companion for Police Leaders. London/New York: Routledge.

Richardson R, Schultz J and Crawford K (2019) Dirty Data, Bad Predictions: How Civil Rights Violations Impact Data, Predictive Policing Systems, and Justice. NYU Law Review Online 192: 1-30.

Robinson D and Koepke L (2016) Stuck in a Pattern: Early Evidence on "Predictive Policing" and Civil Rights. Washington, DC: Upturn.

Saunders J, Hunt P and Hollywood J S (2016) Predictions Put into Practice: A Quasiexperimental Evaluation of Chicago's Predictive Policing Pilot. Journal of Experimental Criminology 12(3): 347-371.

Savage S P (2007) Police Reform: Forces for Change. Oxford: Oxford University Press.

Schauer F (2003) Profiles, Probabilities and Stereotypes. Cambridge/London: Belknap Press of Harvard University Press.

Schinkel W (2011) Prepression: The Actuarial Archive and New Technologies of Security. Theoretical Criminology 15(4): 365-380.

Schweer T (2015) "Vor dem Täter am Tatort" - Musterbasierte Tatortvorhersagen am Beispiel des Wohnungseinbruchs. Die Kriminalpolizei 32(1): 13-16. 
Schweer T (2016) Predictive Policing - Straftaten erkennen und verhindern, bevor sie passieren. Deutsches Polizeiblatt 34(1): 25-27.

Shapiro A (2019) Predictive Policing for Reform? Indeterminacy and Intervention in Big Data Policing. Surveillance \& Society 17(3/4): 456-472.

Sheehey B (2019) Algorithmic Paranoia: The Temporal Governmentality of Predictive Policing. Ethics and Information Technology 21(1): 49-58.

Sherman L W, Gartin P R and Buerger M E (1989) Hot Spots of Predatory Crime: Routine Activities and the Criminology of Place. Criminology 27(1): 27-56.

Sherman L W and Weisburd D (1995) General Deterrent Effects of Police Patrol in Crime "Hot Spots": A Randomized, Controlled Trial. Justice Quarterly 12(4): 625-648.

Short M B, Brantingham P J, Bertozzi A L and Tita G E (2010) Dissipation and Displacement of Hotspots in Reaction-Diffusion Models of Crime. Proceedings of the National Academy of Sciences 107(9): 3961-3965.

Sidebottom A and Wortley R (2016) Environmental Criminology. In Piquero A R (ed.) The Handbook of Criminological Theory. Chichester: Wiley Blackwell, 156-181.

Skogan W G (2008) An Overview of Community Policing: Origins, Concept and Implementation. In Williamson T (ed.) The Handbook of Knowledge-Based Policing Current Conceptions and Future Directions. Chichester: John Wiley \& Sons, 43-58.

Smith M J and Clarke R V (2012) Situational Crime Prevention: Classifying Techniques Using "Good Enough" Theory. In Welsh B C and Farrington D P (eds.) The Oxford Handbook of Crime Prevention. Oxford: Oxford University Press, 291-315.

Sommerer L (2017) Geospatial Predictive Policing - Research Outlook \& a Call for Legal Debate. Neue Kriminalpolitik 29(2): 147-164.

Stanley J (2014) Chicago Police "Heat List" Renews Old Fears about Government Flagging and Tagging. ACLU. 25 February. Available at www.aclu.org/blog/privacy-technology/ chicago-police-heat-list-renews-old-fears-about-government-flagging-and (accessed 30 April 2020).

Tayebi M A and Glässer U (2016) Social Network Analysis in Predictive Policing. Basel: Springer. Telep C W and Weisburd D (2014) Hot Spots and Place-Based Policing. In Bruinsma G and Weisburd D (eds.) Encyclopedia of Criminology and Criminal Justice. New York/Heidelberg/ Dordrecht/London: Springer, 2352-2363.

Terpstra J, van Stokkom B and van der Vijver K (2014) Community Policing. In Bruinsma $\mathrm{G}$ and Weisburd D (eds.) Encyclopedia of Criminology and Criminal Justice. New York/Heidelberg/Dordrecht/London: Springer, 416-426.

Thomson S (2018) 'Predictive Policing': Law Enforcement Revolution or Just New Spin on Old Biases? Depends Who You Ask. CBC News. 24 September. Available at www.cbc. $\mathrm{ca} /$ news/world/crime-los-angeles-predictive-policing-algorithms-1.4826030 (accessed 30 April 2020).

Tilley N (2008) Modern Approaches to Policing: Community, Problem-Oriented and Intelligence-Led. In Newburn T (ed.) Handbook of Policing. 2nd Edition. Cullompton/ Portland: Willan Publishing, 373-403.

Townsley M, Homel R and Chaseling J (2003) Infectious Burglaries: A Test of the Near Repeat Hypothesis. British Journal of Criminology 43(3): 615-633.

Trojanowicz R C and Bucqueroux B (1990) Community Policing. Cincinnati: Anderson.

Uchida C D (2009) Predictive Policing in Los Angeles: Planning and Development. Justice \& Security Strategies, Inc. Available at newweb.jssinc.org/wp-content/uploads/2012/01/ Predictive-Policing-in-Los-Angeles.pdf (accessed 8 November 2019). 
van Brakel R and de Hert P (2011) Policing, Surveillance and Law in a Pre-crime Society: Understanding the Consequences of Technology Based Strategies. In De Pauw E, Ponsaers P, Van der Vijver K, Bruggeman W and Deelman P (eds.) Technology-Led Policing. Antwerpen/Apeldoorn/Portland: Maklu, 163-192.

Walsh W F (2001) Compstat: An Analysis of an Emerging Police Managerial Paradigm. Policing: An International Journal 24(3): 347-362.

Wang X, Gerber M S and Brown D E (2012) Automatic Crime Prediction Using Events Extracted from Twitter Posts. In Yang S J, Greenberg A M and Endsley M R (eds.) Social Computing, Behavioral-Cultural Modeling and Prediction. Berlin/Heidelberg: Springer, 231-239.

Weisburd D and Eck J E (2004) What Can Police Do to Reduce Crime, Disorder, and Fear? The Annals of the American Academy of Political and Social Science 593(1): 42-65.

Weisburd D and Telep C W (2014) Hot Spots Policing: What We Know and What We Need to Know. Journal of Contemporary Criminal Justice 30(2): 200-220.

Willis J J (2014) A Recent History of the Police. In Reisig M D K and Robert J (eds.) The Oxford Handbook of Police and Policing. Oxford/New York: Oxford University Press, 3-33.

Wilson D (2019) Platform Policing and the Real-Time Cop. Surveillance \& Society 17(1/2): 69-75.

Wortley R and Townsley M (eds.) (2017) Environmental Criminology and Crime Analysis. London/New York: Routledge.

Završnik A (2019) Algorithmic Justice: Algorithms and Big Data in Criminal Justice Settings. European Journal of Criminology. Online first. doi:10.1177/1477370819876762.

Zedner L (2007) Pre-crime and Post-criminology? Theoretical Criminology 11(2): 261-281. 


\section{The police and technology}

This chapter develops an understanding of technology within police contexts and introduces a theoretical framework for our analysis of predictive policing practices. The police do have a long-standing relationship with technology. Technology is at times framed as a "silver bullet" that will be able to fix all of the police's problems (Marx, 1995), and police organizations have over the past century or so incorporated a plethora of technological tools for different purposes, from patrol cars and two-way radio to DNA forensics (Nogala, 1995; Byrne and Marx, 2011; Ariel, 2019). At times, the police have been the drivers of technological innovation. At other times, they have had to cope with the repercussions of implementing new technologies into established strategies, tactics, and operations. Against this backdrop, the relationship between the police and technology is not easily defined. Research suggests that it should best be understood as a mutually constitutive one in which the police shape technologies, and technologies simultaneously reshape how the police fulfil their tasks by facilitating new capabilities and forms of action (Ackroyd et al., 1992; Manning, 1992a, 1992b; Ericson and Haggerty, 1997; Chan, 2001; Chan et al., 2001; Manning, 2008). The first part of this chapter reviews the specific relations between technology and police organizations.

The second part of the chapter conceptualizes the emergence of sociotechnical systems around new technological tools. Building on seminal works from criminology, sociology, and Science and Technology Studies (STS), we propose to study technology not as a variable that can be analytically isolated. Rather, it should be understood as entangled within larger sociotechnical systems that involve a multiplicity of human and nonhuman as well as material and nonmaterial elements. Implementing a new technological tool into an already complex police assemblage that consists of data and patrol cars as much as it does of formal divisions of labor, occupational cultures, and established work practices tends to produce a number of frictions, adjustments, unintended side effects, and practical reappropriations. STS approaches that highlight how technologies come into being through a web of relations can help us to understand how they end up in a specific form and with specific functionalities that correspond with their operational environment. As Ackroyd et al. (1992: 26) have diagnosed 
with regard to the implementation of early information technology (IT) systems in police organizations:

Devising information systems that can serve as instruments of police work requires some conception about the nature of that work, how it is organized day-to-day, what tacit understandings are built into this organization, its situatedness within a network of other organizational arrangements, and so on. And, wider than this, what authoritative expectations are placed on, in our particular concern, the police themselves and what relation their work is to have to, for example, the public, the state, the community and, not to be forgotten, its own members. All of these considerations, and more, are important to understand the role of IT within the police.

Building on such an understanding of how sociotechnical systems emerge in practice, we analyze how police departments were able to carve out an experimental space within which they could observe the formation of sociotechnical relations and tweak these formations such that predictive policing would align with a number of organizational and political priorities. They primarily managed to do so by framing the implementation of predictive policing in terms of trial runs, field tests, and research projects, allowing them to explore its capacities and effects in mutual dialogue with developers. Due to the degree of variation between different police departments, there can in fact hardly be any off-the-shelf solutions for predictive policing. Instead, we highlight how predictive policing needed to be carefully shaped with regard to specific institutional needs and infrastructures.

The last part of the chapter introduces the notion of "translation" (Callon, 1980b, 1984; Latour, 1984) as an analytical lens for the everyday practices of predictive policing with which we are primarily concerned throughout this book. STS scholars have developed a sociology of translation to study how knowledge and power are produced through the interactions of different human and nonhuman elements within sociotechnical systems. We suggest an understanding of translation processes that allows us to investigate the "hinges" in predictive policing processes: How crime is turned into data, how algorithmically produced risk estimates become confirmed and communicated, and how patrol officers bring analytical insights to the streets. The question that translation allows us to formulate and address, in its essence, is this: How does an algorithm move people? Studying predictive policing practices as a "chain of translation" (Latour, 1999: 311) foregrounds how different social and technical elements need to be brought together and aligned in order to make predictive policing work.

\section{Technology and police organization}

The impetus of technology, as Mastrofski and Willis (2010: 79-80) write, pertains to virtually all domains of police work, including "coercion (weapons and 
martial arts), mobility (transportation vehicles), detection (forensics methods, such as DNA analysis), surveillance (closed-circuit-television [CCTV], digital imaging for facial recognition, and remote sensing devices), and analysis (data mining software)". In fact, technology appears attractive for the police for various reasons. From a practical perspective, it equips them with new capacities and modes of action (Harper, 1991). And from a political and managerial point of view, technological innovation is often regarded as a suitable strategy to address perceived police failure (Weisburd and Braga, 2019: 11). This applies, as we discussed in the previous chapter, to the issue of crime itself (i.e., crime rates and clearance rates) but also to questions of efficiency and accountability of the police, both internally and vis-à-vis the public (Chan et al., 2001: 3). Technology has in this sense sparked an increased managerialism that measures police work according to criteria that have carried over from the business world such as efficiency, controlling, and optimized working processes (O'Malley and Palmer, 1996). Finally, the incorporation of new technological tools has, over the last few decades, contributed to the professionalization of the police as an organization (Ericson and Haggerty, 1997).

In light of such considerations, criminologists and sociologists have studied how specific technologies have transformed the police in particular ways. Seminal empirical works such as those by Ackroyd et al. (1992), Manning (1992a, 1992b, 2008), Ericson and Haggerty (1997), and Chan (Chan, 2001; Chan et al., 2001) have drawn attention to the intricacies of "fitting" technologies into police organizations. These studies, broadly revolving around the implementation of IT systems in police departments, show how the effects of new technologies are anything but straightforward and might in some cases differ considerably from the goals and intentions that were the initial drivers behind their development or procurement. In the words of Manning (1992b), the introduction of new technologies can even cause outright "drama" in the form of internal resistance and discursive statements that counter the alleged benefits of new tools. Such resistance can be traced to the capacities of disruptive technological tools to "erode or destabilize long-standing organizational practices" (Manning, 1992b: 328). The more a new technology is seen to threaten to restructure entrenched working cultures, the more likely it is to be met with hostility (Sanders and Condon, 2017).

Other scholars have similarly foregrounded modes of actively resisting the impact of new technologies and how such resistance is facilitated by the institutional inertia of police organizations. Chan et al. (2001) have shown that even though structural conditions might be changing due to the novel or enhanced capacities that technologies bring to police work, cultural assumptions and traditional policing practices often remain unchanged. Thus, new tools may at times end up being aligned with established processes rather than fundamentally reforming how police officers approach their tasks. As they argue, "giving police access to computers, increasing the range and quantity of information that is stored electronically and automating what were previously manual 
processes will not change how the business of policing is conducted by the agency" (Chan et al., 2001: vii). These findings do not rule out the possibility of organizational change. They do, however, direct our attention to the fact that technology is not the clear-cut, easily applicable variable that politicians, private companies, and not least police managers at times seem to believe it is. Technology, in fact, "more often ... has changed police work in unexpected ways; less often has it enhanced work" (Ackroyd et al., 1992: 13).

From the perspective of organizational theory, the clash between technoscientific imaginaries of improvement and efficiency on the one hand and the unanticipated or negligible consequences of implementation and everyday use of technological tools on the other does not in fact come as much of a surprise. Maguire (2003) has pointed out how the organization of police departments is firmly rooted in historical trajectories and national, regional, and local specificities. Together these specificities account for the large degree of variation between different police organizations, but they also hint at why change, although often inevitable in the long run, is likely to occur only slowly and over longer periods of adjustment (Vera and Jablonowski, 2017). These findings correspond closely with Braga and Weisburd's (2019: 556) argument that "police history shows that it takes a long time for new models of policing to fully develop".

Others have pointed out how technological innovation, once it found traction within police organizations, has transformed the ways in which the police carry out their mandate and how they position themselves vis-à-vis society. Ericson and Haggerty (1997) have analyzed how the introduction of computers and incipient digitization of police data throughout the 1990s enabled the police to turn to risk as a practical guiding principle in unprecedented ways. Driven by the newly found desire to accumulate data in order to render risk assessment procedures more powerful and accurate, the profession of the police officer took a turn toward "knowledge work" (Ericson and Haggerty, 1997) and "rationalization" (Manning, 2001, 2008) that was characterized by the ability to exploit data and quantify decision-making processes and ensuing action. Technology can in this sense contribute to the formation of novel organizational goals and strategies at a higher level (Byrne and Marx, 2011: 17). As we argued in the previous chapter, such strategic change became particularly pertinent with regard to new approaches to crime prevention and their development alongside technological innovations.

Just as well, technological tools have given the police a scientific appeal. Police work, understood in terms of the production and management of knowledge, in fact in some regards closely resembles scientific practices. This is demonstrated, for example, by methods such as digital forensics (Holt et al., 2015), DNA analyses (McCartney, 2005), fingerprinting (Cole, 2001), and drug testing (Paul and Egbert, 2016). These practices claim to produce credible evidence by means of the application of scientific theories and methods, thereby claiming to establish "truth" in criminal investigations (Lynch et al., 
2008). In doing so, they make use of criminological theories or hypotheses (usually quantitative ones) that guide and support innovative forms of mobilizing technologies and data for police purposes. The assumption here is that a scientifically informed perspective will not only yield superior results but also be more objective and accountable (Cole, 2017).

As became apparent throughout our research, the production of crime risk makes no difference in this regard (D013; D016). Police departments would claim that their philosophy was fundamentally based on research (I02; I18; I35; I48; I62; P49; P75) and referred to predictive policing as "the science of where" (P49). As a matter of fact, German and Swiss police departments have subscribed to a technoscientific attitude that includes sending representatives to conferences and generally keeping an open mind toward allegedly innovative and research-based technologies (I07; I12; I76; I80). The presentation of predictive policing as an avenue toward data-driven, evidence-based police work that would be superior to traditional crime analysis thus fell on fertile ground (P49). A scientific approach to the production of risk was in this sense seen as a possibility to lend enhanced credibility to crime analysis, both internally and toward the public (I20).

However, scientific aspirations and the crime analysis techniques that go with them also require new skills and forms of knowledge that are necessary to perform police work. Being literate in working with information and communication technologies became a requirement for keeping up with the changing tools and methods of police work throughout the 1990s and early 2000s (Wilz and Reichertz, 2008). As Chan et al. (2001: xvii) have argued, police knowledge became "synonymous with data that are too complex and voluminous for the human brain to cope with", and the capacity to command new technological tools to harness and apply such knowledge became essential for the profession of the police officer. Modern police work is increasingly conceived of as an interdisciplinary process that relies on specialized knowledge in a number of distinct domains and requires collaboration between different experts in order to achieve the desired results (Ericson, 1994; Ericson and Haggerty, 1997: 19ff).

When it comes to predictive policing in particular, police departments now face the challenge to assemble expertise in data science. As data need to be cleaned and prepared for analysis, data from different sources need to be integrated and managed, and algorithmic crime analysis tools need to be configured and maintained, skilled personnel are needed. Our interviewees in fact foregrounded how the police are in need of specialized experts and how this need clashes with established police career paths and training programs (I31; I50; P61; D142). Traditionally, within Swiss and German police organizations, officers are considered "generalists" who need to be proficient in all fields of police work (Mahnken and Rabitz-Suhr, 2019: 23f). Accordingly, standard career tracks require that officers pass through different specialized divisions in order to gain a coherent perspective on the tasks and organizational processes of police departments. Importantly, this is seen as a requirement for promotion 
into strategic or management positions. On the flip side, such a career path, however, means that specialized knowledge periodically gets lost, as individual officers are transferred between divisions.

As a result, police departments are looking for new methods of institutional knowledge management (I12; I17; I18; I31; P49). Calls for new career tracks within single domains have been put forward (Wendekamm and Model, 2019: 275), and some departments have used the implementation of predictive policing technology as an opportunity to consider or put into practice such specialized career paths for data scientists and other scientific staff (I31; I51; P61). In some departments, this has produced up to a 50/50 split between police officers and scientists/researchers within crime analysis divisions (I79; P19). And in cases where the requirements for this "new knowledge and information culture" (P61) could not be met from internal staff, additional scientific expertise was brought in from the outside (P30). The turn toward science is also reflected in the fact that some of the departments we studied had started to recruit staff with degrees in forensics or crime analysis straight out of university (I18; I26; I42; I78; I79; P18) or had implemented their own in-house research and development units (I75; I76). We will pick up these tendencies once more in the context of structural reform in Chapter 10.

This reinforced attention to specialized skills and expertise was generally considered a welcome tendency, as it could arguably help to overcome entrenched yet ineffective internal organizational structures. More senior officers, in particular, tended to look strategically beyond the immediate operational capacities of predictive policing and hinted at the potential long-term effects of a reinforced focus on advanced algorithmic forms of data analysis:

[Predictive policing] has a number of positive side-effects: you change police culture, and there is a need for our police culture to change. There will be new professional fields within the police, analysts will have a very different status. Technology will have a very different status.

Another way in which scientific aspects figured into the emergence of predictive policing technology concerned the modes in which field trials were set up and evaluated. Framed as "research projects" to begin with, development and field-testing of predictive policing software were scientifically accompanied or supported by external research institutions (P49) or carried out in cooperation with universities (I02; I18). Such collaborations were supposed to ensure that both methods and results could be considered "scientifically sound", thus creating legitimacy for predictive policing methods. Evaluation was moreover supported by several accompanying studies in the form of bachelor's and master's theses (I18; I44; I51; I76; I77; I78; I79; P20; D013; D016) that served to further demonstrate the scientific seriousness with which police departments approached predictive policing. 
Despite the various ways in which the police render themselves and their activities "scientific", one should, however, keep in mind that differences remain between the formalized, rigorous ways of scientific knowledge production that take place within the academic community and the "practical science" that can at times be encountered in police work. Geared toward the practical prevention of crime, police scientification should in fact be understood as a much more hands-on and less rigorous practice. When in doubt, in other words, not everything needs to comply with high scientific standards, but it suffices when things are workable and applicable (P49).

Scholars have also pointed out how new technologies have changed the ways in which the police regulate themselves internally (Mastrofski and Willis, 2010: 57). Digital work practices can rather easily be quantified, tracked, and analyzed (Whitson, 2013; Walz and Deterding, 2014). From a managerial perspective, technology renders the police transparent not only toward the public but also for internal purposes of human resources management, the assessment of officers' performance, and decisions about promotions (Sheptycki, 2017). However, the continuous measurement of performance rates has also produced a number of unintended side effects, the most prominent of these being the adjustment of work practices so that they are more likely to produce outcomes matching the evaluation criteria. Innovations like COMPSTAT, widely praised for incentivizing rationalization and efficiency in police work (Willis et al., 2007), have in this sense brought about a "gamification" of police work that is primarily interested in tangible and quantifiable results such as individual arrest rates or the "improvement" of crime statistics for a given district (Eterno and Silverman, 2012).

New police technologies, mainly those geared toward surveillance and intelligence production, have also been met with a good deal of normative skepticism in academic analyses. The implementation of information and communication technologies, in particular, has sparked concerns. Against the backdrop of unprecedented capacities to accumulate and process data, scholars have warned against increased, potentially pervasive police powers (Marx, 1988; Lyon, 1992). Such concerns are still prevalent, although they are, against the backdrop of digitization, large databases, and complex algorithmic analyses, now geared toward novel challenges. Fears of a "maximum security society" (Marx, 1988: 221) within a liberal democratic framework (Lyon, 1992) are, however, persistent in current debates about surveillance, discrimination, profiling, and algorithmic bias in predictive policing (Ferguson, 2017; Bennett Moses and Chan, 2018; Brayne, 2021). We will return to such questions in more detail in Chapter 9.

Finally, sparked by insights into the largely unforeseeable and sometimes even creative methods with which police forces have absorbed new technologies and accompanying managerial logics, a prevalent theme throughout criminological and sociological analyses of technology and police organizations has been the question of how to determine whether the implementation 
of a specific tool or set of tools can be considered a "success". The question of success must be understood in relation to the hopes and rationales that motivated the decision to implement a technology in the first place. Success would thus usually be defined in terms of questions such as "Did the technology improve effectiveness and efficiency?" or "Did the technology produce the desired results (for example, reducing crime statistics or improving clearance rates)?" However, this kind of straightforward conceptualization of success would hardly align with the findings from the literature we have discussed.

Rather than subscribing to determinist arguments about the capacities of technological tools, their success (or failure) must be carefully measured against wider contexts that affect how the police function as an organization and within society. In order to do so, Chan et al. (2001: 8) propose that when thinking about technological change, we should not only consider technical factors but also account for cultural and political ones. Cultural factors, in their view, include the values and assumptions that informed the development and design of a technology and how these correspond with the values and assumptions of the organizational context in which the technology is supposed to be used. Political factors are the interests and positions of different actors within processes of technological change. In cases where technical, cultural, and political positions cannot be broadly aligned, it is likely that internal resistance will occur and undermine at least some of the potential new technical capacities (Manning, 1992b). As Chan and Bennett Moses (2017: 316) have argued with regard to predictive policing,

a better understanding of how cultural assumptions (part of habitus) can influence the impact of new technology is not only important for managing technological change within organisations, but also for designing regulatory or governance regimes (other techniques of security) for the benefit of the broader community.

Overall, Chan et al. (2001: 13) propose five criteria that are likely to play decisive roles in answering the question of whether the implementation of a new technology can be considered a success: (1) the technology itself and its design, (2) the form of the implementation process, (3) potential clashes between the technological imaginaries of designers and the practical needs of users, (4) resulting shifts in power balances and responsibilities within the organization, and (5) resulting additional forms of accountability toward the public. All these criteria are in themselves complex issues that might not be easily resolved. Taken together, they outline the multilevel challenges that police agencies have to face in coming to terms with new technological tools that are often imposed on them from the outside (i.e., by politicians, police managers, and private companies). We will empirically pick up questions of the success of predictive policing and how such success (or failure) might be measured and evaluated in Chapter 8. 
In summary, existing criminological and sociological works on the role of technology within the police have pointed to the complex and sometimes unpredictable ways in which organizational change happens. Most of the literature agrees that while organizational change will occur on many different levels of police work, it will seldom do so exclusively in the intended forms. Rather, studies have highlighted how technologies have restructured the tasks that the police need to address and how they do so, they have highlighted how the profession of the police officer has changed according to new organizational goals, and they have highlighted how managerialism has increasingly colonized how the police analyze themselves and carry out internal checks. Overall, as Braga and Weisburd (2019: 555) argue, police organizations are averse to fundamental change, as they "most easily adopt innovations that require the least radical departures from their hierarchical paramilitary organizational structures, continue incident-driven and reactive strategies, and maintain police sovereignty over crime issues". These findings are in fact very much in line with what our interlocutors told us (I09; I18; I77). As one senior officer framed it:

The job description favors skepticism, and many police officers are rather conservative. They are comfortable within a familiar environment, where they know how things work, where they can replicate successful routines. And if there's something new, regardless in which area ... new things in our department were always difficult and it took some time to settle in. . . There are simply lots of people who have their routines, who have been doing their thing for twenty years - and it has worked for twenty years. And then there's some innovation or reform, and the reaction is: "But we have always done it like this and it has worked, why should we change it now?"

Moreover, general concerns about technology-induced change are aggravated by the digital, arguably reinforced through the dystopian narratives about predictive policing that can be found throughout science fiction and media accounts of future law enforcement (Mor, 2014; Gent, 2017). These narratives are largely characterized by imaginaries of automation, artificial intelligence, and black-boxed technologies that can no longer be understood by humans. It is interesting to note that fears about such scenarios are not only prevalent in critical academic analyses or civil rights activists' accounts but are also uttered by police officers. As one respondent framed it:

Automation is something that creates concerns: should we be afraid of algorithmization, of robotization, and such things? That's probably not only a police concern, but also a concern for other professional fields. There are already police robots in America, devices that patrol with sensors and report incidents. This will happen here as well. 
We will deal at greater length with how the police deal internally with automation and novel configurations between humans and machines in Chapter 5. For now, in light of the multiple ways in which police organizations and technologies mutually influence and transform each other, the task is to develop a theoretical understanding of the relationship between the police and technology. For this task, we propose to turn to STS literature. The criminological and sociological findings we have discussed so far correspond well with conceptual STS work pointing to the inevitable embeddedness of technology within wider societal and organizational frames.

\section{The emergence of sociotechnical systems}

For Jasanoff (1996, 2004), science and technology and the forms of knowledge and action they enable and facilitate are key to understanding how particular forms of social order are produced and maintained. STS as a discipline to a large extent emerged from conceptual discontent with sociology's treatment of science and technology in the attempt to explain the constitution of social order. Rather than upholding an artificial analytical separation between the technical and the social as different spheres, STS scholars propose to think of the social and the technical as inextricably entangled within a "seamless web" (Hughes, 1986). In the words of Law (1991: 10), "what appears to be social is partly technical. What we usually call technical is partly social. In practice nothing is purely technical. Neither is anything purely social."

STS thus suggests to study the social and the technical in an entwined fashion, conceptually understanding them as sociotechnical systems that are comprised of heterogeneous material and nonmaterial elements (Latour, 1991; Bijker and Law, 1992). However, approaching the social and the technical as enmeshed and mutually constitutive phenomena does not merely mean acknowledging the complexity (and messiness) of empirical realities but also serves to problematize reductionist ontologies and to dismantle naive or consciously simplistic (political) statements about the capacities of technologies.

STS proposes that technology is neither something that is exclusively the result of social relations (and that thus would be fully controllable by humans) nor an uncontrollable external force that determines social order. Rather, technology comes to matter through a multiplicity of relations and interactions with its environment. Research into the role and effects of sociotechnical systems thus needs to account for specific configurations around technologies in order to enable localized and context-dependent perspectives on how technology comes to matter (Suchman, 2007). To a certain extent, such a stance rules out generalizable statements about science and technology and their role within society. STS must rather be understood as an empirical research program that aspires to cover sociotechnical constellations through qualitative and especially ethnographic methods that serve to create an in-depth understanding of the variegated relations and entanglements throughout sociotechnical systems (Latour, 1993). 
Such an approach corresponds well with analyses of technology within idiosyncratic contexts of regional or local police agencies. In fact, Ackroyd et al. (1992) similarly draw on a sociotechnical understanding when exploring how new technological tools enter police organizational contexts. As they write:

As a social object, technology needs to be understood not simply as the nuts and bolts, the wires and transistors, the keyboards and semiconductors, but also as the collage of activities involved in its use. One could go further and insist that technology as nuts and bolts is but the material instantiation of a complex set of ideas, knowledge and activities, which not only make it possible to design and build a piece of technology, but also to shape and guide its use.

(Ackroyd et al., 1992: 10)

An important strand of STS literature concerns the question of how technology comes into being. Starting from the premise that "both science and technology are socially constructed cultures and bring to bear whatever cultural resources are appropriate for the purposes at hand" (Pinch and Bijker, 1984: 404), STS scholars have analyzed these cultural resources and the ways in which they factor into the creation of scientific knowledge and the design of technological objects. Researchers have in this sense highlighted how technological innovations come into being through dense networks of multiple actors and in close correspondence with existing infrastructures and other material factors (Callon, 1980a; Hughes, 1983; Bijker et al., 1987; Callon, 1991). Going against the popular notion that innovations can be reduced to the ideas of a single brilliant inventor, the STS paradigm thereby contends that epistemic and material innovation emerges through complex social interactions, cultural norms, political dynamics, and historical trajectories (Callon, 1984; Pinch and Bijker, 1984; Latour and Woolgar, 1986; Law, 1987).

In doing so, STS approaches reject the teleological assumptions that can be found in essentialist or determinist understandings of technology. Innovation does not follow a predefined path of incremental technological development that will inevitably lead to some (desirable) end point (Godin and Vinck, 2017). Instead, what is highlighted is the general open-endedness of development and design. Technological trajectories are susceptible to change or adjustment through a plethora of choices at technical, legal, moral, political, or economic junctions throughout the innovation process:

During invention and development inventor-entrepreneurs solve critical problems; during innovation, competition, and growth managerentrepreneurs make crucial decisions; and during consolidation and rationalization financier-entrepreneurs and consulting engineers, especially those with political influence, often solve the critical problems associated with growth and momentum. 
In retracing how such choices emerge, STS scholars emphasize that technology is never the neutral tool it is at times presented as in political discourse and/ or marketing. Rather, any sociotechnical system must be understood as highly political, as it has been continuously exposed to social, institutional, economic, legal, ethical, and not least, material possibilities and constraints alongside the preferences of, and frictions between, developers, engineers, designers, and eventually users (Winner, 1980).

Predictive policing is no exception in this regard. As we detailed throughout the previous chapter, the currently available software tools have not emerged in a technical vacuum but come with considerable conceptual baggage in terms of policing strategies, crime prevention paradigms, and organizational change. However, these larger trajectories were by no means the only factors that were involved in the development and design of specific predictive policing applications. On the contrary, they came into being through a complex assembly of criminological theories, technical means, data, crime rates, politics, and not least police departments themselves. Some of our interlocutors in fact interpreted their role within this assemblage as "mediators" that tied together different parts of the network and facilitated innovation (I02; I31; I80). As one police officer detailed, their department had been monitoring developments in algorithmic crime analysis software for some time and had been waiting for the right opportunity to get actively involved in the further development and operationalization of predictive policing:

We have our networks [with regard to predictive policing] the national and international level. So we are aware of any new developments and of course we think of ways we might be able to make use of innovations and how we could possibly implement them. And then we got the opportunity to start something . . . and everyone was like: "Alright, let's see how this works out." And the Ministry of the Interior told us: "We'll give you the opportunity and finance a pilot study. So you guys do your thing and then you'll tell us whether this is something worthwhile, ok?" It's a lot of things that needed to come together.

An important factor in the implementation of new technological tools and the resulting formation of sociotechnical systems is the level of complexity of both technology and environmental context. The more relations a technology needs to form with its surroundings, the more pertinent will be the repercussions of environmental factors. STS scholars have pointed, for instance, to the preeminent roles of infrastructures and technical standards that need to be considered during innovation processes and that have considerable effects on the emergence of sociotechnical systems (Hughes, 1986; Star and Griesemer, 1989; Star, 1999). Others have emphasized how research funding predefines research agendas as well as eventual outcomes and have problematized the monetary interests that exert influence on the formation of sociotechnical systems (Downey and Lucena, 1995; Möllers, 2017). 
Not surprisingly, financial questions also played an important role in the development and design of predictive policing software, and in considerations related to whether predictive policing would be a worthwhile investment in the analytical and operational capacities of police departments in the first place. We have already hinted at the crucial role of project grants from the Bureau of Justice (BJA) and the National Institute of Justice (NIJ) for the development of crime prediction software in the US (Perry et al., 2013: 4; Ferguson, 2017: 32). Cost considerations were also a major issue in Germany and Switzerland (I07; I80). As one respondent told us, police departments would carry out careful cost-benefit analyses before deciding whether to start experimenting with predictive policing applications or not:

The costs were an issue. Particularly when you measure the costs vis-àvis potential application areas. It's only for residential burglary . . . so you need to ask yourself whether there's a reasonable relation between costs and effects. But we were convinced by the method, particularly in relation to other things that we do, and so our outlook was: it's not just about the idea, but in the future this is supposed to become a system that will support crime analysis and situational assessment, and that will spill over to other areas. So we decided to think ahead.

The cost-benefit analysis was in this case underpinned by an understanding of how the department saw its future positioning, strategies, and work practices within an increasingly digitizing police environment. Such imaginaries form another important analytical theme in the emergence of sociotechnical systems. Understood as technoscientific and cultural visions that inform innovation processes, sociotechnical imaginaries lay out blueprints for desirable social and political order according to which technologies will be designed, and which they in turn will help to engender once implemented and used on a regular basis (Rammert, 2002; Jasanoff and Kim, 2009).

Predictive policing tools are underpinned by an imaginary of crime as a normalized, pattern-related social phenomenon that can, due to its regular occurrence, be identified and preventively targeted (Kaufmann et al., 2019). Equally, predictive policing relates closely to technoscientific imaginaries of modernization, innovativeness, "Big Data", efficiency, and speed (Brayne, 2017; Ferguson, 2017: 28ff; Egbert, 2018). Together, they bring about a vision of a society in which crime will continue to exist but can be largely controlled by innovative and powerful means of knowledge generation and "smart" operational measures.

In order to turn such imaginaries into concrete applications, predictive policing must thus be understood through a set of sociotechnical relationships that were already partly formed long before specific software packages entered operational police contexts. It was subject to the formation of a network 
of actors and materials that made its emergence possible in the first place. It needed to be coordinated between companies from the private sector and police departments, negotiated between politicians and police managers, and aligned between designers and users. It needed to be financed and facilitated. It needed to be conceptually integrated into existing systems and processes through suitable interfaces. It needed to correspond with legal frameworks and public perception. And, not least, it needed to be analytically compatible with already available crime data that the police generate (P49; I07).

For Woolgar (1987), these diverse influences and entanglements throughout innovation processes are reflective of larger epistemic and normative questions concerning the relations between the social and the technical. As he frames it, "discussions about technology - its capacity, what it can and cannot do, what it should and should not do - are the reverse side of the coin to debates on the capacity, ability, and moral entitlements of humans" (Woolgar, 1987: 312). At the same time, as Winner (1980: 121) reminds us, technology will always be productive of social and political power relations and thereby reconfigure social orderings: "The machines, structures, and systems of modern material culture can be accurately judged not only for their contributions of efficiency and productivity, not merely for their positive and negative environmental side effects, but also for the ways in which they can embody specific forms of power and authority." It should in this sense once more be emphasized that an STS perspective runs fundamentally counter to statements about the alleged "neutrality" or "objectivity" of technological tools. The existence of predictive policing - its algorithm, its data input, and the ways in which it becomes implemented and used - must be understood as the result of the dense construction networks through which innovations come into being.

The complexity of sociotechnical innovation is not limited, however, to the networks that enable development and design. It extends further into the practical contexts in which technologies are envisioned to be used. With regard to the "fitting" of technologies into organizational contexts and their specific user requirements, STS scholars have drawn particular attention to the practices of experimentation and field-testing that innovations usually undergo (Henke, 2000; Gieryn, 2006; Winance, 2006). Subjecting a new technological tool to a trial run - either in simulated environments or in partially controlled live test cases - allows developers, designers, and end users to explore what works and how what does not work could be better aligned with organizational and practical needs (Pinch, 1993). The main rationale behind field testing is usually to reflexively explore challenges that could not have been anticipated at earlier stages of development or to assess how technologies could be configured for particular application contexts or work environments. For Suchman et al. (2002: 175), trial runs with unfinished but already workable technologies should thus be understood in the sense of "a tangible, but also provisional, apparatus - an object that reconfigure[s] material and discursive practice in an accountably relevant way". 
During our research, methods of field-testing predictive policing software were a prevalent theme in all the police departments we studied. In most departments, the development and implementation of predictive policing would be conceived in terms of a "research project", a "trial run", or a "pilot study" (I02; I14; I36; I43; I44; D142). Independent of the label, the aims of the project would be to determine the best ways of fitting new analytical capacities and the production of spatiotemporal risk as a guiding principle for patrolling into larger trajectories of organizational structure and work practices. The emergence of predictive policing technology was in this sense not predefined by the form of an externally developed tool; it was kept deliberately open and characterized by a notion of "learning by doing" that software developers and police departments would go through together in a mutually responsive way (I02). This process would usually start with a simulation in order to determine whether available data could be used for algorithmic crime forecasts in the first place, and this simulation would then make its way into an actual everyday police environment and be turned into a hands-on practical experiment (I76; I79). As one of our respondents told us, this would be done with the option of later widening the operational scope if it turned out that experimentation with predictive policing software was yielding promising results:

Eventually, we decided to do a simulation. So in a back office, we tried to simulate what [predictive policing] would look like with historical data. And then we decided to invest some money in a pilot study, got the right people on board, and started to test it locally over a period of six months. And the results were encouraging, so we decided to expand city-wide. And again the results were good, so we decided to implement it on a regular basis.

Framing a phase of six months or longer as research, police departments would be able to take advantage of possibilities to tinker with the software and its requirements, adjust established forms of crime analysis, internal communication, and operational measures, and generally figure out in practical ways what predictive policing could mean for them and how they might be able to accommodate it. What one officer framed as "open-heart surgery" (I57) enabled police departments to incorporate predictive policing processes as part of their regular work routines and thereby to encounter potential bugs, absent functionalities, or usability issues in everyday practice (I44). Such a hands-on approach, although likely to cause some operational friction in the beginning, was, by our respondents, described as beneficial for both software developers and police departments:

I'm not always a big fan of everything that the Americans do, but they really do one thing well: they put things into practice much faster. In [own country] 
we have to think about an issue for 20,000 years, and then it needs to be perfect before we decide to use it. But systems are developed best in practice. Think of PRECOBS: PRECOBS is not a perfect system - no system is perfect. But when I remember what PRECOBS looked like when it started, and how it advanced through the ongoing exchange between practitioners and developers. ... I think that's a great advantage.

You just start doing things. In that case, we followed a very pragmatic approach. We didn't sit down for six months to develop a concept and a project design. Instead we just started doing it. . . . You need to grapple with stuff, and you need to try things that will fail. Things where you thought "This could work, this should work", and then you realize that you were wrong.

The notion of failure must here, of course, not be understood in a final sense. Rather, when it comes to field trials, there is usually an implicit agreement that failure will be part of the process - coupled with the promise that it will upon discovery be tackled and eradicated (Leese, 2015). It is important to point out that technological tools that are subjected to pilot studies are usually not finished in the sense of market-ready products. On the contrary, when exposed to the challenge of live operational environments for the first time, technological tools still need to offer a certain degree of flexibility. After all, there is a high probability that they will need to be (at least partially) reconfigured in accordance with the practical findings of the trial. New functions might need to be added or unusable ones removed, user interfaces might be adapted to the requirements of those people working with the tool, or interfaces with other technological systems might need to be fixed.

What Suchman et al. (2002: 166) call "prototyping" must in this sense be understood as a "strategy for 'uncovering' user needs, taken as already existing but somehow latent, unarticulated or even unrecognized by practitioners themselves". Framing a technology as a "beta version" or "prototype" allows developers to react flexibly to results from practical tests and accommodate them within future stages of product development, and friction is an integral part of any field experiment (Schulz-Schaeffer and Meister, 2017). As trials are designed to uncover potential misalignments in order to provide the opportunity to readjust, they might also undercut larger sociotechnical imaginaries or particular expectations of how the capacities of a certain tool will translate into particular work environments. One of our respondents gave the following example of a serious misalignment between sociotechnical imaginaries and police practices:

Some things will work out, and other things . . . take for example the "mobile office": an insurance agent comes to your apartment, puts his 
laptop on the table, and this works perfectly. In our environment, where I might have to defend myself against an attacker and at the same time look after the laptop so it won't fall down or something ... it's not always as easy as you would imagine from behind a desk.

In the end, as Suchman et al. (2002: 164) argue, "making technologies is . . a practice of configuring new alignments between the social and the material that are both localized and able to travel, stable and reconfigurable, intelligibly familiar, and recognizably new". Predictive policing tools, in this sense, need to speak to larger political priorities and policing strategies, but they must just as well take into account specific national, regional, and local cultures and operational requirements. Highlighting the importance of local implementation foregrounds the possibly wide variations between ways in which the same technology comes to matter within different organizations.

Latour (1990) has similarly argued that in order to get traction within the world, technologies need to be able to move between different contexts. This means they need to be adjustable to specific needs and processes, they need to be able to transcend cultural boundaries, and they need to be easy to understand and to handle. During our research, particularly more senior police officers, even though they used a slightly different vocabulary, demonstrated an understanding of technology within organizations that was in fact very close to STS conceptualizations of the emergence of sociotechnical systems:

You can't just build a system, or an organizational model, and then try to implement that and expect that it will work right away. That's not the way to do it. You need to think about how everything works together, and about all the implications that you need to consider. Often people only consider certain parts, and then things go wrong.

Predictive policing did not emerge out of the blue, nor was it simply imposed on the police from the outside. On the contrary, police departments played (and continue to play) an active role in the formation of local sociotechnical systems that integrate and align a variety of cultural, organizational, technical, legal, economic, and ethical elements. Predictive policing, if it is to succeed, must be able to relate to and correspond with its environment. This means that variation between the organizational structures and technical infrastructures in different police departments will also extend to the ways in which predictive policing becomes part of local practices. It needs to connect to databases as much as it needs to relate to police officers, communication channels, and operational resources. This also means that in order to understand the potentially transformative effects predictive policing could have on police work, it needs to be studied empirically within these localized sociotechnical environments. In 
order to do so, we will build on the notion of translation to trace the production and mobilization of knowledge and power within sociotechnical systems.

\section{Predictive policing as a chain of translation}

As we outlined earlier, proponents of new technologies tend to emphasize the argument that technological tools can perform tasks quicker, with more precision, endurance, and reliability than humans - and even do things that humans are just not cognitively capable of. While this is certainly true, in itself it tells us little about how such technological tools come to matter in the everyday practices of those who work with them. The more important question is how technological tools, as part of the sociotechnical systems that they form with their surroundings, shape the behavior of other elements within the sociotechnical system. For predictive policing, this means that the analytical task is to investigate how an algorithm eventually makes patrol officers move into specific areas and renders them more attentive to potentially suspicious activities. In other words, how are knowledge and power produced and transmitted through the interactions between data, computer software, human analysts, shift briefings, maps, patrol cars, and all the other elements that play a role in predictive policing?

We have in Chapter 1 already illustrated how predictive policing must be understood as a process that needs to align numerous actors and their professional rationales (see Figure 1.1). Similarly, Perry et al. (2013: xviii) conceptualize predictive policing as a "business process" that must be perpetually repeated because its outputs feed back into its data basis. Once one cycle of predictive policing comes to an end with the targeted operational measures, the altered criminal environment that results from crime prevention produces new empirical relationships between crime, time, and space - and the process starts again at square one. From an STS perspective, a processual understanding of predictive policing serves well to illustrate the different domains that play a role in the production and prevention of criminal futures. Even though these different domains might be inhabited by different actors and technologies, might be organized by different cultures and structures, and might not intuitively correspond with each other, they need to be tied together throughout the predictive policing process.

The important analytical parts of this model are, however, not so much the different domains themselves, but the gaps between them. These gaps allow us to study how different logics and rationales become bridged and aligned in predictive policing. The questions that we need to address include the likes of: What happens between data production and analysis? How is crime analysis intelligence enacted through patrolling practices? And how do targeted patrols impact criminal activity? STS literature draws our attention to the connections between previously unconnected elements and how they can be conceptualized as sites of translation that enable modes of meaning-making across different 
spheres. Studying predictive policing through the lens of translation allows us to follow the production of knowledge and power across different specialized fields of police work and to analytically foreground the active labor that needs to take place between them.

For Callon (1984: 224), translation is "the mechanism by which the social and natural worlds progressively take form. The result is a situation in which certain entities control others." A translational approach foregrounds the interactive moments between different actors and what happens between them. It foregrounds how knowledge claims come into being, how they are consolidated, and how they are mobilized to convince or persuade others to carry out specific actions. For Latour (1984: 264), similarly, the central mechanism of translation consists of "enrolling many actors in a given political and social theme". The focus of study should, in his view, therefore be on "the way in which people are associated together ... and pay attention to the material and extrasomatic resources ... that offer ways of linking people" (Latour, 1984: 264).

As we will illustrate throughout the following chapters, these resources play a key role in the translation processes that characterize predictive policing. What Latour (1984) calls "inscriptions" or "tokens" are crucial means to mobilize and enroll relevant elements at the subsequent stage of action into larger strategic aims. As he writes, "in the translation approach the initial force does not count for more than any other; force is never transmitted in its entirety and no matter what happened earlier, it can stop at any time depending on the action of the person next along the chain; again, instead of a passive medium through which the force is exerted, there are active members shaping and changing the token as it is moved" (Latour, 1984: 268). In the case of predictive policing, the inscriptions and tokens include the likes of reporting forms, interfaces, emails, and maps that facilitate communication and meaning-making between and within specialized police divisions. What unites them is that they are productive of knowledge about criminal futures, render them relatable across different domains, and unfold the power to mobilize other elements for the sake of intervention into these futures.

Translation, in the words of Callon (1980b: 211), is fundamentally characterized by "creating convergences and homologies by relating things that were previously different". In predictive policing, numerous unrelated or only loosely related elements need to be brought together. The generation of crime data involves epistemic and classificatory challenges, and data must be amended and consolidated before they can be used for algorithmic crime analysis. The analytical process reconfigures the relationships between human officers and machines, requires specific professional skills, and is likely to produce frictions between algorithmic knowledge and human expertise. Results from the analysis must be disseminated and communicated in ways that are both intelligible and acceptable to those who are set to enact them. Resources need to be managed, and shifts need to be scheduled. Patrol officers must squeeze special 
attention to risk areas into their already busy work schedule. And in the end, the question of whether operational measures had a measurable impact on criminal activity is not easily answered.

At all these translation sites, there is considerable room for failure and breakdown. In order to make predictive policing work, police departments must ensure that sites and modes of translation are properly configured - otherwise, analytical insights might not make it to the street level after all. Predictive policing, conceptualized as a chain of translation, is then about "the capacity of certain actors to get other actors - whether they be human beings, institutions or national entities - to comply with them [and] depends upon a complex web of interrelations" (Callon, 1984: 201). Different divisions, tasks, and technological tools within police work, in other words, need to be carefully woven together so that their rationales and operational capacities can function together.

\section{Conclusion}

Throughout this chapter, we have investigated the relationship between the police and technology. Criminological and sociological literature shows that the implementation of new technological tools is likely to cause friction and possibly even active resistance, as it has the potential to unsettle established routines, practices, and occupational cultures. In the long run, technological innovation often goes hand in hand with organizational change. Such change does, however, seldom unfold exclusively along the projected lines but includes a number of unintended side effects and other consequences. In light of these considerations, we have proposed to understand technology not as an isolated analytical variable or as a deterministic force, but as part of a larger sociotechnical system that is inevitably formed once a technological tool enters into organizational contexts and relates to other human, material, and nonmaterial elements. With reference to STS literature, we have retraced how sociotechnical systems of predictive policing have emerged and have been refined in practice in the form of trial runs, field experiments, and research projects. These setups have enabled police departments and developers to tinker with new analytical tools in a live environment and adjust organizational processes and practices as well as predictive policing applications in a mutually constitutive fashion.

Eventually, we have proposed to study predictive policing through the conceptual lens of translation. Translation is about the "hinges" in predictive policing. It highlights how different social, technical, and organizational elements are made to relate to each other and how knowledge and power are produced and transmitted, and thus ultimately how algorithmic crime analysis is turned into targeted operational crime prevention measures in the streets. Using the notion of translation as a theoretical frame of reference, the following chapters will reconstruct what it means to "do predictive policing" as a part of everyday police work. We will highlight how criminal futures are produced, translated, 
and enacted through a focus on different sites, actors, and the transmission processes that occur between them.

\section{References}

Ackroyd S, Harper R, Hughes J A, Shapiro D and Soothill K (1992) New Technology and Practical Police Work. Buckingham/Philadelphia: Open University Press.

Ariel B (2019) Advocate: Technology in Policing. In Weisburd D and Braga A A (eds.) Police Innovation: Contrasting Perspectives. 2nd Edition. Cambridge: Cambridge University Press, 485-516.

Bennett Moses L and Chan J (2018) Algorithmic Prediction in Policing: Assumptions, Evaluation, and Accountability. Policing and Society 28(7): 806-822.

Bijker W E, Hughes T P and Pinch T J (eds.) (1987) The Social Construction of Technological Systems: New Directions in the Sociology and History of Technology. Cambridge/London: MIT Press.

Bijker W E and Law J (eds.) (1992) Shaping Technology/Building Society: Studies in Sociotechnical Change. Cambridge/London: MIT Press.

Braga A A and Weisburd D (2019) Conclusion: Police Innovation and the Future of Policing. In Braga A A and Weisburd D (eds.) Police Innovation: Contrasting Perspectives. 2nd Edition. Cambridge: Cambridge University Press, 544-563.

Brayne S (2017) Big Data Surveillance: The Case of Policing. American Sociological Review 82(5): 977-1008.

Brayne S (2021) Predict and Surveil: Data, Discretion, and the Future of Policing. Oxford: Oxford University Press.

Byrne J and Marx G T (2011) Technological Innovations in Crime Prevention and Policing: A Review of the Research on Implementation and Impact. In de Pauw E, Ponsaers P, van der Vijver K, Bruggeman W and Deelman P (eds.) Technology-Led Policing. Antwerpen/ Apeldoorn/Portland: Maklu, 17-40.

Callon M (1980a) The State and Technical Innovation: A Case Study of the Electrical Vehicle in France. Research Policy 9(4): 358-376.

Callon M (1980b) Struggles and Negotiations to Define What Is Problematic and What Is Not: The Socio-logic of Translation. In Knorr K D, Krohn R and Whitley R (eds.) The Social Process of Scientific Investigation. Dordrecht: D. Reidel Publishing, 197-219.

Callon M (1984) Some Elements of a Sociology of Translation: Domestication of the Scallops and the Fishermen of St Brieuc Bay. The Sociological Review 32(1): 196-233.

Callon M (1991) Techno-Economic Networks and Irreversibility. In Law J (ed.) A Sociology of Monsters: Essays on Power, Technology and Domination. London/New York: Routledge, $132-161$.

Chan J (2001) The Technological Game: How Information Technology Is Transforming Police Practice. Criminology \& Criminal Justice 1(2): 139-159.

Chan J and Bennett Moses L (2017) Making Sense of Big Data for Security. British Journal of Criminology 57(2): 299-319.

Chan J, Brereton D, Legosz M and Doran S (2001) E-Policing: The Impact of Information Technology on Police Practices. Brisbane: Criminal Justice Commission.

Cole S A (2001) Suspect Identities: A History of Fingerprinting and Criminal Identification. Cambridge/London: Harvard University Press.

Cole S A (2017) Establishing Culpability: Forensic Technologies and Justice. In McGuire M R and Holt T J (eds.) The Routledge Handbook of Technology, Crime and Justice. London/ New York: Routledge. 
Downey G L and Lucena J C (1995) Engineering Studies. In Jasanoff S, Markle G E, Petersen J and Pinch T J (eds.) Handbook of Science and Technology Studies. Thousand Oaks/ London/New Delhi: Sage, 167-188.

Egbert S (2018) About Discursive Storylines and Techno-Fixes: The Political Framing of the Implementation of Predictive Policing in Germany. European Journal for Security Research 3(2): 95-114.

Ericson R V (1994) The Division of Expert Knowledge in Policing and Security. British Journal of Sociology 45(2): 149-175.

Ericson R V and Haggerty K D (1997) Policing the Risk Society. Oxford: Clarendon Press.

Eterno J A and Silverman E B (2012) The Crime Numbers Game: Management by Manipulation. Boca Raton: CRC Press.

Ferguson A G (2017) The Rise of Big Data Policing: Surveillance, Race, and the Future of Law Enforcement. New York: New York University Press.

Gent E (2017) Could Predictive Policing Lead to a Real-Life Minority Report? Singularity Hub. 2 February. Available at https://singularityhub.com/2017/02/02/could-predictivepolicing-lead-to-a-real-life-minority-report/ (accessed 30 April 2020).

Gieryn T F (2006) City as Truth-Spot: Laboratories and Field-Sites in Urban Studies. Social Studies of Science 36(1): 5-38.

Godin B and Vinck D (2017) Introduction: Innovation - From the Forbidden to a Cliché. In Godin B and Vinck D (eds.) Critical Studies of Innovation: Alternative Approaches to the Pro-Innovation Bias. Cheltenham/Northampton: Edward Elgar, 1-14.

Harper R R (1991) The Computer Game: Detectives, Suspects, and Technology. British Journal of Criminology 31(3): 292-307.

Henke C R (2000) Making a Place for Science: The Field Trial. Social Studies of Science 30(4): 483-511.

Holt T J, Bossler A M and Seigfried-Spellar K C (2015) Cybercrime and Digital Forensics: An Introduction. London/New York: Routledge.

Hughes T P (1983) Networks of Power: Electrification in Western Society, 1880-1930. Baltimore: John Hopkins University Press.

Hughes T P (1986) The Seamless Web: Technology, Science, Etcetera, Etcetera. Social Studies of Science 16(2): 281-292.

Hughes T P (1987) The Evolution of Large Technological Systems. In Bijker W E, Hughes T P and Pinch T J (eds.) The Social Construction of Technological Systems. Cambridge/London: MIT Press, 51-82.

Jasanoff S (1996) Beyond Epistemology: Relativism and Engagement in the Politics of Science. Social Studies of Science 26(2): 393-418.

Jasanoff S (ed.) (2004) States of Knowledge: The Co-Production of Science and Social Order. London/New York: Routledge.

Jasanoff S and Kim S-H (2009) Containing the Atom: Sociotechnical Imaginaries and Nuclear Power in the United States and South Korea. Minerva 47(2): 119-146.

Kaufmann M, Egbert S and Leese M (2019) Predictive Policing and the Politics of Patterns. British Journal of Criminology 59(3): 674-692.

Latour B (1984) The Powers of Association. The Sociological Review 32(1_suppl): 264-280.

Latour B (1990) Drawing Things Together. In Lynch M and Woolgar S (eds.) Representation in Scientific Practice. Cambridge/London: MIT Press, 19-68.

Latour B (1991) Technology Is Society Made Durable. In Law J (ed.) A Sociology of Monsters: Essays on Power, Technology and Domination. London/New York: Routledge, 103-131. 
Latour B (1993) Ethnography of a "High-tech" Case: About Aramis. In Lemonnier P (ed.) Technological Choices: Transformation in Material Cultures since the Neolithic. London/New York: Routledge, 372-398.

Latour B (1999) Pandora's Hope: Essays on the Reality of Science Studies. Cambridge: Harvard University Press.

Latour B and Woolgar S (1986) Laboratory Life: The Construction of Scientific Facts. 2nd Edition. Princeton: Princeton University Press.

Law J (1987) On the Social Explanation of Technical Change: The Case of the Portuguese Maritime Expansion. Technology and Culture 28(2): 227-252.

Law J (1991) Introduction: Monsters, Machines and Sociotechnical Relations. In Law J (ed.) A Sociology of Monsters: Essays on Power, Technology and Domination. London/New York: Routledge, 1-23.

Leese M (2015) 'We Were Taken by Surprise': Body Scanners, Technology Adjustment, and the Eradication of Failure. Critical Studies on Security 3(3): 269-282.

Lynch M, Cole S A, McNally R and Kathleen J (2008) Truth Machine: The Contentious History of DNA Fingerprinting. Chicago: Chicago University Press.

Lyon D (1992) The New Surveillance: Electronic Technologies and the Maximum Security Society. Crime, Law and Social Change 18(1-2): 159-175.

Maguire E (2003) Organizational Structure in American Police Agencies: Context, Complexity, and Control. Albany: SUNY Press.

Mahnken J and Rabitz-Suhr S (2019) Auswertung und Analyse 4.0: Das Projekt "Entwicklung Berufsbild Kriminalitätsanalytik”. der kriminalist 51(12): 21-26.

Manning P K (1992a) Information Technologies and the Police. Crime and Justice 15: 349-398.

Manning P K (1992b) Technological Dramas and the Police: Statement and Counterstatement in Organizational Analysis. Criminology 30(3): 327-346.

Manning P K (2001) Technology's Ways: Information Technology, Crime Analysis and the Rationalizing of Policing. Criminology \& Criminal Justice 1(1): 83-103.

Manning P K (2008) The Technology of Policing: Crime Mapping, Information Technology, and the Rationality of Crime Control. New York/London: New York University Press.

Marx G T (1988) Undercover: Police Surveillance in America. Berkeley: University of California Press.

Marx G T (1995) The Engineering of Social Control: The Search for the Silver Bullet. In Hagen J and Peterson R D (eds.) Crime and Inequality. Stanford: Stanford University Press, 225-246.

Mastrofski S D and Willis J T (2010) Police Organization Continuity and Change: Into the Twenty-first Century. Crime and Justice 39(1): 55-144.

McCartney C (2005) The DNA Expansion Programme and Criminal Investigation. British Journal of Criminology 46(2): 175-192.

Möllers N (2017) The Mundane Politics of 'Security Research': Tailoring Research Problems. Science \& Technology Studies 30(2): 14-33.

Mor Y (2014) Big Data and Law Enforcement: Was 'Minority Report' Right? Wired. Available at www.wired.com/insights/2014/03/big-data-law-enforcement-minority-reportright/ (accessed 30 April 2020).

Nogala D (1995) The Future Role of Technology in Policing. In Brodeur J-P (ed.) Comparisons in Policing: An International Perspective. Aldershot: Avebury, 191-210.

O’Malley P and Palmer D (1996) Post-Keynesian Policing. Economy and Society 25(2): 137-155. 
Paul B and Egbert S (2016) Drug Testing for Evidence? A Sociotechnical Practice. In O'Gorman A, Potter G and Fountain J (eds.) Evidence in Social Drug Research and Drug Policy. Lengerich: Pabst, 99-112.

Perry W L, McInnis B, Price C C, Smith S C and Hollywood J S (2013) Predictive Policing: The Role of Crime Forecasting in Law Enforcement Operations. Santa Monica: RAND Corporation.

Pinch T J (1993) “Testing - One, Two, Three . . Testing!”: Toward a Sociology of Testing. Science, Technology, \& Human Values 18(1): 25-41.

Pinch T J and Bijker W E (1984) The Social Construction of Facts and Artefacts: Or How the Sociology of Science and the Sociology of Technology Might Benefit Each Other. Social Studies of Science 14(3): 399-441.

Rammert W (2002) The Cultural Shaping of Technologies and the Politics of Technodiversity. In Sørensen K H and Williams R (eds.) Shaping Technology, Guiding Policy: Concepts, Spaces and Tools. Cheltenham/Northampton: Edward Elgar, 173-194.

Sanders C B and Condon C (2017) Crime Analysis and Cognitive Effects: The Practice of Policing through Flows of Data. Global Crime 18(3): 237-255.

Schulz-Schaeffer I and Meister M (2017) Laboratory Settings as Built Anticipations: Prototype Scenarios as Negotiation Arenas between the Present and Imagined Futures. Journal of Responsible Innovation 4(2): 197-216.

Sheptycki J (2017) Liquid Modernity and the Police Métier: Thinking about Information Flows in Police Organisation. Global Crime 18(3): 286-302.

Star S L (1999) The Ethnography of Infrastructure. American Behavioral Scientist 43(3): 377-391.

Star S L and Griesemer J R (1989) Institutional Ecology, 'Translations' and Boundary Objects: Amateurs and Professionals in Berkeley's Museum of Vertebrate Zoology, 190739. Social Studies of Science 19(3): 387-420.

Suchman L (2007) Human-Machine Reconfigurations: Plans and Situated Actions. 2nd Edition. Cambridge: Cambridge University Press.

Suchman L, Trigg R and Blomberg J (2002) Working Artefacts: Ethnomethods of the Prototype. The British Journal of Sociology 53(2): 163-179.

Vera A and Jablonowski L (2017) Organisationskultur der Polizei. In Stierle J, Wehe D and Siller H (eds.) Handbuch Polizeimanagement: Polizeipolitik - Polizeiwissenschaft - Polizeipraxis. Wiesbaden: Springer, 475-494.

Walz S P and Deterding S (eds.) (2014) The Gameful World: Approaches, Issues, Applications. Cambridge/London: MIT Press.

Weisburd D and Braga A A (2019) Introduction: Understanding Police Innovation. In Braga A A and Weisburd D (eds.) Police Innovation: Contrasting Perspectives. 2nd Edition. Cambridge: Cambridge University Press, 1-24.

Wendekamm M and Model T (2019) Arbeitskultur und Berufsbilder der Polizei: Zwischen gesellschaftlichen Megatrends und Herausforderungen der Inneren Sicherheit. In Lange H-J, Model T and Wendekamm M (eds.) Zukunft der Polizei: Trends und Strategien. Wiesbaden: Springer VS, 261-279.

Whitson J R (2013) Gaming the Quantified Self. Surveillance \& Society 11(1/2): 163-176.

Willis J J, Mastrofski S D and Weisburd D (2007) Making Sense of COMPSTAT: A TheoryBased Analysis of Organizational Change in Three Police Departments. Law \& Society Review 41(1): 147-188. 
Wilz S M and Reichertz J (2008) polizei.de oder: Verändert das Internet die Praxis polizeilichen Arbeitens? In Lange H-J, Ohly H P and Reichertz J (eds.) Auf der Suche nach neuer Sicherheit: Fakten, Theorien und Folgen. Wiesbaden: VS, 221-230.

Winance M (2006) Trying Out the Wheelchair: The Mutual Shaping of People and Devices through Adjustment. Science, Technology \& Human Values 31(1): 52-72.

Winner L (1980) Do Artifacts Have Politics? Daedalus 109(1): 121-136.

Woolgar S (1987) Reconstructing Man and Machine: A Note on Sociological Critiques of Cognitivism. In Bijker W E, Hughes T P and Pinch T J (eds.) The Social Construction of Technological Systems. Cambridge/London: MIT Press, 311-328. 


\section{Data and the need for speed}

This chapter analyzes the first translation process in predictive policing - the creation and consolidation of crime data under time pressure. A major sales pitch for predictive policing is speed: With predictive policing software, this sales pitch claims, crime analysis can be algorithmically accelerated to such an extent that the police will be able to dynamically intervene in criminal futures as they unfold. The drive for acceleration is therefore deeply engrained in the logics of predictive policing software packages. In order to speed up police work, these applications are supposed to seamlessly integrate their analytical capacities into police database infrastructures, run analyses in the background, and instantly present new insights about possible criminal futures. Manufacturers such as PredPol or IfmPt accordingly advertise their products in ways that suggest up-to-date awareness "as new crimes come in"1 and through "current crime data". ${ }^{2}$ The rationale at work here is that the quicker crime data are available for analysis, the quicker risk estimates can be computed and enable immediate responsivity on the street level, which means that patrols can react flexibly whenever new insights about tempospatial risk estimates become available.

For Wilson (2019: 69), this imaginary of live awareness culminates in police ecosystems that "edge ever closer to real time" and produce "surplus value that is generated through temporal instantaneity". Predictive policing is in this sense imagined as an uninterrupted process that continuously produces and adjusts the criminal futures the police act upon, while at the same time requiring as little human input as possible (Bratton and Malinowski, 2008). As Sheptycki (2017: 286) argues, "new theorists of policing and security governance have imagined information flows across a nodal landscape of networked governance". What results from such an angle is the notion of an always present relationship with the future, creating minimum response times to whatever threat or risk might be identified within the ongoing stream of live data. This idea of seamlessness corresponds with a supposedly dynamic, contingent, and rapidly changing criminal environment in which police departments and other security agencies need to be able to react and adapt quickly, and therefore keep their "situational awareness" at a maximum level at any time (Krasmann and Hentschel, 2019). 
Importantly, predictive policing is not about the future in the sense of longterm foresight and strategy, but about the ability to respond to and intervene in ongoing developments. As Aradau and Blanke (2017: 384) observe, in general, algorithmic analytics are "not primarily about the turn to the future but about near-real-time decision-making". The assumption here is that on the operational level, flexibility and reactive capacities rely crucially on a continuous situational awareness that empowers swift and effective interventions. The efficiency promise behind predictive policing is predicated on the presumption that algorithmic predictions will seamlessly blend into the operational environment of policing and that risk-based patrolling practices will not require any additional analytical or organizational attention. Only then can algorithmically generated predictions be translated into street patrols who arrive at the crime scene before the criminal in order to capture the offender - or at least prevent the offense materializing.

Predictive policing is in fact about the "need for speed". All these imaginaries must, however, be taken with a couple of grains of salt. As we will demonstrate throughout this chapter, considerable deceleration of predictive policing practices is, in everyday police work, caused not only by the temporal characteristics of crime and its reporting but also by issues of data creation and consolidation. Crime data are characterized by a high degree of uncertainty that stems both from the ontological characteristics of crime and from epistemic questions of how to generate data from criminal events. In order to feed predictive policing software with data that are as accurate and complete as possible, police departments thus have to invest considerable resources in multiple layers of quality control. After all, only analyses run on reliable data will yield meaningful results. This in turn raises the question of when it is appropriate to analyze crime data. Our research shows that there is a trade-off between data that are available early but that have potentially bad quality vs. consolidated data that are more reliable but only become available at a later point in time.

Another important factor that needs to be taken into consideration when thinking about the temporalities of predictive policing is the rhythm of crime and policing. Most types of crime tend to occur more frequently at specific times of the day, and domestic burglary is a particularly pertinent example of such rhythmic occurrence. It is to a large extent prestructured by windows of opportunity that open up when residents leave their homes and close upon their return as well as by daylight hours and lighting conditions. Paired with the typical "working hours" of criminals (who also need to eat, sleep, and drive to their "workplaces"), this constitutes an intricate temporal interplay between crime, its datafication and analysis, and possible response measures.

This chapter illustrates how crime and data practices unfold under the rationale of acceleration that predictive policing dictates. It argues that, rather than blindly following the supposed need for speed, police departments need to balance accuracy and timeliness in a domain where data are generally characterized 
by a considerable amount of uncertainty. Understanding the creation of crime data as a translation process of empirical phenomena into digital forms of representation, it problematizes the ontology of residential burglary and corresponding police practices and proposes that we should understand epistemic questions of how to produce data and knowledge in relation to the rhythmic interplay between crime and policing.

\section{Detecting crime, reporting crime}

Near-repeat approaches to predictive policing operate under the idea that burglary series take place within limited spatial areas and within limited time periods. The assumption is that the shorter the time frame, the more likely is the occurrence of follow-up offenses (Johnson, 2008: 219). In turn, this means that only "fresh" crime and resulting up-to-date data can yield maximum analytical and operational value. "Old" burglary cases are certainly still interesting when it comes to identifying crime patterns retrospectively and over longer periods of time, but outdated crime data do not provide the police with any way to intervene in events as they happen. The police are thus understandably keen on getting their hands on burglary data as quickly as possible, in the best case scenario right after the offense has been committed (I02; I07; I11).

This, however, is not so easy. First of all, a considerable period of time might pass between a burglary and its detection. There are obvious reasons for this: As criminals seek to minimize the risk of getting caught, successful cases of residential burglary usually target vacant premises. Residents thus only realize that their home has been broken into upon their return from their activities away from home. This might be a couple of hours later (when they return from work or other activities in the near vicinity), but it might equally well be a week later (if they were on a business trip or on holiday). Depending on the time period during which the dwelling was vacant, it can thus be difficult or even impossible to determine the exact point in time when the offense actually happened, and data from a burglary that might have happened as long as a week ago will only yield very limited analytical value for operational responses predicated upon quick reaction times (I01; I07; I26).

Another important factor is that burglary is a "reporting crime", meaning that burglaries are usually not detected by the police themselves but by the victim, who then reports the incident to the police. This renders burglary fundamentally different from other types of crime, for example possession of illegal substances or speeding, which are in most cases only actively detected through police controls and otherwise largely go unnoticed and/or unreported. With reporting crimes, a general concern is the reporting quota. Many types of crime, for example domestic violence or rape, come with a significant number of unreported cases that never end up as crime data (Biderman and Reiss, 1967), because people are ashamed or for other reasons are reluctant to 
admit that they have been the victim of such a crime. However, there is generally a high level of reporting when it comes to burglary, as most victims are insured and will need a police report in order to make a claim to their insurance company (I44; I55). This means that burglary data usually give a fairly accurate picture of the actual number of burglaries that have occurred.

While reporting quotas might be generally high for residential burglary, the timeliness of reporting is a different issue. As our interlocutors pointed out, there might also be considerable delay between the detection and the reporting of a burglary (I19; I44; I45). This sounds rather surprising, as one would assume that burglary victims would want to deal with the violation of their private home as quickly as possible. It is, however, not unusual for people not to report crimes to the police immediately. There was no consensus about the exact reasons for such behavior, but our interlocutors were pretty clear about what delayed reporting of burglary incidents means for the analytical capacities of predictive policing software:

If, for example, people only report a burglary five days later - even though the approximate time of the incident is known - then the system will produce an alert nonetheless, because it considers the burglary as 'new' and within an alert zone. But of course we can't work with that alert, because the trigger was already five days ago. And that actually happens a lot, that people don't go to the police right away and report something. I have no idea what they do in the meantime.

(I19; see also I44; I45)

In summary, while residential burglary is a type of crime of which the police have comparably good knowledge, there is often considerable uncertainty regarding a key variable for near-repeat approaches to predictive policing: the time of the incident. Delay in detection and/or reporting further aggravates this problem. Lagging just a couple of days behind has the potential to eat up much of the acceleration potential that predictive policing so fundamentally relies on. These issues cannot be easily mediated or even resolved, and the police have little influence on them.

From the perspective of translation and the formation of a sociotechnical system of predictive policing, things start to get more interesting once police officers are called to the scene of a crime and start generating data from the incident. We have already discussed how crime data quickly lose their value for predictive policing once they are outdated. The more prevalent question, however, is how they come into being in the first place. In the next section, we will look into the question of how the production of crime data translates empirical phenomena into data points through a series of choices and interpretations and how these processes transform epistemic uncertainty into bureaucratic classification categories that render crime intersubjectively relatable and intelligible as well as administrable and analyzable in the first place. 


\section{Creating crime data}

Data are the foundation of predictive policing. Simply speaking, there is no data analysis without data. And without data analysis, there is no crime risk. The good news is that the police have plenty of data. Police departments produce large amounts of data about crime as part of their daily activities. These data are needed for criminal investigations and knowledge production about criminal phenomena at scale as much as they are needed for administrative purposes, insurance claims, court proceedings, and the production of statistics and reports. As Harper (1991: 294) puts it, "in sociological terms, detectives have the task of transforming the various features of reported crime into bureaucratic phenomena", such that they can be processed and correspond to these different needs. As police work is generally considered an information-rich environment (Ericson and Haggerty, 1997), the availability of data is in discourses of predictive policing often not considered a primary issue. Rather, the police have been concerned with how they can most effectively exploit the data they already have available (Beck and McCue, 2009; Perry et al., 2013; Babuta, 2017), how they might be able to professionalize long-standing practices of crime analysis (Mahnken and Rabitz-Suhr, 2019; Schneider and Leutenegger, 2020), and how to implement operational measures based on the analysis (Willis and Mastrofski, 2018; Ratcliffe, 2019; Ratcliffe et al., 2020).

Data themselves have, apart from the fact that they are prone to notoriously bad quality (Maltz, 1999; Cope, 2008; Santos, 2013), been problematized less frequently. This comes as a bit of a surprise. If police officers, as Harper (1991) has argued, transform crime into bureaucratic phenomena, then such transformation is by no means a straightforward process. Creating crime data means trying to fit messy and ambiguous empirical realities into predefined bureaucratic classification systems, and there are many potential pitfalls here (Haggerty, 2001). It is thus appropriate to start thinking about how crime data come into being and form the foundation for algorithms and operational crime prevention measures at later stages of predictive policing. Critical data studies literature can provide valuable analytical hints here.

The widespread introduction of computer systems in the 1990s was accompanied by a first wave of data enthusiasm, as newfound storage capacities started to be filled with data, and digital networks made information more easily (and remotely) accessible and fueled new organizational processes and business models. Ensuing data-centered practices brought questions of the origin of these new quantities of data to the fore and sparked critical inquiry from social scientists and philosophers who interrogated the nexus of data production and the entrenchment or aggravation of social, economic, and political power positions (Lyon, 1992; Gandy, 1993; Marx, 1995; Rip et al., 1995). As Bowker (1994: 245) writes, "the global statement that everything is information is not a preordained fact about the world, it becomes a fact as and when we make it so". The epistemic authority to decide how the world is turned into data cannot 
in this sense be separated from questions about who gets to produce what kind of knowledge about the world and how such knowledge is turned into action.

These questions have arguably become even more pertinent over the past decade. Narratives about "Big Data" revolve around the notion that data would allow us to unlock hitherto unknown secrets about the world - and the only requirements would be to combine as much data as possible, draw different sources together, and use smart analytical techniques such as machine learning algorithms (Anderson, 2008; Manyika et al., 2011; Mayer-Schönberger and Cukier, 2013). The question of how data are created in the first place seldom figures prominently in such narratives. Data are today, to a large extent, generated automatically in the form of metadata that document transactions, communications, and the use of services (Lyon, 2014), or they are created autonomously by sensing devices (Andrejevic and Burdon, 2014). In any case, from a "Big Data" perspective, data are largely taken for granted, and the brave new data-savvy world does not care much for ontological and epistemic reflection (Wolf, 2010). Sociologists and critical data scholars have cautioned, against this backdrop, against an overreliance on data without understanding where they come from and how they have been conceived (boyd and Crawford, 2012; Dalton and Thatcher, 2014; Kitchin, 2014a).

Gitelman and Jackson (2013: 3) remind us that, even though the commonly used terminology for data includes such terms as "collecting", "entering", "compiling", "storing", and "mining", all of these terms imply that data are already out there in the world, just waiting to be plucked. This is not the case. There are no data without someone translating a given empirical phenomenon into data points, and this translation is characterized by a number of choices that have wide-ranging implications for the resulting dataset: How to perceive or sense something? How to describe it? How to measure it? How to assign numbers or categories to it? Creating data means finding answers to questions about how to cognitively and bureaucratically grapple with the world, and these answers influence what kinds of stories the data will later tell about the world from which they were created. As Kitchin and Lauriault (2014: n.p.) write,

how data are conceived, measured and employed actively frames their nature. . . Data do not pre-exist their generation, they do not arise from nowhere and their generation is not inevitable: protocols, organizational processes, measurement scales, categories, and standards are designed, negotiated and debated, and there is a certain messiness to data generation.

Data creation is, to a certain extent, a creative process. For Gitelman and Jackson (2013: 3), "data are imagined and enunciated against the seamlessness of phenomena", and this process of imagination and enunciation closely corresponds with the later purpose of the data. Different cultural or professional predispositions in this sense inevitably shape how and what kind of data are 
produced from a given phenomenon. Police officers create data from a crime scene, looking for pieces of information that will later on inform and guide their professional practices and speak to the organizational needs of police work. Other phenomena will not be considered relevant and will thus not end up as crime data. Data are in this sense always already imbued with sociocultural assumptions that give them a specific form and information value. In the words of Bowker (2008: 184), there cannot in fact be any "raw data", as such a notion of untainted, intersubjective information would have to be considered an oxymoron. On the contrary, data always need to be considered as already "cooked" in specific ways, as they are the result of active work, rendering them a selective and specific representation of the world vis-à-vis their purpose and their social embeddedness (Kitchin, 2014b: 3).

The fact that data are socially constructed is of course not a particularly new or spectacular insight. Epistemic questions of counting, measuring, quantifying, or standardizing have throughout history been closely entangled with questions of power and knowledge as well as with state-building and government and have been subject to detailed study (Hacking, 1990; Scott, 1998; Desrosières, 2002). The social construction of data is, however, highly significant for predictive policing, as algorithmic crime analysis will only be as good as the data that go into the system. It is thus important to study the ways in which the police "cook" their data as they generate information about space and time and the criminal activities that take place within these coordinates. If the form of data takes shape according to their later use, then predictive policing tools have the capacity to preconfigure how crimes are translated into analyzable information bits and to prestructure the behavior and epistemic practices of police officers who investigate the crime scene.

On the most fundamental level, what happens after a burglary has been detected is the following: Either the burglary victim visits the police station to file a complaint or, more likely, they call the police and a patrol car will be dispatched to the crime scene in order to register the offense and collect evidence. Throughout this process, both actual crime data and metadata are created. One of our interviewees illustrated this procedure as follows:

A burglary will first be registered at the emergency call center, and they create a file where primary information is recorded: When was the call? What is the street address? Who called? And then they request operational resources, and our patrol officers drive to the crime scene and register the incident. Back in the day, they used to have a little black notebook where they wrote down the details. Nowadays they do that with an iPad . . . that comes with a simplified reporting form, and many significant details already go into that reporting form: What was the exact time of the crime, or the period of the crime? What are the characteristics of the location? What was stolen? How did the offender operate? And all that goes straight into the database. 
What is important here is that crime data are usually created "in the field", as police officers visit the crime scene and produce information from the crime scene and information provided by victims and/or witnesses. In the specific case of residential burglary, basic data usually include the location of the dwelling, the (approximate) time of the offense, the modus operandi (i.e., how the offender gained access to the dwelling), the haul, and potential eyewitness reports as well as any available forensic evidence (Santos, 2013: 69). These are also the main variables that near-repeat-based predictive policing applications such as PRECOBS or PredPol use for their models (I01; I02; I07; I18). Proponents of place-based predictive policing often highlight such data sparsity as an advantage, as these data are usually easily available and can be quickly anonymized in order to comply with privacy and data protection regulations (Schweer, 2015a, 2015b; Balogh, 2016).

While it is true that PRECOBS processes only a limited number of data points, these data points are in practice characterized by a considerable degree of uncertainty. We have already noted that the date and time of a burglary are often not exactly known and can fall within a period ranging from a couple of hours up to a couple of weeks. This is also true for the modus operandi. Modus operandi is a second analytical key variable in near-repeat approaches, as the exact way in which a burglar gained access to a dwelling can provide hints at the offender profile and whether or not an offense was the work of a professional. In practice, though, the modus operandi might not be clearly identified or assigned - maybe there was a cracked window that anyone could have easily opened, maybe the back door was unlocked, or maybe even a combination of both. Or in case a locked window was forced open, the traces from the tools that were used might not be clearly assignable to a certain method - for instance, whether it should be considered "levering" or "drilling" (I03; I51).

Additionally, it might not immediately be clear what was actually stolen, as the victim might not yet be aware of all missing items. This is equally problematic, as haul is used as another key variable for the distinction between professional burglary with a risk for near repeats on the one hand and occasional one-off offenses on the other. Last, but not least, the fact that burglary data are generated in the field also means that their production depends on the work of the police officer at the crime scene. There might be considerable variation between how two different persons conceive of a phenomenon and produce data from it, even if those two persons underwent the same professional training. In summary, both ontological uncertainty and subjectivity complicate the translation of criminal phenomena into crime data. A lack of coherence, accuracy, and reliability in how criminal phenomena are represented within resulting datasets, however, in turn potentially undercut the analytical viability of the data.

While not all of these issues might be easily resolvable, standardization is set to reduce variation in the creation of crime data and to provide compatibility and comparability within datasets. In order to standardize the capture 
and translation of crime into data, the police use reporting forms that serve both as a checklist for the officers at the crime scene and as a means of classification. Reporting forms are supposed to ensure that the data created from each burglary can be analytically combined, as they are in the same format and cover the same set of questions. During our research, there was some variation between police departments that were still using pen and paper forms (I26; I46; I78; I79; I80) and others that were already working with electronic means of data capture, either using laptop computers or tablets/phones (I76; P07; P70) There was, however, an overall tendency to move toward digital devices for reporting (I26; I79).

In filling out reporting forms, no matter whether on paper or on a computer or tablet, police officers are faced with a number of decisions concerning how to classify empirical phenomena under conditions of potentially limited information. These choices are considered extremely important for later purposes of crime analysis, as only accurate crime data will yield meaningful analytical insights and so have the potential to inform operational measures. The use of predictive policing software thus already extends into epistemic practices of data production and reinforces the importance of this work in relation to the later analytical use of crime data (I02; I09; I24; I26; I44; I51). Police departments have intensified their efforts to train officers in data generation issues and raise awareness for the fact that translation processes in the field will have analytical repercussions and might actually come back to the field in the form of risk areas that need to be more intensively patrolled (I09; I24; I44; I51; P49; P77). One respondent talked about how their department decided to run a data awareness campaign even before they started to implement predictive policing:

Before we started [using PRECOBS], we organized an information event. We have about 1,600 officers. Additionally, we sent out information sheets, including our reporting manual. How do I capture domestic burglary correctly? What do I particularly need to consider? Including a reminder to complete the report within 24 hours after the incident was first reported.

Despite these efforts, during our research we found evidence of a surprising disconnect between the analytical need for accuracy and the sometimes "sloppy" ways in which crime data were produced in the field. A major problem that our interlocutors repeatedly pointed out was the division of labor within police organizations and the ensuing specialized roles and tasks that come with specific job profiles (I07; I51). Specifically, the misfit between the different lifeworlds and professional rationales of analysts and patrol officers was considered problematic. As one senior police officer put it:

The patrol officer just doesn't want the same thing as the analyst. The officer wants to get rid of that case as quickly as possible, and the analyst 
wants good data. So we have to explain to the patrol officer why we need good data. And that's not easy.

These challenges are additionally aggravated by the overall workload and time pressures that patrol officers often have to operate under, incentivizing them to do the reporting work as quickly as possible and thus potentially rendering data generation more superficial and error prone (I03). But data quality - or more precisely, the lack thereof - can have many potential sources. It can, for instance, be caused by the patrol officer who simply "forgets" to fill out a specific field in the report, leading to the analyst having to consult other sources in order to fix the mistake and complete the data from the incident. There is hardly any malicious intent behind such errors, and analysts are generally quite understanding of the fact that human mistakes come with the job. One analyst framed it as follows:

I can totally understand that, I know that from my own time in the field: when you come into the station at three or half past three in the morning after an assignment, and you're supposed to get off at four - then you do the reporting the next day. Or you just quickly enter the most important bits of information. And sometimes, at three in the morning, you forget something, simply because you're so tired.

Working conditions such as long hours and night shifts, as this quote illustrates, play an additional role when it comes to the accuracy and completeness of crime data. Analysts and senior police officers were reluctant to blame their colleagues for mistakes that happened under these conditions. Instead, they pointed to another challenge with regard to crime data production. Difficulties in coming up with accurate data representations of empirical phenomena not only are complicated by ontological uncertainty, professional rationales, and workload but also become further entrenched by overly complicated classification systems in crime reporting forms. One analyst gave the following illustration of the challenges that patrol officers are confronted with when trying to represent what they found at the crime scene within a complex classification system:

We have a very complicated and exhaustive system of keys that was originally supposed to facilitate the generation of crime statistics. Proper crime statistics should be detailed, and you can't do that if you only use "residential burglary" as a key value. So we have a key for "residential burglary", one for "armed residential burglary," one for "organized residential burglary," one for "grand larceny within a dwelling," and so on. In the end we have 50 different keys that have something to do with residential burglary, 
and it's quite the art to find the right one. A grand larceny from a dwelling is probably a residential burglary. A grand larceny that took place within a dwelling is probably also a residential burglary, but maybe the patrol officer used the wrong key, because he couldn't think of 436000 and he didn't have the time to do his research. So he used 400000 , which is just "grand larceny", but the report also says that the site of the crime was an apartment. Now I'll have to look into the free text description: maybe it was the brother who smashed the piggy bank and took the money. Technically that's grand larceny. The money was secured, and the incident took place within the apartment. Hence, it's grand larceny within a dwelling. Maybe the door was kicked in, then all of a sudden, it's residential burglary. And in the end, I have to try and sort this out.

This example illustrates vividly how standardization can backfire when classification systems are too complex. Crime data need to be rather finegrained, as the ability to distinguish between slightly different types of crime is important with regard to legal proceedings, internal management, and the production of crime statistics. In practice, this means, however, that there are almost endless possibilities for how to classify a given crime event, potentially producing cognitive overload. Essentially, the more fine-grained a system of predefined classification categories for crime reporting is, the more complicated it will be perceived as by patrol officers, and the more likely it becomes that this will lead to misclassifications of empirical phenomena. This is particularly pertinent with regard to ambiguous phenomena that are open to interpretation and could therefore be classified in one way or another.

The quote also refers to the fact that in crime reporting forms, for each variable (e.g., haul, modus operandi), there is a list of possible "keys" (i.e., numerical combinations that can be used as shorthand for a specific category) that can be selected from a predefined list in order to specify what was found at the crime scene. These keys decide how an empirical phenomenon becomes translated into a particular data category. The use of predefined categories as a means of data standardization must be understood here as a way of taming the recalcitrance of real-world phenomena just as much as it must be understood as a safeguard against the effects of human interpretation. In practice, keys for more specialized subcategories are, however, particularly likely to be ignored or bypassed by patrol officers in favor of generic categories. One analyst gave an example of this:

Our colleagues can easily differentiate between cash and a TV set. But modus operandi is a different story. How did someone get access to an apartment? Mostly it's levering. And even if it's not levering, the key for levering is the one that our colleagues know by heart. So to be honest, it's 
often standard values that end up in the report. It is what it is. I have to live with these uncertainties.

In this example, rather than going for a specific, possibly more accurate (sub) category to describe the modus operandi encountered at the crime scene, the patrol officer simply opted for the "standard value" (levering) that occurs most often, and this enabled them to quickly complete the report. Patrol officers using generic categories in the production of crime reports, either as a strategy to avoid having to deal with ontological ambiguity, or simply as a shortcut to save time, was described as a persistent problem by our interviewees (I03; I31; I50). Ironically, this problem was further aggravated by the use of digital devices for reporting. As data generation in the field is increasingly being done via electronic devices such as laptops, tablets, or phones, our interlocutors told us that while this would generally be a welcome development, the available applications for reporting were in many instances poorly designed. Due to a lack of semantic support in variable fields or due to cumbersome and unwieldy user interfaces, officers would, for example, often simply pick the key value at the top of the drop-down menu in order to save time (P77). What was originally supposed to facilitate both data generation and accelerate data transfer into police databases turned out to reinforce practices of bypassing complex classification systems and further contributed to inaccuracy in crime data.

Crime reporting forms usually also contain a free text field where the officers can add details, clarify possible confusion, and explain why they were forced to squeeze an empirical phenomenon into a category that might not be a great fit. Free text, however, comes with its own set of issues. Our interlocutors specifically pointed out how officers would use incoherent language and abbreviations and how even free text explanations of empirical phenomena could remain ambiguous (I07). Some of our interviewees even questioned the added value of free text fields, as these needed additional analytical attention before they could become computable data points (I26; I80). In the end, our interviewees acknowledged that there is an inherent tension between the different ways in which the police generate data from crime scenes, and none of them is seen as an ideal solution (I03; I07).

In summary, there are various "error" sources in the production of crime data. Some of them emanate from a lack of knowledge about the criminal incident itself. Others stem from the heavy workload of patrol officers, from overly complex classification systems, from poorly designed reporting forms and interfaces, or from any combination of these elements. Taken together, they render crime data uncertain and such uncertainty would, if unmediated, extend to algorithmic modes of data analysis and undermine predictive policing practices. As Cope (2008: 407) writes, crime analysts often "struggle with incomplete, unreliable and inaccurate information, all of which affects the 
quality of analytical reports", and police departments are therefore looking for ways to address these issues.

\section{Quality control}

In order to enhance the coherence, accuracy, and reliability of their data, police departments usually have a number of quality control measures in place. A seemingly banal, yet important, aspect is double-checking crime reports before they go into the system in the first place. This can involve a number of different actors and extend throughout different organizational units within a department. One analyst detailed the process of double-checking data in their department as follows:

There is a workflow for quality control across different levels. The first level is the person who fills out the reporting form. Then the supervisor should have a look at it. Then we have a quality control manager at the station who will give it another thorough look and identify flaws or inconsistencies. Then we have a central unit for database management, they are also concerned with quality control. And in case there are any obvious errors, I can also ask for corrections.

A completed report from a crime scene, as the aforementioned quote vividly illustrates, must not be confused with the notion that the data from the report would already be "complete" and ready to be analyzed. Double-checking for errors is, however, only a first step. Crime data are even after the initial process of data generation still very much in flux and subject to correction and/or amendments. Details are likely to change or be complemented with additional information during ongoing investigations, after the initial report has been created and submitted to the central system. As additional information becomes available, the data in the system must thus be amended. A pertinent example of retrospective data correction with regard to burglary would be the actual haul, which is in its entirety seldom known right away and is accordingly complemented later when the victim has identified all items that were stolen (I26). The time of the offense can be similarly difficult to determine in the beginning, but additional information such as witness reports may make it possible to approximate a narrower time frame later on.

Amending the data produced originally by adding such new information in a timely fashion is important for the police in order to ensure that crime analysts can work with data that are as accurate as possible. Our interviewees did, however, express some frustration about the lack of awareness and follow-through by their colleagues. As one analyst framed it:

It's quality control, quality control, quality control. . . The time of the offense, that's a classic example. Throughout investigations, we can often approximate 
the time of the offense, or we can even determine an exact point in time. But no one changes that in the database. The file still says "weekend". It is important to do that, and we need to convince our people to do it. The thing is, they don't get any benefit from it. So it's hard to tell them: Listen guys, please make those changes as soon as you have new information.

This statement mirrors the misalignment between the professional rationales of patrol officers and analysts already mentioned earlier. Again, though, our interlocutors showed a great deal of understanding for the working conditions of patrol officers and appreciated why timely amendment of initial data produced from a crime scene can be difficult. One senior officer referred for example to the seemingly banal fact that patrol work is carried out in shifts and that no one can reasonably be expected to come into the station on the weekend or on their day off just to amend a crime report:

In the beginning, we have an initial report. And then there might be an addendum at some point, there might be some corrections. And because our guys work in shifts, it's possible that we get that additional information only three days later. And then all of a sudden, burglary turns into property damage.

Data amendments, as this quote also illustrates, might have quite far-reaching repercussions. New insights from ongoing investigations might even change the type of crime itself and therefore affect the validity of risk estimates. For example, a case that might at first appear as a professional burglary, and therefore potentially as part of a larger series of criminal activities, might a couple hours later, due to emerging details or additional forensics or witness statements, appear more likely to be a spontaneous, emotional, or relationshiprelated deed that would not warrant an increased risk of follow-up crime (I02; I07; I11; I16; I44; I76).

This raises the question of when quality control should be considered finished. In other words, when are crime data "good enough" to actually be ready for analysis? The speed rationale at the core of predictive policing would logically require a minimal time lag between the detection of a burglary, the creation of data about it, and the ensuing data analysis. However, as we have shown, crime data are characterized by a fundamental trade-off between speed and quality. Police departments are thus faced with a choice: Is it preferable to analyze crime data at an early stage and be able to translate the full potential of the risk estimate produced into operational measures, while accepting the possibility that missing values and inaccurate classifications might interfere with the results from the analysis - or is it better to wait a bit longer, work with consolidated data, and run the risk that alerts may already be (partially) outdated when they arrive at street level? Waiting too long, as one respondent framed it, essentially means that 
the police "get alerts that are basically already over before they started, because a case only made it into the system two or three days later" (I26).

This trade-off situation is also reflected in the actual data infrastructure that police departments use to manage and work with crime data. Although, due to the local and regional specificities of police departments in Germany and Switzerland, there was considerable variation in IT infrastructure and database systems, essentially all of the departments we studied had at least two different types of databases in place: (1) a process management database and (2) a case file management database.

Process management databases are systems that first and foremost serve administrative purposes. A process file consists of a unique identification number to which metadata about the process as well as primary information about the incident are linked. Usually, entries in the process management database are created automatically once a citizen gets in touch with the police in order to report a crime, file a complaint, or otherwise create a working process that needs to be administered. The primary rationale of process files is to quickly produce rudimentary knowledge that enables the police to manage work processes internally. For example, police departments use process management databases to keep track of responsible persons and relevant communications. One interviewee described it as follows:

You have to imagine it like this: Every time I make a service call to the police, a file is automatically created. And if my call concerns something that will produce a report, then this report will eventually be forward to the central database, and the report will be linked to the file.

Case file management databases, on the other hand, are geared toward knowledge production in a criminal investigation. They are structured in a similar way - that is, they consist of a unique case file number to which information, reports, documents, and other media files can be linked. Case files are less formalized, but the data they contain are generally considered more reliable (I07; I09; I26). They are, however, also considerably slower, as new data might only be added during the investigation, and after some time has passed since the original reporting of a crime. From a predictive policing perspective, case file management databases are therefore not a good fit, as they overstretch the trade-off between speed and quality too much toward quality. When starting to work with predictive policing software, police departments therefore needed to decide which data source to use as input for algorithmic crime analysis. As our respondents framed it, this decision was pretty much contingent on experimenting with what kind of data quality could be considered "good enough":

In the case file management system we have good quality in terms of verified data on the time and location, as well as haul. This is information that tends 
to be very volatile at the beginning of an investigation: what was the exact time of the offense, what exactly was stolen, and so on. So for us it was clear that when we start using [predictive policing software], we would have to deal with these issues. Because in theory we have little time to react: if there's a burglary today, then we'll have to be in that risk area tomorrow. And not in a week, because it will be over by then. That was the main challenge: to really find out if it works with weak data, with [process management] data, with the data that the emergency call center records, and with the data that our patrol units collect at the crime scene with their tablets.

The idea of a process management database is to capture what you see: you go to the crime scene, you speak to the victim, and you get an idea of the crime. . . Whatever you know or think you know at this point. It needs to be quick, and it gets transferred to the central system immediately. . . . The purpose here is not investigation, it's process management, and it's not good data. Our crime analysis division basically uses these completely invalidated data half an hour later and tries to generate situational insights from them. There's a lot of uncertainty. Things are wrongly classified, wrong key values are used, generic categories are used even though there are specific sub-categories, free text explanations are off because there was a misunderstanding at four in the morning or because the victim was not exactly sure what had happened. And then we must try to validate as many data points as possible as quickly as possible.

As these quotes illustrate, the police departments we investigated eventually came to the conclusion that the data provided by process management databases could in fact be used as input for predictive policing software, despite their obvious shortcomings (I07; I09; I18; I45; I50; I51; I78). This means they opted for the repurposing of data that were never meant to provide the basis for crime analysis. This happened because the need for timely data in predictive policing had rendered the more logical analytical source - that is, the case file management database, useless for operational response. As one analyst summarized the situation:

[The process management database] is always a bit blurry. . . It is supposed to administer internal information: who is responsible for a case, when did they distribute what kind of information to whom. The fact that we use that for analytical purposes is more like a by-product.

Notably, as process management databases provide the primary data input for predictive policing software, police departments put the knowledge that is 
produced in crime analysis on shaky epistemic foundations. Process management databases have a deliberately provisional and volatile character that speaks to the uncertainties that can hardly be avoided in police work and the production of crime data. The choice to work with potentially unreliable data, however, was largely preconfigured by the near-repeat rationale and the assumption that the likelihood of follow-up crime decreases rapidly after the first 72 hours following a trigger incident. At the same time, police departments are fully aware that the potentially precarious data foundation of predictive policing means they must pay even more attention to quality control and that the analyst has to act as an additional fail-safe and double-check every algorithmically created alert for the consistency of its database. We will deal with the role of human analysts in predictive policing in more depth in Chapter 5.

\section{The rhythm of crime and policing}

Issues with data quality in predictive policing might, however, in the end not turn out to be as problematic as one might think. Even though analysts are understandably keen on getting their hands on good quality data as quickly as possible in order to be able to generate meaningful and timely recommendations for operational measures, the need for speed becomes considerably mediated when risk estimates are translated into street-level policing. As the eventual rationale of predictive policing is to have targeted patrols in risk areas to potentially deter offenders from committing near-repeat burglaries, the production of risk estimates must from an operational point of view not be geared toward maximum acceleration but rather be synchronized with the occurrence of crime and corresponding patrols and other prevention measures.

Environmental criminology has long foregrounded the importance of opportunities for the occurrence of crime, and it has in turn highlighted how through a modification of such opportunities crime might effectively be prevented. Opportunities can, for instance, be caused by architecture or design that facilitates criminal activities, they can be caused by poor lighting, or they can be caused by a lack of access protection or the availability of unguarded objects (Clarke, 1980; Brantingham and Brantingham, 1981; Wortley and Townsley, 2017). Starting from the assumption that opportunities for crime are, equally, dynamically caused by the movement of people and goods throughout the day, Felson (2006: 6) has conceptualized crime as a fluid process that "has a metabolism, a rhythm of life responding to other rhythms". His analysis is pertinent for predictive policing and burglary prevention, as it foregrounds how windows of opportunity open and close rather regularly as people go about their daily business. As he argues, "residential burglars depend on the rhythmic shift of residents away from home in the morning, and they better watch out for their return later" (Felson, 2006: 7).

Such considerations closely correspond with routine activity theory (Cohen and Felson, 1979) and assumptions of rational offender behavior (Becker, 
1968), and render residential burglary a type of crime that is widely considered to occur rhythmically, with regular intervals of offender activity and inactivity. A professional burglar is not expected to operate $24 / 7$, but only during specific hours of the day when premises are vacant and/or lighting conditions provide additional cover (I09; I26; I62). The classic example of such rhythmic offender behavior caused by environmental factors is the dusk period during fall and winter, when the sun sets early and creates a "window of darkness" between early afternoon and the time when residents return to their homes by early evening. During this window of opportunity, burglars are able to operate more comfortably, as they are less likely to be seen and/or identified. Additionally, unoccupied dwellings can be easily identified when no lights are showing.

The police are well aware of these rhythms. For them, targeting professional residential burglars with intensified patrols in risk areas thus only makes sense during the assumed "working hours" of offenders, which depend on the preferred method of the burglar as much as they depend on environmental factors that open and close windows of opportunity (I02; I03; I06; I07; I11; I43; I45; I50). Assuming a daily rhythm during which residents pursue their routine activities thus means that a burglar will once per day be able to seize the opportunity to enter vacant premises with comparably little risk - which in turn means that the police have almost a full day to produce data from the offender's activities, analyze the data, devise operational measures, and implement these measures in the identified risk area during the assumed active hours of the offender on the next day. For a series of residential burglaries that occurs during a winter dusk window of approximately three to four hours, this means that the police have about 20 hours to prepare for the next cycle - including quality control processes to ensure that predictive policing is operating on the best data basis possible.

At the same time, such a rhythmic interplay of crime and policing implies that the risk estimates produced by predictive policing software can in the best case be narrowed down considerably in accordance with the temporal characteristics of the presumed burglary series that is to be operationally targeted. Police departments do this by compartmentalizing algorithmically produced risk time into segments that correspond with the assumed operational hours of a specific burglary "profile". In this way, they are able to rule out certain periods of the day and deploy patrols in an even more targeted fashion (I20; I26). The overall temporal reach of risk estimates (usually five to seven days) remains untouched by this practice, but throughout the active period of an alert, patrols will only actively cover the predicted risk area during those hours when near repeats can reasonably be expected (P01). One analyst detailed their ways of narrowing down operational hours in accordance with the rhythm of crime as follows:

We use time stamps. ..: "Giorno" for daytime burglaries, "Sera" for dawn, and "Notte" for nighttime. And sure, we are still dealing with an overall time period of seven days [for an active alert], but within these seven days we do not need to cover all 24 hours of the day. Instead, we limit ourselves to the 
time stamps. "Sera," in this case, is a twilight burglary . . . and that means that our patrols over the next seven days will only have to cover this time of day.

The criminal futures that predictive policing engenders are thus very much focused on the rather narrow operational task at hand, which is to prevent residential burglary as a specific type of crime. Crime and policing must in this sense be understood as alternating cycles that supersede each other at regular daily intervals (Leese, 2020). Further acceleration, while technically possible, is considered to create no additional value for operational crime prevention measures. As one respondent explained, from an operational perspective, the police "need to get ahead of the next cycle. That is when the offender might return. And that's 24 hours" (I78). The particular interval that emerges through the relation of the temporal characteristics of crime and the process of data collection, consolidation, and analysis is in fact a rather static one that has little in common with imaginaries of predictive policing as a responsive, flexible, and dynamic method. There is little, if any, "real-time" data flow and no "live" situational awareness.

The daily rhythm of predictive policing practices becomes further entrenched through the ways in which crime risk needs to be made relatable to wider organizational practices. In order to bring predictive policing to the streets and make crime forecasts amenable to the practices of patrol forces, analyses need to be readily available for shift briefings where patrol forces are instructed about current risk areas and preferred patrolling strategies. This means that analysts will need to stick to fixed "delivery times" that are predefined by the work schedule of the department. The life cycles of crime data, crime analysis, and larger organizational trajectories must thus be aligned and synchronized, in such a way that internal communication is facilitated and risk alerts can be translated into operational measures at the right moment. We will engage with dissemination and communication in more depth in Chapter 6. Our interviewees illustrated the challenge of matching different temporal logics as follows:

The day shift starts at 07:00, and most burglary cases are reported and captured between 16:00 and 02:00, when there are only few officers on duty at the station. There is a supervisor who has the lead and who is also in charge of quality control. But there's usually a lot going on at our station, so he won't really get around to that. So the actual quality control will start in the morning, when the day shift starts at 07:00. And then we have the morning meeting at 08:00, and quality control is usually finished by 09:00, 09:30, and we want to wait for that.

We extract [burglary] data on a running basis from our process management database. . . . That is usually possible. By the next morning these cases are consolidated and have a certain quality, and then we verify the 
information once more and amend it if need be. Once this re-examination, this quality control process, is finished, the data become part of the dataset to be analyzed.

In all the departments we studied, the modes of temporal alignment would be similar, meaning that crime analysis with predictive policing software would usually start at some point between 10:00 and 11:00 in the morning, when crime data would be seen as robust and reliable enough for analysis and the results from the analysis could still be distributed in time for the start of the next patrol shifts (I07; I26; I45; I76; I78).

Due to the automation of the actual analytical process, crime analysis with predictive policing software does not in fact take up a great deal of time, and this is where the advantages of algorithmic means of analysis can be witnessed. Depending on the amount of criminal activity to be analyzed, reports will usually be ready for distribution about 15-30 minutes later (I26; I39; I44; P75; P76). When software companies advertise the speed advantage of their product compared to manual crime analysis, they may be making a justified claim if one looks exclusively at the time that passes between data import and the distribution of alert memos. When we look at the wider sociotechnical practices of predictive policing, however, it becomes clear that acceleration cannot be something that is produced through an algorithm in relation to data alone. Rather, speed can only emerge through a diverse set of sociotechnical relations (I07; I18; I26; I31). In the end, predictive policing entrenches what one of our respondents aptly summarized as a "daily rhythm" of crime and policing:

At the moment we have a daily rhythm.... We realized that once per day is enough for situational analysis. In the morning, you have to determine which new burglaries came in, because what happened overnight is usually noticed in the morning and then reported. That means you wait until you can include these and run the analysis once for the daily situational analysis, and that's enough.

Some of the departments we investigated did experiment with more frequent iterations of data analysis, hoping in this way to enhance the quality of their forecasts. One department chose to run predictive policing software twice per day, as they reasoned that crime risk should be updated before the start of the early evening patrol shifts (I80). Another department even chose to add another iteration of analysis in the evening, but it quickly became clear that this was of little use as usually no residential burglary cases would be expected to occur during the night, which meant crime analysis in the morning sufficed (I44).

Work organization within police departments, in close correspondence with the criminal phenomenon to be dealt with, thus predefines the rhythm of 
crime analysis in very clear-cut ways. Technoscientific imaginaries of maximum acceleration, live data feeds, and real-time awareness might sound great on paper, but they would offer limited additional value for everyday police practice. Criminal futures, from the perspective of the police, do not need to be about the production of ultimately precise renderings of risk throughout time and space, but they must present actionable means to make an overall situation intelligible and manageable. One officer summarized the practical stakes with regard to questions of timing, speed, and frequency within predictive policing as follows:

I think we should not forget that we are talking about a larger situational picture here. . . . We must not overburden our people with continuous new alerts. You run the analysis in the morning, and that's just like the weather forecast: what will the weather be like today? You don't want to be constantly updated, and usually that's not necessary either.

The weather analogy used by our interviewee is in fact a good way to understand the relevant temporal characteristics of crime risk with regard to the police's organizational needs. It is good to know in the morning that there is a chance of rain today, so you can bring an umbrella. There might not actually be any rain (the weather forecast is only a statement about statistical likelihoods), and maybe by midday, the forecast has been adjusted and tells you that rain is now unlikely. Again, this is good to know, but since you set off with your umbrella this morning anyway, it does not actually change anything. Similarly, if crime risk areas were to be updated multiple times throughout the day it might not be easily possible for patrol forces to accommodate the updates. We will deal with patrolling practices and risk areas vis-à-vis other tasks of patrol officers in more detail in Chapter 7. For police departments, in summary, it turns out to be more sensible to plan operational measures based on a rather static, daily-rhythm notion of criminal futures, allowing for sufficient leeway to construct operational measures and corresponding organizational processes around each risk area.

\section{Conclusion}

The formation of a sociotechnical system around predictive policing has, at the stage of the first translation process of empirical phenomena into data, drawn renewed attention to the ways in which the police produce crime data, the challenges they face in doing so, and how data continue to be produced and reproduced even after their initial inception. Crime data undergo a notable journey throughout their life cycle, starting with their creation at the crime scene, continuing with their consolidation and amendment at various stages of police work and preliminarily ending with their incorporation in crime 
analysis. Throughout this journey, concerted efforts to accelerate the process from data collection to analysis and to operational measures continue to hit speed bumps in the form of quality control processes. The speed of data quality is closely tied to and therefore limited by the speed of criminal investigations.

Police organizations are well aware that crime data will never be perfect. The implementation of predictive policing has once again forced them to acknowledge this fact and has drawn reinforced attention to quality control measures that are supposed to curb incoherence, inaccuracy, and unreliability in data as far as possible. A sociotechnical understanding of predictive policing highlights the importance of data creation practices, the different professional lifeworlds of patrol officers and analysts, and the need to address data quality issues early on. Raising awareness about best practices in data production is from a police perspective seen as a necessary and worthwhile way of addressing the foundations of predictive policing and, by extension, as valuable for other forms of crime analysis and data handling. This might not always be successful. But, as we will discuss in more detail in Chapter 10, it has reproblematized entrenched problems and put them on the agenda for future reform.

Data troubles are, however, to a certain extent mediated by the fact that crime and policing are tied together by a rhythmic interplay that limits the additional benefits of further acceleration and provides additional room for quality control and data amendments. Even though crime data will never be perfect, the need for speed in predictive policing prescribes to put imperfect data to use. Most notably, against this backdrop, police departments were careful not to blindly rely on their own data. Multiple layers of quality control and the supervision of algorithmic production of risk estimates by a human analyst are testaments of a good deal of skepticism they showed towards the data basis of crime forecasts. This seems appropriate for a domain such as policing, where errors can have severe consequences.

\section{Notes}

1 PredPol, www.predpol.com/technology (accessed 30 April 2020).

2 PRECOBS, www.ifmpt.de (accessed 30 April 2020).

\section{References}

Anderson C (2008) The End of Theory: The Data Deluge Makes the Scientific Method Obsolete. Wired. 16 July. Available at https://www.wired.com/2008/06/pb-theory/ (accessed 30 April 2020).

Andrejevic M and Burdon M (2014) Defining the Sensor Society. Television \& New Media 16(1): 19-36.

Aradau C and Blanke T (2017) Politics of Prediction: Security and the Time/Space of Governmentality in the Age of Big Data. European Journal of Social Theory 20(3): 373-391.

Babuta A (2017) Big Data and Policing: An Assessment of Law Enforcement Requirements, Expectations and Priorities. London: Royal United Services Institute for Defence and Security Studies. 
Balogh D A (2016) Near Repeat-Prediction mit PRECOBS bei der Stadtpolizei Zürich. Kriminalistik 70(5): 335-341.

Beck C and McCue C (2009) Predictive Policing: What Can We Learn from Wal-Mart and Amazon about Fighting Crime in a Recession? The Police Chief 76(11): 18-24.

Becker G S (1968) Crime and Punishment: An Economic Approach. Journal of Political Economy 76(2): 169-217.

Biderman A D and Reiss A J (1967) On Exploring the "Dark Figure" of Crime. The ANNALS of the American Academy of Political and Social Science 374(1): 1-15.

Bowker G C (1994) Information as Mythology: The World of/as Information. In BudFrierman L (ed.) Information Acumen: The Understanding and Use of Knowledge in Modern Business. London: Routledge, 231-247.

Bowker G C (2008) Memory Practices in the Sciences. Cambridge/London: MIT Press.

boyd d and Crawford K (2012) Critical Questions for Big Data: Provocations for a Cultural, Technological, and Scholarly Phenomenon. Information, Communication \& Society 15(5): 662-679.

Brantingham P J and Brantingham P L (1981) Environmental Criminology. New York: Macmillan.

Bratton W J and Malinowski S W (2008) Police Performance Management in Practice: Taking COMPSTAT to the Next Level. Policing: A Journal of Policy and Practice 2(3): 259-265.

Clarke R V (1980) "Situational" Crime Prevention: Theory and Practice. British Journal of Criminology 20(2): 136-147.

Cohen L E and Felson M (1979) Social Change and Crime Rate Trends: A Routine Activity Approach. American Sociological Review 44(4): 588-608.

Cope N (2008) 'Interpretation for Action?' Definitions and Potential of Crime Analysis for Policing. In Newburn T (ed.) Handbook of Policing. Cullompton/Portland: Willan Publishing, 404-429.

Dalton C and Thatcher J (2014) What Does a Critical Data Studies Look Like, and Why Do We Care? Available at www.societyandspace.org/articles/what-does-a-critical-datastudies-look-like-and-why-do-we-care (accessed 30 April 2020).

Desrosières A (2002) The Politics of Large Numbers: A History of Statistical Reasoning. Harvard: Harvard University Press.

Ericson R V and Haggerty K D (1997) Policing the Risk Society. Oxford: Clarendon Press.

Felson M (2006) Crime and Nature. Thousand Oaks/London/New Delhi: Sage.

Gandy O H (1993) The Panoptic Sort: A Political Economy of Personal Information. Boulder: Westview.

Gitelman L and Jackson V (2013) Introduction. In Gitelman L (ed.) "Raw Data” Is an Oxymoron. Cambridge/London: MIT Press, 1-14.

Hacking I (1990) The Taming of Chance. Cambridge: Cambridge University Press.

Haggerty K D (2001) Making Crime Count. Toronto: University of Toronto Press.

Harper R R (1991) The Computer Game: Detectives, Suspects, and Technology. British Journal of Criminology 31(3): 292-307.

Johnson S D (2008) Repeat Burglary Victimisation: A Tale of Two Theories. Journal of Experimental Criminology 4(3): 215-240.

Kitchin R (2014a) Big Data, New Epistemologies and Paradigm Shifts. Big Data E Society 1(April-June): 1-12.

Kitchin R (2014b) The Data Revolution: Big Data, Open Data, Data Infrastructures \& Their Consequences. Los Angeles/London/New Delhi/Singapore/Washington, DC: Sage.

Kitchin R and Lauriault T P (2014) Towards Critical Data Studies: Charting and Unpacking Data Assemblages and Their Work. The Programmable City Working Paper 2. 29 July, Maynooth. 
Krasmann S and Hentschel C (2019) 'Situational Awareness': Rethinking Security in Times of Urban Terrorism. Security Dialogue 50(2): 181-197.

Leese M (2020) 'We Do That Once Per Day': Cyclical Futures and Institutional Ponderousness in Predictive Policing. In Jasper U, Wenger A and Dunn Cavelty M (eds.) The Politics and Science of Prevision: Governing and Probing the Future. London/New York: Routledge, 213-226.

Lyon D (1992) The New Surveillance: Electronic Technologies and the Maximum Security Society. Crime, Law and Social Change 18(1-2): 159-175.

Lyon D (2014) Surveillance, Snowden, and Big Data: Capacities, Consequences, Critique. Big Data \& Society (July-December): 1-13.

Mahnken J and Rabitz-Suhr S (2019) Auswertung und Analyse 4.0: Das Projekt "Entwicklung Berufsbild Kriminalitätsanalytik”. der kriminalist 51(12): 21-26.

Maltz M D (1999) Bridging Gaps in Police Crime Data: A Discussion Paper from the BJS Fellows Program. Washington, DC: U.S. Department of Justice.

Manyika J, Chui M, Brown B, Bughin J, Dobbs R, Roxburgh C and Hung Byers A (2011) Big Data: The Next Frontier for Innovation, Competition, and Productivity. McKinsey Global Institute. Available at www.mckinsey.com/ /media/McKinsey/Business\%20Functions/ McKinsey\%20Digital/Our\%20Insights/Big\%20data\%20The\%20next\%20frontier\%20 for\%20innovation/MGI_big_data_full_report.ashx (accessed 30 April 2020).

Marx G T (1995) The Engineering of Social Control: The Search for the Silver Bullet. In Hagen J and Peterson R D (eds.) Crime and Inequality. Stanford: Stanford University Press, 225-246.

Mayer-Schönberger V and Cukier K (2013) Big Data: A Revolution That Will Transform How We Live, Work, and Think. London: John Murray.

Perry W L, McInnis B, Price C C, Smith S C and Hollywood J S (2013) Predictive Policing: The Role of Crime Forecasting in Law Enforcement Operations. Santa Monica: RAND Corporation.

Ratcliffe J (2019) Reducing Crime: A Companion for Police Leaders. London/New York: Routledge.

Ratcliffe J, Taylor R B and Fisher R (2020) Conflicts and Congruencies between Predictive Policing and the Patrol Officer's Craft. Policing and Society 30(6): 639-655.

Rip A, Misa T J and Schot J (eds.) (1995) Managing Technology in Society: The Approach of Constructive Technology Assessment. London/New York: Pinter.

Santos R B (2013) Crime Analysis with Crime Mapping. Thousand Oaks/London/New Delhi/Singapore: Sage.

Schneider C and Leutenegger J (2020) Predictive Policing als Herausforderung für das polizeiliche Datenmanagement: Erfahrungen aus einem Pilotprojekt der Kantonspolizei Zürich. In Bode F and Seidensticker K (eds.) Predictive Policing: Eine Bestandsaufnahme für den deutschsprachigen Raum. Frankfurt am Main: Verlag für Polizeiwissenschaft, 273-287.

Schweer T (2015a) Musterbasierte Prognosetechnik bei der Kriminalitätsbekämpfung - Die Methodik der Near Repeat Prediction. Polizeispiegel 49(6): 22-24.

Schweer T (2015b) "Vor dem Täter am Tatort" - Musterbasierte Tatortvorhersagen am Beispiel des Wohnungseinbruchs. Die Kriminalpolizei 32(1): 13-16.

Scott J C (1998) Seeing Like a State: How Certain Schemes to Improve the Human Condition Have Failed. New Haven/London: Yale University Press.

Sheptycki J (2017) Liquid Modernity and the Police Métier: Thinking about Information Flows in Police Organisation. Global Crime 18(3): 286-302.

Willis J J and Mastrofski S D (2018) Improving Policing by Integrating Craft and Science: What Can Patrol Officers Teach Us about Good Police Work? Policing and Society 28(1): $27-44$. 
Wilson D (2019) Platform Policing and the Real-Time Cop. Surveillance \& Society 17(1/2): 69-75.

Wolf G T (2010) The Data-Driven Life. The New York Times Magazine. 28 April. Available at www.nytimes.com/2010/05/02/magazine/02self-measurement-t.html (accessed 30 April 2020).

Wortley R and Townsley M (eds.) (2017) Environmental Criminology and Crime Analysis. London/New York: Routledge. 


\section{Humans and machines}

Acceleration in predictive policing is primarily brought about by automation. As algorithms relieve humans of some of the burdens of crime analysis, it is worth interrogating automation and its effects on the relations between humans and machines in more detail. In this chapter, we investigate how predictive policing reconfigures sociotechnical practices of crime analysis and how police departments aspire to balance machine power and human competencies. In particular, we foreground how different types of perception and knowledge production can lead to conflicts around the redistribution of authority and reasoning and how such conflicts are institutionally curbed by a number of safeguards to "keep the machine in check".

The chapter starts by reviewing the rationales of automation. Drawing on Human-Computer Interaction (HCI) literature, it explores some of the general benefits and drawbacks of workload distribution between humans and machines and how different levels of automation vis-à-vis given tasks reconfigure the relationships between systems and operators. The second part empirically retraces why there is a persistent need for human analysts in predictive policing and how automation of crime analysis transforms the job profile of operators. We then proceed to illustrate some of the possible conflicts that can emerge when humans and algorithms interact in the production of crime risk. We specifically engage with how operators tinker with software configurations in order to align system outputs with other elements of the sociotechnical system and how police departments provide a number of support measures that are supposed to facilitate human arguments against algorithmic recommendations.

\section{Automating things}

In crime analysis, predictive policing software essentially promises to take care of tasks that are monotonous (such as executing the same analytical operation over and over again for each registered burglary case), complex (such as advanced analytics within large datasets), error prone, and/or surpass human capacities in the first place (as would, for example, be the case with machine learning techniques). The general assumption that underpins automation is 
that machines are more suitable to do the heavy lifting, carry out tasks much quicker and do so without producing random errors or needing a break. One software developer summarized the advantages of automated algorithmic analysis as follows:

Particularly with types of crime that occur in large numbers, the system can compute the statistics in a couple of seconds. If I want to look at a specific neighborhood in [city], I can ask the system: "What's the near repeat quota in this area?" . . And the system tells me: "In this area, there's a near repeat quota of 45 per cent." . . . Any analyst could do the same thing. What PRECOBS does could be done by any capable police officer. The difference is: a machine doesn't get tired, it reduces complexity, and, if properly configured, it produces no errors.

Predictive policing, in this sense, ties into a long-standing tradition of engineering and design that has, since the early days of computing in the middle of the 20th century (Fitts, 1951), explored how to use machine capacities to best relieve humans of some of their workload. The practical guiding question for research on HCI can be summarized as follows: What tasks within a given domain can be automated in the first place, and to what extent should they be automated? Automation is thereby understood as "the full or partial replacement of a function previously carried out by the human operator" (Parasuraman et al., 2000: 287).

In order to find out how much automation would be desirable for a given task within a particular operational and organizational environment and how a specific degree of automation would restructure the relationship between system and operator, Sheridan and Verplank (1978) have specified ten "levels of automation" (LOA), ranging from no assistance offered by the system at all to a fully automated system that carries out all tasks by itself and completely ignores the human operator. This conceptual differentiation allows engineers and designers to specify how much workload should be delegated to automated processes within the system, how much and what kind of control the human operator should have over these processes, and what the interface between operator and system would need to look like in order to ensure proper cooperation and the desired level of human control within a given configuration of workload distribution.

Tinkering with different configurations of automation and control vis-à-vis legal, organizational, psychological, cognitive, and not least, moral aspects of the relations between humans and machines is seen, then, from an HCI perspective, as a way of moving toward the establishment of an optimal trade-off between relocating tasks to system functions while at the same time ensuring human awareness and the possibility of intervention in automated processes if necessary. In HCI research, the highest possible level of automation was long 
perceived as desirable, as it was assumed that this would free up human capacities that could then be redirected to other tasks where they could be applied in a more meaningful fashion (de Greef, 2016: 139). Very much in line with such a drive toward maximum automation are narratives of automation as an innovative way to more effective and cost-efficient ways of doing things (Miller and Parasuraman, 2007: 58). As we discussed in Chapter 2, such narratives are strongly reflected in predictive policing and correspond closely with efforts to render the police more effective and efficient. It is no wonder, then, that automation is presented in crime prevention and other domains of law enforcement as a desirable development.

HCI scholars, however, are increasingly cautioning against the assumption that automation can be seen as a panacea for human shortcomings and lack of adequate institutional budgets. Research has demonstrated that high levels of automation must not necessarily be a good thing. On the contrary, it has been shown that high levels of automation tend to produce a set of problems, including negative effects on operator awareness and a decline in operator skillsets (Parasuraman et al., 1993; Endsley and Kiris, 1995; Wickens et al., 1998; Parasuraman and Miller, 2004). In other words, the more tasks are delegated to a machine, the more human capacities will deteriorate - which can turn out to be problematic if the system fails and the operator has to take over.

These issues are aggravated when humans are no longer able to properly understand machine tasks in the first place. As algorithms carry out complex calculations or identify patterns in large amounts of data, their operations tend to become too complex to retrace for humans. The creation of such "black boxes" (Latour, 1987: 1ff) is part of the very idea of automation, as complexity is supposed to be hidden from the human eye. And yet, a lack of visibility has potentially troublesome repercussions on the relations between humans and machines. Most notably, it impacts the human ability to carry out meaningful forms of control over machine processes, as such control should be based on a general understanding of the task that has been automated. In other words, the more processes are delegated to machinic calculations and thereby rendered invisible and the more complex these calculations become, the less understandable and retraceable do machine-produced outputs become for humans. This gives considerable authority to machines, as a lack of knowledge about how their outputs come into being renders them less challengeable by human users (Leese, 2014; Pasquale, 2015).

Notably, visibility and traceability play a crucial role in decision-making processes that are, in environments where humans and machines work together, often underpinned by knowledge that was produced by the system and then presented to the human operator - usually in the form of recommendations for a specific course of action. While in most application domains, it is typically asserted that machines will not "decide" anything by themselves, looking more closely at automation and HCI reveals that decisions can in many cases not easily be attributed to either humans or systems. Coupled with often relatively short time frames for 
human decision-making based on algorithmically produced recommendations, high levels of automation have been shown to produce "automation bias" - that is to say, an overreliance on automated system functions - at times even against one's own judgment of a situation (Skitka et al., 1999; Cummings, 2004; Wickens et al., 2015). Automation bias demonstrates that in domains where humans and machines work together, there is a tendency to "blindly follow" the machine under assumptions of alleged accuracy and impartiality.

Uncritically following automated processes creates concerns in terms of accountability for ensuing action (Skitka et al., 2000; Jones, 2017) - and most notably for "wrong" decisions, whether they are based on faulty data, inadequate models and/or algorithms, or other error sources. This is particularly pertinent for high-risk environments - that is, for domains where sociotechnical systems are used for safety or security tasks. Nuclear safety, global health, and counterterrorism are just some examples of domains where erroneous assessments, decisions, and resulting actions can have severe consequences for those affected by them. In order to safeguard against automation bias and retain responsibility and accountability for decision-making within the human realm, Parasuraman and Wickens (2008: 514) have thus argued that "in high-risk settings . . . decision automation should be set at a [level of automation] that allows operator input into the decision-making process".

During our research, we saw this principle strongly reflected in the practical implementation of predictive policing software. Algorithmically produced risk estimates, as we show throughout this chapter, are in everyday use subjected to rather strong means of human control for several reasons. For police organizations, it is important to be able to understand and retrace decision-making processes in crime analysis, not least because they need to be able to justify and legitimate operational measures based on analytical insights. This is particularly pertinent in predictive policing and other forms of risk-based, future-oriented measures, as such methods can potentially extend data bias to the street level and have tangible repercussions in terms of discrimination and over- or underpolicing. We will engage what notions of automation and black-boxing mean for the accountability of police work in Chapter 9.

Practices of predictive policing thus closely resonate with research in engineering and design, which highlights that humans are "still vital after all these years of automation" (Parasuraman and Wickens, 2008: 511) and that this fundamental constellation is not likely to change. Despite the technological advances we have witnessed over the last few decades, the need for human control speaks to fundamental ethical and legal concerns that are largely independent of the concrete processes subject to automation. Rather than a purely technical question, automation is thus much more about the art of balancing the workload between humans and machines such that benefits from automation can be maximized while meaningful control can at the same time be guaranteed.

Building on this understanding of automation, HCI has over recent decades paid increased attention to the human factors within sociotechnical systems 
and the ways in which communication and interfaces between operators and systems could be optimized. Suggestions for human-centered design involve concepts such as "flexible automation" (Miller and Parasuraman, 2007), "team play" (Klein et al., 2004), and "machine etiquette" (Parasuraman and Miller, 2004). In order to realize modes of workload distribution that speak to the need for human control, medium LOAs have been foregrounded as the most important area of study. As Miller and Parasuraman (2007: 58) argue, the design of a sociotechnical system then "requires that neither human nor automation be exclusively in charge of most tasks but, rather, uses intermediate levels of automation and flexibility in the role of automation during system operations and places control of that flexibility firmly in the human operator's hands".

\section{The need for an operator}

The fact that predictive policing software requires an operator does not come as a surprise against the backdrop of insights from HCI research. From a technical perspective, high levels of automation could in crime analysis unquestionably be realized and indeed bring predictive policing closer to the imaginary of an uninterrupted, steady process that runs in the background and produces analytical insights without any unnecessary delay. The empirical reality, however, differs quite a bit from this scenario. Police departments as much as software developers themselves have come to the realization that in predictive policing, automation must be handled with care and curbed by the software itself and/or organizational constraints that ensure meaningful human control. In all the departments we studied, predictive policing software was implemented in ways that made sure that, in the military jargon of decision-making under the use of assistance systems (Endsley and Kiris, 1995), a human operator was not only "on the loop" (i.e., supervising the process without necessarily getting actively involved in it), but properly "in the loop" (i.e., automated processes would at some point come to a halt and only continue upon approval by the human operator)(P01; P49; P67; P77). One interviewee summarized this rationale as follows:

We deliberately set it up this way. You could have it fully automated, but we chose not to. The human makes the final decision. It could be fully automated, no problem at all. The technology is ready for that. The system can process any kind of data: personal data, different sources, not a problem from a technical point of view. But it makes no sense to have a fully automated system.

The main reason to opt against high levels of automation in predictive policing was at times quite bluntly formulated as a lack of trust: "I would never trust a machine $100 \%$. I would always double-check whether I come to the same conclusion" (I03). Such a generalized stance of suspicion might appear 
intuitive in the first place, particularly, as we discussed in Chapter 3, in the light of the skepticism police organizations have historically shown when confronted with the implementation of new technological tools. Equally, it speaks to HCI research that has pointed to lack of trust in the system as one potential effect of high levels of automation (Parasuraman and Miller, 2004).

In predictive policing, however, a lack of trust in algorithmically produced crime risk estimates does also speak to concerns about the reliability of crime data. Data quality, as we pointed out in the previous chapter, is generally seen as a critical issue in crime analysis - even with multiple layers of quality control in place. In predictive policing, time pressure additionally aggravates the problem of potentially unreliable data. The amendment and consolidation of crime data usually takes some time and thus potentially compromises police capabilities to intervene in presumed ongoing crime series. The data that feed predictive policing software must thus be understood as a major reason why police departments tend to distrust complete automation and seek to subject algorithmically produced recommendations to dedicated human oversight.

It should be noted at this point that the perceived lack of data quality is of course a homemade problem. Concerns about predictive policing should thus first and foremost be understood as concerns about the police's own practices of data production and consolidation. This constellation tells us quite a lot about police perceptions of predictive policing software. In simple terms, what the police do not trust is the ability of the algorithm to make sense of potentially faulty data. As algorithms are "context blind" (i.e., their "cognition" is limited to the data that they are presented with), everything that they know and tell us about the world hinges on that data input.

The potentially shaky nature of crime data then renders the safeguard of a human operator an intuitive choice to contextualize algorithmically produced knowledge with a different perspective. One interviewee described the problems at the intersection of the fluidity of crime data and internal quality control processes as follows: "PRECOBS would process the data right away. And that's why you need an operator who is able to dig a little deeper if necessary, and is able to evaluate a crime on the basis of his criminological knowledge" (I77). The human operator is in this sense not only supposed to act as a last instance of quality control by double-checking the data on which the analysis is predicated for completeness and reliability, but more importantly, supposed to make sure that the machine output can be trusted. The operator in predictive policing is accordingly conceptualized as a corrective who does the research, fills the blanks, and checks whether there might be hitherto unknown hints at anti-triggers (I02; I03; I07; I19; D001).

This ties in with a second concern about predictive policing. Algorithms are generally considered at their best when it comes to looking for patterns in data at scale, but they are seen as less reliable and trustworthy when it comes to evaluating idiosyncratic cases. In other words, when a decision has to be made about whether the details of a burglary case within a larger situational context 
really indicate an increased crime risk and therefore warrant operational prevention measures, an algorithm might not be trustworthy after all. Our interlocutors framed this potential shortcoming of predictive policing applications in terms of the different skill-sets that machines and human analysts bring to the table, insinuating that the system was lacking the human capacity of sensitivity and instinct. As one analyst framed it: "The system itself does nothing but search list values for patterns. But the thing is, these list values never give you the entire story that you need to really evaluate a risk area" (I76).

It appears rather obvious that software is not able to produce "a story" - and yet the capability to situate a crime within a narrative was seen as key when it came to proper evaluation of the risk of follow-up incidents (I02; I07; I76; I79). This demonstrates a certain mismatch between what the police consider sensemaking and machine evaluations of data. Different modes of seeing and interpreting the world and the potentially troublesome relationship between humans and machines that results from these modes are, first and foremost, reflected in the ways in which police departments position human oversight vis-à-vis predictive policing software.

This problematization can also partially be encountered in the ways in which software manufacturers conceptualize how their products are to be used. PRECOBS vendor IfmPt, for example, actively draws attention to the potential mismatches between machinic evaluations and human evaluations of the same criminal environment (D001). In order to facilitate human oversight, the PRECOBS interface is thus designed in a way that actively assists human contextualization and evaluation of alert areas through a color-coded system that guides the operator through potential issues with the underlying data. For every alert that is produced by the system, the software marks missing values in the data in yellow. If the alert involves dedicated trigger criteria for near-repeat alerts, these are marked in blue. And if the analysis of crime data involves dedicated anti-trigger criteria that formally prevent the creation of an alert, these are marked in magenta (I03; D001). Using these color codes, the operator is then supposed to be able to more easily investigate whether the system's assessment of the data can be confirmed or whether it needs to be corrected.

The distribution of labor in predictive policing is thus essentially one where the system carries out the crime analysis and the human clears up the potential mess - or, in the more courteous words of one of our respondents: "evaluates the results" (I10). In its core, predictive policing then fundamentally transforms the job profile of the crime analyst. Whereas analysts used to be the experts carrying out the actual analysis, their role vis-à-vis automation has turned into that of a supervisor/researcher/quality control manager. One respondent framed the new focus for the human in predictive policing as one of weighing pros and cons vis-à-vis machine recommendations: "Generating an alert is not complicated. But the evaluation? Should we distribute that alert or not? Are there criteria in favor or against it?" (I79) Grappling with these criteria has become the main task for the operator as the machine computes risk estimates, and the 
human is supposed to suppress "wrong" risk estimates (P28) and bring the background to the table in order to produce the story around the alert. Several of our respondents gave examples of what such "narrativization" entails in everyday practice:

So the system produces an alert for an apartment, but you know that this apartment has been vacant for four weeks. Maybe someone broke in because they needed a place to sleep - that is not burglary. But the system does not know that. The system does not know that background, the empty apartment. Or maybe there was an actual burglary, but the only thing that was stolen was a PlayStation. In that case there's a high probability that it was a relationship issue or drug related. I don't need an alert for that, there's no risk for a near repeat.

We had burglaries where the only stolen item was a TV that was retrieved after a break-up. In situations like that you just need to do the math.

Think about basements, for example. Technically, the basement is a part of the apartment, but if someone breaks into a basement and steals bicycles, we rule near repeats out. Those are not the professionals that we want to target.

In all these cases, the larger picture and the corresponding narrative of the crime instantly became clear to the human operator, and they were certain that the computed risk area should be discarded because there would be no actual risk of follow-up burglaries. The system, however, was not capable of creating a reasonable story around the data, because evaluation criteria in favor of or against an algorithmically produced risk estimate usually require the consultation of additional information that is not accessible for the software. For the operators, in the examples given earlier, the disconnect between the human interpretation of a burglary context and the algorithmic analysis of the available crime data in fact seemed to be quite obvious. They understood how machinic "misinterpretations" can occur, for example, due to inadequate data quality or the incorrect classification of empirical phenomena during data generation and why a human operator must act as a corrective in such cases.

Human evaluation activities, framed as finding the fault lines between the narrative and the "naked" data, raise the question of what the job profile for a software operator should look like. Normally, crime analysis is conducted by specially trained analysts - either police officers or civilians with the specific professional skill-set needed to analyze crime data, identify patterns, derive tactical or strategic intelligence from these patterns, and give recommendations for operational measures. Debates about the particular job profile of a 
traditional crime analyst have always been somewhat controversial, specifically with regard to the question of whether a good analyst should first and foremost be familiar with the intricacies of the police profession or rather have a professional background in advanced statistics (Santos, 2013: 12). Predictive policing software, however, fundamentally questions the necessity to have specialized experts as operators in the first place. If all that it takes to come up with actionable analytical results is to press a button and then double-check the results vis-à-vis their underlying data, then this task could in principle be executed by a layperson with no particular analytical or police skill-set. And such facilitation would of course also speak to shrinking police budgets and the need for efficiency. Yet, the ability to create a story around algorithmically produced risk estimates and interpret that story would at the same time require a certain level of professional expertise and experience.

Police departments in fact struggle with the job profile of the operator in predictive policing. During our research, we found little unanimity as to who could be considered for the job and what skill-set they should have. The majority of our respondents tended to agree that an operator ought to have at least some experience in crime analysis, should have proper command of IT and software (particularly spreadsheet software and other statistics applications), and should have had positive evaluation reports throughout their career (P03). In those departments working with PRECOBS, operators were typically recruited from existing police staff and underwent a dedicated two-day training program provided by IfmPt (I18; I44; I76; I77; I78; I79; I80). In addition to in-house recruiting, there was a parallel tendency to professionalize crime analysis in general - not only with regard to predictive policing but also with regard to other analytical tasks. In order to do so, some police departments additionally chose to recruit new analysts straight from university (I78; I79). Most departments retained a small pool of staff who could act as software operators, usually between three (I19; I31; P03), four (I07; P75) and six (I26; I79), depending on the size of the department and the crime analysis division.

From our research, the job profile for an operator in predictive policing could be described as follows: He or she requires a certain understanding of crime analysis (i.e., of what has been automated by the software); how algorithmic analysis relates to the underlying crime data; and what the strengths, weaknesses, and limitations of these data are. The operator is thus conceptualized as someone who has a certain domain knowledge and is capable of supervising logically structured, but to a certain extent "contextually ignorant" algorithmic calculations.

The workload redistribution between humans and machines in predictive policing can in this sense be understood as an only half-hearted attempt to mobilize the opportunities of digitization for crime analysis and prevention measures. While the algorithm does in fact do the heavy lifting, it cannot be trusted to produce the correct results and thus needs to be closely supervised. Human operators are considered capable of doing things that cannot easily be translated into code (contextualizing data and placing them within a crime narrative), and these capacities 
are seen as crucial so that the department can avoid allocating scarce resources to the "wrong" places for preventive measures that would miss the target.

As mistrust toward predictive policing software centrally revolves around data, the specific practical configuration between algorithmic crime analysis software and human oversight can in large part be attributed to the ontological and epistemic challenges of crime data production that we discussed in the previous chapter. As both criminal incidents and their classification are infused with uncertainty, crime data are considered generally unreliable and volatile and need to be subjected to ongoing practices of quality control and correction. The need to stay in control of decision-making processes arguably also speaks to institutional concerns about accountability in a domain where erroneous decisions could have potentially far-reaching consequences.

\section{Tinkering with the machine}

Decision-making remains a sensitive issue in predictive policing. Even as the workload distribution between system and operator is implemented in a way that allegedly plays to the strengths of each, we should not assume that this cooperation will by default be a consensual and friendly one. In the end, any form of crime analysis - independent of whether it was carried out by a human, a machine, or some combination of the two - requires a decision as to whether and how analytical insights should be put into practice. At times, there is no straightforward answer to that. Even in cases where the operator generally agrees with the software output, there might be other factors that could prevent the dissemination of alerts and their implementation on the street.

In this section we will engage cases where operators actively contradicted risk estimates - not because they thought they would not be accurate, but because they were aware of the fact that the production of multiple parallel criminal futures would put too much of a strain on their colleagues in the field. In order to avoid an overload of work tasks for patrols, analysts would thus actively tinker with the evaluation criteria in the software configuration in order to bring the number of alerts down. To understand this practice, we must first briefly relate back to the question we discussed in the previous chapter: What kind of futures does predictive policing actually produce and engender?

Criminal futures, as we noted, are produced at regular intervals, usually once per day. Each new iteration of crime analysis with predictive policing software thereby brings into being a new layer of risk with a life span of five to seven days. Predictive policing thus forms numerous overlapping cycles of short-term futures that regularly supersede each other by means of fresh crime data. That is to say, each iteration of crime analysis, executed after a previously defined interval of new data production and quality control, will yield slightly updated criminal futures, which in turn tend to modify or complement the previously created set of futures and accordingly adjust statements about possible modes of intervention (i.e., where and when to patrol, run prevention campaigns, etc.). 
The cyclical creation of new criminal futures does, however, not mean that the previously constructed ones would no longer be relevant. On the contrary, as a risk area remains active throughout its entire life span, the risk estimates that the police are supposed to react to are continually being added to by new alerts, and at the same time, old alerts are fading out of the picture, as they reach their expiry date. In concrete terms, as one particular risk area may on a given day already have been active for two days (and will remain active for five more days), a new, distinct risk area may begin a new life cycle of seven days and thus will supersede the first one by two days. During an overlap of five days, they will however be considered as simultaneously active criminal futures that may or may not be related but must be acted upon, nonetheless (I03; I19; I50).

The multiplicity of simultaneous criminal futures speaks to the fact that, within a given space that is being monitored with predictive policing software, there may be more than one offender and more than one potential series of burglaries to be detected and intervened in. The larger the area and the higher the population density of that area, the more likely it is that there will in fact be a multiplicity of parallel criminal activities - and crime prevention measures must of course not stop at only one of them, but take into account all possible opportunities to prevent multiple possible undesired futures from unfolding at the same time. The cyclical futures that each instance of data analysis creates will thus be aggravated by the multiplicity of criminal phenomena across space and add another layer of risk to the criminal horizon.

At least in theory, this means that there could be an infinite number of parallel criminal futures to be considered. And in fact, one of the promises of predictive policing is that algorithmic crime analysis will help to identify them all. Doing things that humans cannot do, such as running analyses on large datasets in very short time, is one of the main perks of automation - and predictive policing software is likely to not only identify ongoing burglary series faster than a human analyst but also detect patterns that a human analyst might have overlooked or would not have noted due to time and resource constraints. In summary, a peculiar side effect in predictive policing is that it tends to "multiply" crime risk. Not because there will be more criminal activity, of course, but simply by detecting things that would otherwise not have been detected. Particularly in urban areas, predictive policing tends to actively foster the multiplication of risk and in doing so to overstrain the resources police departments have in place for operational measures. In other words, now there might be risk where there would have been none without the algorithm - and it cannot be ignored.

This puts additional pressure on the human operator. All of a sudden, their task is no longer to simply ensure the plausibility of risk estimates. Just as well, they have to weigh different risk estimates against each other and decide which ones would potentially yield better outcomes in terms of crime prevention measures in the streets (I02; I18; I26; I78). As one analyst framed this situation:

At one point, we had twenty simultaneously active alerts. . . . It's just not possible to implement all of them. And then you have to go back and 
manually prioritize which alerts have a high quality, and which ones to discard - although I have no criteria for how to make such a decision. So I make a choice at random and say: "Maybe we go with number eight or number ten, and let's just postpone the rest and see how it goes." And maybe I realize at some point that my selection wasn't optimal and that I should have prioritized differently.

What this statement illustrates is a friction between the notion of responsivenessthrough-data and the organizational capacities of the police. Whereas software companies, politicians, and police managers tend to echo the claims that predictive policing would present an elegant way to "do more with less" (Beck and McCue, 2009: 18), this does not necessarily hold true in everyday police practices. Crime analysis, if properly understood as a sociotechnical system, as Tilley (2008: 384) points out, "requires staffing, procedures and structures to elicit information, interpret it and act on it promptly and systematically". This becomes a problem when we consider the general workload that patrol forces have to carry out during a regular shift. As most of the departments we studied did not have specific patrol units for crime prevention in risk areas at their disposal, risk area patrols would be carried out by regular patrol forces - in addition to a multiplicity of other tasks:

One thing that became crystal-clear was that our stations, especially those in areas close to the city center . . . on a regularly busy day between Thursday and Saturday, [our patrol units] have no additional capacities for actual patrolling. They go from assignment to assignment. They handle a traffic accident, and then they drive to a burglary site. And when they are finished there, they move on to deal with a robbery. They have no time to patrol a risk area in between. So for us it became clear that [predictive policing] will have absolutely no effect as long as we don't provide our stations with additional manpower. Basically, you need additional forces for every alert, no matter where they come from.

Such "fire brigade policing" (Gordon, 1984) as illustrated here was highly pertinent during our research (I06; I09; I17; I20; I21; I22; I23; I24; I26; I29; I42; I43; I46; I76; I78; I80). Our respondents would refer to the fact that, with regard to new tasks brought about by predictive policing, they felt understaffed and would not be able to adequately respond to risk areas. Predictive policing thus demonstrates a tendency to aggravate already existing resource tensions within police forces. It presupposes, even in the form of a rather slow daily rhythm of producing futures, enhanced organizational flexibility and responsiveness, and these prerequisites are closely tied to the availability of sufficient staff.

If the managerial aspiration of predictive policing is to resolve the quandary of shrinking budgets and decreasing numbers of available personnel on the 
ground through a flexible and target-oriented reallocation of resources, then what tends to be forgotten is that sufficient resources will still be required to enable police departments to be responsive to their newly acquired flexibility (Ratcliffe, 2019: 349f). Predictive policing practices, rather than putting police departments in a position to do more with less, more often than not make the police "do more with more" (Leese, 2020) - more futures, more risk, and more frequent crime analysis are all likely to aggravate the basic budgetary and resource problems that were supposed to be resolved with the help of algorithmic crime analysis tools.

Some departments tried to counter the overload of criminal futures in creative ways. Faced with the dilemma that they were producing too many alerts to properly incorporate within daily operations, they started tinkering with the analytical parameters that the software used to calculate risk areas in order to artificially bring down the number of actionable futures (I03; I46; I79). As one operator told us:

If I get too many alerts, I adjust the criteria a bit. Then there will be fewer alerts with better quality. And if I have only a few alerts and there is little activity, I can again adjust and work with lesser quality alerts. The thing is that I have to know what I'm doing.

Through this kind of manual prioritization, operators opted to deliberately and systematically shut down some criminal futures they felt could not be acted upon and modulated anyway. The selection process that underpins this practice, as the aforementioned quote illustrates, is rather idiosyncratic and subjective. During our research, we found that only experienced, senior analysts would "dare" to tinker with predictive policing in such a way. Arguably, it takes considerable confidence to prioritize some alerts over others, and this includes the willingness to be held accountable for the consequences if the "wrong" risk estimate was picked and follow-up burglaries occurred in a nonselected risk area. The same is true for the adjustment of computation criteria. It might be the case that by tinkering with software preferences, potentially valuable risk estimates are suppressed. However, as our respondents also made quite clear, crime prediction software does not operate in a vacuum. As part of a larger sociotechnical system, predictive policing needs to relate to a number of elements, and the resources available for patrolling are a decisive factor with regard to which criminal futures can be acted upon.

Practices of tinkering with the machine also draw attention to the fact that there may be disagreements between algorithmic recommendations and human rationales. These disagreements might not necessarily be caused by the evaluation of the recommendation itself but might take the shape of reverse effects from future stages of predictive policing (i.e., the enactment of risk on the street). Senior analysts were able to resolve such disagreements in a particular 
way that simply ignores or overrides machine outputs. Other, less senior operators reported significantly less assertiveness in conflict situations between human and machine.

\section{Arguing against the machine}

Research on automation bias, as argued earlier, has shown that algorithmically produced recommendations for action are often regarded as highly authoritative and that humans tend to accept machine outputs even against better knowledge or common sense. The reasons for this are well known: Machines are widely believed to be objective and impartial, and a properly programmed algorithm is assumed to produce no errors in processing data. These assumptions are problematic for various reasons, and we will discuss the implications of blind faith in technological innovations in more depth in Chapter 9.

During our research, police departments were in fact careful to curb possible beliefs that machine knowledge would be somehow superior to human knowledge and to ensure that human operators would be able to come to unbiased decisions even when assisted by algorithmic analysis tools. Relations between humans and crime prediction software thus would need to be configured in a way that allowed contestation and decisions that contradict machine output. As we have shown in the preceding sections, police departments in fact actively sought to deconstruct presupposed algorithmic authority and the potential for automation bias by carefully subjecting predictive policing software to formalized oversight, as human operators were put in place as a safeguard against anticipated shortcomings of crime data and resulting erroneous crime risk estimates.

Acting as a safeguard and final decision-making instance formally gives considerable discretionary power to the operator. To be sure, such discretionary power has historically speaking always been ascribed to human analysts in crime analysis. The analyst used to be the domain expert who produced knowledge and decided upon its dissemination. However, with the implementation of predictive policing software, this domain expertise now has to be shared with an algorithm. It is in this sense noteworthy that the discretionary power of the human operator still persists in a new era of (black-boxed) algorithmic crime analysis and automation. In addition to being suspicious of algorithmic crime analysis tools and the data that feed them, police departments put considerable trust in the operator's overall assessment of a situation and their eventual judgment that includes information and criteria that are not formalized in the analytical model of the software. One interviewee gave an example of how human interpretation can trump an algorithmically produced risk alert:

Personally, if there's for example a description of the offender, I would not communicate that alert. If someone saw the offender, then it's likely that the offender noticed that. And if I was the offender, in that case I would 
not return to that neighborhood. The risk that someone will recognize me and call the police is too high.

Senior officers in fact encouraged arguments like the one above by reassuring operators that they could trust in their own judgment and would not have to worry about the potential ramifications of "wrong" decisions. They would at times even actively seek to prevent potential automation bias and insist on the possibility of contradicting algorithmic recommendations (I77; I80). After all, operators should be aware of the fact that any algorithm works on the basis of statistical principles and not on the basis of common sense:

It is a matter of probabilities. And the software uses a certain probability threshold. I have to be aware of that. And if the software has produced an alert, I can go ahead and ask myself whether I have additional information. Can I substantiate the alert? What does that additional information tell me? And there's always the possibility of rejecting the alert. That's ok.

As this quote vividly illustrates, discretionary power explicitly includes the option to decide otherwise. In fact, the operator is even actively expected to challenge the suggestions made by the system, as they might collide with professional experience and expertise or contradict the larger situational picture. Moreover, analysts as well as senior police officers highlighted the fact that predictive policing should be seen as only one element of the police's analytical toolbox and that its influence should not be overstated:

It's an overall assessment of the situation. What is going on around the alert area? What other burglary series do we know about? And so on. PRECOBS is a part of that, but it's not like everything revolves around PRECOBS. PRECOBS supports our situational analysis, but PRECOBS doesn't decide. It helps, but time and again we get alerts that we reject, because we feel like they are not accurate or they won't amount to anything. PRECOBS is a part of crime analysis. It's a valuable part, an important part, but it's not authoritative or decisive.

This statement creates an impression that predictive policing software would be treated as nothing more than an assistant and that algorithmically produced risk estimates would be regarded as recommendations rather than instructions. In everyday predictive policing practices, we did, however, experience substantial uncertainty among operators in terms of how to deal with algorithmically computed recommendations (P49). One question that came up repeatedly was whether operators actually dared to reject alerts even though they were formally reassured that it was completely fine to do so. Some departments 
reported an acceptance rate of about 50\% (I07; I46; I76), while others reported an acceptance rate of up to $80 \%$ (I18; I26; I45).

Particular uncertainty prevailed about the question of whether operators could be blamed for rejecting accurate alerts and so missing an opportunity to prevent near-repeat burglaries. The operators we spoke with about this more than once hinted that it would be safer to accept even doubtful alerts rather than having to justify a "wrong" rejection ex post facto (I03; I19). Such a stance was to a certain extent reinforced by official documentation that explicitly specifies that operators should only reject alerts in cases where their additional contextual knowledge would clearly contradict the system's evaluation - for example, when an arrest has been made, but this arrest has not yet been entered into the database (D001).

Machine authority was additionally reinforced by the operators' inability to formulate reservations about algorithmically produced risk estimates in a formal sense. The operator's duties of contextualization and eventual acceptance or rejection of an algorithmically produced alert must be understood as a rationalized process that is supposed to take into account criteria such as hitherto unknown anti-triggers that would contradict the result of the analysis. Surprisingly, however, our interviewees would frequently frame their arguments against machine recommendations not in the expected rational, formal fashion (I19; I46; I50; I79). On the contrary, they would refer to subjective and hard-toexplain criteria such as "gut feelings" when looking for reasons to reject an alert:

I don't consider PRECOBS a system that can work on its own. As operator, you need to actively get involved, actively think, and sometimes you need to overrule the machine - even if it's just based on a gut feeling. Most of the time, the gut feeling is not that far off. If the system and I come to the same conclusion, the alert is a good one.

Calling it a gut feeling might be a bit exaggerated, but it is experience. If I have a neighborhood, a classical burglary neighborhood such as [name]. Wealthy, old houses, text-book burglary territory. If we don't have a single burglary there throughout the summer, and then we get two or three consecutive ones, then I don't care whether this is formally classified as near repeat. I know that there will be more burglaries over the next two to five days. I don't need near repeat for that.

Among other things it's a gut feeling. Sure, the system specifies that when a perpetrator is interrupted and seen by someone, the probability of near repeats decreases. But in case we know of a series in that municipality or in the surroundings, we work with the alert, nonetheless. We don't have formal criteria for that, we decide ad hoc. . . It's based on a gut feeling. 
These quotes illustrate how operators at times struggled to put their concerns into words. This inability to articulate concrete reasons why an alert should be rejected or crime prevention measures should be undertaken even in the absence of an alert is problematic against the backdrop of humanmachine relations and decision-making processes. The gut feelings that our interlocutors referred to might be justified. In fact, given the data uncertainties we outlined in the previous chapter, their nonrationalized assessment of the situation might even be more accurate than the result of crime analysis software. And yet, the inability to express concerns in concrete terms arguably puts human operators at an argumentative disadvantage vis-à-vis the rational calculations performed by the software. Winning an argument based on a gut feeling is not an easy thing to do, and it becomes an even bigger challenge when analysts are expected to give reasons for rejected risk alerts (I19; P42).

The fundamentally different forms of knowledge and reasoning that humans and machines employ are in fact not easily bridged. Police departments did, however, seek to come up with institutional and bureaucratic means of strengthening human arguments against machinic reasoning. One of these strategies was to simply outnumber the machine. Rather than having one human operator challenge the algorithmic decision in a "one vs. one" situation, upping the number of human reviewers is an easy way to create a quantitative advantage. Discussing interpretations, doubts, or larger operational concerns vis-à-vis algorithmically produced risk estimates either with another colleague or even with the entire team during a meeting was considered an intuitive yet effective way of challenging machine authority. In this way human operators could reassert and support each other, thus gaining argumentative ground:

We established a four-eyes-principle. That means the system generates an alert ... and the verdict whether to accept or to reject the alert must be discussed with another team member. No matter what. And the operator needs to explain to the other person why they think "yes" or "no". And only then there will be a decision.

We discuss that every morning: we have a PRECOBS alert for this or that area, should we accept it, should we disseminate it?

Another strategy to strengthen human reasoning was to support human operators with means of formalization. In one department, analysts were provided for this purpose with a checklist they could refer to in order to make sure that they were considering all relevant issues when evaluating risk estimates. Figure 5.1 shows the operator checklist for automatically generated alerts used 

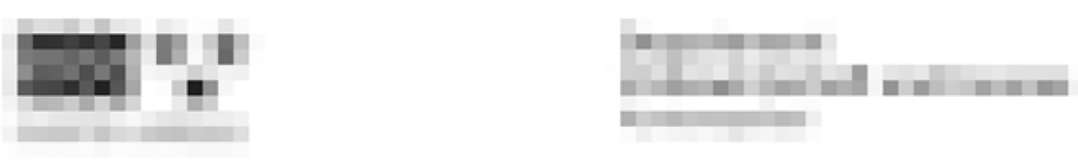

\section{Precobs}

\section{Checkliste für Operatoren LAZ bei ausgelösten Prognosen}

\section{Systemgenerierte Prognosen}

Folgende Punkte müssen überprüft werden, bevor der Alarm kommuniziert wird:

$\square$ Fand das EBD-Delikt im Wohnbereich statt?

$\square$ Ist das Delikt aktuell?

$\square$ Liegt ein Antitrigger vor?

$\square$ Gibt es Hinweise auf einen Insider?

$\square$ Gibt es Hinweise auf einen Täterkontakt oder Verhaftung des mutmasslichen Täters?

$\square$ Besteht eine Wahrscheinlichkeit für Folgedelikte? Hohe Wahrscheinlichkeit während 4 Tagen ab der Tatzeit, sowie am Freitag- und Samstagabend. Geringste Wahrscheinlichkeit am Sonntag.

$\square$ Kann dem Delikt ein Zeitphänomen zugeordnet werden?

$\square$ Wenn möglich Zweitmeinung einholen.

\section{Operatorprognosen}

Menü Prognose -> Operatorprognose -> Operatordelikte zeigt die Delikte an, für die Operatorprognosen erstellt werden können.

$\square$ Fand das EBD-Delikt im Wohnbereich statt?

$\square$ Ist das Delikt aktuell?

$\square$ Wie hoch ist die Folgedeliktchance (unter Menü Prognose -> Operatorprognose -> Folgedeliktchance)?

$\square$ Falls sich das Delikt zwischen mehreren Areas befindet: Für welche Area wird die Operatorprognose gelten?

$\square$ Liegt ein Antitrigger vor?

$\square$ Gibt es Hinweise auf einen Insider?

$\square$ Gibt es Hinweise auf einen Täterkontakt oder Verhaftung des mutmasslichen Täters?

$\square$ Besteht eine Wahrscheinlichkeit für Folgedelikte? Hohe Wahrscheinlichkeit während 4 Tagen ab der Tatzeit, sowie am Freitag- und Samstagabend. Geringste Wahrscheinlichkeit am Sonntag.

$\square$ Kann dem Delikt ein Zeitphänomen zugeordnet werden?

$\square$ Befinden sich im operativen Kreis Kacheln mit mittlerer oder hoher Wahrscheinlichkeit?

$\square$ Wenn möglich Zweitmeinung einholen.

Figure 5.1 Operator checklist 
by this particular police department. The list specifies, among other questions, spatial issues (Did the burglary actually target a living area, or did it target a basement/garage that is formally part of the dwelling but could be considered as an anti-trigger?) and temporal ones (How recent was the burglary? Can a particular time period during the day be approximated?) that are important for the contextualization of the alert. Further questions are directed at the characteristics of the crime itself: Could it have been an inside job? Did someone see and/or identify the offender? Are there indicators that the offender might already have been arrested in the meantime? The highly formalized structure provided by the checklist can in fact guide the human operator with a predefined and easy-to-use set of arguments that facilitate the contestation of an algorithmically produced verdict.

The overarching rationale at work here is to put the operator(s) in a position from which they can reasonably challenge and/or override alerts produced by the system and, in the best case scenario, improve the overall quality of the algorithmic risk calculations that become translated into operational crime prevention measures. Putting the human operator firmly in the driving seat and protecting their position with additional safeguards arguably also speaks to the institutional need for accountability and (at least internal) transparency. Particularly, vis-à-vis potential problems in terms of discrimination and over-/underpolicing that the police could run into with predictive policing methods, staying in full control of automated processes and having an operator making volitional, deliberate decisions rather than just following predefined paths can be seen as an attempt to preemptively keep algorithmic software packages in check. We will pick up these questions again in Chapter 9.

\section{Conclusion}

As we have shown throughout this chapter, making humans and machines work together is not easy. Automation, while often presented as a driving force for innovation and efficiency, can backfire when it conceals complexity and puts human arguments at a disadvantage vis-à-vis the authority of technological tools. HCI literature helps us to understand these challenges and to conceptualize the ways in which humans and machines enter into complex relationships of workload distribution. The position of the human is in these constellations often characterized by a struggle to remain in control. Human operators are - especially in critical domains such as security - supposed to stay in the loop and be able to challenge technologically produced recommendations and contrast them with human forms of sensemaking. In order to do so, police departments seek to contextualize the outputs from predictive policing software within wider trajectories of police work and an overall situational picture. Some of them even attempt to strengthen human reasoning through numbers (i.e., discussing alerts with colleagues) and bureaucratic 
tools that are supposed to assist human operators in formalizing their doubts and concerns.

Taken together, these strategies reveal a good deal about organizational challenges with regard to sociotechnical security tools. Understanding algorithmic crime analysis through the lens of human-computer interaction draws attention to the ways in which knowledge and interaction between human operators and predictive policing software is structured. Our analysis has foregrounded how power relations enter crime analysis and create concerns about a diminished role and possible helplessness of the human vis-à-vis the machine. The police departments we studied were thus bent on curbing the agency of crime prediction software and to constrain its power through different protocols that prescribe the precise ways in which human-computer interaction was supposed to be executed (manually, with maximum levels of oversight, using bureaucratic aids, considering contextual factors).

The emergence of such rigid layers of control can, to a certain extent, be attributed to public and organizational unease with regard to algorithmic analysis tools, not least, sparked by dystopian media representations of predictive policing (e.g., referencing fictional works such as Minority Report). It also speaks to the relative helplessness that humans experience when operating complex and possibly black-boxed algorithmic security tools. Place-based predictive policing methods must thereby be understood as a rather low-level case of algorithmic crime analysis, where the supporting theoretical model is based on criminological theory and the algorithm itself is not self-learning but deterministic. However, the disadvantages in terms of cognition and processing power that humans face even vis-à-vis such a comparably simple algorithmic tool stand emblematically for the challenges that automation and black-boxing in knowledge production and decision-making bring about.

There is an apparent drive toward further automation in predictive policing, and this drive includes additional tasks (e.g., data production, data transfer, data consolidation) as much as it includes more complex models and algorithms, new types of crime, and new operational measures (I78; I79). Questions of how to safeguard these processes and how to properly configure the relationship between humans and machines will in this sense persist, and the role of the operator will be even more important when future systems increase complexity and decrease transparency. We will deal with questions of how future versions of predictive policing might aggravate already existing troubles in Chapter 10.

\section{References}

Beck C and McCue C (2009) Predictive Policing: What Can We Learn from Wal-Mart and Amazon about Fighting Crime in a Recession? The Police Chief 76(11): 18-24.

Cummings M L (2004) Automation Bias in Intelligent Time Critical Decision Support Systems. AIAA 1st Intelligent Systems Technical Conference, Chicago, IL. 
de Greef T (2016) Delegation and Responsibility: A Human-Machine Perspective. In di Nucci E and Santoni de Sio F (eds.) Drones and Responsibility: Legal, Philosophical, and Sociotechnical Perspectives on Remotely Controlled Weapons. London/New York: Routledge, 134-147.

Endsley M R and Kiris E O (1995) The Out-of-the-loop Performance Problem and Level of Control in Automation. Human Factors 37(2): 381-394.

Fitts P M (ed.) (1951) Human Engineering for an Effective Air Navigation and Traffic Control System. Washington, DC: National Research Council: Division of Anthropology and Psychology Committee on Aviation Psychology.

Gordon P (1984) Community Policing: Towards the Local Police State? Critical Social Policy 4(10): 39-58.

Jones M L (2017) The Right to a Human in the Loop: Political Constructions of Computer Automation and Personhood. Social Studies of Science 47(2): 216-239.

Klein G, Woods D D, Bradshaw J M, Hoffman R R and Feltovich P J (2004) Ten Challenges for Making Automation a "Team Player" in Joint Human-Agent Activity. IEEE Intelligent Systems 19(6): 91-95.

Latour B (1987) Science in Action: How to Follow Scientists and Engineers through Society. Cambridge: Harvard University Press.

Leese M (2014) The New Profiling: Algorithms, Black Boxes, and the Failure of Antidiscriminatory Safeguards in the European Union. Security Dialogue 45(5): 494-511.

Leese M (2020) "Mehr Mit Weniger"? Warum Predictive Policing Nicht Automatisch Effizienzgewinne Bedeutet. In Bode F and Seidensticker K (eds.) Predictive Policing: Eine Bestandsaufnahme für den deutschsprachigen Raum. Frankfurt am Main: Verlag für Polizeiwissenschaft, 249-260.

Miller C A and Parasuraman R (2007) Designing for Flexible Interaction between Humans and Automation: Delegation Interfaces for Supervisory Control. Human Factors 49(1): $57-75$.

Parasuraman R and Miller C A (2004) Trust and Etiquette in High-Criticality Automated Systems. Communications of the ACM 47(4): 51-55.

Parasuraman R, Molloy R and Singh I L (1993) Performance Consequences of AutomationInduced 'Complacency'. The International Journal of Aviation Psychology 3(1): 1-23.

Parasuraman R, Sheridan T B and Wickens C D (2000) A Model for Types and Levels of Human Interaction with Automation. IEEE Transactions on Systems, Man, and Cybernetics - Part A: Systems and Humans 30(3): 286-297.

Parasuraman R and Wickens C D (2008) Humans: Still Vital after All These Years of Automation. Human Factors 50(3): 511-520.

Pasquale F (2015) The Black Box Society. Cambridge: Harvard University Press.

Ratcliffe J (2019) Advocate: Predictive Policing. In Braga A A and Weisburd D (eds.) Police Innovation: Contrasting Perspectives. 2nd Edition. Cambridge: Cambridge University Press, 347-365.

Santos R B (2013) Crime Analysis with Crime Mapping. Thousand Oaks/London/New Delhi/Singapore: Sage.

Sheridan T B and Verplank W L (1978) Human and Computer Control of Undersea Teleoperators. Cambridge: Man-Machine Systems Laboratory: Department of Mechanical Engineering.

Skitka L J, Mosier K L and Burdick M D (1999) Does Automation Bias Decision-Making? International Journal of Human-Computer Studies 51(5): 991-1006.

Skitka L J, Mosier K L and Burdick M D (2000) Accountability and Automation Bias. International Journal of Human-Computer Studies 52(4): 701-717. 
Tilley N (2008) Modern Approaches to Policing: Community, Problem-oriented and Intelligence-led. In Newburn T (ed.) Handbook of Policing. 2nd Edition. Cullompton/ Portland: Willan Publishing, 373-403.

Wickens C D, Clegg B A, Vieane A Z and Sebok A L (2015) Complacency and Automation Bias in the Use of Imperfect Automation. Human Factors 57(5): 728-739.

Wickens C D, Mavor A S, Parasuraman R and McGee J P (eds.) (1998) The Future of Air Traffic Control: Human Operators and Automation. Washington, DC: National Academies Press. 


\section{Chapter 6}

\section{Putting risk on the map}

If predictive policing is supposed to prevent crime, risk must move out of the back office where it was brought into being and into the streets where it can guide the actions of patrol officers. In this chapter, we analyze how crime risk is visualized and disseminated within police departments and how the memos and maps that are generated for this purpose are modulated so that they can speak to the requirements of local staff and shift planning as well as to the informational needs of patrol officers. As we discussed earlier, police organizations are complex constructs that consist of various specialized units. Patrols are usually organized and carried out by local police stations that are granted a considerable degree of discretion in their decisions about where to send their patrol forces (Santos and Taylor, 2014). Likewise, patrol officers themselves traditionally decide how to best carry out their tasks in the field (Brown, 1981; Ericson, 1982; Worden and McLean, 2014). Predictive policing contradicts this structure, as it identifies presumably risky areas that need to be given particular attention in order for analytical insights to have potential effects and is therefore likely to interfere with local practices.

This renders knowledge dissemination and communication processes, while generally considered an important part of crime analysis (Cope, 2004; Cordner and Biebel, 2005), particularly pertinent for predictive policing. This importance is not only due to the spatial distance between centralized crime analysis units and local police stations, but it is additionally aggravated by the different "lifeworlds" of analysts, managers, and patrol forces. Crime analysts, as we have seen, must not necessarily be police officers who are on a traditional police career track (i.e., starting on the street level and then eventually moving up and, in doing so, passing through several subfields of police work) but can have an academic background and/or be civilian employees. Moreover, crime analysts tend to work in a secluded back office environment with little direct interaction with other divisions, and their work with data and computers is perceived to be quite far removed from "real police work" - that is, fighting crime and catching criminals.

From a practical perspective, analysts must disseminate insights in ways that are intelligible and tangible for different audiences within the police (Chan 
et al., 2001: 116; Santos, 2013: 59). Proper communication, in other words, must create connections between different police units and align them behind the rationales of predictive policing so that risk estimates can effectively find their way into the streets. In predictive policing, this translation work is to a large extent done through visual representations that draw together risk and space in the form of maps. Maps, as we will show throughout this chapter, are used as a primary means to guide patrol officers with regard to presumably risky spaces and must therefore be considered as central for the translation of knowledge and power from crime analysis to operational crime prevention. "Good" visual representation, from a practical perspective, guides street-level patrols in intuitive ways and compels them to implement recommendations from crime analysis into their work, whereas "bad" representation could possibly undermine the effects of predictive policing, as it might not be able to "convince" patrol officers of the existence of crime risk and the need to act upon it (Taylor et al., 2007; Cope, 2008).

In the following, we trace how operators craft visual representations from their analyses with predictive policing software and follow these representations as they make their way through different parts of police departments before they eventually end up informing the work of patrol officers. We will pay special attention to how memos and maps are designed in order to render analytical insights intelligible and actionable across professional boundaries within different units. We show how visual representation makes predictive policing actionable, while at the same time establishing credibility for the existence of crime risk in the first place. Building on literature that engages practices of representation (Latour and Woolgar, 1986; Latour, 1990; Burri and Dumit, 2008; Latour, 2014), we retrace how through a cascade of translations, the credibility conveyed by crime maps becomes stabilized and is made relatable to different police actors and their professional requirements and rationales.

\section{The power of maps}

An image says more than a thousand words, as the proverb tells us. And a crime map says more than a thousand data points we could add with regard to predictive policing. Crime maps direct attention to specific geographical spaces, and additional graphical elements on these maps highlight how certain neighborhoods or streets might be especially dangerous or vulnerable. Visualization makes crime tangible, and putting it into the coordinates of a map makes it relatable within space. As one interviewee framed it: "a red area inside the blue circle, those are clearly the hottest spots" (IO2) - and, by extension, this is where more crime is clearly bound to happen unless prevented (IO3; I19; I20). Even a lay person can easily decipher that message. No expert knowledge or additional contextual information is needed to understand a crime map. And there are countless ways of designing crime maps. Figure 6.1 shows four different examples of crime maps produced from predictive policing software. 


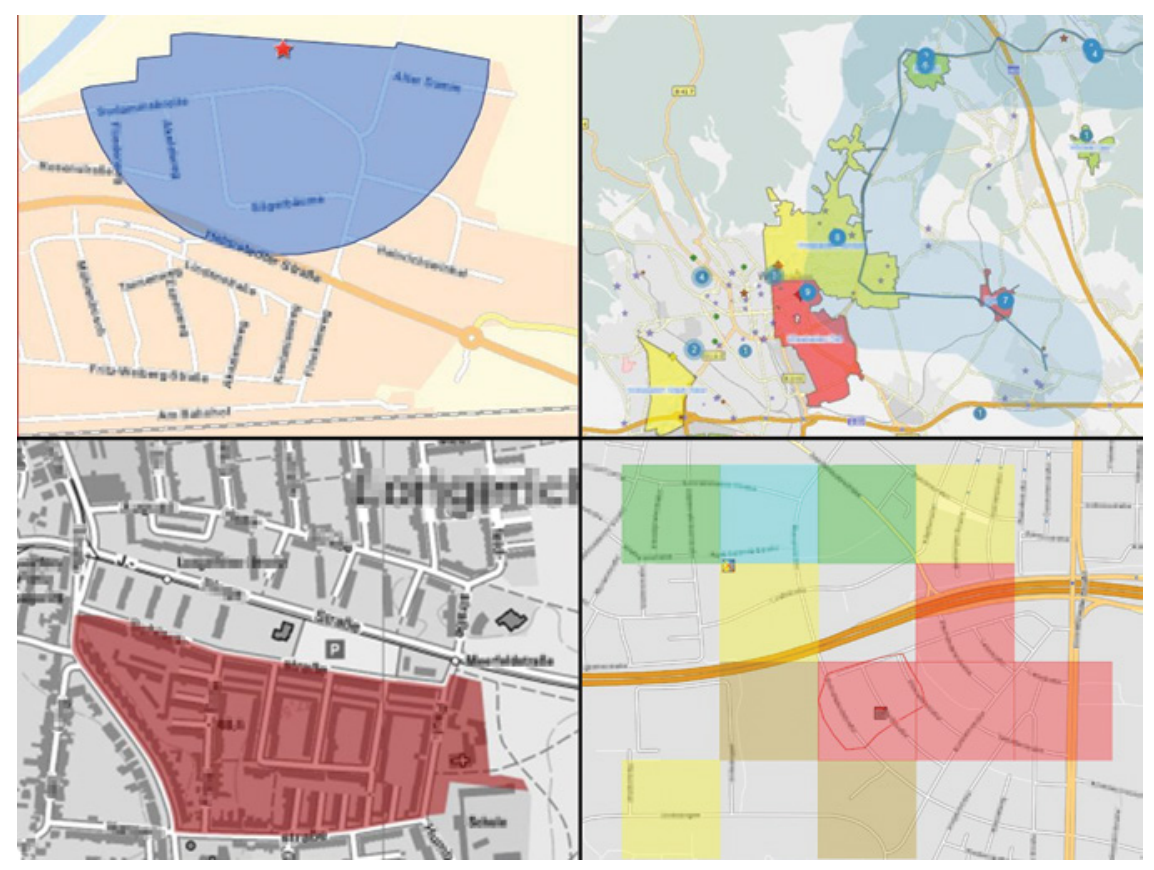

Figure 6.1 Different risk maps

Even though they use different visual indicators, it appears immediately clear where there is crime risk and where corresponding countermeasures need to be taken.

Crime maps are in fact powerful tools, and they have attracted much scholarly attention. Criminologists have explored the role of crime maps in policing from various angles. Historical perspectives have highlighted both change and consistency in crime mapping over time (Chamard, 2006; Kindynis, 2014). Practice-oriented approaches have foregrounded strategies for turning crime data most effectively into compelling and intuitively understandable visuals, particularly in conjunction with the ongoing digitization and the rise of GIS tagging (Weisburd and McEwen, 1998; Harries, 1999; Ratcliffe, 2000; Chainey and Ratcliffe, 2005; Eck et al., 2005; Santos, 2013; Bowers and Johnson, 2014). Others have engaged the cognitive effects of crime maps both on police officers and citizens (Rengert and Pelfrey, 1998; Paulsen, 2004; Zurawski and Czerwinski, 2008). Not least, scholars have pointed to the considerable political power that comes with the visual, as it could be used to deliberately instill suspicion or spark fear of crime and to legitimize surveillance and other crime control measures (Manning, 2008; Wallace, 2009; Jefferson, 2018). 
Against the backdrop of such power, critical criminologists have called for closer investigation of the construction of crime maps and their visual features. Importantly, scholars have argued strongly that crime, understood as a dynamic and socially embedded phenomenon, by definition, can never be fully represented through maps (Kindynis, 2014; Belina and Germes, 2016). Crime maps, as Kindynis (2014: 230) argues, "inevitably fail to capture the spatial dynamics of crime, as they reduce complex phenomena to dots or shadings on a twodimensional surface". Maps should thus be considered as abstractions that foreground certain phenomena (while leaving others out) and notably as a means of suggesting a causal connection between the depicted space and criminal phenomena (Belina, 2016: 93).

Moreover, as crime maps usually rely almost exclusively on data produced by the police, they inevitably draw a picture of crime and space that represents police knowledge - which does not necessarily correspond with the actually existing amount of criminal activity and its spatial distribution (Kindynis, 2014: 229). Finally, due to their persuasive character, crime maps can easily entrench or aggravate stereotypes about neighborhoods and their inhabitants and thereby reinforce problematic practices such as racial profiling (Jefferson, 2018). As Farrell (2009: 78) argues, maps mobilize the "persuasive aesthetic of authority" that "provide $[\mathrm{s}]$ an assuring sense of precision and order". Crime maps thus might easily be mistaken as "proof" that crime exists within the depicted coordinates (Wallace, 2009: 19).

These problematizations correspond closely with works from critical cartography. Critical cartographers have pointed out how maps must not be mistaken for true representations of the world as it is and have highlighted their contingent and relational nature as well as their capacities for affecting our ideas about the spatial constitution of the world and the ways in which we think and act within it (Harley, 1989; Crampton and Krygier, 2005; Crampton, 2010). If we start from the assumption of the social constructedness of maps, the analytical task will then be to deconstruct their seemingly smooth surface and reveal the power relations and strategic rationales that underpin their composition (Monmonier, 1991; Wood, 1992; Crampton, 2001).

Questions of maps and power also tie in closely with STS literature that engages the role of the visual in the representation and consolidation of scientific findings (Lynch and Woolgar, 1990; Coopmans et al., 2014). STS research is particularly helpful for an analysis of crime maps in predictive policing, as it explicitly draws attention to the translation functions of visual artifacts. Starting from the assumption that representation should not be understood as a fixed or preset process but rather as the socially and culturally mediated construction of "visually flexible phenomena whose boundaries, extension and identifying details are themselves at stake" (Amann and Knorr Cetina, 1988: 135), STS research draws attention to the epistemic characteristics of what becomes visualized. Risk, as we discussed earlier, is a contingent phenomenon, and its existence and form crucially depend on the data, models, and calculative operations 
that are mobilized to bring it into being. Crime risk, in other words, is not self-evident, and crime maps must not merely communicate its location within space but at the same time persuade the beholder of its existence in the first place.

The question of how representations are crafted in order to such establish credibility has perhaps been most explicitly discussed by Latour, who argues that in order to be successful, they need to be "mobile but also immutable, presentable, readable and combinable with one another" (Latour, 1990: 26). In other words, crime maps need to be shareable and easily intelligible and should have the capacity to "draw together" (Latour, 1987) different audiences and discourses. For Latour, the creation of representation as a relay for the production and transformation of knowledge and power then needs to speak to the principles of resemblance, symbolic reference, abstraction, and exemplification. Together, they facilitate the production of particular "inscriptions" (Latour and Woolgar, 1986: 45ff) in the forms of tables, graphs, images, diagrams, photographs, or maps. These inscriptions should not be mistaken for a replication of "objective" natural order or scientific findings but are the end result of choices, negotiations, and controversy.

For Latour, the crucial point is that the more instances of representation a thing or a phenomenon is subjected to, the more credible truth claims about the accuracy and reliability of the representation become. With each additional layer of inscription, he argues, representation moves further away from the thing or finding that it is representing and thereby conceals the "interpretive flexibility" (Pinch and Bijker, 1984) of the original object or data, thus making it harder to contest the "evidence" suggested by the representation (Latour, 2014). A crime map, after having passed through several professional and local layers of police work, in this sense becomes validated and actionable, and the contingency of crime risk itself becomes obscured.

For Latour (1990: 40), analyses should thus not question "inscription per se, but the cascade of ever simplified inscriptions that allow harder facts to be produced". His only seemingly ironic statement "the more manipulations, the better" (Latour, 2014) has a double significance. On the one hand, homing in on processes of transformation opens up the analytic possibility of foregrounding the differences between each iteration of representation, thereby providing us with a perspective on the workings of representation as a mechanism of hardening facts. And on the other hand, it draws attention to the fact that a longer chain of representation makes "success" (i.e., establishing credibility) more likely for the actors who craft these representations.

In predictive policing, such success implies that risk estimates successfully travel through different layers of police work. Insights from algorithmic crime analysis need to become intelligible and relatable for bureaucratic planners as much as for local supervisors and patrol units. Maybe most importantly, they need to convince patrol officers to enact crime prevention measures within designated risk areas. As we will discuss in more detail in the next chapter, for 
different reasons, the movement of patrols is hard to track or monitor, which makes it necessary to get patrol officers "on board" if predictive policing is to successfully cover allegedly risky space. Risk representations thus need to speak to different actor rationalities within the police and must succeed in aligning these actors in order to intervene in unfolding criminal events.

Against this backdrop, Burri and Dumit (2008: 299) suggest that we should pay analytical attention to "the trajectories of scientific images from their production and reading through their diffusion, deployment, and adoption in different social worlds to their incorporation into the lives and identities of individuals, groups, and institutions". They argue that analyses of representation should not stop short of investigating the meaning that representations unfold when they are perceived and acted upon by different audiences. They thus propose to study representation practices through the distinct sites of "production", "engagement", and "deployment" (Burri and Dumit, 2008: 300). Taken together, Burri and Dumit argue, these sites provide a perspective on the full life cycle of representations, while at the same time accounting for specific functions and requirements that representations need to fulfill during each stage of their life cycle. In particular, they draw attention to the links between the sites of production, engagement, and deployment, where representations undergo transformations as "the result of a series of hand-offs among individuals" (Burri and Dumit, 2008: 301).

Taken together, Latour's emphasis on cascades of translation and Burri and Dumit's notion of the institutional embeddedness of representations provide two key pointers for our analysis of risk maps in predictive policing. We will highlight how, on their journey from crime analysis units to streel-level patrolling, risk representations undergo a series of modulations that stabilize the credibility of the statement that crime is bound to happen at a specific point in time in a specific neighborhood. At the same time, we will pay attention to how each version of a representation speaks to distinct organizational needs at the respective stage of police work.

\section{The chain of communication}

We will take the institutional embeddedness of predictive policing as a starting point here. The organizational complexity and functional differentiation within police organizations foreground the importance of communication practices. This is particularly pertinent for the "scientific" part of police work, which is often spatially and topically separated from the operational parts. In our research, we found that crime analysis with predictive policing software was either a task of specialized crime analysis units (D252; D282; D284) or directly subordinated to the command branch (D153). In one case, predictive policing was housed in a specialized department that ran crime analyses for a number of smaller local police departments, using pooled data from a centralized database (D372). 
Moreover, due to the fact that police competencies in Germany and Switzerland are mostly aligned with the territorial organization of the federal state, most of the departments we studied covered not one city or municipality but a rather large territory (usually the entire Bundesland or Kanton). Analytical insights from predictive policing thus needed to be communicated from the center to the periphery (i.e., the local police stations that would be responsible for the implementation of prevention measures based on the analysis).

Generally, the dissemination of crime risk would be done in a rather straightforward fashion. The software operator would create a memo from the analysis and then send this memo to the central planning and operations unit via email. From there, the memo would be further distributed to local police stations, where supervisors would pass the information on risk areas on to patrol forces (I04; I09; I18; I19; I24; I25; I26; I79; D142). Some of our interviewees illustrated this chain of communication within their respective departments and with regard to regional and local specificities:

[At the station], we have a briefing every morning where we discuss the current situation. The supervisor, the group leaders, and so on. And if we have information on risk areas, we discuss that information. . . . Everybody gets the email from the headquarters, and we forward it to the group leaders. And they forward it to their staff and tell them: "Here, we have a new PRECOBS alert, please have a look at it." So it basically goes from central planning to the group leaders, and from there to the patrol forces.

Our chief has a look at incoming risk alerts and evaluates them. And then he forwards the information to the relevant local stations, where it will be dealt with by the staff division. So he will be like: "Here's what we have, including the visualization. My evaluation is this or that." And then he can either recommend operational measures, or he can tell them to act at their own discretion. In that case it's up to the local supervisors.

The operator sends out a pdf document from the analysis as an email attachment. So in [city] all of our stations receive that email every morning. And the email details how many new burglaries have been reported since the day before, and where they took place. Then it says how many of them were considered trigger incidents, and specifies any new alerts. Then it lists the new alerts and gives details on their status, so our stations can get a good overview of what is currently going on. And for each alert the email determines which station is responsible for implementation.

These statements vividly illustrate the various stages that risk estimates have to pass through before they end up in the hands of those whose task it is to 
carry out preventive patrols or other operational measures. They also hint at the variance in organizational structure and corresponding ways of communication between the different departments. What unites all of them, however, is the fact that communication is directly targeted at those local stations and individuals who will be affected by identified risk areas. While such custom-tailored communication procedures are the standard form of dissemination in predictive policing, some police departments also complemented them with forms of untargeted, more generalized forms of dissemination. This would first and foremost be done by uploading predictive policing memos to the internal police intranet, where they could in principle be accessed by every member of staff (I19; I22; I29; I42; I43; I45). In this way, as one interviewee framed it, patrol officers could "just have a look and see if there's anything you should take into account" (I22) before or even during their shift.

While such availability of information was, in general, considered a viable strategy to supplement the awareness of predictive policing and risk areas, the patrol officers among our interlocutors admitted that in their everyday work practices they paid little or no attention to any additional information that they would need to actively seek on the intranet (I23; I25). And even in those cases where patrol officers were put on a mailing list and automatically received predictive policing memos via email, information about risk areas tended to be overlooked among the many other bits of work-related information that police officers receive on a daily basis. As one respondent told us: "I mean the thing with emails is that everyone wants to disseminate their stuff, and in the end, you get so many emails that [the predictive policing memo] easily gets overlooked" (I25).

Police departments would therefore make sure that risk estimates were curated throughout their dissemination, particularly with regard to the final step from local supervisors to patrol officers. Such curation would mostly take place during the briefings that patrol forces attend before they start their shift. During these briefings, risk areas within their patrol territory would be actively communicated by supervisors and patrol forces would receive custom-tailored crime map handouts (I21; I22; I23; I24; I25; I29; P49). As one patrol officer put it, "the supervisors are the ones who are responsible for ensuring that our analytical products really get traction on the street" (I21).

Apart from supervisors at local police stations, central planning and operations units also take on a key role in the chain of communication. As the decision on whether and how to implement alerts in practice usually lies with planning and operations units, they are the ones who determine how crime analysis is translated into concrete patrolling practices and/or other operational prevention measures (I20; I21; I78; P75). As one senior officer described this pivotal role:

Planning and operations decide how an alert will be implemented. They take stock of available staff and decide when and where to deploy them. 
And this decision is then forwarded to the local supervisors, and they are the ones who are responsible for the implementation.

The role of operators within the dissemination of crime risk is limited. Although they are the ones who create maps and predictive policing memos in the first place, they have little actual control over their analytical products once they attach them to an email and hit the "send" button. What is left for them is to use informal communication channels to additionally point out the existence of risk estimates to their colleagues, particularly in those cases where alert memos are passively available on the intranet. As one analyst put it:

I can only be the guilty conscience, the guy who tells people: "Look, there's something for you. Check it out!" Quite often I call, or send an email. And sometimes they tell me that they had seen the alert already. But at other times they are surprised because they had not yet realized that there was a new one. I think generally what we need is better "internal PR." The way this should be done is that our colleagues should regularly check and be aware of risk areas without someone calling them.

Apart from such informal awareness practices where analysts still try to actively intervene in the fate of crime risk, we could also observe a change of professional context in predictive policing during the dissemination phase. As crime risk starts to travel out of the analyst's office, its destiny will be decided by people whose primary concern is not necessarily crime prevention. Rather, it becomes part of wider considerations for everyday police work. It enters a struggle for operational prioritization and allocation of resources, and its opponents are powerful ones: traffic accidents, other crimes, calls for service, major events - and the general availability and capacities of a sufficient number of patrol forces. This shift of context illustrates one of the potential fault lines in predictive policing: When insights from crime analysis are not disseminated in a convincing fashion, they might not get any traction beyond the analyst's desk and the potential effects of foresight and prevention might prove ineffective.

In the words of Latour, if inscriptions do not travel well, translation processes might come to a halt, and the production of power that makes people do things will stop. Crime maps and predictive policing memos must thus be carefully crafted in order to enroll such different actors as regional chiefs, local supervisors, staff planners, and not least, patrol officers in a joint cause. As Santos (2013: 13) summarizes this task, "to be successful, an analyst must be able to explain complex ideas clearly to many different types of individuals (e.g., police officers, managers, city officials, citizens) in a way that is not condescending". A condescending tone might not even be the biggest issue here - rather, as we will show throughout the rest of this chapter, crime risk must be visualized and 
communicated in ways that make it tangible, intelligible, and actionable for different audiences.

The creation of a suitable representation of crime risk is thus considered crucial in predictive policing. Once crime risk leaves the analyst's desk, it must basically be able to speak for itself. In order to successfully gain traction within operations and planning units as well as local police stations, and eventually serve as an intuitive guidance tool for patrol activities, it must convincingly relate to the organizational and practical requirements of various professional environments and their rationales. Throughout the remainder of this chapter, we will follow the journey of risk representation from the analyst's desk to the street level. We pay special attention to how representations are crafted and modulated with specific audiences in mind and how these audiences perceive and act upon the visually represented information. At the same time, we examine how each additional layer of transformation of crime risk must also be understood as a further instance of concealing the interpretive flexibility of the original calculations, thus "hardening" the credibility of the connection between space and future crime that is being represented.

\section{Crafting a risk memo}

In predictive policing software, the creation of a map is usually the default and most important way of depicting crime risk. Crime mapping has a long history in police work, and predictive policing software ties into this tradition by taking up established practices of depicting the spatial distribution of crime and enhancing its visualization with the capacities of digital technologies. One senior officer remembered how the implementation of digital technologies continued but at the same time transformed established practices of making criminal activity throughout the city visible and thereby identifying patterns and/or clusters of crime:

Back in 1998 we got these new computer screens that could do graphics, Microsoft applications that gave us the possibility to look into new stuff, . . . to visualize in a meaningful way. . . . In our situation center during these days we still had a map of the city on the wall, city and surroundings, and our colleagues . . . came up there at 04:00 in the morning to put pins in that map.

Needless to say, pins are no longer being put in maps. Patterns are identified by predictive policing software directly in the data, and the possibilities that digital technologies provide to visually represent these patterns are unprecedented (Coopmans et al., 2014; Carusi et al., 2015). The map on the wall has now been replaced by a digital map that can be scaled, amended, and enhanced in almost any conceivable way. There are many different ways in which crime 


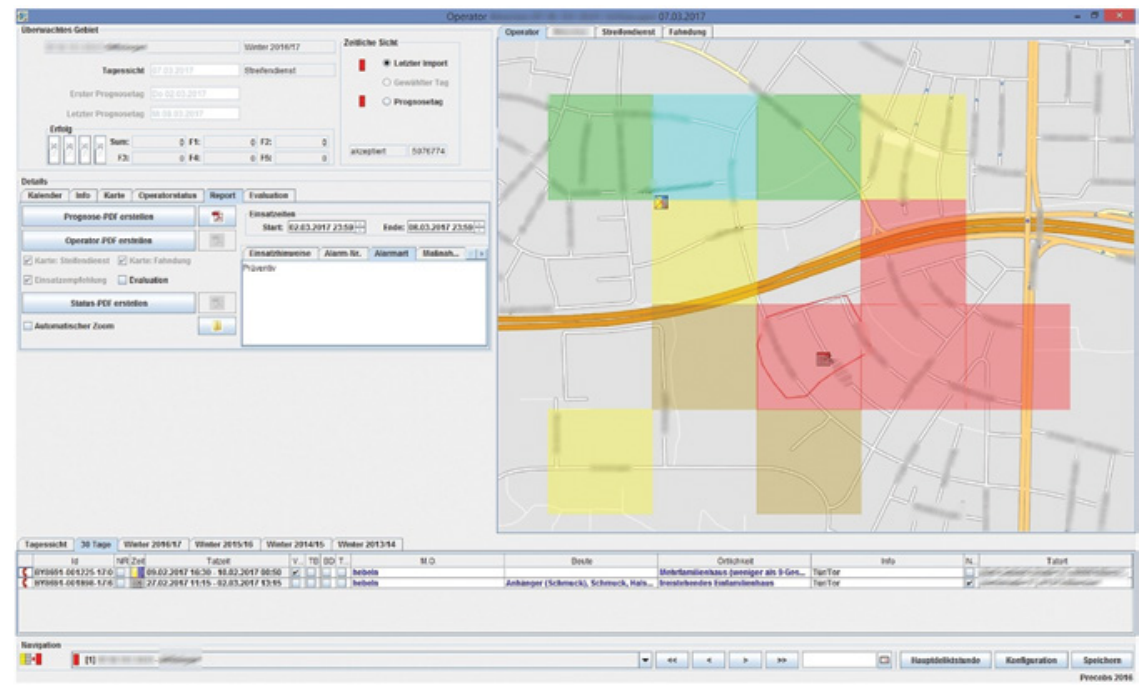

Figure 6.2 PRECOBS operator interface

risk can be visually represented. Some of them might be more intuitive than others, some of them might convey more contextual information than others, and some might be more colorful or aesthetic than others. Figure 6.1 already provided some examples of how risk can be put on a map. None of these are given or set in stone. They all use different techniques in order to highlight specific aspects of the presumed connection between risk and space, and they all shape the perception of crime within the world in a particular way. In the following paragraphs, we retrace how a crime risk memo is crafted by operators using PRECOBS.

Figure 6.2 shows the PRECOBS software interface as presented to the operator. As becomes apparent from the breakdown of the screen, PRECOBS is already in the analytical phase strongly geared toward the visual representation of crime risk in the form of a map. In order to depict both actual crime and estimated risk areas, it uses street-level map material amended by several graphical layers. The burglary that triggered the currently selected alert is represented by the dot at the center of the map section. Around this dot, crime risk is visualized by two distinct graphical elements. First of all, the close vicinity around the trigger burglary is demarcated by a line. This is where - according to calculations based on the near-repeat victimization model - the highest likelihood of follow-up incidents is expected. Moreover, color-coded tiles provide additional information on the general vulnerability of the wider space around the risk area. The tiles, each covering areas of $250 \times 250$ meters, are derived 

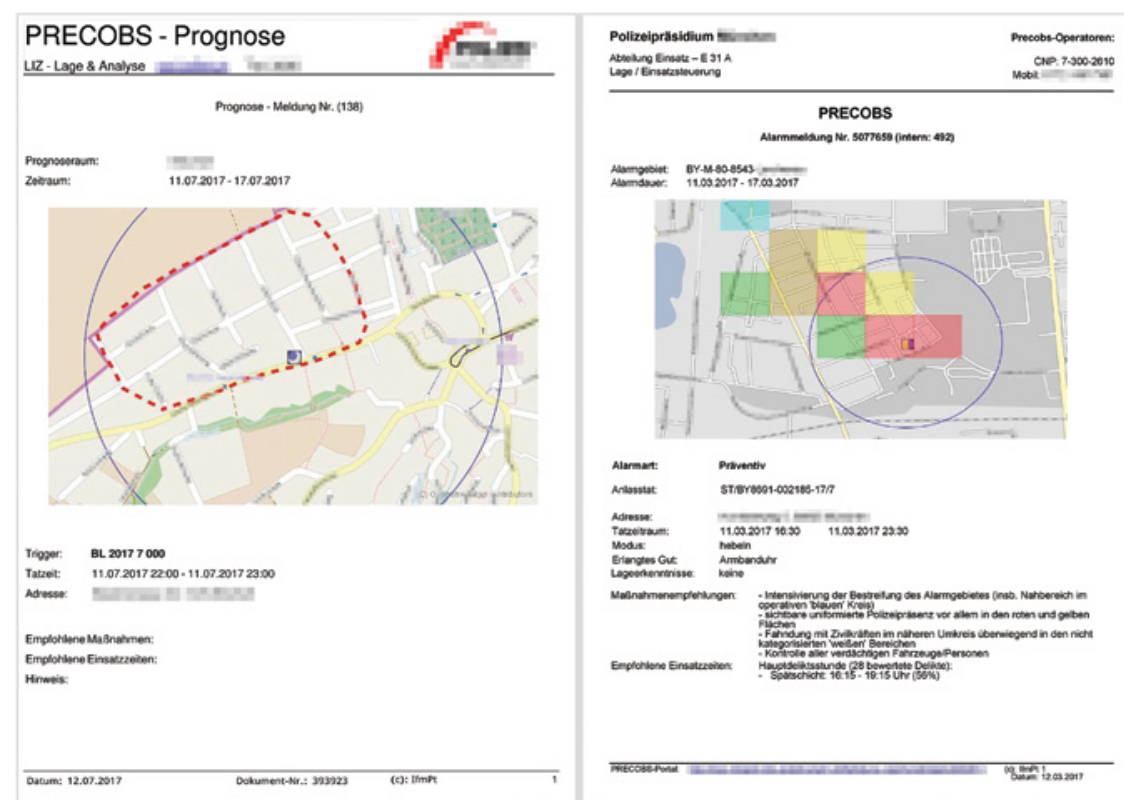

Figure 6.3 Two PRECOBS memos

from historic burglary distributions within the neighborhood. Red indicates the highest burglary activity in the past, whereas green indicates the lowest frequency of past incidents. The tiles are supposed to provide additional assistance for the route planning and attentiveness of patrol forces (I01; I02; I19; D001).

Operators have several options if they want to adjust the visual representation of crime and crime risk on the map. First of all, the baseline layer of the map itself can be changed to a satellite view of the area or other map types. This might make sense in order to get a better feeling for the topography of the area, including natural barriers such as walls, hedges, or creeks. Understanding the topography of an area is in fact helpful for the operator in order to determine the specific local characteristics of risk spaces. By default, PRECOBS indicates an "operational circle" of 400 meters around the trigger burglary where, based on the near-repeat prediction pattern, the highest likelihood for follow-up incidents is expected (see Figure 6.3). This model-based "logical" circle, however, seldom corresponds with the actual topographical characteristics of the area and thus needs to be adjusted. The operator has the option to manually draw a more intuitive risk area around the trigger - for instance, using larger streets (see Figure 6.2) or train tracks as natural demarcations of a small-scale neighborhood within which the offender is expected to operate (for a more detailed view, see also Figure 6.1). The eventual design of the map 
largely depends on the preferences of the operator. As one analyst described this process:

I choose the map section that I want to show. I can zoom in a bit more if I decide that I do not want them to look at this other stuff, the motorway for example. . . . It's up to me how the map looks in the end, and then I create the memo.

As this quote illustrates, it is the operator who has a fundamental role in guiding vision and directing attention via the creation of crime maps. However, the specific characteristics of the maps that the operator produces with PRECOBS must not only speak to the preferences of the analyst but also already correspond with the requirements of later stages of police work. The color-coded tiles are a pertinent example of this. During our research, we found that some police departments would use them in order to further facilitate the intuitive intelligibility of crime maps and the depicted connection between space and risk. Others, though, concluded that the tiles affected the behavior of patrol forces too strongly. They told us that patrol officers would almost exclusively pay attention to the red areas and neglect the yellow and green ones (I44; I45; I80). Thus, when crafting the initial risk representation, ensuing stages of police work and their operational requirements must always already be present at the analyst's desk, and they affect the choices that bring into being a specific form of visual representation.

In line with such considerations, operators and senior officers told us repeatedly that visual representation of analytical insights was considered one of the most important tasks in predictive policing, as crime maps would preconfigure to a large extent how crime risk information would be understood by their colleagues (I12; I19; I76; I77; I79; I80). This puts a rather large degree of responsibility on the operator, particularly given that "bad" visuals would, apart from potentially disrupting the predictive policing process, also cause mockery. One operator gave an example of how the visualization choices for maps impact the ways in which patrol officers see the connection of risk and space:

Visualization is really the key. It needs to be sophisticated and precise. . . . The more precise the visualization, the better the acceptance will be in my opinion. In [neighborhood] we had an example where the river and the sluice gate were part of the map, and our guys were like: "Great, now we have to police fish."

Quite obviously, no patrol officer would seriously consider patrolling under water. And yet, this anecdote about misguided visual representation illustrates how important maps are for patrol work. The construction of risk maps 
translates epistemic practices of algorithmic data analysis into intelligible and immediately actionable instructions for police work in the form of street-level patrols. Regardless of the exact type of graphics used, visual representation allows the police to make the future, while not yet here, tangible and relatable. Criminal futures, once depicted, must no longer unfold in reality before they come into being in the imagination of the beholder. At the same time, they render the need for crime prevention measures rather obvious and intuitive.

In a next step, operators would then go on to craft a risk memo based on the results of the analysis with PRECOBS. This memo would usually consist of a single-page summary document that would be converted into a shareable pdf document and then distributed via email. Figure 6.3 shows two distinct versions of a PRECOBS memo as used by two different police departments. The general layout, based on the standard template provided by the software, is very similar. Both memos are dominated by the map and specific visual representations of risk (on the left: an operational circle and a manually drawn target neighborhood superimposed on the topography of the estimated risk area; on the right: an operational circle and color-coded tiles).

The crime map is in the context of the memo supported by a number of contextual details. In the top section (above the map), it specifies the alert number and the risk area as well as the validity period of the alert. The bottom half of the memo then lists further details about the alert itself as well as available information about the trigger burglary that it refers to. It therefore usually links the memo to file numbers, database references, and other internal remarks (I79). Moreover, the memo provides information on the street address of the trigger incident, the time (or presumed time period) of the crime, the modus operandi, and the haul - which are essentially the data points based on which the risk estimate was calculated in the first place.

Maybe most importantly, predictive policing memos would usually outline recommended forms of intervention and specific operational hours based on the characteristics of the trigger incident and a broader assessment of the situation (I03). For example, a report could recommend that patrols in uniform should be favored over plainclothes patrols, that vehicles should be checked within the demarcated risk rea, or that patrols should be intensified during a particular time of day. These contextual details are key, as they instruct the planning and operations units to assess which resources would be necessary to put the recommended measures into action, to accommodate those activities vis-à-vis other tasks, and to adjust shift scheduling or vehicle management. Other additional information that could be added to the memo would, for example, be knowledge on already registered follow-up incidents of the presupposed burglary series or on other reported crimes outside the identified risk area. One analyst described the composition of a memo as follows:

It's more or less the output from the system. . . In addition, we provide some tips, like for example: "This is a sera [i.e. dusk] alert, no staff needs to 
be scheduled for the morning shift." Or we remind them of general things, for instance: during this "sera" alert, no action is required on Sundays. We don't get any burglaries on Sundays, because people are at home on Sunday evening.

There was a good deal of variation between different police departments in the amount and depth of contextual information provided. As Figure 6.3 illustrates, the memo on the left contains no additional information on recommended operational measures and times, nor does it provide additional hints or tips. The memo on the right, on the other hand, includes a list of detailed recommendations, including the use of uniformed and plainclothes patrols at specific times. Decisions about whether and what kind of operational advice to provide as part of the memo might be due to the specific organizational structures of the department and the competencies and responsibilities as distributed between different divisions.

We have seen that there is a considerable degree of freedom and creativity in the ways in which crime risk becomes visualized and communicated in predictive policing. The eventual shape and informational content of both map and memo must speak not only to the question of how to make algorithmically produced crime risk tangible and actionable in the first place but also to the question of how to "best" visualize crime risk for different audiences at later stages of the predictive policing process. Notably, by means of the creation of an inscription in the form of a memo, crime risk has been enabled to travel across different contexts and cross police-internal boundaries between specialized units.

At this point, crime risk is no longer an issue of data, algorithms, and the collaboration of humans and machines. Epistemic questions concerning data quality and the plausibility of risk alerts within larger narratives of crime have been settled. Rather, crime risk now turns into a managerial task. Planning and operations units need to decide whether and how to implement risk alerts based on the general availability of resources and the particular requirements of a specific alert. Predictive policing, in other words, has now turned into a question of resource management, and knowledge dissemination has to take the informational needs of the more bureaucratic and managerial side of police work into account (I17; I45). As one respondent framed this shift of context and their task within predictive policing:

What we do is essentially patrol management, and this relates to predictive policing as we receive the reports from the analysts, and we have to turn them into concrete patrols.

The design of the risk memo must, as argued earlier, in this sense be understood against the backdrop of the organizational structure of police organizations. As 
Burri and Dumit (2008: 300) put it, "visual representations cannot be understood in isolation from the pragmatic situations in which they are used". In this case, the representation of risk now speaks to the practical requirements of coordinating patrols and other police activities rather than to the logic of reviewing alerts issued by software algorithms.

Equally importantly, however, the turn away from questions of knowledge production and toward suitable ways of visualization and dissemination at the same time hardens the "truth claim" of crime risk. Through its inscription in the form of a map and its incorporation within the predictive policing memo, crime risk is translated from a possibility into a quasi fact. The visual representation, precisely because it is intuitively intelligible, brings the connection between the depicted space, crime, and more future crime into being. An image might indeed say more than a thousand words, but it also says a lot less by leaving out explanations in favor of the self-evidence of the visual. Notably, it says nothing about the quality and reliability of the underlying data, it says nothing about the model, the algorithm, and the criminological theories that risk estimates are predicated upon, and it says nothing about the confidence of the operator in the likelihood of follow-up crime.

The power of visualization lies, of course, precisely in the capacity to break down complexity and to make information easily accessible. At the same time, however, it conceals possible doubt and makes the existence of crime risk less contestable. Crime maps have been both praised and criticized for their persuasiveness - what they most certainly do is to reduce interpretive flexibility. As Latour (1990: 42) reminds us, "although in principle any interpretation can be opposed to any text and image, in practice this is far from being the case". In this case, the transformation of data, theories, and algorithms into a one-page document that is dominated by a crime map makes it hard to argue for a future without crime in the indicated area. The credibility claim conveyed by risk representation is furthermore backed up by specific recommendations on how to act upon the future in order to prevent it from becoming a criminal one.

\section{Guiding street patrols}

Crime risk has now entered the managerial realm of operations and planning, and it has traveled from mostly centralized crime analysis units to local police stations. It has already undergone considerable transformation along this journey. It must, however, still travel across another professional boundary. As outlined earlier, alerts must be communicated to patrol officers in order to get to the street level. One might expect that for this purpose police departments would simply further distribute the memo, but we found that most departments chose to further modify them. Modification here primarily means stripping the memo of most contextual information, expanding the risk map, and only supplementing it with basic details on the validity period of the alert, the 
characteristics of the trigger incident, and the preferred mode of prevention measures. One interviewee described this process as follows:

We adjust [the memo] a bit more. Based on our prognosis, we create another map with an indication of how our forces are supposed to operate: either static controls, officers in the neighborhood, plain-clothes or in uniform, or whatever is relevant. That defines the operational measures. The area itself . . they receive the period of the alert and the map, and that's it. That's the access that the operational forces have.

Figure 6.4 shows an example of the predictive policing handout that street patrol officers would be presented with by most of the police departments we studied. As can be seen, the handout comes more or less exclusively in the form of a risk map. In Figure 6.4, the map includes landscape features such as parks and woodlands that facilitate an intuitive understanding of the neighborhood's topography. The operational radius around the trigger burglary has been kept here, but since the circle would cut across larger streets and a park, it has been supplemented with a manual demarcation of a more practical risk area where follow-up burglaries could presumably be expected. Patrol officers would thus, in their predictive policing-related work practices, almost exclusively refer to a visual representation in the form of a map with risk indicators.

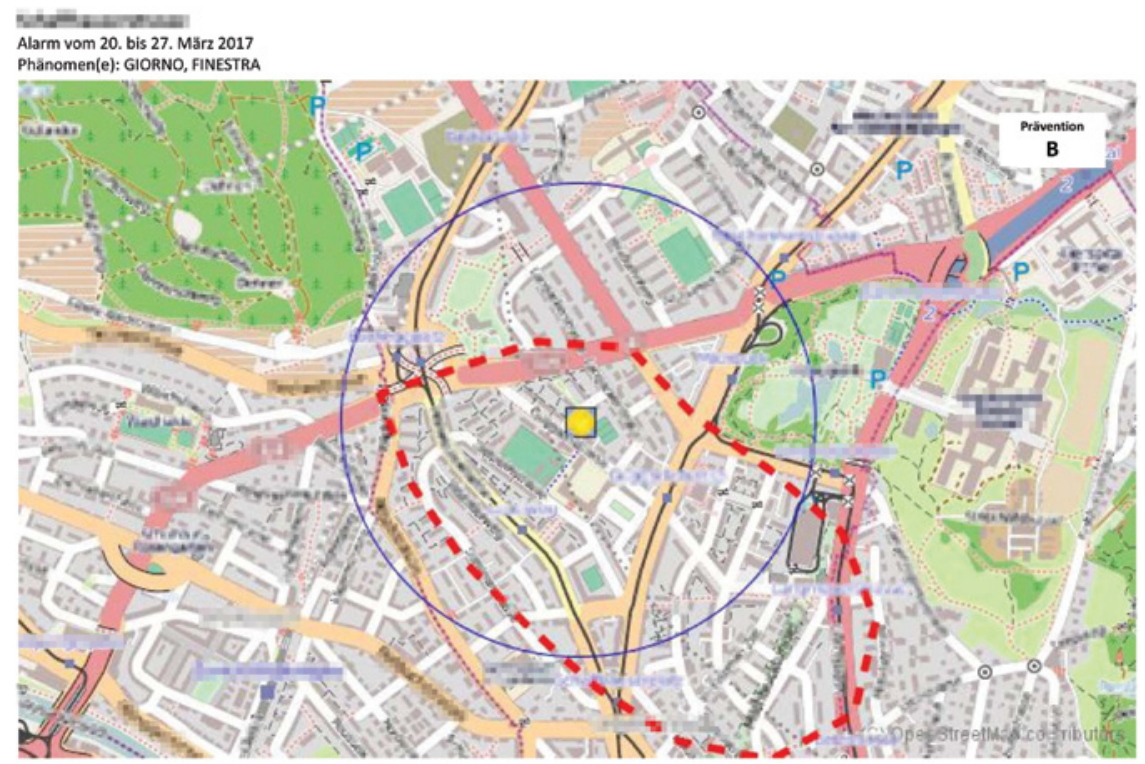

Figure 6.4 PRECOBS patrol handout 
Once more, the simplicity of the risk map closely speaks to organizational requirements of police work. We found that intuitive intelligibility and immediate actionability were seen as the main goals of risk representation at this stage. One interviewee described the rationale of the design of the predictive policing handout for street patrol officers in their respective departments as follows:

It needs to be intuitive. [Patrol officers] need to feel comfortable. . . . It needs to be quickly accessible, so that they can immediately put it to practice, and it needs to function effectively and without any difficulty. It must be suitable for everyday operations, and therefore no frills.

From an organizational perspective, immediate cognitive accessibility certainly makes a lot of sense. Patrol officers' primary professional skills are to observe and interact in the streets. They need to be able to engage the population, carry out controls, and demonstrate that the police are actively fighting crime and protecting the population (Ericson, 1982). In order to successfully fulfill these tasks, they do not necessarily have to understand the intricate details of how risk areas came into being or even the characteristics of the specific trigger that sparked the emergence of risk in the first place. Rather, they need to receive the necessary information to locate presumably risky areas within their patrol space in a tangible and intelligible way.

From a patrol officer's point of view, the straightforward visual clarity of the predictive policing handout was in fact described as a welcome element that facilitated their daily work routines. Patrol officers that we spoke with told us that they found the visual representation of crime risk as conveyed by the handout helpful in several regards. It was framed as intuitive (I06) and as supportive, especially for younger officers who lacked experience and in-depth knowledge of the city (I09). Mostly, however, the handout was described as helpful in terms of structuring patrol routes, as it was considered easily readable and as providing clear anchor points that could be accommodated within their work practices (I18; I21; I22; I23; I24; I27; I29). As one patrol officer framed it, "if I can look at a graphic, . . . then I can immediately picture the area, I know where we are, and what's up. ... That really helps us, the visualization" (I06).

The information conveyed by the visual representation of the memo in this sense is very instructive in terms of how police patrols structure their relationship with their spatial surroundings. It enables them to place indicated risk areas in context within the topographical characteristics of the larger neighborhood or district, looking for natural demarcations that will enable them to stay in or at least in the near vicinity of - the indicated patrol areas (I06; I09; I17; I20; I26; I27; I76; I77). One respondent gave us an example of such spatializing practices with regard to a specific predictive policing memo:

Ok, so I have this area between [street A], and east of [street B], that's my core area. And the train tracks are a border here, and [street $C$ ] here. And 
entry points are [street D] here and [street E] here. So for me this means: I enter the area here, and then work my way through towards this end. For me, the area will not be exactly the blue circle or the colored squares. I would rather say: okay, maybe up until [street F], and if I drive into [street G], this won't do any harm. But I have a rough area in mind where I will do my rounds, carry out controls, be especially attentive.

As this quote aptly illustrates, the predictive policing handout - which is at this stage essentially congruent with the risk map that was created by the software operator - almost seamlessly translates crime risk to the street levels and ties in with the practical requirements of patrol practices, which are already geared toward a heavily spatialized understanding of police work. The further simplification of visual representation in the handout strongly resonates with earlier arguments about both the capacity of inscriptions to travel across boundaries and the hardening of credibility that is sparked by a series of transformations. The predictive policing handout, from the perspective of its audience (i.e., patrol officers), unfolds powerful epistemic authority that virtually brings criminal futures into being and that is hard to challenge or contest. At the same time, its instructive character facilitates the enactment of crime prevention measures throughout space.

From an epistemic perspective, interpretive flexibility has been almost completely removed at this point. The crime-map-as-handout, as the end result of risk representation, in the words of Latour (1990: 42), can be understood as "the staging of a scenography in which attention is focused on one set of dramatized inscriptions". Even though from a practical perspective, it makes sense to gear the handout toward maximum intelligibility and actionability, such a reduction inevitably fosters a partial and biased way of perceiving the world and the alleged criminal activities happening in it. Risk representation, through a series of transformations, has turned the interpretive flexibility of the statement that "in this area there might or might not be a higher likelihood for certain types of crime during a specified period of time" into definite evidence that "there will be crime here". It now appears intuitive that the indicated areas must be preferentially patrolled in order to stop criminal futures from materializing. Effectively, even though the materialization of crime is not a given but rather a literal risk, its eventual existence has been brought into being as an indisputable fact that guides action within the world.

\section{Risk and the public}

A related, yet slightly more complicated aspect of dissemination concerns communication with the public. Larger crime prevention strategies are often geared toward the incorporation of the general public, particularly with regard to property offenses such as residential burglary, pickpocketing, or robbery. 
Residential burglary is in fact one of the most pertinent domains for the active involvement of citizens in crime prevention measures (Hackemack, 2014; Merschbacher, 2018). The police encourage citizens to better protect their homes by making sure that doors are locked and windows are not cracked, by installing reinforced locks and alarm systems, or simply by being vigilant and reporting allegedly suspicious persons or behavior to the police (D032; D255; D377; D378). While such forms of private crime prevention have been criticized for shifting the responsibility for security away from the police and onto the population (Garland, 2001), they also take on an important role in community engagement and in improving relations between the police and citizens (Schreiber, 2011; Mols and Pridmore, 2019).

Traditionally, the police have sought to foster citizen incorporation in crime prevention through awareness campaigns on billboards, newspaper ads, flyers, or through specialized seminars and trainings at community centers. During the period of our research, all police departments that we studied were actively using different means of public communication for situational crime prevention. Most employed traditional outlets in the form of billboards, flyers (I17; I26; I46; I79; P16), and the news media (I18; I78). As one of our interviewees detailed the scope of general prevention campaigns:

We did a lot: at events, in communities, consultations with homeowners how can I protect myself? We did a lot. Also in the media, on public transport. . . . We even gave away automatic timers, so that people can leave the light on during dusk or at night.

While not connected to predictive policing activities per se, such general awareness campaigns were also supported by the practices of street patrols or dedicated community officers. When interacting with citizens, they would more or less casually point to burglary risk and provide tips on how to guard one's own and others' homes (I12; I17; I27; I80). One interviewee described this activity as follows:

You talk to people. You say: "Look, over there, there was a burglary." And you remind people to close their windows and lock their doors when they are not at home. . . . Look out for their neighbors. Usually, people in the neighborhood know each other, and if I know that my neighbor went on a skiing trip over the weekend, and I notice light in his house on Saturday night, then I'll know: “Ok, he's not home. So I'll call the police." . . . Our goal is to raise awareness.

More recently, police departments have also discovered the internet as a communication channel toward the public, and they have started using social media 
platforms for PR strategies (Spiller and L'Hoiry, 2019; Walsh and O'Connor, 2019) and to render their activities more effective and efficient (de Graaf and Meijer, 2019). Although research suggests that PR and social media work are often organizationally separated from operational parts within police departments and are thus more political than issue driven (Crump, 2011), social media enables police departments to communicate with their target audience directly and disseminate information that can include such things as missing person reports, a search for witnesses, or traffic disruptions. Many police departments also offer custom apps that citizens can install on their devices to receive up-todate information and even push notifications on crime alerts (I20; I46; P49). Figure 6.5 shows two separate screenshots taken from the official app of the Cantonal Police of Aargau.

The screenshot on left appeared in the "Crime Stop" category, where the department publishes general advice on crime prevention. Under the heading "Together for more security", the message highlights burglary activities and foregrounds the discomfort caused by the experience of being a burglary victim. It then details how citizens can actively support the police in their fight against residential burglary: by remaining vigilant, by looking out for neighbors, and by reporting suspicious activities to the police immediately. Such a form of communication is in fact pretty common, particularly with regard

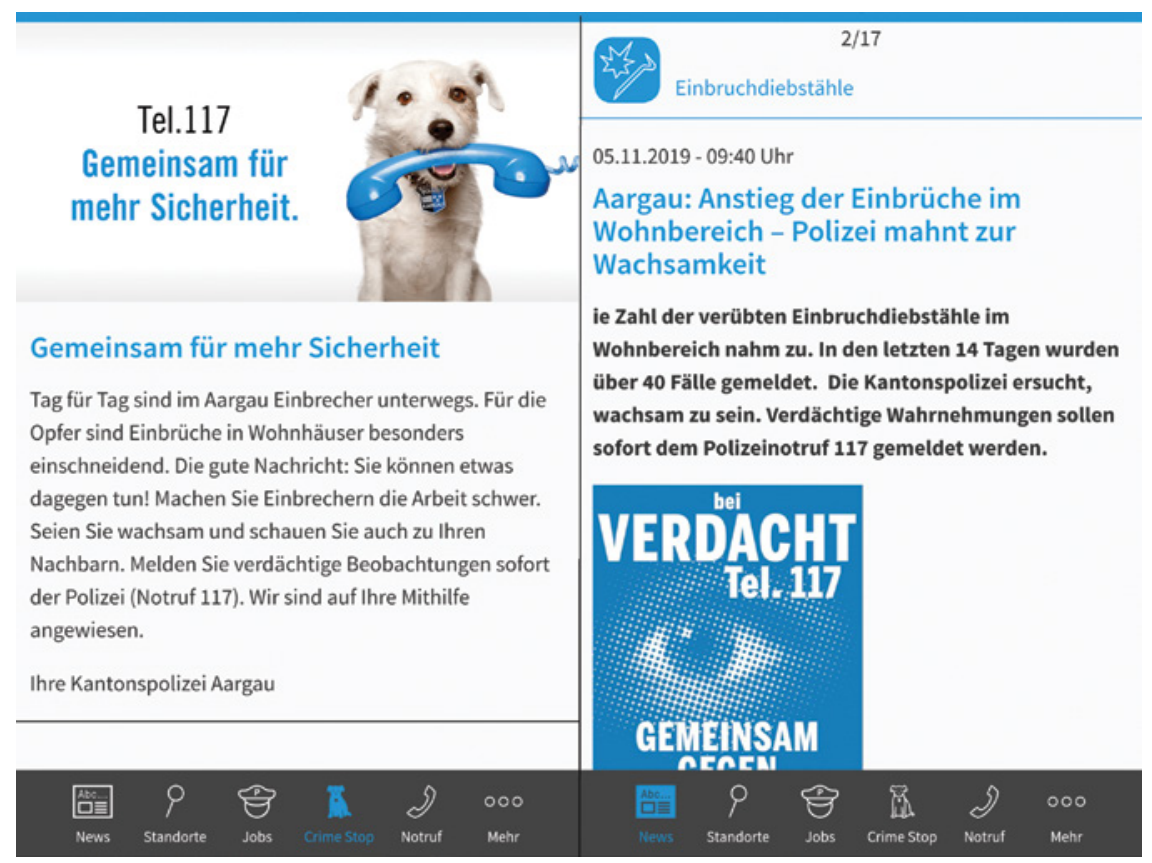

Figure 6.5 Screenshots from the Cantonal Police of Aargau app 
to burglary prevention. Getting the population involved in crime prevention efforts is seen as key to effectively discouraging crime, and police departments more often than not have specific awareness-raising programs in place that are supposed to inform and enable residents to actively contribute to reducing criminal opportunities and to making things more difficult and increasing the perceived risk for offenders (I79; P49).

The screenshot on the right side of Figure 6.5, however, tells a slightly different story. Taken from the "News" category of the app, it specifically details an increase in burglary activity during the past 14 days within a specific area. It then goes on to, once more, outline how citizens can assist the police in their crime prevention activities. Sure enough, the message does not specify the precise neighborhood(s) in which increased burglary risk could be expected and yet there are some similarities to the predictive policing memos and handouts that are produced and disseminated internally by the police. In fact, it is not completely unknown for police departments to make the results of crime analyses available to the general public. As Santos (2013: 209) writes specifically with regard to the US, when they do this, police departments usually revise the content of the message: "When citizens are provided with information about patterns, they receive 'watered-down' or sanitized versions of the bulletins created for police agencies."

An example of such a sanitized version is illustrated by Figure 6.6. The image shows the official Facebook page of the Cantonal Police of Aargau with a post

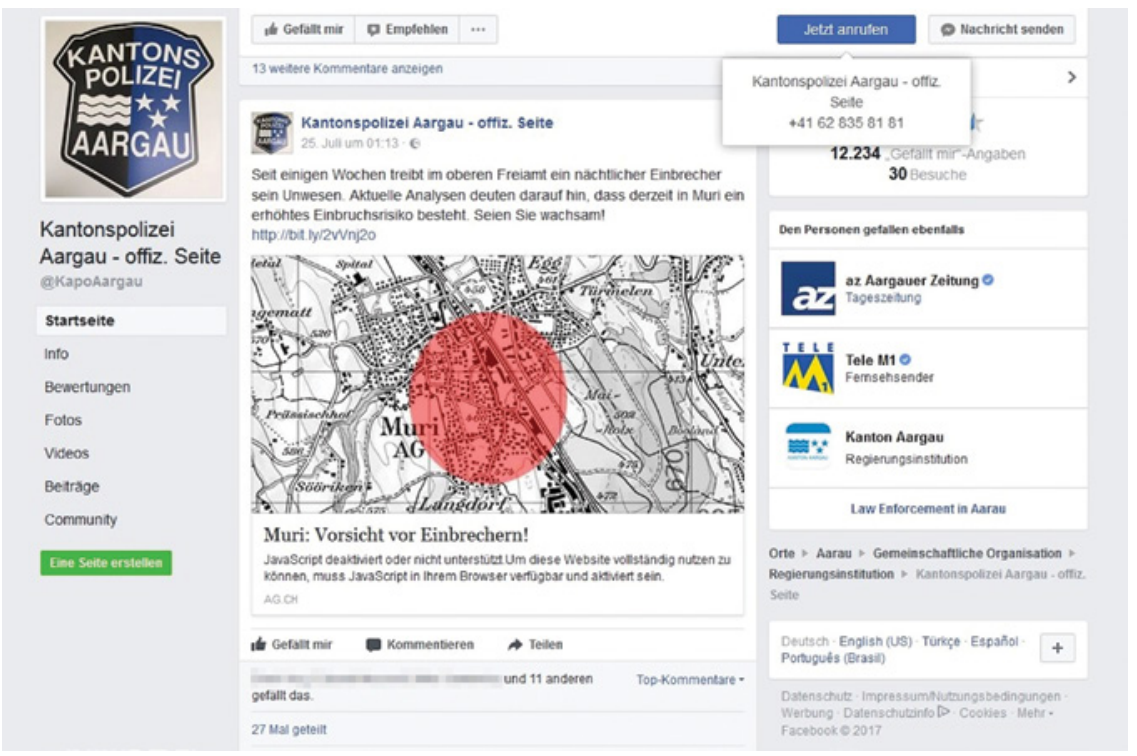

Figure 6.6 Screenshot from the Cantonal Police of Aargau Facebook page 
that, based on "up-to-date analyses", informs the public about an increased residential burglary risk in the small town of Muri. Although not a crime map in the strict sense, the image that goes with the post shows a map of the town overlaid with a large red dot and the message: "Muri: Beware of burglars!" A click on the post redirects the user to Cantonal Police's website, where more information on ongoing nighttime burglary activities is given, including the specification that likely targets include single-family homes and ground-floor apartments. The Cantonal Police thus urge the population to be vigilant and to report suspicious activity (D374).

Such practices raise the question of whether or not concrete risk estimates from crime prediction software should be communicated to the public. If predictive policing transforms the crime prevention measures carried out by the police from generic ones to targeted ones, could and/or should the incorporation of citizen support for these activities also be turned from generic into targeted? In theory, predictive policing provides an opportunity for awareness campaigns to be directed to limited subpopulations of residents within those areas that are, for a short time period, identified as more vulnerable to burglary activity than others. In simple terms, the message communicated could be changed from "There was increased burglary activity in town X - remember to keep your doors locked and your eyes open" to "Your home is located in a risk area where we reasonably expect further burglary activities over the coming days".

Such targeted communication could then arguably facilitate increased response and compliance from residents and thereby render situational crime prevention more effective overall. During our research, this was in fact a question that came up rather frequently, and police departments had at the very least discussed whether this should be done - and if so, how it could be done in a reasonable fashion. However, almost all departments came to the conclusion that the potential drawbacks of targeted public risk communication would outweigh the benefits.

A major reason for this decision was that police departments wanted to avoid potential fearmongering. The literature on risk communication has long stressed that providing information about threats can induce unease, even if it is done properly (Sjöberg, 1998; Renn, 2006; de Vocht et al., 2016). Moreover, the implementation of (situational) crime prevention measures themselves can, although geared toward the reduction of fear, have adverse effects. As Ekblom (1998: 28) argues, "where design or implementation are carried out insensitively, this could increase fear; limit the freedom of legitimate users (of products, environments or services), foster an attitude of victim-blaming; and introduce an unpleasant, fortified and beleaguered environment". Such subjective insecurity must also be understood in conjunction with general attitudes toward security, the police, and the state. For some, increased police presence will mean more perceived protection and therefore more subjectively felt security. For others, increased police 
presence will mean that they will feel threatened by an overpowering presence of the state and an institution that they feel should not be trusted (Shapiro, 2019: 469).

During our research, the most widespread argument against targeted public risk communication from predictive policing was in fact what could be described as a "fear of fearmongering". Our interviewees were concerned about the subjective perception of threat in combination with the potential spatial branding of certain areas or neighborhoods as burglary hot spots (I18; I20; I26; I27; I76; I79). This is somewhat ironic, as the general idea of predictive policing is to move away from the analytical production of stable hot spots and toward a more dynamic understanding of space and crime. In public perception, as one respondent put it, burglary risk could, however, quickly turn from a temporary phenomenon into a solidified fact - and thus potentially put a strain on the relationship between the citizens affected and the police:

Just imagine you live in a neighborhood where there's an alert every month, or every three weeks. You wouldn't be thrilled. Or you'd get the feeling that the police need to be more active. I believe that's quite difficult.

However, as we will discuss in more depth in the following chapter, a feeling of unease can also be caused by the mere presence of police patrols in a neighborhood. Significantly increased police presence would thus leave inhabitants wondering about the possible threats that were seen to warrant special police attention. Unintended side effects of predictive policing must also be put in the context of the political prioritization of the fight against residential burglary that played a key role in the procurement and implementation of algorithmic crime analysis software. Predictive policing, as we discuss in more detail in Chapters 2 and 8, was in Germany and Switzerland seen as an appropriate way of addressing concerns about high crime levels. Police departments were in this context careful not to replace concerns about burglary numbers with concerns about overpolicing and discrimination.

Police departments were, however, not exclusively worried about the reactions of citizens. They also referred to possible negative repercussions of risk communication for a number of other interest groups. Some of our interlocutors mentioned the real estate market and insurance companies as cases where publicly available knowledge about spatial distributions of crime and crime risk could have repercussions beyond crime prevention itself. They were afraid that insurance companies might use available crime risk data in their calculations of premiums, potentially rendering homeowners' insurance policies more expensive for clients who reside in areas that are frequently identified as being at risk. Likewise, real estate owners might fear that the value of their property could decline if it was located in what could become publicly known as an 
area with increased burglary risk. The following two quotes illustrate these concerns vividly:

The market, the real estate market, but also society ... I mean that's simply way too sensitive. If you went ahead and said: "In this street this and that is happening." . . For internal purposes, that's necessary and it makes sense. But we won't make that publicly accessible for everyone.

Real estate agents might go ahead and analyze the data and be like: "Right, so how many alerts did we have here over the past three years?" . . . Or insurance companies.

A different concern revolved around the distribution of crime risk across larger rural areas. In some early cases when police departments publicly communicated risk estimates from crime prediction software, affected municipalities felt actively discriminated against by the publication of the alert. As they considered themselves to be in competition for taxpayers with other local municipalities, they felt that knowledge about burglary activity and ensuing crime risk would reduce their attractiveness as a place of residence. As one interviewee told us: "We made alerts public and then we got pushback from the municipalities. Something like: 'Our community is safe, don't scare off potential taxpayers!"” (I18).

In light of these challenges, the departments that in the beginning opted to actively communicate risk estimates made efforts to counter potential discriminatory effects by manually selecting which alerts to publish, thereby seeking to balance the spatial distribution of communicated alerts (I18; I78; P49). But even such manual curation would at times backfire, as communities would feel misrepresented and/or stigmatized. As one officer gave an example of this:

We might publish an alert concerning a rural area, where there are in fact not so many burglaries. Which then immediately triggers the local community council to say: "We have so few burglaries, why did you publish that?"

Last, but not least, there were some doubts about public risk communication from an operational perspective. Some of our respondents expressed concerns that making information about predictive policing and operational risk areas publicly available would give criminals access to knowledge about policing strategies and thus enable them to "game the system" and counter situational crime prevention measures (I25; I46). These concerns reflect broader considerations about the trade-off between transparency and trust-building in police 
work on the one hand and the prerequisite of secrecy that underpins intelligence and ensuing operational and tactical decisions on the other (I02). It is likely that this tension will be reinforced in the future, as police departments increasingly turn to data and automated forms of analysis.

In the end, while our interviewees generally agreed that raising public awareness is an important aspect of crime prevention and that this aspect is of course relevant for predictive policing, they also agreed that police departments need to proceed with care. Risk communication is a sensitive issue in police work, and its intricacies are aggravated by the potential impact of crime risk estimates that can go way beyond actual crime prevention activities. We found that due to numerous concerns, police departments overwhelmingly refrained from involving the populations within risk areas actively in crime prevention activities. Rather, they stuck to established communication strategies that depict burglary as a generic and unspecific risk that citizens should prepare against independent of current patterns. As one interviewee plainly put it: "We don't publish maps. We simply say: 'There were burglaries, we believe that there is increased risk.' We keep that deliberately vague” (I18).

\section{Conclusion}

Communication, as we have shown throughout this chapter, is an important aspect of predictive policing - and it draws attention to the ways in which knowledge is visually represented and disseminated across different professional contexts. In police work, maps are a primary means of making actual and potential criminal activity intelligible and actionable. However, representations of crime risk change shape as they make their way through different stages of predictive policing (from crime analysis to operational planning, and eventually to local police stations and to the street level). The series of transformations that can be witnessed throughout this journey is important with regard to two main functions. First of all, it speaks to different organizational and knowledge requirements vis-à-vis different tasks of police work. Second, it also establishes credibility for the claim that there is in fact crime risk, as it visually materializes this risk and thus reinforces the notion that the near future will indeed be a criminal one unless crime prevention measures intervene into it.

Crime risk is not a natural "thing" or even a fixed phenomenon but can be conceptualized and calculated in various different ways. Questions about the robustness and meaning of a specific risk estimate must therefore always be kept in mind when assessing whether it should or should not be acted upon. Moreover, any form of risk statement is of course not a statement about whether the predicted event will actually occur or not, but rather a statement about probabilities that are contingent on available data and applied theories and models. In the case of predictive policing, this means that the predicted criminal event may or may not occur, and it may or may not do so within the spatial and temporal boundaries indicated. 
Patrol officers, though, are usually not concerned with such questions. They must in a sense trust their colleagues (and/or the software) to have made the right judgment call, as they have neither the expertise nor the resources to unpack active alerts and check their actual plausibility. In other words, at the analyst's desk, crime risk is still very much contestable, but this contestability will not carry over to other stages of the predictive policing process. The interpretive flexibility of data, theories, and models used for the calculation of risk, as well as the epistemic status of risk itself, gives way to an already hardened version of a criminal future.

\section{References}

Amann K and Knorr Cetina K (1988) The Fixation of (Visual) Evidence. Human Studies 11(2): 133-169.

Belina B (2016) Predictive Policing. Monatsschrift für Kriminologie und Strafrechtsreform 99(2): 85-100.

Belina B and Germes M (2016) Kriminalitätskartierung als Methode der Kritischen Kriminologie? Kriminologisches Journal 48(1): 24-46.

Bowers K and Johnson S D (2014) Crime Mapping as a Tool for Security and Crime Prevention. In Gill M (ed.) The Handbook of Security. Basingstoke/New York: Palgrave Macmillan, 566-587.

Brown M K (1981) Working the Street: Police Discretion and the Dilemmas of Reform. New York: Russel Sage Foundation.

Burri R V and Dumit J (2008) Social Studies of Scientific Imaging and Visualization. In Hackett E J, Amsterdamska O, Lynch M and Wajcman J (eds.) The Handbook of Science and Technology Studies. Cambridge/London: MIT Press, 297-318.

Carusi A, Hoel A S, Webmoor T and Woolgar S (eds.) (2015) Visualization in the Age of Computerization. London/New York: Routledge.

Chainey S and Ratcliffe J (2005) GIS and Crime Mapping. Chichester: John Wiley \& Sons.

Chamard S (2006) The History of Crime Mapping and Its Use by American Police Departments. Alaska Justice Forum 23(3): 1-8.

Chan J, Brereton D, Legosz M and Doran S (2001) E-Policing: The Impact of Information Technology on Police Practices. Brisbane: Criminal Justice Commission.

Coopmans C, Vertesi J, Lynch M and Woolgar S (eds.) (2014) Representation in Scientific Practice Revisited. Cambridge: MIT Press.

Cope N (2004) Intelligence Led Policing or Policing Led Intelligence? British Journal of Criminology 44(2): 155-181.

Cope N (2008) "Interpretation for Action?" Definitions and Potential of Crime Analysis for Policing. In Newburn T (ed.) Handbook of Policing. Cullompton/Portland: Willan Publishing, 404-429.

Cordner G and Biebel E P (2005) Problem-Oriented Policing in Practice. Criminology E Public Policy 4(2): 155-180.

Crampton J W (2001) Maps as Social Constructions: Power, Communication and Visualization. Progress in Human Geography 25(2): 235-252.

Crampton J W (2010) Mapping: A Critical Introduction to Cartography and GIS. Chichester: Wiley-Blackwell.

Crampton J W and Krygier J (2005) An Introduction to Critical Cartography. ACME: An International E-Journal for Critical Geographies 4(1): 11-33. 
Crump J (2011) What Are the Police Doing on Twitter? Social Media, the Police and the Public. Policy \& Internet 3(4): 1-27.

de Graaf G and Meijer A (2019) Social Media and Value Conflicts: An Explorative Study of the Dutch Police. Public Administration Review 79(1): 82-92.

de Vocht M, Claeys A S, Cauberghe V, Uyttendaele M and Sas B (2016) Won't We Scare Them? The Impact of Communicating Uncontrollable Risks on the Public's Perception. Journal of Risk Research 19(3): 316-330.

Eck J E, Chainey S, Cameron J G, Leitner M and Wilson R E (2005) Mapping Crime: Understanding Hot Spots. Washington, DC: National Institute of Justice.

Ekblom P (1998) Situational Crime Prevention: Effectiveness of Local Initiatives. In Goldblatt P and Lewis C (eds.) Reducing Offending: An Assessment of Research Evidence on Ways of Dealing with Offending Behaviour. London: Home Office, 23-38.

Ericson R V (1982) Reproducing Order: A Study of Police Patrol Work. Toronto: University of Toronto Press.

Farrell J (2009) Against Method, Against Authority . . . For Anarchy. In Amster R, DeLeon A, Fernandez L A, Nocella A J and Shannon D (eds.) Contemporary Anarchist Studies: An Introductory Anthology of Anarchy in the Academy. London/New York: Routledge, 73-81.

Garland D (2001) The Culture of Control: Crime and Social Order in Contemporary Society. Oxford: Oxford University Press.

Hackemack C (2014) Von der Sicherheitsberatung bis zur Präventionsplakette: Einbruchschutz mit dem Netzwerk "Zuhause sicher”. Forum Kriminalprävention 4: 27-30.

Harley J B (1989) Deconstructing the Map. Cartographica 26(2): 1-20.

Harries K (1999) Mapping Crime: Principle and Practice. Washington, DC: National Institute of Justice.

Jefferson B J (2018) Predictable Policing: Predictive Crime Mapping and Geographies of Policing and Race. Annals of the American Association of Geographers 108(1): 1-16.

Kindynis T (2014) Ripping Up the Map: Criminology and Cartography Reconsidered. British Journal of Criminology 54(2): 222-243.

Latour B (1987) Science in Action: How to Follow Scientists and Engineers through Society. Cambridge: Harvard University Press.

Latour B (1990) Drawing Things Together. In Lynch M and Woolgar S (eds.) Representation in Scientific Practice. Cambridge/London: MIT Press, 19-68.

Latour B (2014) The More Manipulations, the Better. In Coopmans C, Vertesi J, Lynch M and Woolgar S (eds.) Representation in Scientific Practice Revisited. Cambridge: MIT Press, 347-350.

Latour B and Woolgar S (1986) Laboratory Life: The Construction of Scientific Facts. 2nd Edition. Princeton: Princeton University Press.

Lynch M and Woolgar S (eds.) (1990) Representation in Scientific Practice. Cambridge: MIT Press. Manning P K (2008) The Technology of Policing: Crime Mapping, Information Technology, and the Rationality of Crime Control. New York/London: New York University Press.

Merschbacher A (2018) Sicherheitsfibel. Wiesbaden: Springer Vieweg.

Mols A and Pridmore J (2019) When Citizens Are "Actually Doing Police Work": The Blurring of Boundaries in WhatsApp Neighbourhood Crime Prevention Groups in the Netherlands. Surveillance \& Society 17(3-4): 272-287.

Monmonier M (1991) How to Lie with Maps. Chicago: University of Chicago Press.

Paulsen D J (2004) To Map or Not to Map: Assessing the Impact of Crime Maps on Police Officer Perceptions of Crime. International Journal of Police Science E Management 6(4): 234-246. 
Pinch T J and Bijker W E (1984) The Social Construction of Facts and Artefacts: Or How the Sociology of Science and the Sociology of Technology Might Benefit Each Other. Social Studies of Science 14(3): 399-441.

Ratcliffe J (2000) Implementing and Integrating Crime Mapping into a Police Intelligence Environment. International Journal of Police Science \& Management 2(4): 313-323.

Rengert G and Pelfrey W V (1998) Cognitive Mapping of the City Center: Comparative Perceptions of Dangerous Places. In Weisburd D and McEwen T (eds.) Crime Mapping and Crime Prevention. Monsey: Willow Tree Press, 193-218.

Renn O (2006) Risk Communication - Consumers between Information and Irritation. Journal of Risk Research 9(8): 833-849.

Santos R B (2013) Crime Analysis with Crime Mapping. Thousand Oaks/London/New Delhi/Singapore: Sage.

Santos R B and Taylor B (2014) The Integration of Crime Analysis into Police Patrol Work: Results from a National Survey of Law Enforcement Agencies. Policing: An International Journal of Police Strategies \& Management 37(3): 501-520.

Schreiber V (2011) Fraktale Sicherheiten: Eine Kritik der kommunalen Kriminalprävention. Bielefeld: Transcript.

Shapiro A (2019) Predictive Policing for Reform? Indeterminacy and Intervention in Big Data Policing. Surveillance \& Society 17(3-4): 456-472.

Sjöberg L (1998) Worry and Risk Perception. Risk Analysis 18(1): 85-93.

Spiller K and L'Hoiry X (2019) Editorial: Visibilities and New Models of Policing. Surveillance \& Society 17(3-4): 267-271.

Taylor B, Kowalyk A and Boba R (2007) The Integration of Crime Analysis into Law Enforcement Agencies: An Exploratory Study into the Perceptions of Crime Analysts. Police Quarterly 10(2): 154-169.

Wallace A (2009) Mapping City Crime and the New Aesthetic of Danger. Journal of Visual Culture 8(1): 5-24.

Walsh J P and O'Connor C (2019) Social Media and Policing: A Review of Recent Research. Sociology Compass 13(1): 1-14.

Weisburd D and McEwen T (eds.) (1998) Crime Mapping and Crime Prevention. Monsey: Willow Tree Press.

Wood D (1992) The Power of Maps. New York/London: Guilford Press.

Worden R E and McLean S J (2014) Police Discretion in Law Enforcement. In Bruinsma G and Weisburd D (eds.) Encyclopedia of Criminology and Criminal Justice. New York: Springer, 3596-3607.

Zurawski N and Czerwinski S (2008) Crime, Maps and Meaning: Views from a Survey on Safety and CCTV in Germany. Surveillance \& Society 5(1): 51-72. 


\section{Chapter 7}

\section{Patrolling risk}

Crime risk has at this point already been on a remarkable journey. Its underlying data have been created, amended, and algorithmically processed. Outcomes from the analytical process have been discussed, double-checked, and confirmed. Visualization has located risk within space and time and made it tangible and relatable for different audiences. Operational measures have been recommended and communicated to local police stations. In a final step, crime risk has been disseminated to the patrol officers whose task it is to bring it into being through their actions in the streets. It makes little sense to estimate risk if it is not followed up by operational measures that have the capacity to affect criminal activity in one way or another. And patrol officers are the key actors in this final translation step.

One might expect that the translation of crime risk into patrol practices would be a relatively straightforward operation. After all, it is widely believed that police organizations are characterized by hierarchical structures and a clearcut chain of command (Bordua and Reiss, 1966; Manning, 1992b). In other words, patrol officers will do as their supervisors tell them to. A closer look at the structures and occupational cultures of police work, however, reveals a slightly different picture. Although police organizations might, in general, favor hierarchy and orders, the patrol must be considered a special case. Throughout their historical evolution, patrol activities have always been characterized by a considerable degree of discretion (Brown, 1981; Ericson, 1982; Worden and McLean, 2014). Patrol officers, within certain limits, are free to carry out their tasks as they see fit, based on their individual and professional evaluations. This includes decisions about where to patrol and whether and how to apply rules in interaction with citizens.

Predictive policing contradicts this freedom, as it binds the work of patrol officers to clearly defined spatiotemporal parameters. As we will show throughout this chapter, it thus potentially interferes with a central element of the occupational culture of patrol officers. When additionally read against the backdrop of the police's historical reluctance to embrace new technologies and reform that we discussed in Chapter 3, there is reasonable concern at the level of police managers and senior officers that the last translation step in predictive 
policing could turn out to be particularly difficult. In other words, in order to make sure that crime risk will not simply be ignored by patrol officers in their daily work practices, police departments need to make sure that they get their personnel "on board". In Germany and Switzerland, the need to convince officers of the meaningfulness of predictive policing is especially pertinent, as tracking of patrol cars is not allowed - due to privacy and data protection legislation, but also due to the resistance to workplace surveillance by police unions. There is thus virtually no way to check on the implementation of risk areas into actual patrol work.

This chapter first looks at the historical evolution of the patrol, highlighting the conflict between patrol officers' discretionary power on the one hand and tendencies toward surveillance, measurement, and quantification of patrol activities on the other hand. Based on our empirical research, it then retraces the difficulties that police departments faced in convincing their staff of the meaningfulness of predictive policing. Finally, it engages the question of whether predictive policing changes the relations that patrol officers form with their environment. Does the notion of criminal futures increase suspicion? Are risk areas policed differently? And if so, what do patrols look for in order to potentially prevent crime? As will become apparent, these questions are not easily answered - if it is possible to answer them at all. Apart from the subjective and idiosyncratic views and actions of individual officers, in everyday practice, predictive policing is not clearly distinguishable from "normal" patrol work, and attention to risk areas competes with numerous other tasks that might at times have priority over burglary prevention measures. It does, however, add an element of extra attentiveness and might thus aggravate existing modes of producing deviance and suspicion in relation to space.

\section{Patrolling as a fundamental police technique}

In order to understand the role and status of patrol work within police organizations, it is helpful to place it within larger historical trajectories of policing. The patrol is in fact one of the oldest and arguably most fundamental techniques of modern police work (Read, 1987; Emsley, 1991). Kelling et al. (1974) have famously framed it as the "backbone of police work". It can broadly be defined as

making uniformed police as visible as possible (e.g., using uniforms and marked vehicles on "random" patrol) on the streets and in other public areas to create a sense of police presence sufficient to deter potential wrongdoers from committing offenses and disturbances and to enable police to respond quickly to developing problems and crimes in progress.

(Mastrofski and Willis, 2010: 81)

As this definition illustrates, the patrol serves several key functions. First of all, it makes police work broadly visible to the public. It is the part of police work 
that citizens get to see in their everyday lives, and for many of them, seeing police patrols will also be the only form of relation they will have to the police. Directed at the population, the effect of police presence is thereby considered as reassurance that the police are actively maintaining public order. At the same time, the presence of patrol officers also creates an informal interface for interactions between the police and citizens.

Of course, police presence is anything but a straightforwardly positive matter that will be welcomed by everyone. Rather, depending on the image and perception of the police within the population, police presence must be understood as an ambivalent practice likely to spark different reactions that depend on trust and confidence in the police (Jackson and Bradford, 2010; Tyler, 2011; Cao, 2015). These factors tend to vary considerably across communities and individuals. In other words, whereas for those who have trust in the police as an institution and its practices, a patrol car or uniformed officers will be a welcome sight, others might be less pleased by police presence in their neighborhood (Tyler, 2005; Macdonald and Stokes, 2006; Miles-Johnson and Pickering, 2018). Particularly minority communities have historically expressed (and continue to do so) mistrust in the police as an institution, their representatives, and the work they do (Hagan et al., 2005; MacDonald et al., 2007; Zack, 2015). Questions of trust must also be understood in close connection with overpolicing and underpolicing. While some might see a strong police presence in a neighborhood as evidence that the police care, others might feel threatened by it. Particularly in countries or cities with homogeneous yet segregated neighborhoods, such issues are inextricably entangled with the question of whether different social groups are policed differently (Crowther, 2004; Perry, 2006; Weitzer, 2017).

The second function of police presence through patrolling is directed at (potential) offenders. The patrol is considered "the most elemental crime prevention technology" (Shapiro, 2019: 458), and this elemental character is strongly reflected in predictive policing and other crime analysis techniques that seek to direct patrols to spaces where deterrence might be more necessary and potentially more successful than in other areas. As we discussed in Chapter 2 , the idea that a visible police presence on the streets can prevent crime is grounded in assumptions about rational offender behavior. "Target hardening" in the form of police patrols is considered to increase the risk of detection and arrest, thus making crime less rewarding for potential offenders. If patrolling in this sense can - at least partially and potentially - be understood as a protective measure against crime, then this protective measure should in principle be equally distributed across space (Mastrofski and Willis, 2010: 85). Where to patrol is thus a question of justice as much as it is a question of effectiveness and efficiency. We will return to questions of distribution and fairness again in Chapter 9.

Not least, police presence has an effect on the detection of crime. Since, as Manning (1972: 234) has put it, "crime is, above all, a function of the resources 
available to know it", in areas with a strong police presence, disproportionately more crime tends to be detected by patrols. More detection means, however, that the overall numbers will paint overpoliced neighborhoods as more "dangerous" or "vulnerable" than might actually be the case. Overrepresentation of a certain area in police data might in turn lead to a subjective and/or analytical perception of that area as a crime "hot spot" and trigger even more police presence in response. We will also take up these questions in more detail in Chapter 9.

The patrol not only is a technique of creating and leveraging visibility for different purposes but must also be understood as an internal managerial technique that the police use in order to compartmentalize space for the distribution of resources. It enables them to relate to the world and act within it in a planned and structured fashion. The patrol as a managerial technique speaks directly to how the police perceive the world in terms of differentiated spatial fragments that are characterized by their own threats and vulnerabilities. The patrol is for the police constitutive of the world insofar as it continuously transforms the world through interaction with it. In the words of Shapiro (2019: 457), the patrol can be understood as "an assemblage of sociotechnological mediations that enact urban geographies of authority and legitimacy, risk and danger".

Throughout its evolution, the spatializing and managerial techniques of the patrol have undergone significant transformations, and these transformations closely correspond with the ways in which the police have created knowledge about space and crime (de Lint, 2000). The original form of patrolling employed by modern police departments was the fixed-point system (Mastrofski and Willis, 2010: 81; Wain and Ariel, 2014: 276). On their patrol, officers would walk through a neighborhood and, in doing so, pass through a number of predefined checkpoints. By setting up these checkpoints, police departments were able to ensure efficient coverage of the space to be patrolled. At the same time, as the checkpoints were also linked to time stamps, they were able to monitor their patrol officers and intervene if an officer missed their waypoint for some reason - be it because of noncompliance or because they were in danger. The type of patrol resulting from the fixed-point model, although the order of the checkpoints would be varied regularly in order to not be predictable for criminals, was rather static and inflexible.

This changed radically with the widespread introduction of patrol cars and two-way radio in the 1960s (Wain and Ariel, 2014: 276; Wilson, 2018: 110). Using patrol cars, police patrols were able to cover much larger areas and move much quicker between different locations. At the same time, the ability to communicate with the station while on patrol enabled them to move through space rather freely and still be responsive to specific calls for service received by the emergency call center. As a consequence, patrols were much more independent and able to roam space in a randomized way. Random movement through space was seen as a way of distributing police presence in a more 
fine-grained fashion, making it possible to detect criminal activity that potentially would have gone unnoticed with static patrol routes (Mastrofski and Willis, 2010: 81f).

The evolution of patrolling did have some major repercussions for the work practices and occupational culture of patrol officers. Most notably, although patrolling had always been characterized by a large degree of autonomy of individual officers, randomized car patrol "leaves low-ranking officers the discretion to patrol where and how they choose when they are not otherwise assigned to respond to calls for service or administrative duties" (Mastrofski and Willis, 2010: 80). In police work, discretion primarily refers to the autonomy of decision-making that an officer has within certain parameters, including whether to apply the rules and which ones to apply (Brown, 1981; Ericson, 1982; Worden and McLean, 2014). While this was always true in "negotiated" interactions between police officers and citizens, discretionary power in combination with patrol cars and two-way radio meant that this new form of patrolling "both lessened control over patrol officers and increased their autonomy" (Wain and Ariel, 2014: 276).

A factor that had a major impact on the randomized patrol model was the increasing number of calls for service over time. What Gordon (1984) has described as "fire brigade policing" essentially means that patrols would be in constant communication with central dispatch and often more or less rush from one "fire" (i.e., emergency call) to the next in order to reactively put them out. Preventive work in the sense of simply demonstrating police presence in the streets was therefore often placed lower down the list of priorities, if not rendered impossible at all (Mastrofski and Willis, 2010: 81). This imbalance still persists today and is, as we will see, an important consideration when it comes to whether and how crime predictions can be incorporated into the work practices of patrol officers.

However, the evolution of police patrolling did not come to an end with cars and modern means of communication. Whereas randomized patrols were for a few decades considered the gold standard in patrolling and "preventive patrol in police cars was the main staple of police crime prevention efforts at the beginning of the decade of the 1970s" (Weisburd and Braga, 2006: 6), the model came under increasing pressure when several studies showed that random patrols were largely ineffective in terms of crime prevention (Kelling et al., 1974; Wilson, 1976: 96f). Against the backdrop of rising overall levels of crime, the patrol thus once more became subject to multiple reform programs, including new models such as disorder policing, community policing, problem-oriented policing, intelligence-led policing, and hot-spot policing (Mastrofski and Willis, 2010: 82; Newburn and Reiner, 2012: 818ff). As we discussed in Chapter 2, efforts to restructure crime prevention and patrol techniques increasingly gained momentum throughout the 1990s and were driven by budgetary restraints on police organizations and pressure on managerial regimes to increase effectiveness and efficiency as well as by new scientifically 
inspired methods designed to improve the understanding of the distribution of crime across space and time.

Despite concerted efforts to move toward more directed and targeted forms of police presence distribution across space, randomized patrolling remains today the most widespread method by means of which the police demonstrate presence and seek to deter crime. Crime analysis and the increasing transformation of space into differentiated segments of risk might have had some impact on how the police relate to the world and act within it, but they have not yet managed to fundamentally transform the patrol. In the words of Mastrofski and Willis (2010: 57), "the core police patrol technology has remained essentially unchanged for decades, and early police adaptions to the information technology revolution have not yet profoundly altered policing structures and processes in easily observable ways".

\section{Craft and science}

This might be changing with predictive policing. As we discussed earlier, predictive policing in principle allows for a much more fine-grained partitioning of the relationship between space, time, and crime - and it enables police departments to trace this relationship in a more dynamic fashion. This means that predictive policing enables much more flexible and timely responses to changing criminal environments. However, such responses must by their very nature be centrally coordinated. They are therefore likely to interfere with the discretionary powers of patrol officers, both in terms of where they police and how they police. A fundamental question for predictive policing is thus how it relates to entrenched working cultures of patrol officers. Wilson (2018: 117) has in this sense called for an investigation of the "impacts [of predictive policing] upon policing practice and autonomy at street-level", and Shapiro (2019: 459) has similarly hinted at the potentially fundamental transformations that risk estimates could bring to the patrol.

The central conflict is thereby usually framed as one between "craft" and "science" (Willis and Mastrofski, 2018; Wilson, 2018; Ratcliffe et al., 2020). As Willis and Mastrofski (2018: 27) have argued, "the police science movement expends more effort elevating science's virtues than considering how craft - that is the knowledge, skill, and judgment patrol officers acquire through their daily experiences - may contribute to advancing street-level patrol work". Whereas crime analysis draws its authority from data, theories, models, and algorithms, patrol officers relate to their experience, their expertise, and not least to their intuition as the necessary and irreplaceable tools for good police work. The more precise analytical prescriptions for patrols are, the stronger the devaluation of discretion and the stronger the potential clash between craft and science will be.

The idea of hot spots, broadly defining a relatively stable space with allegedly higher crime risk, still left some room for discretionary decision-making 
by patrol officers within these parameters, but predictive policing tips the scale decisively toward science as it produces fine-grained segments of space that are to be patrolled within equally fine-grained temporal parameters, thus strictly regulating how the patrol is to be carried out (Shapiro, 2019: 468). Deviance from such regulation would undermine the algorithmic production of risk and its scientific authority. As Benbouzid (2019: 11) argues, "predictive platform developers seek to solve the problem of proactivity in policing: optimizing the daily vigilance of patrols in space and time and minimizing the amount of stop and frisk in the population".

Taken seriously, predictive policing leaves little room for any spatial discretion and is therefore likely to reinforce already existing conflicts between the intangibles of human experience and intuition on the one hand and the precision of risk calculus on the other. Indeed, Ratcliffe et al. (2020: 640), in their study on police officer attitudes to predictive policing, foreground how "adopting computer algorithms is complicated by police cultures that often emphasise traditional patrol and response functions" and point out how algorithmically produced crime risk might "intrude on officers' areas of 'craft"' by favoring scientific forms of knowledge over individual expertise and discretionary decision-making. Likewise, Shapiro (2019: 460) argues that "predictive policing coopts the patrol's established surveillance mechanisms (e.g., the beat, the uniform, the prominently placed marked vehicle) while algorithmically remediating its geographies: data analytics determines optimal locales and routes for patrol circulations". Inevitably, in doing so it reorders the relationship of patrol officers to their surroundings based on data.

Predictive policing, in this sense, crucially relates to the question of how much autonomy and discretion patrol officers should be allowed and how much surveillance capacity supervisors should have in order to ensure that insights from crime analysis really become implemented at the street level. Discretion in police work has already before the advent of predictive policing been under pressure from managerial rationales and scientification tendencies, both of which prescribe the tracking and monitoring of patrol officers' activities in order to deliver on their promise of more effectiveness and efficiency. While managerial tools such as COMPSTAT as well as virtually all crime analysis approaches are predicated upon the assumption that they will help to efficiently redirect resources for police work, many police departments lack precise knowledge about the activities and whereabouts of their patrol officers in the first place. As Wain and Ariel (2014: 274f) write:

How much time is spent by police on "every" street? Where "exactly" are officers patrolling during their shifts? What "exactly" are they doing when they are out there? To what extent do police officers follow their directed patrol routes? What is the necessary dosage for special or routine police operations? Most police leaders worldwide are not in a position to answer these questions, despite technological advancements. 
Such lack of knowledge can, to a large extent, be traced to fierce resistance to location tracking and activity monitoring within the police. Police managers have praised tracking and monitoring as viable ways to improve both efficiency and accountability, but workplace surveillance is generally opposed by police officers. Research has shown that police officers more or less openly resist any kind of managerial infiltration (Marx, 2003) or micromanagement (Ericson and Haggerty, 1997) - and this is particularly true for the occupational culture of street patrols (Terrill et al., 2003; Wain and Ariel, 2014).

During our research, we found that conflicts surrounding workplace surveillance were in fact pertinent during the implementation of predictive policing software. The tracking of patrols is virtually impossible in both Germany and Switzerland, as it is strongly opposed by police unions that frame the use of GPS data as "spying" on employees (I23; I44; I46; I50; I79; I80). Moreover, it is additionally impeded by strict privacy and data protection legislation (I44; P67). As we will discuss in more detail in the following chapter, these strong safeguards against tracking and monitoring have turned out to be particularly problematic with regard to evaluation studies seeking to analyze how patrol units move throughout space with regard to predictive policing and specific risk alerts (e.g., evaluating how quickly patrols will be able to arrive at a risk area and how long they will remain there).

\section{Getting people on board}

Against the backdrop of these conflicts, we found that police departments struggled with a straightforward answer to the question whether risk areas would be effectively patrolled after all. Essentially, the lack of possible tracking of patrol activities meant that police managers, analysts, and planners needed to trust their colleagues in the streets to translate crime risk into operational measures (I09; I23; I24; I27; I78). This was particularly pertinent vis-à-vis possible internal resistance. As we discussed in Chapter 3, predictive policing is not much different from the introduction of any other technology that potentially meddles with how police officers do their job and might thus not sit well with patrol officers. There was, after all, a chance that patrol units would choose to simply ignore risk areas and continue with their regular patrol activities instead.

During our research, the conflict between institutional surveillance and micromanagement of police practices on the one hand and the discretion of police craft on the other hand was in this sense a pertinent topic. As Manning (1992a: 364) has pointed out, "as long as the power and authority to make decisions remains with the patrol officer, the most significant organizational questions lie in examining the use and response of patrol officers to this technology". In light of this situation, senior officers and analysts expressed a certain feeling of powerlessness. They had a new, potentially powerful tool at 
hand, and yet they had no proper control over its practical implementation (I02; I09; I11; I51; I46). One interviewee framed this problem as follows:

There are some people in the force who are like: "PRECOBS alert order, great, sure, I'll take care of it." And then they put the handout in their back-pocket and forget about it. I can't reach these guys. We would like to track our patrol forces, we have wanted that for a long time, but we don't get the permission.

Police departments thus needed to find ways to reconcile craft and science and to strengthen support for predictive policing among their staff. As Willis and Mastrofski (2018: 39) have argued, when it comes to the question of how to integrate the potential opposites of occupational culture and statistics, "officers need to be convinced that the practices for which there is strong supporting scientific evidence do actually work". The most intuitive and straightforward way to convince police officers of the meaningfulness of a new tool or method would be to demonstrate how it contributes to the successful fulfillment of their work tasks. This is, however, not easy when it comes to crime prevention, as prevention work seldom yields concrete results. As one respondent described it:

We send our officers into risk areas with patrol cars. Blue and silver cars, good visibility. You will understand that we won't catch a criminal by doing that. But that is deliberate.

Prevention is usually considered successful if no event materializes. A nonevent, however, is not only precisely that - literally nothing - but it also does not correspond particularly well with a police culture that is largely geared toward action (i.e., arresting criminals). As our respondents framed it, police work is often perceived, especially by patrol officers, as "hunting" (I77), and "the desire to catch criminals is engrained in police DNA" (I11). Crime prevention through police presence, though, is essentially the opposite of hunting. There is no "prey" to be tracked down and slain. Quite on the contrary, prevention is successful when no prey ever comes into sight. As such, it is a "tedious activity" (I18). One senior officer put it as follows:

Basically, our officers would rather arrest the offender. And they need to accept the fact that they are part of a system that reduces the overall burglary numbers at the end of the year. Even if they never got to see a burglar. Just because of their presence. To understand that, and to accept that - that takes some time. 
The cultural misfit of prevention work with what police work should be about from the perspective of officers is obviously not an issue that is exclusive to predictive policing. A non-event remains a non-event, independent of whether the lack of its occurrence is related to risk space or to "regular" space. With the algorithmic production of crime risk, however, the boredom of prevention work and the lack of tangible action can now be ascribed to a machine - and this machine can potentially be more easily ignored in the field (P29).

Cultural aspects are additionally aggravated by assessment criteria and career paths that are largely predicated upon measurable and countable success (I02; I18; I50; I77; I80). One senior officer vividly illustrated how crime analysis and prevention work create tensions with the need for quantification that is prevalent in police organizations:

I can't really count prevention, I don't have a way to measure it. So if I spend three hours in a residential area and nothing happens, what do I tell my supervisor back at the station? That I prevented burglaries? He will ask me for proof. My colleagues have that proof. They have confiscated three driving licenses during that time. So instead of doing prevention work, our guys prefer to conduct traffic controls. Where they can check a Mercedes Benz limousine on a main road at ten at night on a Friday, and there's a good chance that they catch a business guy who has been drinking. In fact, every other driver has probably had a bit too much to drink. Compare that to checking two Romanians sitting in a car in a residential area. Of course these two are burglars, but it takes two hours to properly search their car, to get an interpreter to be able to speak with them, and so on. And then after three hours I have to let them go. In the meantime, my colleagues recorded three instances of drunk driving, confiscated three driving licenses, and produced three blood tests. They have been busy. And what did I do? I prevented burglaries? It's a structural problem.

Another problem with prevention work based on predictive policing is that any potential success - whether tangible or intangible - can in principle no longer exclusively be considered a human achievement. A decrease in burglary numbers without predictive policing could be attributed to good individual police work, whereas a decrease in burglary numbers with predictive policing is now largely credited to the algorithm (I04). Predictive policing thus diminishes the recognition of the human work involved in translating crime risk into crime prevention. This problem bears some resemblance to the reconfiguration of workload between predictive policing software and operator that we explored in Chapter 5 - only that in the case of operational measures, the patrol officer does not even directly interact with the software that takes some (or all) of the credit for the non-materialization of crime. 
As we discussed in the previous chapter, visualization is considered a viable means of convincing patrol officers of crime risk and the need for action. The production of a handout with a map is considered a crucial way of establishing the existence of crime risk and of rendering its location within space easily intelligible and actionable. Understood as a relay of knowledge and power, visualization thus plays a key role in aligning street patrols and predictive policing, as it is considered a viable means to compel street patrol officers to restructure their patrol routes in accordance with the predicted risk areas. Our respondents pointed out that visual communication can, however, only really unfold its benefits if there is a general acceptance of algorithmic crime analysis (I02; I07; I11; I48). As one senior officer put it:

There is little sense in creating colorful images and telling our people: "OK, now you do that!" If I want to create an effect, my colleagues out there need to accept these premises, and they need to go to these areas. And our colleagues want to know why they should be doing that. There is no blind faith in technology.

Predictive policing, as we argued earlier, is largely marketed as a tool that reduces the complexity of crime analysis, as it black-boxes the actual analytical process and removes the knowledge and labor that go into the production of crime risk from sight. But as the aforementioned quote illustrates, such blackboxing can have adverse effects. Patrol officers did express the desire to at least in principle understand how predictive policing software functions in order to be able to assess its benefits for their work (I02; I11; I16; I31; I44). We found that police departments therefore put considerable emphasis on educating their patrol officers, making substantial efforts in "internal public relations" (I02) in order to foster acceptance for predictive policing among patrol officers. Some, for instance, ran internal campaigns or convened information events for their staff (I42; I44; I48; I80). Clearly, street patrols do not need the same level of detailed knowledge about data, theory, models, and algorithms that analysts need. And yet, our respondents told us that there were considerable benefits in incorporating the entirety of a department's staff into algorithmically driven crime prevention programs. One senior officer detailed how explaining things was considered in their department as a way of fostering acceptance for predictive policing:

Police officers are generally skeptical people. And when the manufacturer advertised the product, one of the main messages was: you don't need additional training for that, crime maps are intuitive. That is true, of course. But I believe that you need to understand the rationale, you need to understand the reason why you should patrol that area. Because otherwise you don't do it. A skeptical person wonders: What is the basis for this? 
Why is that one area riskier than the other? ... We need to get people on board, we need to trigger their curiosity, we need to show them the method, and we need to demonstrate the meaning.

As these considerations illustrate, there is much uncertainty around the last translation instance in predictive policing. In practice, risk-based patrolling is fundamentally reliant on trust relationships between crime analysis divisions, planners, supervisors, and patrol officers. All things considered, police departments were, however, fairly certain that their patrol forces would in fact incorporate risk alerts into their daily work (I18; I20; P27). Our respondents also pointed to the fact that the discretionary power of patrols would not imply that they were completely free in how they did their job, but that their discrete decision-making took place within defined parameters. As one shift supervisor framed it:

I mean sure, they are free to choose where they want to patrol, to a certain extent. But daily orders are clearly defined, and every single patrol unit knows that. . . . If planning and operations defines a certain area as to be patrolled, then this order stands.

The patrol officers that we spoke with largely backed the assessment that risk areas would in fact be actively patrolled. All of them more or less unanimously confirmed that they tried to incorporate risk alerts into their daily schedule if possible (I20; I21; I22; I23; I24; I25; I26; I27; I29). However, this possibility would not always be a given. Crime prevention is by no means the only task patrol officers have to perform during their time in the streets. The "fire brigade" approach to patrol work in practice means that patrol officers particularly vis-à-vis limited resources and increasing numbers of calls for service - often need to rush from one incident to another. This complicates matters for predictive policing quite a bit. Police departments usually differentiate between situations that require immediate action and situations that can be dealt with at a later point in time. If there is an emergency situation, for example a robbery or an accident with injuries, patrol forces will not be able to take a detour through a risk area on their way to the incident and deter potential burglars through their presence (P42). As one patrol officer framed problems of workload and their consequences for predictive policing:

In principle, we can integrate [risk areas] easily. It's just possible that, depending on the overall situation during the shift, nobody manages to go there. ... When you are out there in the patrol car, you can't just decide to drive into an alert area. We continuously get orders from central dispatch. And in case of doubt, PRECOBS has a lower priority. 
Predictive policing, contrary to regularly reiterated claims about efficiency that are grounded in the assumption that in order to more effectively prevent crime one simply needs to spatially rearrange existing capabilities, in fact needs a lot of street-level resources if it is to be implemented in the daily activities of patrol officers. The availability of residential burglary risk predictions does not cause the rest of police work to grind to a halt. Additionally, tasking already overworked patrol officers with the intense coverage of risk areas is in fact unlikely to yield the crime prevention practices that predictive policing prescribes. On the contrary, the availability of algorithmically produced risk estimates might actually prescribe an additional provision of resources (i.e., patrol staff) to make sure that officers will have enough free capacity to actively show increased police presence in those areas that are supposed to be more vulnerable (Leese, 2020).

\section{Policing risky spaces}

If we assume that crime risk is in principle successfully translated to the street level and gets traction within the work practices of patrol officers, the ensuing question is whether police work changes within these risk areas. In other words, do officers behave differently when there is an allegedly higher risk level? Do they perceive their environment as more "dangerous", do they act upon things that they would have otherwise ignored, and how does potentially increased suspicion play out in concrete actions? These questions are not easily answered, as they largely hinge on individual and idiosyncratic behavior and preferences. Moreover, they might not easily be attributed to predictive policing in the first place. Crime prevention in risk areas is not necessarily different from crime prevention in nonrisk areas - and risk areas might already have been covered by patrols independent of their being designated as risk areas by crime prediction software. In fact, as one senior officer admitted, police departments have little knowledge about how risk estimates influence the spatial behavior of patrols:

The question is whether [the behavior of patrol officers] changes in the first place. . . . Because it might be the case that patrol officers already intuitively react to burglaries. Our patrol officers get a briefing before each shift, they get a report on what has been going on in the previous days. They are the ones who "live" in that environment. And when they get the information that there has been a burglary or two, they might intuitively have an increased focus on that area.

Most patrol officers we spoke with agreed that predictive policing did not fundamentally change their everyday work practices. Rather, they highlighted that they would largely still be doing "regular" patrolling - admittedly, with a 
little extra attention to details, but without engaging in extraordinary activities (I24; I29; I53). This does not come as much of a surprise when we consider the job description of a patrol officer. Patrolling is to a significant extent about the perception of, and interaction with, the environment, and police officers, as Ericson (1982: 8) puts it, by default "patrol with a suspicious eye for the wrong people in the wrong places at the wrong times, reproducing a 'social penality of time and place"'.

Our respondents largely echoed this description. They often described suspicion as defined by some kind of deviance, mostly in terms of a mismatch of a person with their surroundings, thus rendering them as a "misfit" (I24; I29; I53) and therefore allegedly up to no good. As one officer framed it, patrolling means "check[ing] everyone who does not really fit into the structure of a residential neighborhood" (I42). As such, patrol work always fundamentally involves a matching process of space and its inhabitants for the sake of a subjective production of threat and vulnerability. Predictive policing does not uproot these entrenched practices. As patrol officers are trained to pay attention to "environmental misfits", most of our respondents did not explicitly differentiate between patrolling risk areas and patrolling randomly. As one patrol officer told us:

I can only speak for myself, but we generally keep our eyes open. In case we notice a suspicious person, we control them. And to be honest: I don't think that has changed. We have always done that. When we get an alert, these things are put on the agenda, and we pay particular attention to them. But otherwise we do that automatically.

Even though construction criteria of misfit and suspicion must always be understood and evaluated against the backdrop of (social) space, our respondents also regularly referred to specific ethnic groups or nationalities - mostly Eastern European - that from their perspective could be considered as "suspicious by default" (I09; P23; P24). By referring to these groups as the usual suspects for residential burglary, patrol officers made it implicitly clear that, based on their own professional experience as well as crime statistics, they already "knew" who to look for - and that they would be able to identify these persons as potential offenders even if they did not stick out so clearly from their surroundings. For our interlocutors, it was in this sense obvious that "if you see specific vehicles with Eastern European license plates, you want to have a closer look at these vehicles, check the people sitting in that car" (I24) and that "vehicles with foreign license plates - France, Romania, Bulgaria, Serbia - stick out, and then you have a closer look" (I29).

Against the backdrop of such arguably racialized and/or ethnically coded practices of suspicion and control in predictive patrolling (Egbert, 2018), there were also some pertinent legal debates around what it means to declare an 
area more risky than other areas. For instance, police departments discussed whether it would be legal to check people and vehicles without probable cause for suspicion, as the existence of risk estimates themselves would render space the defining criteria for threat and vulnerability (P28). Following a logic of "ecological contamination" (Smith, 1986: 316), residing within a risk area would then already spatially constitute a person as "risky" - independent of their activities, looks, or the license plates on their car. In the German context, such considerations must arguably be understood against the backdrop of political and legal debates around the declaration of "danger zones" with increased police competencies (Ernst, 2014; Keller and Leifker, 2017; Keitzel, 2020). We will pick up questions of space, racism, and discrimination again in more depth in Chapter 9. In the end, however, our respondents made it rather clear that predictive policing should not be put in the same category as emergency legislation and extraordinary executive powers:

We do not declare a state of emergency for a risk area. We are not allowed to check anyone and everything.

And yet, patrol officers admitted that their behavior in the streets potentially would in one way or another be affected by the knowledge that a specific neighborhood had been classified as potentially more vulnerable than other areas to burglaries. Most of them did not refer to specific behavioral changes (as in concrete actions), but rather to a sense of more attentiveness and attention to detail (I09; I22; I23; I24; I25; I27; I44). As one patrol officer framed it with regard to the information conveyed by the handout and the crime map that they received during their shift briefing: "The thing is, you know that in this area something could happen. . . And of course it makes you more attentive to all the little details" (I23). Other respondents told us that they would "drive a little slower", or "park in the shadow or in a gateway and then just observe" (I24), that they would "turn down the radio in these areas and pull down the car window, so that you can hear what is going on outside" (I23), or that their "radar [would be] just a bit more fine-tuned, more focused" (I25). Apart from such an intensification of "regular" suspicion, patrol officers would also slightly modify the ways in which they moved through space within risk areas. As one respondent framed it:

Something that's definitely different is that we pay specific attention to the small roads within the area. Drive through them, show presence. Get out of the car maybe, walk around for 15 minutes. . . . The important thing is that people see us. Which means that our target group, the burglars who might be on the prowl in that area, see us too. And they realize: "Ok, we are not alone." 
Some police departments, during the period of our research, chose to additionally supplement regular patrols in risk areas with increased community engagement activities. Although community policing is formally separated from regular patrol work, patrol officers were encouraged to actively chat with residents, ask them to be vigilant, or provide them with tips on how to protect their homes (I09; I22; I23; I24; I27). These measures, although they were usually not prioritized, were considered as a viable means to further support burglary prevention through police presence. They must be understood, in keeping with situational crime prevention theory, as an additional form of "target hardening" that can contribute to an overall reduction in burglary numbers in a risk area. One interviewee summarized their experiences with community engagement as follows:

We did a lot of community engagement - particularly in the context of prevention campaigns. We had postcards, for example, that you could drop in someone's mailbox if you saw that a window was cracked. Just to raise awareness. And the interesting thing was that we saw a certain relationship between these activities and a decrease of near repeat offenses. Not a strong one, but there was an effect.

\section{Conclusion}

As we have shown throughout this chapter, predictive policing at the level of street patrols cannot, from an analytical perspective, be neatly separated from general patrol work. Rather, from a translation angle, it must be understood as inextricably intertwined with larger trajectories of patrolling vis-à-vis society and space. Not only is the police patrol characterized by a considerable history and an occupational culture that comes with a large degree of officer discretion, but its evolution has produced a number of potential practical conflicts that render the translation of burglary risk from the abstract level of crime analysis to the concrete level of police work on the streets a challenge. Predictive policing is affected by and reflects the tensions between craft and science as well as clashes over the prioritization of patrol officers' attention vis-à-vis a multiplicity of tasks and emergencies that need to be taken care of.

Given that police departments have few possibilities to actually track and monitor the activities of patrol forces, the enactment of crime risk to a large degree hinges on trust relationships between different police divisions. As we have shown, police departments invest considerable resources in order to convince patrol officers of the meaningfulness of algorithmic risk production for the fulfilment of their daily tasks - even though there might not be a visible and tangible result of prevention work in the first place.

As predictive policing managerializes patrol space and thereby challenges the discretionary decision-making of patrol officers about where to carry out their work, it arguably also influences the spatial relationship that patrol officers 
form with their environment. The perception of space as "risk space", as we have seen, at least implicitly demands increased levels of attentiveness to detail. Predictive policing might not be fundamentally transforming the rationale of patrolling - after all, the work description of the patrol officer remains the production of deviance in the form of a perceived mismatch between a person and the environment. The explicit assignment of risk to space can, however, unfold an amplification effect on suspicion. Paired with existing prejudice, targeted patrols could thus aggravate issues of profiling and racial/ethnic stereotypes. We will take up this discussion in Chapter 9.

\section{References}

Benbouzid B (2019) To Predict and to Manage: Predictive Policing in the United States. Big Data \& Society 6(January-June): 1-13.

Bordua D J and Reiss A J (1966) Command, Control, and Charisma: Reflections on Police Bureaucracy. American Journal of Sociology 72(1): 68-76.

Brown M K (1981) Working the Street: Police Discretion and the Dilemmas of Reform. New York: Russel Sage Foundation.

Cao L (2015) Differentiating Confidence in the Police, Trust in the Police, and Satisfaction with the Police. Policing: An International Journal of Police Strategies \& Management 38(2): 239-249.

Crowther C (2004) Over-Policing and Under-Policing Social Exclusion. In Burke R H (ed.) Hard Cop, Soft Cop: Dilemmas and Debates in Contemporary Policing. Cullompton: Willan Publishing, 54-68.

de Lint W (2000) Autonomy, Regulation and the Police Beat. Social \& Legal Studies 9(1): $55-83$.

Egbert S (2018) Predictive Policing und die soziotechnische Konstruktion ethnisch codierter Verdächtigkeit. In Pfadenhauer M and Poferl A (eds.) Wissensrelationen: Beiträge und Debatten zum 2. Sektionskongress der Wissenssoziologie. Weinheim/Basel: Beltz Juventa, 653-663.

Emsley C (1991) The English Police: A Political and Social History. London: Longman.

Ericson R V (1982) Reproducing Order: A Study of Police Patrol Work. Toronto: University of Toronto Press.

Ericson R V and Haggerty K D (1997) Policing the Risk Society. Oxford: Clarendon Press.

Ernst C (2014) Anlassunabhängige Personenkontrollen und Gefahrengebiete. Neue Zeitschrift für Verwaltungsrecht 33(10): 633-637.

Gordon P (1984) Community Policing: Towards the Local Police State? Critical Social Policy 4(10): 39-58.

Hagan J, Shedd C and Payne M R (2005) Race, Ethnicity, and Youth Perceptions of Criminal Injustice. American Sociological Review 70(3): 381-407.

Jackson J and Bradford B (2010) What Is Trust and Confidence in the Police? Policing: A Journal of Policy and Practice 4(3): 241-248.

Keitzel S (2020) Varianzen der Verselbstständigung der Polizei per Gesetz: "Gefährliche Orte" im bundesweiten Vergleich. Kriminologisches Journal 52(3): 191-209.

Keller N and Leifker M (2017) Gefahrengebiete. In Lemke M (ed.) Ausnahmezustand: Theoriegeschichte - Anwendungen - Perspektiven. Wiesbaden: Springer VS, 243-255.

Kelling G L, Pate T, Dieckman D and Brown C E (1974) The Kansas City Preventive Patrol Experiment: A Summary Report. Washington, DC: Police Foundation. 
Leese M (2020) “Mehr mit weniger"? Warum Predictive Policing nicht automatisch Effizienzgewinne bedeutet. In Bode F and Seidensticker K (eds.) Predictive Policing: Eine Bestandsaufnahme für den deutschsprachigen Raum. Frankfurt am Main: Verlag für Polizeiwissenschaft, 249-260.

Macdonald J and Stokes R J (2006) Race, Social Capital, and Trust in the Police. Urban Affairs Review 41(3): 358-375.

MacDonald J, Stokes R J, Ridgeway G and Riley K J (2007) Race, Neighbourhood Context and Perceptions of Injustice by the Police in Cincinnati. Urban Studies 44(13): 2567-2585.

Manning P K (1972) Observing the Police: Deviants, Respectables, and the Law. In Douglas J D (ed.) Research on Deviance. New York: Random House, 213-268.

Manning P K (1992a) Information Technologies and the Police. Crime and Justice 15: 349-398.

Manning P K (1992b) Technological Dramas and the Police: Statement and Counterstatement in Organizational Analysis. Criminology 30(3): 327-346.

Marx G T (2003) A Tack in the Shoe: Neutralizing and Resisting the New Surveillance. Journal of Social Issues 59(2): 369-390.

Mastrofski S D and Willis J T (2010) Police Organization Continuity and Change: Into the Twenty-First Century. Crime and Justice 39(1): 55-144.

Miles-Johnson T and Pickering S (2018) Police Recruits and Perceptions of Trust in Diverse Groups. Police Practice and Research 19(4): 311-328.

Newburn T and Reiner R (2012) Policing and the Police. In Maguire M, Morgen R and Reiner R (eds.) The Oxford Handbook of Criminology. Oxford: Oxford University Press, 806-837.

Perry B (2006) Nobody Trusts Them! Under- and Over-Policing Native American Communities. Critical Criminology 14(4): 411-444.

Ratcliffe J, Taylor R B and Fisher R (2020) Conflicts and Congruencies between Predictive Policing and the Patrol Officer's Craft. Policing and Society 30(6): 639-655.

Read D (1987) Peel and the Victorians. Oxford: Blackwell.

Shapiro A (2019) Predictive Policing for Reform? Indeterminacy and Intervention in Big Data Policing. Surveillance \& Society 17(3-4): 456-472.

Smith D A (1986) The Neighborhood Context of Police Behavior. In Reiss A J and Tonry M (eds.) Communities and Crime. Chicago/London: University of Chicago Press, 313-342.

Terrill W, Paoline E A and Manning P K (2003) Police Culture and Coercion. Criminology 41(4): 1003-1034.

Tyler T R (2005) Policing in Black and White: Ethnic Group Differences in Trust and Confidence in the Police. Police Quarterly 8(3): 322-342.

Tyler T R (2011) Trust and Legitimacy: Policing in the USA and Europe. European Journal of Criminology 8(4): 254-266.

Wain N and Ariel B (2014) Tracking of Police Patrol. Policing: A Journal of Policy and Practice 8(3): 274-283.

Weisburd D and Braga A A (2006) Introduction: Understanding Police Innovation. In Braga A A and Weisburd D (eds.) Police Innovation: Contrasting Perspectives. Cambridge: Cambridge University Press, 1-24.

Weitzer R (2017) Theorizing Racial Discord Over Policing Before and After Ferguson. Justice Quarterly 34(7): 1129-1153.

Willis J J and Mastrofski S D (2018) Improving Policing by Integrating Craft and Science: What Can Patrol Officers Teach Us about Good Police Work? Policing and Society 28(1): $27-44$. 
Wilson D (2018) Algorithmic Patrol: The Futures of Predictive Policing. In Završnik A (ed.) Big Data, Crime and Social Control. London/New York: Routledge, 108-127.

Wilson J Q (1976) Thinking about Crime. New York: Basic Books.

Worden R E and McLean S J (2014) Police Discretion in Law Enforcement. In Bruinsma G and Weisburd D (eds.) Encyclopedia of Criminology and Criminal Justice. New York: Springer, 3596-3607.

Zack N (2015) White Privilege and Black Rights: The Injustice of U.S. Police Racial Profiling and Homicide. Lanham/Boulder/New York/London: Rowman \& Littlefield. 


\section{Does it work, though?}

Throughout the preceding chapters, we have zoomed in on the sociotechnical labor that is involved in the prediction and possible prevention of criminal futures. We have witnessed a plethora of contingencies, choices, frictions, and even contradictions that come to the fore once predictive policing software forms relations with the larger organizational and practical trajectories of police work. We have highlighted the constructedness of data and questions of visualization and representation, the multiplicity of temporalities that emerge when addressing the future, and the different ways in which crime predictions can be communicated or muted. The question that we have largely bracketed so far is: Does predictive policing actually work?

There is no definite answer to this question. A number of methodological issues make it almost impossible to sufficiently prove causal effects of targeted patrols and other prevention measures on the occurrence of crime. These epistemic difficulties are reflected in the existing literature. Only a few empirical studies have so far attempted to systematically evaluate the effects of predictive policing, and they have come to contradictory conclusions. While Mohler et al. (2015) found that patrols based on algorithmic crime predictions led to a reduction in crime rates when compared to patrols that were not based on software forecasts, the Shreveport Predictive Policing Experiment conducted by Hunt et al. (2014) found no evidence that crime was reduced in districts that were patrolled using predictive policing methods.

The evaluation study of the PRECOBS trial run in the German state of Baden-Württemberg hints at indicators for an effect of predictive policing patrols on residential burglary numbers but refrains from making causal claims (Gerstner, 2017, 2019). Similarly, evaluation studies on the SKALA and PreMAP software packages have come to the conclusion that an effect of predictive policing could not be statistically proven (Landeskriminalamt Niedersachsen, 2018; Landeskriminalamt Nordrhein-Westfalen, 2018b). Visà-vis such a doubtful empirical basis, Gluba (2020) even goes as far as to claim that predictive policing is to a large extent underpinned by a "belief" that the method will work rather than by actual proof. 
This chapter explores the question of whether predictive policing works through the perspective of police departments themselves. We retrace how "success" was framed as a key variable during the implementation of predictive policing and how police departments struggled to provide evidence for such success. We then look into how, through a redefinition of success criteria, formal evaluation procedures were in many cases able to nevertheless present predictive policing as a valuable contribution to crime prevention that should be continued rather than prematurely dismissed due to a lack of "hard proof". In fact, when faced with the decision whether to keep using predictive policing software after an initial trial phase, all the police departments we studied decided to stick with it in principle - independent of concrete software packages, models, or targeted types of crime.

\section{The importance of success}

There are several reasons why it is important for the police to demonstrate that predictive policing works - the most obvious one arguably being the general political salience and agenda-setting capacities of high-crime rates (Wilson, 1976; Pritchard and Berkowitz, 1993; Beckett, 1994). Throughout almost all German and Swiss federal states, a continuous increase in residential burglary rates - with a spike in 2012 - put the fight against this particular type of crime high on the political agenda, and governments felt the need to address the issue, thus creating a link between crime numbers, politics, and potential police reform (Egbert, 2018). The political prioritization of burglary prevention must additionally be understood in the context of news media reports and their influence on the public perception of crime (Schlesinger et al., 1991; Ericson, 1995; Holbrook and Hill, 2005). With regard to unusually high residential burglary numbers, some media outlets used fear-mongering framings such as a "failing state" (Krauel, 2013; Elflein et al., 2014) and recommended that citizens should "protect themselves" as the police would not be able to protect them (Budras, 2015). Overall, the blame for high crime levels was largely attributed to the inactivity or inadequate actions of the police, and this increased the pressure on politicians and on police departments themselves to demonstrate that they were actively tackling the issue.

As we discussed in Chapter 2, the turn to predictive policing must, vis-àvis the political situation at the time, be understood as an allegedly easy way to more effectively address residential burglary and bring the numbers down quickly. PRECOBS, though still in its infancy, was readily available as an offthe-shelf commercial product and was presented as a straightforward solution to a pressing problem (Gluba, 2014; Schweer, 2015b, 2015a). Moreover, many police departments had already been experimenting with approaches to crime analysis that went beyond the mere mapping of static hot spots and/or were in the process of modernizing their IT infrastructures and data handling processes 
and were thus in a position to integrate predictive policing software as an additional tool for crime analysis and crime prevention right away (I02; I26; I80).

However, as we discussed in Chapter 3, the media discourse and the political agenda, while opening up a window of opportunity for a rapid implementation of predictive policing, did not necessarily provide a supportive environment for carefully planned and methodologically sound testing of new software tools. An apt example is one German state, where residential burglary numbers had increased by 80\% between 2007 and 2012 (I38; for similar experiences in other German and Swiss jurisdictions, see I31; I37; I39; I40; I78) and where the peak level coincided with upcoming elections. Naturally, politicians felt compelled to demonstrate to the electorate that they were doing something about the problem. In some cases, this led to rather overconfident political promises that predictive policing would be a quick and easy fix for burglary rates (P17). One police officer recounted how political tactics and police work against this backdrop were drawn together:

The Minister of the Interior at the time wanted to use predictive policing for his campaign. So he publicly said: "By the way, we have this new software, and the police will soon use it. We will prioritize the fight against residential burglary." And that kicked off the whole process for us.

Political pressure to introduce crime prediction software was also reinforced by parliamentary debates. Opposition parties would in some cases frame the nonuse of predictive policing software as a failure of state governments and demand the immediate implementation of available technology in the fight against domestic burglary (D161), thus creating additional pressure for immediate action.

Almost inevitably, the political activism around predictive policing caused some annoyance within the police. As predictive policing software was politically portrayed as a technoscientific miracle fix that just needed to be applied to the domestic burglary problem, police departments faced misguided and overblown public expectations about its immediate effects. Our respondents told us that they felt that an unnecessary level of pressure to rapidly produce results was put on them (I02; I13; I36; I33; P09; D089; D172). At the same time, the expectations of politicians were seldom matched by their expertise in terms of police work and crime. As one senior officer put it:

Politicians are our representatives. They are elected. But I know of no single politician, at least at the Ministerial level, who has the necessary domain knowledge [to assess how predictive policing works].

On the other hand, our interviewees also understood that governments needed to address pressing crime rates, especially when leading to such immediate 
and tangible victimization experiences as residential burglary (I07; I22; I78). One senior police officer summarized how violations of privacy and intimacy contributed to putting predictive policing on the political agenda and even legitimize exceptional budgetary commitments:

[Predictive policing software] costs a lot of money, but in order to fight residential burglary, they were happy to spend that because there was a lot of pressure from the public. The thing with burglary is that the victim is really personally affected. It's not like car theft, where you have a $99 \%$ insurance rate. I mean, some people are even happy when their car gets stolen, because then they will get a new one.

The Ministry of the Interior of one German state, in response to our inquiry concerning predictive policing within their jurisdiction, issued the following statement that vividly illustrates the link between crime rates, subjectively felt insecurity, fear of crime, and the pressure for political action to mediate the situation:

The phenomenon of residential burglary is being prioritized politically and by the police in [state]. Rising case numbers, in conjunction with the problem of "travelling offenders" and the decline of clearance rates, have negatively impacted the subjectively felt security of the population. Residential burglary violates the most private space of the victims, making them feel insecure within their own home.

Predictive policing was, however, not only perceived as a promising way to cope with the residential burglary situation by governments. Just as well, police departments themselves decided to take advantage of the political agenda and leverage the willingness of governments to spend money and accelerate processes into new competencies. Several of our interviewees foregrounded how their departments managed to "ride the wave" (I02) and to turn the political climate into unprecedented opportunities to push the boundaries with regard to data, IT infrastructures, and crime analysis (I02; I26; I79; I80). According to one police officer, the high crime numbers were in fact perceived as a windfall for innovation:

We had this [burglary] problem and we knew that we had to exhaust every possible solution. . . . Had the software been on the market five years earlier, we probably would not have been able to purchase it, because back then we did not have that problem.

This interpretation is backed up by the fact that other German and Swiss states, when at a later point in time faced with the decision of whether to start using 
predictive policing software or to expand the use of already implemented software to other cities and/or regions, were far more reluctant to do so (I41; I46). In a statement from November of 2017, one Swiss state, for example, found that there already had been "a continuous decrease in [residential burglary] numbers since 2014 . . . Therefore, the procurement of the software would not yield much added value" (I41). Several of our interlocutors also noted that after the peak in residential burglary numbers in 2012 and the ensuing political activity, the hype around predictive policing had already started to die down slightly and political attention shifted to other matters (P49; P52).

\section{Lots of pressure}

Generally speaking, the political prioritization of predictive policing had ambiguous effects on police departments. On the one hand, it bolstered budgets and provided a window of opportunity for police departments to tinker with new methods and technoscientific tools. On the other hand, the framing of predictive policing as a "strategic goal" (I18) in the fight against residential burglary put pressure on the police in a number of different ways. First of all, as we have already briefly discussed in Chapter 3, things needed to move a lot faster than usual. In almost all the jurisdictions covered by our research, governments pushed police agencies to initiate research projects and/or trial runs as quickly as possible (I04; I12; I26; I36; I42; I44; I45; I79; I80; P30; P44) - up to the point that police departments felt rushed and only partially prepared for a systematic approach to implementation. As one senior officer recalls:

The project was just really political, it was initiated very quickly, and we had no chance to prepare our people for what was coming. I wasn't really prepared either. The order was: "We start next week".

This "time pressure" (I43) put police departments in a position where they had to choose either to purchase off-the-shelf commercial software (with the only readily available tool at the time being PRECOBS) or to get their own R\&D projects off the ground without adequate preparation in terms of data and infrastructure but also in terms of qualified and available personnel. Notably, in various instances, governments demonstrated a willingness to fast-track field tests, development, and/or procurement of software packages, coupled with a willingness to make adjustments later on should they turn out to be necessary (I02; I03; I11; I16; I17; I48; I57).

The initial time pressure, once predictive policing was up and running, then turned into what one police officer framed as "innovation pressure" (P28). Being given the political carte blanche to experiment with data and different theoretical approaches and models, police departments were put in a position where the results from predictive policing experiments would almost by default 
have to demonstrate that what they were doing was indeed innovative and would present an unprecedented and new way to address the age-old problem of domestic burglary (Hessisches Ministerium für Inneres und Sport, 2016). After all, politicians had already promised that predictive policing would be the technoscientific remedy for what was troubling the population (Egbert, 2018). Established criminological knowledge, according to the prevalent imaginary, could now be infused with data and algorithms and thus be mobilized in novel ways - a combination that had already proven to be effective in other domains of public administration and police work (Hauber, 2019).

Last, but not least, police departments experienced what could be best described as peer pressure. As some early adopters had already started to work with predictive policing software, and in doing so had generated considerable attention from the media and the public, other - particularly neighboring jurisdictions suddenly needed to explain why they were not using such presumably cutting-edge technoscientific methods as well (P13). As one police officer described the justification ripple effects that were created once predictive policing went "live" in the first jurisdictions:

With [police technology], it's the same thing everywhere. Zurich started the trend. And then Bavaria quickly followed. The guys in Bavaria had in fact been preparing for something like this for a long time and had just waited for an opportunity to put it into practice. . . And that put a lot of pressure on other states and cities, because they saw that everyone around them was implementing and using predictive policing systems.

The logic at play here is of course the very same one that compelled governments and police departments to look into predictive policing in the first place: high levels of crime leading to public demand for effective countermeasures, which in turn led to governments prioritizing new approaches to crime prevention, thereby enabling police departments to make use of the latest technological tools. Now, though, the pressure was additionally aggravated by comparisons with other states and cities (I13; D054; D161). One senior officer described the peer pressure effects among police departments in different jurisdictions as follows:

I'm convinced that when other Swiss cantons all of a sudden have to deal with a burglary problem, they will feel the pressure. And they will be asked why they don't have that software that the others are using. And what's the argument then? To say that they don't need it? That's going to be tough to justify.

These diverse pressures were aggravated still further by the media hype surrounding predictive policing. Especially in 2014/15, when predictive policing 
software had already been fully implemented or was subject to ongoing research projects or trial runs, some police departments were almost overrun by media inquiries (I02; I07; I16). And while media coverage presented a welcome opportunity for the police to demonstrate that they were actively pushing the boundaries in the fight against residential burglary, our informants told us about several instances where they felt predictive policing was seriously misrepresented by journalists. Common themes were that media reports would conflate the spatiotemporal approaches to predictive policing used by German and Swiss police departments with profiling, mass surveillance, or science fiction works such as Minority Report (I44; I45; I80). Generally, police officers complained about the lack of adequate detail and contextualization of predictive policing in media accounts - something they attributed to the ignorance of journalists as much as to media formats and the attention economy. One senior officer recounted the following anecdote that vividly illustrates how harshly the lifeworlds of the police and journalists clashed at times:

These media types came to us with a crystal ball. They wanted footage with a crystal ball. It was impossible to get that out of their heads. We told them we wanted nothing to do with crystal balls. We use mathematical formulas, it's calculus. If we put ten smart colleagues to the task, they could do the same thing. But no: crystal ball. They had the crystal ball in mind, and they wanted to use that as a selling point for their story.

While the use of actual crystal balls is certainly an extreme example, our interlocutors also told us about cases where police representatives would be interviewed for 20 minutes, but only the very last sentence from the interview would end up as part of the eventual TV feature - and this would be the part where they stated that they could not tell whether predictive policing actually prevented burglaries. The footage where they explained the intricacies of crime prevention and why it is so difficult to establish statistical proof for causal effects would be cut entirely (I07; I44). Even though our respondents showed some understanding for the news media perspective that needs to look for an angle and come up with a catchy headline (I36), at that time some police departments became quite cautious when speaking with the media and even got advice from their internal police PR divisions about what could be said publicly (I07). In the end, most of our respondents who had been featured in various media outlets came to similarly unfavorable conclusions about the journalistic coverage of predictive policing. One senior officer summarized the verdict as follows:

That media hype had some really negative effects on our work. All of a sudden, [predictive policing] was portrayed as the ultimate solution. And of course, we said that this is exactly what it is not. It is a supplement to what we have been doing already. But nobody wanted to hear that. So 
yeah, that was a problem for us. That created certain expectations that such systems can never meet, never mind which specific software application we are talking about here.

Last, but not least, demonstrable success of predictive policing was also considered a key requirement for the police force itself. As we discussed in Chapter 3, new police strategies, tactics, or technologies are often met with skepticism. This is particularly the case when they have the potential to unsettle established work practices, foster organizational restructuring, and thus force police officers out of their comfort zone. Resistance to the introduction of new technoscientific tools is not unusual and can, for example, lead to the nonadoption of new analytical tools or simply to ignorance about new types of knowledge that are produced by these tools.

In summary, political prioritization of the fight against residential burglary not only opened a window of opportunity for the police to put novel approaches and tools to practice but also generated a considerable number of interlinked pressures on police departments. The level of attention that predictive policing was subjected to forced police departments to continually demonstrate to governments, the media, and not least, the general public that they, as one police officer framed it, "tried everything to get on top of the burglary problem, to push the numbers down. Not just in terms of personnel, but also in terms of infrastructure, software, organization, everything" (I79). For the police, the ultimate way to prove that what they were doing was not a waste of taxpayers' money would be to find a way to demonstrate that predictive policing had an actual, causal effect in terms of declining burglary rates. This turned out be rather problematic, however.

\section{Epistemic uncertainties}

The key assumption behind predictive policing is that custom-tailored crime prevention measures based on data-based prediction methods and resulting spatiotemporal risk estimates should, if properly translated into operational prevention measures, lead to less crime - which can then be equated with the successful implementation of the approach. The question is, however: How can "hard evidence" for success be conceptualized and demonstrated? Usually, evidence for any kind of new policy or tool would be presented in the form of statistics that show a significant and robust relationship between the measure and the desired goal. In the case of predictive policing, however, it is not clear exactly what should be considered success in the first place. Moreover, epistemic uncertainties render the measurement and statistical demonstration of success criteria rather difficult. During our research, we found that police departments were in fact struggling with the production of statistical evidence for the successful application of predictive policing methods. 
In the best case scenario, in order to statistically measure the impact of predictive policing one would need to conduct a study in an experimental setting that is both randomized and controlled. Only such a setting would make it possible to eliminate selection bias and intervening variables and thus establish causal relations between the independent and dependent variable (i.e., between patrolling based on risk estimates and variation in residential burglary numbers). To do so, one group would need to receive the treatment - that is, a selection of geographical areas (districts, neighborhoods, or streets) would need to be patrolled based on algorithmic crime predictions. Another group, the control group, would not receive this treatment. Not receiving the treatment could, for example, mean that the control group would be patrolled in a nondirected, random fashion (Hunt et al., 2014). It could, however, also mean that the control group would be patrolled on the basis of human analysts' recommendations, as opposed to algorithmic calculations (Mohler et al., 2015). At the end of the experiment, crime statistics from the treatment and the control group could be compared, and variation in crime numbers between the groups could be attributed to the treatment, thus establishing statistical evidence that targeted patrols did or did not lead to declining burglary numbers.

The problem is that experiments in real-life social settings face a number of constraints (Harrison and List, 2004). Not only is it practically and ethically questionable to run experiments on public service provision, especially when this public service is security (Mohler et al., 2015: 1400), but it is also very difficult to properly randomize studies on predictive policing due to the idiosyncrasy of space. The idea behind randomization is that the overall sample covered by a study could be randomly distributed among the treatment group and the control group so that each element of the sample has an equal chance of being part of either the treatment or the control group. Running the same experiment with different randomized treatment/control groups and replicating the findings then ensures the robustness of the results. While this can be achieved in a straightforward fashion in a controlled laboratory setting, it does not easily translate to the real world. There is a lot of variation among cities, districts, neighborhoods, and even streets, which makes it difficult to create reliable treatment and control groups from them. They differ in topology, infrastructures, architecture, and the sociodemographic characteristics of their population. Most importantly, however, they differ with regard to the occurrence of criminal activity. As Mohler et al. (2015: 1401) put it, "crime problems of one region are never strictly equivalent to those of another region". This puts severe constraints on randomization as a key principle of statistical reasoning.

Moreover, it is almost impossible to run a social experiment in a controlled setting. Ideally, one would need to keep stable all variables that could have any effects on the dependent variable (i.e., crime statistics), except for the actual treatment variable (i.e., predictive policing). In this way, the measured effect could then be attributed to the treatment alone, and distortion by one or more 
intervening variables could be ruled out. Again, such a setting can be realized comparatively easily in a laboratory environment where possibly interfering factors can be controlled for. However, complex real-world social settings with lots of uncontrollable dynamics present a major challenge for an evaluation of predictive policing effects. One police officer vividly illustrated what dynamic live environments mean for a possible attribution of causal effects:

Let's say we have a risk area, effective from today. Then we increase patrols in this neighborhood. And when the burglar gets there, he will be observed by our PRECOBS forces and they watch him entering and exiting a house, and they arrest him. PRECOBS success. We had that two or three times. It becomes more difficult however when the neighbor hears suspicious noises coming out of the apartment, and he calls the police and tells us: "I think someone broke into my neighbor's apartment." Now remember: this happens during a PRECOBS alert, and maybe we also have several regular patrol units nearby. Then the whole thing turns into a service call issue. We inform our patrols, they drive over there, see how the burglar exits the house, and they arrest him. Had there not been a PRECOBS alert, the service call would still have happened. The patrol would still have responded. Maybe they would have arrived 30 seconds later, who knows. So is the success due to PRECOBS or not? Hard to tell.

In a controlled setting, there would not have been a vigilant neighbor. Depending on the study design, there might not have been a regular, random patrol in the area either. There would only have been a designated risk area patrol - and had that patrol caught the offender red-handed, this could have been directly attributed to algorithmic calculations and operational crime prevention measures based on the risk estimate. These measures, however, could have included additional activities besides patrolling. There could have been additional plainclothed forces, or traffic controls, or maybe the police would have run a prevention campaign that made residents more aware of burglary risks. The fact that crime prevention is not one single measure but often consists of a multiplicity of parallel activities that could create interaction effects presents a major challenge for the assessment of predictive policing. One of our interlocutors described this constellation in the following words:

Measuring the effect of preventive work is generally very difficult, particularly when several prevention measures are active at the same time. And that was the case with PRECOBS. So we had community engagement officers who went from door to door and informed people about technical access protection, and why this would be a good idea at the moment. And PRECOBS analyses and targeted patrols ran simultaneously. And then we arrested someone because they attempted a burglary but failed. Did they 
fail because of upgraded access protection or because of PRECOBS? You simply cannot tell what the reason was. We would need to run a study where we have one single preventive measure and an identical control group without that preventive measure. ... Very difficult.

The fact that it is extremely difficult to set up conditions under which the effects of predictive policing could be measured and analyzed does not, however, mean that this would be completely impossible. Coincidentally, the extraordinarily high numbers of migrants and the temporarily open borders of the European Union in 2015 had created a situation that at least resembled an experimental setting and provided the police with argumentative ground for the success of what they were doing. As one senior police officer recalled:

We had that whole refugee situation in the fall of 2015, quite massively in [city]. And the support forces that we usually assign for PRECOBS were not available because they were dispatched to help out with the refugee situation. And so what happened was the following: PRECOBS kept on producing alerts that indicated the risk of near repeats. And all of them actually happened. During that period we had a significant increase in residential burglaries in [city]. And thank God that happened. I mean every burglary is one too many, but that was just the right thing with regard to methodology, because it demonstrated: if you take away the forces that are usually on patrol, then all of a sudden there's crime again in these areas.

Evidence from this situation would need to be considered anecdotal at best. It does, however, foreground normative issues in studying the effects of predictive policing. Producing a situation like the one described would create severe ethical concerns. As we discussed in Chapter 7 and will pick up again in Chapter 9, police presence and crime prevention should for the sake of justice in principle be more or less equally distributed. The police's mandate prescribes the protection of the entire population and a deliberate exposure of selected subgroups (i.e., neighborhoods or streets) to less crime prevention and thus higher risk should therefore be ruled out.

More epistemic trouble with regard to predictive policing and crime prevention is caused by possible displacement effects (Gabor, 1981; Cornish and Clarke, 1987). Based on the same assumption of rational actor behavior that underpins crime prevention theories, crime displacement theory assumes that prevention measures will not actually prevent the occurrence of crime in the first place but simply push criminals to other geographical areas where no (or at least fewer) prevention measures are in place (Bowers et al., 2011; Johnson et al., 2014). Moreover, the likelihood of displacement effects will, under the assumption of a rationally acting criminal, increase when the knowledge base 
for crime prevention is made publicly available. Our interviewees in fact suspected that media reports about predictive policing software could have rendered other jurisdictions (spatial displacement), times (temporal displacement), or types of offences (offence displacement) more attractive (I02; I03; I06; I07; I36; I41; I43; I44; I76; I77; I80). The following statement illustrates how this turned out problematic for the question of whether the success of predictive policing could be proven:

It's easy to say [that burglary numbers go down] because we dispatch more patrols. But we will probably never know what the real reason was. When the "opposing party" notices what is going on, that we increase patrols after a reported burglary . . . that could be a reason why we don't get so many near repeats. That they have done their research. It has been in the media a couple times.

Measuring potential displacement effects is not easy, and during our research, no evidence for actual displacement effects was available. In fact, crime statistics in neighboring jurisdictions with no predictive policing measures did not show sudden or unusual increases in residential burglary activity, thus implying that predictive policing did not produce any measurable spatial adjustments in residential burglary activity (I02; I16; I48). The apparent lack of spatial displacement was thereby largely attributed to the "sunk costs" that professional criminal behavior produces - that is, that burglars need to invest considerable time and resources to scout particular neighborhoods and that in case these neighborhoods should become subject to increased police presence and other target hardening measures, they would simply not be able to readjust their scope to other jurisdictions in a timely enough fashion (P38).

As the aforementioned statement also highlights, media coverage and the public availability of information about predictive policing activities pose another problem for the measurement of successful crime prevention. Most police departments, as we discussed in Chapter 6, did not actively disseminate information about risk areas to the public. Nonetheless, predictive policing was a pertinent topic in news media throughout our research period, both nationally and locally. In particular, local media reports about police activity in the fight against residential burglary were framed by our interviewees as ambiguous: On the one hand, they were considered welcome PR for the police's active and innovative efforts to protect the public, while on the other hand, there were concerns that such reports would also be noticed by offenders and used to their advantage (I02; I29). Professional burglars who did their research would in this sense be able to "game the system" and use an understanding of spatial patterns and near-repeat theory to restructure their activities. Equally, they could mobilize available information about trigger and anti-trigger criteria in order to adjust their modus operandi - that is, actively trying to conceal 
their work as nonprofessional in order to prevent the software from producing an alert.

Some of our interviewees also hinted at larger regional trends that could have played a role in the development of crime statistics regardless of whether or not police departments used predictive policing software. Residential burglary had more or less simultaneously become a pertinent problem in many German and Swiss states (as well as in other European countries) between 2010 and 2012, whereas a less sharp, yet similarly ubiquitous, trend in the opposite direction could be observed roughly after 2014/2015. This broader tendency toward decreasing residential burglary numbers was not limited to those areas where predictive policing had been implemented. In light of these overall statistics, police departments struggled to situate their work with predictive policing software vis-à-vis larger trends. One senior officer framed the situation as follows:

What's also interesting, of course, is when we have a decrease [of residential burglary numbers] in [city A] and [city B]. And the other districts, where they don't use PRECOBS, also have a decrease in that same period of time. Why do they have the same effects that we have? Would we have had them anyway, because the others had them as well? Or do we exert some kind of influence on them, including via the media? Do criminals avoid the whole region because of PRECOBS? We can't answer these questions.

Others voiced the suspicion that larger crime trends had nothing to do with predictive policing in the first place. Arguing on the assumption that a large proportion of professional burglars would come to Western European countries from Eastern Europe for orchestrated raids, they considered increased cooperation with Eastern European police agencies, as well as the temporary reinstatement of border controls in the Schengen zone, as major factors for declining overall numbers. The reasoning here was that cross-border police cooperation would lead to higher conviction and incarceration rates of known offenders in their home countries, while border controls would increase the risk of being identified and arrested and thus de-incentivize criminals from coming to Germany, Switzerland, and other Western European countries (I43).

Taken together, all these factors considerably complicate the gathering of evidence for the success of predictive policing. However, an even larger issue undermining the measurement of successful crime prevention lies in the fundamental contingency of the future. For a long time, security professionals have sought to get a grip of the future in order to fold it back into the present and make it amenable to interventions so that specific, desired futures would unfold and other, undesired futures would be prevented. Arguably, the trend toward anticipatory security methods and tools has been aggravated by events such as 9/11 and has been further enabled by the onslaught of data that are now produced and turned into predictions on an everyday basis (Amoore and 
de Goede, 2008; Anderson, 2010; Aradau and van Munster, 2011). The case of predictive policing vividly illustrates how the police are participating in this quest to tame the future.

However, whether anticipatory modes of knowledge production are framed in terms of risk, probability, preemption, prevention, or even possibility, what unites them is the fact they have to face the general openness of the future. Each specific mode of addressing the future produces a specific set of possible narratives that depend on the methods and the data mobilized to create them. None of them might ever materialize, though. Contingency prescribes that any set of calculated, imagined, or otherwise enacted futures is possible but not necessary. The future, in other words, might turn out to be crime ridden - but it might as well remain peaceful.

In predictive policing, it must thus always be kept in mind that crime predictions are precisely that - statistical predictions that have been brought into being under the conditions of practical constraints and theoretical assumptions, the most important of them being the assumption of rationality in human behavior. Predictions thus may or may not be accurate, and they may easily be canceled out by human behavior that does not follow the paradigm of rational choice. What if a criminal decides to go with their gut feeling rather than acting on the basis of meticulous cost-benefit calculations? Or what if it is simply bad weather conditions that deter an offender from "going to work" rather than prevention measures carried out by the police? One police officer framed general conditions of contingency and their epistemic effects as follows:

If an offender doesn't strike, we have no idea whether he was really discouraged by enhanced patrols or whether there were other reasons. Maybe he got sick, or he would have moved on [to a different city or neighborhood] anyway.

Sure enough, if no burglaries materialize in a designated risk area, one could consider preventive police work as successful. But maybe the offense would not have happened anyway, even without predictive policing - maybe even without any police patrols at all. Measuring something that has not happened, is not happening, and may never happen is something of a conundrum. If predicted criminal activity does not materialize, does this actually mean that the prognosis was correct and criminal activity was prevented due to prevention measures based on the prediction? Or does it, quite on the contrary, mean that the prediction was not correct in the first place? The police will likely never find out what would have happened in counterfactual scenarios. As one officer put it:

In the end, it's impossible to measure. That's our problem. When we increase patrols and nothing happens, when we offensively demonstrate 
presence in uniform, for a full week, when we check license plates and persons - we still won't be able to say that we actually prevented crimes because of our work.

While the combination of diverse epistemic uncertainties renders it almost impossible for the police to come up with robust evidence that predictive policing actually helps to prevent crime, it equally well renders it quite difficult to understand which parts of predictive policing would have failed in case of an assumed non-effect of risk estimates and operational crime prevention measures (Hunt et al., 2014; Gerstner, 2017). Were the underlying data faulty or incomplete? Was the model of the software or the algorithm flawed? Did the human operator accept or reject the wrong system recommendations? Were police internal communication structures for the dissemination of crime risk inadequate? Did patrol units consciously neglect predictive policing orders, or were they simply swamped with calls for service and had no time to properly patrol risk areas? Along the complex chain of translations that make up predictive policing, any single element or a combination of these elements could be the one that disrupts the production and transmission of knowledge and power, thus thwarting any potential impact of crime prevention measures on the criminal environment.

In summary, there is a rather stark contrast between the epistemic uncertainties that surround predictive policing and its "success" in fighting crime on the one hand and the considerable financial and organizational resources that governments and police departments have spent on the procurement and implementation of predictive policing software. After all, staff needed to be trained, work processes needed to be adapted, in some cases IT infrastructure needed to be overhauled, and some departments even used the implementation of predictive policing as an opportunity to restructure their crime analysis divisions (I02; I18; I35; I31; I36; I48; P 61). These efforts inevitably raise the question of how police departments managed to justify the continuous use of predictive policing software against the backdrop of an apparent lack of hard evidence for its effects.

\section{Redefining success}

Faced with the lack of statistical proof for the effects of predictive policing and targeted crime prevention, police departments came up with a number of ways to redefine success criteria, such that the use of algorithmic crime analysis software could nonetheless be presented as a valuable addition to their toolbox and its use could be continued. The arguably most pertinent strategy was to abandon the idea of evidence in the first place. Instead of trying to come up with viable measurements and statistical evaluations, police departments would opt to simply stick to crime numbers. Indeed, in many cases, the declining 
residential burglary statistics (i.e., the development of burglary cases since predictive policing had been implemented) could in a vacuum be interpreted as success and be rather easily presented as such to politicians and the public. During the time of our research, some police departments recorded a decrease in residential burglary numbers in the range of $10 \%$ (I18), 30\% (I02), or even $40 \%$ (I17). This ties in with reports from other jurisdictions that also recorded decreases of between $20 \%$ and $30 \%$ (I32; I43; I44; I48). For our interlocutors, these numbers could be considered to speak for themselves, never mind whether there was actual evidence that they could be attributed to the use of predictive policing software. As one senior officer put it:

After the trial run, we felt like our experiences were good. And funnily enough, residential burglary numbers went down by $30 \%$. PRECOBS yes or no - doesn't matter. It was 30\% less, so we could not really argue that it wasn't getting the job done. That's the experience that we had. . . . Of course we did a lot, we had a lot of patrols in the streets, we also increased controls. With predictive policing, there are lots of things in the mix: patrol presence, the software, new internal organization forms. But the success validated our approach. What exactly caused it did not even matter.

Such an outcome-oriented perspective on predictive policing was in many cases also backed up by official political positions. The ministerial response to one of our inquiries included the following statement with regard to the success of the KrimPro software package:

For the first nine months of 2016, statistics indicate an increase of residential burglaries by $5.8 \%$ (compared to the previous year period). Since the KrimPro trial started in October of 2016, monthly residential burglary numbers have consistently been below the numbers for the respective previous month. . . Expectations regarding the implementation of KrimPro in all six districts have been met. Whether the effects can be attributed to the use of KrimPro is not clear. . . Regular implementation will be rolled out gradually.

Rather than looking for "real" (i.e., epistemically viable) evidence to demonstrate the success of predictive policing and justify its continued application, for both police departments and governments, it was seemingly sufficient to be able to show that the original problem (i.e., high residential burglary numbers) had been effectively addressed. Instead of critically questioning how declining burglary numbers came about, the actors involved were, in this sense, willing to let the numbers speak for themselves in order to effectively brush aside epistemic uncertainties and methodological critique. 
This stance, though, has profound implications for how the police understand and address the complex relations between society, space, and crime. Without proper statistical proof of whether (and what elements of) predictive policing did or did not work, there can be no inferences about the underlying root structures of crime. Predictive policing will thus by default be limited to a treatment of symptoms rather than addressing the causes of criminal phenomena (Wilson, 2018: 124; Završnik, 2018: 142). A "numbers only" approach to predictive policing, in this sense, resembles the "good enough theory" approach that police agencies in the US in the 1980s resorted to in response to the predominant penal pessimism that had resulted from fruitless attempts to address the root causes of crime (Martinson, 1974; Weisburd et al., 2017). The subsequent mentality was to throw any promising new method at crime without insisting on a robust theoretical understanding of the complex relationships between crime, society, and the police - as long as it was seen to be workable and produced the desired results. Without proper comprehension of its epistemic underpinnings and its effects on society and space, predictive policing could fall into a similar trap. We will discuss this question in more detail in the following chapter.

However, the invocation of numbers was not the only strategy that could be observed as a way of turning predictive policing into a success despite the lack of statistical evidence. Initial trial runs with predictive policing software were in most police departments followed up by formal evaluation studies. The results and recommendations of these studies were considered crucial for whether departments would proceed with algorithmic crime analyses and targeted prevention measures. Evaluations were either conducted internally or contracted to external research institutes. While the results of such studies are usually not publicly accessible, some departments decided to publish them. The most pertinent available studies come from three German states: the report on the SKALA software developed by the State Police Department of North RhineWestphalia (Landeskriminalamt Nordrhein-Westfalen, 2018b, 2018a; Dungs and Erzberger, 2020), the report on the PreMAP software developed by the State Police Department of Lower Saxony (Landeskriminalamt Niedersachsen, 2018, 2019; Gluba, 2020), and the report on the PRECOBS pilot study in Baden-Württemberg (Gerstner, 2017, 2018, 2019).

Especially the SKALA report, conducted by the State Police Department in cooperation with the independent social science research institute GISS ${ }^{1}$ (Landeskriminalamt Niedersachsen, 2018), paints a surprising picture of what police departments file under "success" with regard to predictive policing. Rather than opting for an impact evaluation (i.e., foregrounding the effects of risk estimates and targeted patrols on crime prevention), the report reframes the success of predictive policing in terms of a much broader process evaluation that covers organizational aspects that go way beyond a narrow technical scope of risk estimation and crime statistics (Dungs and Erzberger, 2020: 201). Overall residential burglary numbers were in this case considered as only one 
of six main criteria for the evaluation of whether predictive policing should be continued after the initial trial phase.

The full list of evaluation criteria, as defined by the report, reads as follows: (1) risk estimates for all included neighborhoods have been calculated, visualized, and ordered by magnitude; (2) SKALA has been successfully implemented in all departments participating in the project, and risk estimates have been integrated into the situational picture and daily operations; (3) patrols can be dispatched more effectively; (4) the more effective use of patrols leads to improved operational measures; (5) improved operational measures lead to decreasing case numbers and an increase in clearance rates; (6) the system opens up new potentials for crime prevention (Landeskriminalamt NordrheinWestfalen, 2018b: 35f). Similarly, the PreMAP report highlights how, although no direct effects on crime numbers could be proven, the software had unfolded positive effects on communication structures and cross-unit cooperation and had accelerated the process of equipping patrol units with mobile devices. Moreover, it highlights the successful in-house development of the software without reliance on external expertise or resources (Landeskriminalamt Niedersachsen, 2018: 48).

Such evaluation criteria, needless to say, differ quite a bit from an understanding of success in terms of decreasing crime numbers. Rather, they correspond closely with a more holistic understanding of predictive policing as a process that is embedded within complex organizational structures, and it speaks to issues of potential resistance as much as it speaks to the sociotechnical character of predictive policing. Implementing new technological tools within police organizations, as we discussed in Chapter 3, is not an easy task. As predictive policing software forms a number of sociotechnical relations with functionally differentiated environments, it needs to align both human actors and other technical tools and infrastructures. The SKALA evaluation report foregrounds such alignment work as an accomplishment that must in itself be considered a success. While it might appear rather banal that the police were able to compute risk estimates and disseminate them throughout their organizational structure, it is, as we have seen throughout the previous chapters, by no means self-evident that police departments would be able to seamlessly integrate predictive policing software into entrenched occupational cultures and work practices.

In fact, many of the success criteria identified by the SKALA report speak to an understanding of predictive policing as a chain of translation activities that enable risk to come into being and travel through several stages of police work. Predictive policing, from such a perspective, could be considered successful if it triggers organizational adaptation. In other words, the capability of police departments to translate data into action without breakdowns along the way would in itself be a more profound achievement than short-term statistical reductions in residential burglary numbers. The implementation of the complex sociotechnical processes that predictive policing requires could just 
as well be considered as a positive indicator for further reform in terms of IT infrastructure and analytics. Success criteria are moreover already geared toward possible future functionality upgrades of the software, such as successful integration of data from other sources into the system and an expansion of analytical capacities (Landeskriminalamt Nordrhein-Westfalen, 2018b: 137). We will discuss these trends in more depth in Chapter 10.

Notably, not all of the evaluation studies produced positive outcomes. The Ministry of the Interior of Baden-Württemberg, after two rounds of rather controversial evaluation of PRECOBS (the results of the second round have at the time of writing not yet been published; for the first round, see Gerstner, 2017, 2019), decided in 2019 to discontinue the use of the software package (Mayer, 2019). Ironically, a major political criticism of the use of predictive policing software was that, due to the massive decrease in residential burglary case numbers, no robust statements about the quality of the algorithmically produced risk estimates could be made (I44; D18; P71). Moreover, the lack of increased arrest rates in risk areas was also interpreted as an indicator for the lack of effects (Mayer, 2019). Similarly, the Cantonal Police of Zurich, unlike the Municipal Police, also decided to discontinue the use of PRECBOS in 2019 after an initial test phase (D363). Major criteria for that decision were the complicated integration of the software into the IT infrastructure of the organization, the rather high number of baseline cases required for the meaningful application of the software in everyday use, and the restriction of the experiment to residential burglary (Schneider and Leutenegger, 2020). Both the State Police Department of Baden-Württemberg and the Cantonal Police of Zurich have stressed, however, that their respective decisions should be understood as decisions against a specific software package, and not against predictive policing in general. The Cantonal Police of Zurich in this sense decided to explore inhouse development capacities for predictive policing software (D363).

\section{Conclusion}

In summary, the question of whether predictive policing actually works is not easily answered. However, it is not a single question either. Depending on how one conceptualizes the "success" of predictive policing, how one decides to operationalize and measure success factors, and how one seeks to establish evidence, questions and possible answers will differ quite considerably. We have in this chapter discussed how public pressure and the political prioritization of the fight against residential burglary have served as catalysts for the implementation of predictive policing and have created the demand for proof that it actually yields results. Police departments, as we have shown, faced a number of pressures vis-à-vis this constellation. Not only did they have to cope with unrealistic expectations in terms of the effects of predictive policing but they also needed to rapidly integrate new software into their working routines, present themselves as innovative actors mobilizing the latest cutting-edge technological 
advances, and demonstrate that they were not lagging behind other police departments in the fight against crime.

These pressures stand in stark contrast to the epistemic uncertainties that surround the possibilities of actually measuring the impact of predictive policing and targeted crime prevention measures. Establishing causal claims that "prove" that it was actually predictive policing that brought about a reduction in residential burglary numbers is an almost insurmountable task. In complex social settings with dynamic interaction effects, there are numerous possible intervening variables that can hardly be controlled. Moreover, contingency renders possible criminal futures as possible yet not necessary, thus crucially limiting the possibility of making definite statements about the reasons for the occurrence or non-occurrence of events.

In light of these quandaries, police departments found rather creative ways of bypassing epistemic troubles. Apart from framing the favorable development of crime statistics as proof in itself, they managed to reformulate success criteria from a narrow focus on statistical relations between independent (i.e., predictive policing and targeted crime prevention) and dependent (i.e., residential burglary numbers) variables into a wider agenda of organizational reform. By focusing on the successful production and translation of knowledge and power, a processual perspective on success goes beyond specific software packages or even predictive policing itself, as it foregrounds the sociotechnical future-readiness of police departments in terms of data, algorithms, and the capacity to enact any kind of digital intelligence in the streets.

\section{Note}

1 Gesellschaft für innovative Sozialforschung und Sozialplanung e.v., Bremen (Association for Innovative Research and Social Planning), https://giss-ev.de (accessed 30 April 2020).

\section{References}

Amoore L and de Goede M (eds.) 2008. Risk and the War on Terror. London/New York: Routledge.

Anderson B (2010) Preemption, Precaution, Preparedness: Anticipatory Action and Future Geographies. Progress in Human Geography 34(6): 777-798.

Aradau C and van Munster R (2011) Politics of Catastrophe: Genealogies of the Unknown. London/New York: Routledge.

Beckett K (1994) Setting the Public Agenda: "Street Crime" and Drug Use in American Politics. Social Problems 41(3): 425-447.

Bowers K, Johnson S D, Guerette R T, Summers L and Poynton S (2011) Spatial Displacement and Diffusion of Benefits Among Geographically Focused Policing Initiatives: A Meta-Analytical Review. Journal of Experimental Criminology 7(4): 347-374.

Budras C (2015) Schütze sich, wer kann. Frankfurter Allgemeine Zeitung. 25 May. Available at www.faz.net/aktuell/wirtschaft/wie-der-staat-bei-der-hauseinbruch-bekaempfungversagt-13608811.html (accessed 30 April 2020). 
Cornish D B and Clarke R V (1987) Understanding Crime Displacement: An Application of Rational Choice Theory. Criminology 25(4): 933-947.

Dungs I and Erzberger C (2020) Kooperative Evaluation des Predictive-Policing-Projektes "SKALA" im LKA NRW. In Bode F and Seidensticker K (eds.) Predictive Policing: Eine Bestandsaufnahme für den deutschsprachigen Raum. Frankfurt am Main: Verlag für Polizeiwissenschaft, 201-214.

Egbert S (2018) About Discursive Storylines and Techno-Fixes: The Political Framing of the Implementation of Predictive Policing in Germany. European Journal for Security Research 3(2): 95-114.

Elflein C, Hasenbeck M, Lehmkuhl F, Hufelschulte J, Schattauer G, Siemens A, Spilcker A and Wisniewski M (2014) Der Staat versagt. Focus Online. 13 October. Available at www.focus.de/immobilien/wohnen/politik-der-staat-versagt_id_4196533.html (accessed 30 April 2020).

Ericson R V (ed.) (1995) Crime and the Media. Dartmouth: Aldershot/Brookfield.

Gabor T (1981) The Crime Displacement Hypothesis: An Empirical Examination. Crime \& Delinquency 27(3): 390-404.

Gerstner D (2017) Predictive Policing als Instrument zur Prävention von Wohnungseinbruchdiebstahl: Evaluationsergebnisse zum Baden-Württembergischen Pilotprojekt P4. Freiburg: MaxPlanck-Institut für ausländisches und internationales Strafrecht.

Gerstner D (2018) Predictive Policing in the Context of Residential Burglary: An Empirical Illustration on the Basis of a Pilot Project in Baden-Württemberg, Germany. European Journal for Security Research 3(2): 115-138.

Gerstner D (2019) Using Predictive Policing to Prevent Residential Burglary: Findings from the Pilot Project P4 in Baden-Württemberg, Germany. European Law Enforcement Research Bulletin 10(4): 113-123.

Gluba A (2014) Predictive Policing - eine Bestandsaufnahme: Historie, theoretische Grundlagen, Andwendungsgebiete und Wirkung. Kriminalistik 6: 347-352.

Gluba A (2020) PreMAP - Predictive Policing in Niedersachsen. In Bode F and Seidensticker K (eds.) Predictive Policing: Eine Bestandsaufnahme für den deutschsprachigen Raum. Frankfurt am Main: Verlag für Polizeiwissenschaft, 167-180.

Harrison G W and List J A (2004) Field Experiments. Journal of Economic Literature 42(4): 1009-1055.

Hauber J (2019) Postfaktizität und Predictive Policing. In Lange H J and Wendekamm M (eds.) Postfaktische Sicherheitspolitik: Gewährleistung von Sicherheit in unübersichtlichen Zeiten. Wiesbaden: Springer VS, 191-209.

Hessisches Ministerium für Inneres und Sport (2016) Innenminister Peter Beuth stellt Prognose-Software "KLB-operativ" vor. 20 July. Available at www.hessen.de/pressearchiv/pressemitteilung/innenminister-peter-beuth-stellt-prognose-software-klboperativ-vor (accessed 30 April 2020).

Holbrook R A and Hill T G (2005) Agenda-Setting and Priming in Prime Time Television: Crime Dramas as Political Cues. Political Communication 22(3): 277-295.

Hunt P, Saunders J and Hollywood J S (2014) Evaluation of the Shreveport Predictive Policing Experiment. Santa Monica: RAND Corporation.

Johnson S D, Guerette R T and Bowers K (2014) Crime Displacement: What We Know, What We Don't Know, and What It Means for Crime Reduction. Journal of Experimental Criminology 10(4): 549-571.

Krauel T (2013) Der Staat versagt bei seinem Kernauftrag. Welt.de. 15 May. Available at www.welt.de/debatte/kommentare/article116223952/Der-Staat-versagt-bei-seinemKernauftrag.html (accessed 30 April 2020). 
Landeskriminalamt Niedersachsen (2018) PreMAP - Predictive Policing in Niedersachsen: Bericht zur Bewertung der ersten Projektphase. Hannover: Landeskriminalamt Niedersachsen.

Landeskriminalamt Niedersachsen (2019) Predictive Policing in Niedersachsen - Das Projekt PreMAP. Available at www.lka.polizei-nds.de/startseite/kriminalitaet/forschung/ premap/predictive-policing-in-niedersachsendas-projekt-premap-114083.html (accessed 30 April 2020).

Landeskriminalamt Nordrhein-Westfalen (2018a) Abschlussbericht Projekt SKALA. Düsseldorf: Landeskriminalamt Nordrhein-Westfalen.

Landeskriminalamt Nordrhein-Westfalen (2018b) Kooperative Evaluation des Projektes SKALA: Abschlussbericht der Zentralstelle Evaluation beim LKA NRW (ZEVA) und der Gesellschaft für innovative Sozialforschung und Sozialplanung e.V. Bremen (GISS). Düsseldorf: Landeskriminalamt Nordrhein-Westfalen.

Martinson R (1974) What Works? Questions and Answers about Prison Reform. The Public Interest 35: 22-54.

Mayer N (2019) Strobl entscheidet sich gegen Precobs. Stuttgarter Nachrichten. 3 September. Available at www.stuttgarter-nachrichten.de/inhalt.aus-fuer-die-einbruchvorhersagesoftware-strobl-entscheidet-sich-gegen-precobs.19a18735-9c8f-4f1a-bf1b80b6a3ad0142.html (accessed 30 April 2020).

Mohler G O, Short M B, Malinowski S, Johnson M, Tita G E, Bertozzi A L and Brantingham P J (2015) Randomized Controlled Field Trials of Predictive Policing. Journal of the American Statistical Association 110(512): 1399-1411.

Pritchard D and Berkowitz D (1993) The Limits of Agenda-Setting: The Press and Political Responses to Crime in the United States, 1950-1980. International Journal of Public Opinion Research 5(1): 86-91.

Schlesinger P, Tumber H and Murdock G (1991) The Media Politics of Crime and Criminal Justice. The British Journal of Sociology 42(3): 397-420.

Schneider C and Leutenegger J (2020) Predictive Policing als Herausforderung für das polizeiliche Datenmanagement: Erfahrungen aus einem Pilotprojekt der Kantonspolizei Zürich. In Bode F and Seidensticker K (eds.) Predictive Policing: Eine Bestandsaufnahme für den deutschsprachigen Raum. Frankfurt am Main: Verlag für Polizeiwissenschaft, 273-287.

Schweer T (2015a) Musterbasierte Prognosetechnik bei der Kriminalitätsbekämpfung - Die Methodik der Near Repeat Prediction. Polizeispiegel 49(6): 22-24.

Schweer T (2015b) "Vor dem Täter am Tatort" - Musterbasierte Tatortvorhersagen am Beispiel des Wohnungseinbruchs. Die Kriminalpolizei 32(1): 13-16.

Weisburd D, Farrington D P and Gill C (2017) What Works in Crime Prevention and Rehabilitation: An Assessment of Systematic Reviews. Criminology \& Public Policy 16(2): 415-449.

Wilson D (2018) Algorithmic Patrol: The Futures of Predictive Policing. In Završnik A (ed.) Big Data, Crime and Social Control. London/New York: Routledge, 108-127.

Wilson J Q (1976) Thinking about Crime. New York: Basic Books.

Završnik A (2018) Algorithmic Crime Control. In Završnik A (ed.) Big Data, Crime and Social Control. London/New York: Routledge, 131-153. 


\section{Chapter 9}

\section{“Bad" predictions}

The impact of predictive policing on police work, as we discussed in the previous chapter, has been systematically explored by a number of evaluation studies. The focus of these studies was, by design, on the police themselves. They have assessed whether targeted crime prevention measures based on algorithmically produced risk estimates do actually stop the occurrence of crime. Faced with a number of epistemic quandaries that make statements about a causal relation between predictive policing and crime numbers difficult or even impossible, they have chosen to partly redefine success in terms of the effects of algorithmic crime analysis tools on larger organizational capabilities for handling data and communicating intelligence. However, studies that analyze the effects of predictive policing on police work are only one side of the coin. The other side of that coin is how algorithmically produced crime predictions affect the relations between the police and society.

This chapter is dedicated to a systematic exploration of the normative and ethical aspects of predictive policing. A critical perspective on predictive policing and society should not be limited to an assessment of the technical perils and pitfalls of algorithmic risk calculations but should also include considerations of the real-world implications that targeted crime prevention measures based on algorithmic calculations can unfold (Degeling and Berendt, 2018: 355; Benbouzid, 2019: 129f). Policing is a fundamental function of the state's monopoly of violence, and the actions of police officers are bound to interfere at times with people's lives, including their physical integrity and morally and legally enshrined values such as privacy and intimacy. There is a fine line between legitimate and illegitimate police action, and the boundary between what the police are allowed and forbidden to do vis-à-vis the protection of civil liberties and human rights on the one hand and the execution of necessary coercive force on the other is constantly being renegotiated through normative considerations and court decisions.

Bringing a new technological tool into this fragile balance can have considerable effects. Predictive policing, as we have shown, redefines to a certain extent how the police produce knowledge about society and crime, and it reconfigures how they carry out some of their core tasks. Police patrols and 
crime prevention measures directly affect citizens, and they have an effect on how the police and their actions are perceived by the population. As predictive policing respecifies where police presence is considered particularly effective, it redistributes the provision of policing as a service throughout space - being welcomed by some, and seen by others as a nuisance or a threat.

As has become apparent throughout the previous chapters, there are in fact a number of ways in which crime predictions can turn out to be "bad". They can be plain wrong - for instance, because they are based on faulty or incomplete data or because there were errors in modeling or in the programming of the software - and send patrols into neighborhoods where there is no increased crime risk after all. They can, however, just as well be "bad" in terms of the behavior they encourage or the policing strategies they enable and reinforce. And they can even be "bad" because they undercut traditional forms of knowledge generation and decision-making and replace it with opaque, automated processes that lead to a lack of accountability for subsequent action. "Bad" predictions should in this sense be broadly understood in terms of the possible undesirable effects predictive policing can unfold at the interface between the police and society.

Several issues are particularly pertinent for data-driven analytical tools, including the production and perpetuation of bias in computational processes (Friedman and Nissenbaum, 1996; Barocas and Selbst, 2016) and the lack of transparency in complex and black-boxed systems (Zarsky, 2013; Kroll et al., 2017). In the words of Ferguson (2019: 497), predictive policing "involves real risk when it comes to justice, equality, and protecting individual liberty", and there is no shortage of critical legal and ethical literature that has analyzed the effects of prediction tools for policing and criminal justice on civil liberties and human rights (Ferguson, 2012; Bennett Moses and Chan, 2014; Joh, 2014; Miller, 2014; Ferguson, 2015; Koss, 2015; Angwin et al., 2016; Lum and Isaac, 2016; Barrett, 2017; Ferguson, 2017a; Selbst, 2017; Bakke, 2018; Bennett Moses and Chan, 2018; Robinson, 2018; Mann and Matzner, 2019; O’Donnell, 2019; Susser, forthcoming).

Most of the available literature on predictive policing and civil liberties/ human rights, however, is geared toward person-based approaches to risk profiling and primarily addresses how threat/vulnerability comes into being based on information about individual persons and their social networks. Many arguments presented in these analyses are thus only applicable to place-based predictive policing approaches in a limited fashion (Albrecht, 2020). Software packages such as PRECOBS currently do not process individual data. With reference to the nonuse of such sensitive information, software manufacturers and police representatives alike have in fact tried to brush aside normative and legal concerns about predictive policing (Rey, 2014; Okon, 2015; Schweer and Schweer, 2015; Schweer, 2015, 2018, 2020).

There are, however, nonetheless a number of issues that warrant caution even in place-based approaches to predictive policing. In this chapter, we highlight how technoscientific tools and methods can cloak bias and injustice in 
an alleged neutrality and impartiality of machines, how the data foundations of predictive policing can perpetuate bias and produce feedback loops, how spatial risk estimates impact the production of suspicion and physical intervention, how targeted crime prevention perpetuates a focus on the treatment of symptoms rather than addressing the root causes of crime, and how the accountability of the police as an institution might be in danger due to a lack of transparency in complex algorithmic analysis tools.

\section{The cloak of technoscience}

Technology is usually equated with innovation (Rogers, 2003; Godin and Vinck, 2017), and such innovation has regularly been understood as a means to address prevailing social and economic problems and build a better future (Ellul, 1965; Moravec, 1988; Kurzweil, 1992). A rather common theme in narratives of technoscientific progress is to highlight how machines are able to overcome human deficiencies - be it because they can lift heavy things, exercise complex calculations with large quantities of data, or simply because they do not tire or need a break (Sheridan and Verplank, 1978; Parasuraman and Wickens, 2008). More importantly, there is an implicit assumption that machines do not make mistakes. As long as a forklift is properly constructed and a software application is properly programmed, following this perspective, they will reliably execute their tasks and not produce the random failure or error that is so inherent in human behavior. Humans make mistakes for many reasons, be it because they are incapable, overburdened, or distracted. But they also make "mistakes" because their perception of the world and specific situations is preconfigured by prejudice that impacts judgment and decision-making. Proponents of technoscientific tools argue that machines would be free from such prejudice, as they assess situations based on facts alone, thus rendering their judgment impartial, accurate, objective, and fair (Balabanian, 2006; Wolf, 2010).

Although, as we discussed at some length in Chapter 3, such simplistic assumptions have long been deconstructed, they remain surprisingly persistent (Miller, 2020). Advocates of predictive policing tools use them to frame algorithmic risk production and targeted crime prevention as a remedy for many of the problems the police have been blamed for, including prejudice, racism, profiling, and a lack of fairness and just distribution of services (Ferguson, 2017b: 28f; Sanders and Sheptycki, 2017: 10; Shapiro, 2019). Building on the presumption that a machine, unlike a human officer, will not care about skin color, social status, kinships, or neighborhoods, predictive policing is thus advertised as a way of effectively "eliminat[ing] the bias that people have" (Malinowski, cit. in Goode, 2011) and addressing existing concerns about the compliance of police work with civil liberties and human rights.

An understanding of predictive policing as a technoscientific cure for entrenched "human problems" is additionally supported by a second narrative that seeks to establish predictive policing as superior to error-prone human behavior: the 
invocation of science. Science, it is widely believed, is an impartial endeavor that is exclusively driven by the desire to accumulate facts in the pursuit of universal knowledge (Fuller, 2003). There are, in such an understanding, no politics in facts, and scientific theories reflect the best knowledge about a phenomenon that is currently available. Predictive policing tools are, following this logic, designed based on criminological theories, which are in turn derived from empirical research, and their hypotheses have been tested and proven multiple times, thus lending predictive policing a "seal of scientific approval" (Jefferson, 2018: 11).

It almost goes without saying that science is never the value-free project it is at times presented as (Collins, 1985; Latour and Woolgar, 1986; Daston and Galison, 2007). Scientific knowledge is by no means uniform or unanimously accepted but is characterized by a multiplicity of paradigms, theories, and methods - some of which stand in stark contrast to each other and produce continuous debate and contestation with regard to how we should understand and interpret the world. And yet, its popular appeal of being somehow above prejudice, politics, or petty conflicts comes in handy to present predictive policing as something that is based on pure reason and the power of the superior argument alone.

Taken together, the narratives of science and technology can be used to effectively deflect any critique of predictive policing technology itself and its effects. Predictive policing in this sense comes with a shiny algorithmic façade that "tech-washes" (Crockford, cit. in Burrington, 2015) its practices and effects. The possibility of "bad" predictions that discriminate, exclude, overexpose, or violate should, if one was willing to accept these premises, thus be looked for outside the sanitized realm of algorithmic crime analysis itself. Predictive policing would in this sense be largely "immune" to any allegations made with regard to the possible infringement of civil liberties and human rights.

As we have shown in this book, such a techno-solutionist narrative of predictive policing of course fundamentally neglects the sociotechnical effects that are inevitably produced once technologies become institutionally implemented and are put into practice. No technological tool and its capacities can be analyzed in an isolated fashion. On the contrary, technology must be carefully placed in social and organizational contexts, and it must be analyzed through the multiplicity of relations that it forms with its environment. Any kind of predictive policing, this much should have become clear by now, is a highly selective assembly of data, theories, modeling, organizational practices, and operational crime prevention measures. While this complicates the analysis of societal drawbacks, it makes it very clear that for police departments and politicians alike there is no easy way to evade responsibility for "bad" predictions.

\section{Data and bias}

Critical algorithm and data studies have highlighted the social constructedness of data (boyd and Crawford, 2012; Gitelman, 2013; Kitchin, 2014). Data 
do not exist independent of their production, and such production inevitably functions as a selection mechanism that determines what will be represented in a dataset and what will be left out. Moreover, data are not only actively constructed; their construction takes place with specific use cases always already in mind, thus predefining to a large extent how data take shape in order to fit into classification systems, how they can be combined with other data, and how they can be processed and analytical value extracted from them. In summary, data are never raw and cannot be innocent in the sense of providing an untainted reflection of the world.

Moreover, the relation between crime and data is a difficult one. Crime data are notorious for their shaky quality. When the police produce data from crime scenes, there are usually lots of unknowns and uncertainties, rendering the resulting datasets prone to be incomplete and/or faulty. Although police departments aim to mediate concerns about the data basis for predictive policing through multiple layers of quality control, questions about its accuracy and reliability must always be asked. We discussed these issues at length in Chapter 4. Rather than reviewing them once more, we want at this point to draw attention to how bias can in predictive policing be perpetuated and create feedback loops that project it into the production of criminal futures that need to be patrolled.

Bias (i.e., the selective representation and/or over-/underrepresentation of specific features in a dataset) is in fact one of the most persistent issues for any kind of data analysis (Barocas and Selbst, 2016). Disparities in a dataset are not only likely to prevail throughout algorithmic processes but equally likely to be extended, transformed, and, in the worst-case scenario, both aggravated and hidden in alleged machine rationality (Gandy, 2010). Questions of bias are pertinent for predictive policing for various reasons. First of all, not all crime is known to the police. Only crime that has been detected or reported becomes part of official crime data and thus part of any analysis (Biderman and Reiss, 1967). Undetected and unreported crime cannot be represented, thus rendering the data basis for predictive policing almost inevitably partial.

Residential burglary, as we detailed in Chapter 4, is less affected by this problem than other types of crime, as it is usually directly reported by burglary victims and so requires no active control activities. Private property is in the majority of cases insured, and burglary victims have an intrinsic interest in getting the police involved and producing official documentation for insurance purposes. While there is usually a rather good data basis with regard to domestic burglary, this might be much more difficult for types of crime that are only detected by the presence of police officers. Drug dealing, for example, is highly unlikely to be reported by those involved and will thus usually go unnoticed unless actively discovered by police controls.

This means that although there might be a patterned spatiotemporal distribution of incidents that is similar to domestic burglary, any estimates for areas and times of the day with an increased likelihood for drug dealing might be highly biased and represent earlier police activity rather than actual numbers. 
In short, different types of crime come with different types of bias, and not all of them are equally suitable for algorithmic crime analysis (I02; I16; I44; I51; I62; P49). Particularly vis-à-vis the expansion tendencies of predictive policing that we will highlight in the next chapter, not only the existence of bias in the first place but also the existence of different kinds of bias should thus always be kept in mind.

Predictive policing software perceives the world exclusively on the basis of the data it is presented with. Even a "perfect" algorithm - if there was such a thing - would produce biased results based on biased data. Spatial bias resulting from crime data production as a function of patrolling and selective police activity could thus, as Edwards (2016) puts it, in fact turn predictive policing from a practice of predicting crime into a practice of "predicting policing". Spatial bias relating to the past could, in other words, turn into spatial bias relating to the future - indicating a greater likelihood of finding crime in those areas where most crime was actively detected in the past.

A similar problem occurs when arrest data are used as input for predictive policing (Ferguson, 2017b: 74f). Arrests are highly contingent on the actions and decisions of individual police officers. Whereas one officer might decide to take an intoxicated driver to the station to let them sober up (thus producing official documentation and data), another officer might decide to let them off with a warning as long as they are willing to leave the vehicle in a parking lot and call for a taxi instead. Predictive policing in this sense would mean replicating individual choices on where to patrol, who to control, and not least, discrete decisions on whether/how to apply the rules.

Another problematic aspect with regard to data bias is that not all criminals are equally likely to be detected by the police. The risk of being arrested for illegal activities is often unequally distributed among the population and/or space, with ethnic monitories and inhabitants of poor and/or already crimeridden neighborhoods having a greater chance of being controlled, getting arrested, and/or being prosecuted (Weitzer and Tuch, 2006; Bowling and Philipps, 2007; Reiner, 2010: 159ff; Brantingham et al., 2018: 2; Chavis, 2019: 465). Biased police practices in turn become reflected in crime data that show a distorted account of the empirical distribution of crime between different population groups and neighborhoods. Crime analyses based on these data are subsequently likely to overrepresent certain ethnic groups and areas as more dangerous/vulnerable (Sheehey, 2019: 57). Such bias might even persist when individual identifiers are removed, as space and ethnic belonging are often linked (O’Neil, 2016: 87).

As a consequence, predictive policing can lead to significant overpolicing of specific communities or neighborhoods, in turn rendering them even more susceptible to the detection of further criminal activity, thus creating a feedback loop that reinforces data bias over time and can potentially perpetuate supposedly short-lived risk estimates and turn neighborhoods into perceived crime hot spots, leading to long-term spatial stigmatization (Završnik, 2018: 12). This 
can also include secondary consequences, such as declining real estate prices and property values (Rosenbaum, 2019).

The extrapolation of the data basis into the future is a general danger that any kind of risk-oriented analysis faces vis-à-vis biased data. When operational measures are planned and carried out based on insights that came into being through biased data, such measures are likely to reproduce the discriminatory actions that led to the bias in the first place. Moreover, as this happens, they are likely to "confirm" that bias by finding what would be expected based on the selective representation and/or over-/underrepresentation of specific features in the dataset. Crime predictions can, through the algorithmic perpetuation of bias, become self-fulfilling prophecies that create the crime risk they aim to predict (Lum and Isaac, 2016; Ensign et al., 2018; Richardson et al., 2019). Ultimately, persistent data bias could escalate predictive policing into a perpetuum mobile, where crime prediction and crime prevention enter "circular decision-making loops ad infinitum" (Završnik, 2019: 12). Being conscious about the data that go into predictive policing, in summary, is paramount when trying to understand how algorithmic crime analysis tools - even assuming that there is absolutely nothing wrong with how they model and execute the detection of patterns - can reinforce discrimination and stigmatization.

\section{Suspicion and intervention}

In Chapter 7, we discussed how patrol officers described their practices of producing deviance and suspicion against the backdrop of predictive policing and the attachment of risk to space. Whereas from their perspective, at least on the surface, not much had changed through the additional information about risk, it nevertheless became apparent that the notion of specific criminal futures within dedicated areas had effects on how they went about their business. Notably, our interlocutors reported increased attentiveness to their environment, more interest to detail, and longer periods of time spent in risk areas. Most importantly, patrol officers reported that potential mismatches between persons and space would be investigated more carefully, and more controls and checks would be carried out based on a supposed misfit between the appearance of a person and the character of the surrounding neighborhood.

Against the background of these observations, it is important to think about questions of suspicion and intervention vis-à-vis the algorithmic production of crime risk. Although predictive policing does not directly interfere with the techniques and occupational culture of the patrol, the context of allegedly higher risk within dedicated spaces raises concerns about reasonable suspicion, probable cause, and lower thresholds for police intervention (Ferguson, 2012; Joh, 2014: 55f; Ferguson, 2015). Moreover, it raises the question whether inferences about individual threat or dangerousness can be justified on the basis of place-based risk estimates and how such inferences affect fundamental rights such as the presumption of innocence (Hardyns and Rummens, 2018: 214). 
Generally speaking, the notion of risk space can lead to the cognitive and epistemic transfer of spatial characteristics to individuals who reside within that space. With regard to crime and policing, such "ecological contamination" translates into an assumption that, as Smith (1986: 316) puts it, "all persons encountered in bad neighborhoods are viewed by police as possessing the moral liability of the area itself". Risk thus produces a form of spatial liability that equates space and person (Assall and Gericke, 2016: 67; McCarthy et al., 2019: 1092f) - while at the same time introducing what could be described as "generalized suspicion" (Ferguson, 2017b: 125) and removing concrete individual behavior as a variable from the attribution of threat. Subsequently, even "good" behavior would not render a person within a risk space exempt from an alleged implication in criminal futures. As Joh (2014: 59) has argued with reference to the nudging potential of risk, predictive policing "may encourage the police to 'see' suspicious behavior when there may be none".

Carrying out controls more frequently and with more rigor is patrol behavior known from established high-crime areas and hot spots, and it raises questions about the appropriateness and just distribution of police action (Ferguson and Bernache, 2008; Casady, 2011; Ferguson, 2011; Rosenbaum, 2019). The difference between an algorithmically produced risk area and a hot spot is, of course, that the latter is an extrapolation of past crime clusters, whereas the former might not be a crime-ridden neighborhood at all and the presumption of risk is merely based on the identification of a single trigger incident (e.g., a suspected professionally executed burglary). In patrol practice, however, this nuanced distinction might get lost. Predictive policing might thus encourage patrolling behavior similar to that within hot spots, including the assumption that extraordinary measures would be justified (Ferguson, 2017b: 79).

Intervention and control practices in risk areas must also be critically investigated vis-à-vis legal concepts. Within "danger zones” ("Gefahrengebiete”), German police forces are granted exceptional competencies in the fight against persistent crime issues or with regard to other extraordinary circumstances (Assall and Gericke, 2016; Keller and Leifker, 2017; Keitzel, 2020). Patrol officers in those areas are, for instance, allowed to search bags without reasonable suspicion, thus extending a general assumption of dangerousness/criminal intent to anyone residing within predefined spatial parameters (Ernst, 2014). It is possible that risk areas and danger zones could become conflated in the perception and practices of patrol officers. It is therefore important to clarify that algorithmically produced crime risk must not be equated with legally declared exceptional circumstances. The criminal futures engendered through predictive policing are abstract ones that should not be confused with a concrete, imminent threat that would legitimize legally sanctioned enhanced law enforcement competencies (Meinicke, 2015: 377; Rademacher, 2017: 383f).

Patrol behavior in risk areas can also perpetuate existing stereotypes. Ethnic and racial prejudice in policing is well documented (Glover, 2009; Herrnkind, 2014; Philipps and Bowling, 2017; Behr, 2018), and corresponding profiling 
practices are likely to become aggravated against the backdrop of allegedly increased crime risk. As discussed in Chapter 7, we found prejudice and profiling primarily prevalent with regard to persons from Eastern Europe and/or with an Eastern European appearance. Our interviewees would openly admit that these persons, identified either by their looks or by license plates on their cars, would by default be considered potential burglars.

Among German and Swiss police professionals, such an attitude is underpinned by the narrative that professional burglars from Eastern Europe travel throughout the continent - and particularly to rich Western European countries such as Germany and Switzerland - in pursuit of their business and that this behavior is facilitated by the lack of border controls within the Schengen area (Winter, 2015; Egbert, 2018). This narrative is persistent, although there is no actual empirical evidence that a disproportionate number of recorded burglaries are committed by offenders with an Eastern European background (Bartsch et al., 2014). Nonetheless, by specifically looking for individuals that fit the profile of a professional burglar from Eastern Europe, patrol officers perpetuate this cliché through their practices. A disproportionately high number of selective controls, justified by the alleged burglary risk indicated by predictive policing software, is moreover also likely to lead to a disproportionately high number of detections and arrest of persons from Eastern Europe, thus in turn reinforcing the profile through the creation of skewed numbers.

In summary, there is reasonable concern that predictive policing can aggravate already problematic issues such as spatial liability and prejudice. The algorithmic production of risk estimates thereby turns into a reference point for the actions of police officers, allowing them to relate to a supposedly neutral and objective assessment of space. If predictive policing comes to matter within society through the actions it enables, then the generation and reinforcement of suspicion and intervention are issues to which close attention must be paid.

\section{Treating symptoms, not causes}

Predictive policing is in the majority of cases operationalized in a preventive way - that is, to allocate patrols more effectively and deter criminals through increased police presence in allegedly more vulnerable spaces. A tactic that is less frequently used is to deploy plainclothes police officers in risk areas instead, trying to catch offenders red-handed and to arrest rather than deter them (Gluba and Pett, 2017). Such a repressive approach is usually not considered particularly effective, as it requires substantial personnel resources and offers only slim prospects of success vis-à-vis assumed cautious offender behavior and the size and topography of the spaces to be covered. What unites both operational approaches is that they represent law enforcement-oriented strategies of policing. The occurrence of crime is assumed as a given, and the focus of police work is on deterrence and/or arrests. In other words, predictive policing is not interested in the reasons why crime happens in the first place 
but contents itself with its successful short-term prevention (Ferguson, 2017b: 81; Wilson, 2018: 124).

Predictive policing thus structurally prefers the treatment of symptoms over the treatment of root causes. This preference is very much evident in the characteristics of the criminal futures produced. Short-term risk estimates within limited spaces are not suitable for long-term prevention strategies, as they provide no insights about who commits crime and why. The repressive crimefighting activities that predictive policing enables and facilitates have, in this sense, been described as superficial and unsustainable (Singelnstein, 2018: 9). They might be able to grasp the spatiotemporal distribution of crime but fail to penetrate this descriptive surface or make substantive statements about economic conditions or social relations. Predictive policing, in other words, is at its best when it comes to identifying and tackling disruptions to social order, but at its worst when it comes to preventing such disruptions in the first place (The Leadership Conference on Civil and Human Rights et al., 2016; Barabas et al., 2018; Susser, forthcoming).

Predictive policing is thus in many regards narrow and short-sighted - and ironically, these are the attributes that make it a seamless fit with existing policing strategies. In Chapter 2, we discussed how predictive policing has evolved at the intersection of larger trajectories of crime analysis, patrolling, and crime prevention. Maybe most importantly, rational choice theory and situational crime prevention approaches have shaped the idea of algorithmic crime analysis and targeted intervention. Both approaches are rather simplistic in their understanding of human behavior (rational choice theory) and how to influence it (situational crime prevention), but they can easily be translated into operational measures. Predictive policing, in an effort to effectively get traction within police organizations and their work practices, takes up these tendencies and further develops them - without, however, questioning their basic rationales. The choice of policing strategies and the choice of technological tools are in this sense closely entangled and mutually constitutive, with predictive policing tools enabling certain operational measures and foreclosing others (Ferguson, 2019: 493).

This means that turning predictive policing from an operational response tool into a diagnostic tool that helps the police to understand and address the root causes of crime might not be easy after all. Crime analysis is predicated upon the recognition of patterns in data in order to reveal phenomena or relations that had not hitherto been noticed. On the flipside, pattern recognition is fundamentally limited to the existence of patterns in the first place. Anything that does not come in the form of a pattern can by definition not be statistically captured and thus falls out of the scope of analysis (Kaufmann et al., 2019). But the socioeconomic root causes of crime, unlike its manifestations, might not come in a neatly patterned form and are likely to be more complex. In other words, statistics and large-scale datasets, as mobilized in predictive policing, might not be particularly well suited for an in-depth understanding of social issues. 
What predictive policing presents is a strategy of addressing issues that are easily observable, quantifiable, and can be easily exposed to treatment with established operational methods (Ferguson, 2017b: 78; Shapiro, 2019: 469). This can lead to selective policing strategies that turn a blind eye to types of crime that cannot be subjected to algorithmic analyses and large datasets, for instance white-collar crime (O'Neil, 2016: 90; Richardson et al., 2019: 21). Certain types of crime could thus become systematically underpoliced, with a disproportionate emphasis put on specific offences and offenders (Kochel, 2011: 363; Hardyns and Rummens, 2018: 214; Završnik, 2019: 14).

In summary, predictive policing will, by definition, always be confined to the limited perception of social phenomena that an algorithm predicated upon theories, models, and data can offer. This is not per se "bad", but when thinking about predictive policing and its larger societal impacts, it is important to keep in mind that algorithmic crime analysis can only offer added value for a limited range of policing strategies and operational measures. It is a specialized tool with a predefined, narrow application range. Overreliance on algorithmic crime analysis will therefore inevitably result in blind spots in policing strategies, rendering them disproportionately law enforcement heavy and potentially push back on programs that are geared toward exploring how crime comes into being in the first place.

\section{Transparency and accountability}

A final area that is pertinent when examining the wider societal impact of predictive policing concerns the potential lack of transparency of algorithmic crime analysis tools. A lack of transparency could, in the worst case, lead to a fundamental lack of accountability of police action (Bennett Moses and Chan, 2014: 674ff; Ferguson, 2017a: 1169ff; Chavis, 2019: 465f). The idea of accountability is a fundamental principle in democratic systems. It presupposes that those in power - be they governments, administration, or public agencies that act on behalf of the state - have to answer to the public (Mulgan, 2003; Bovens, 2005; Barnett, 2016). Accountability, in practice, means that institutions and their representatives need to be able to "give an account" of how decisions were made and how and why actions were carried out. In doing so, actors are given the opportunity to present their version of what has happened, including personal and institutional roles in the course of events. Actor accounts can then be used to trace decision-making processes, to identify erroneous or irresponsible behavior, or to uncover corruption. Most importantly, responsible actors can be "held to account" for the consequences of their decisions and resulting action, for instance in court proceedings or public hearings.

The police are not exempt from these processes. In democratic systems, police organizations have to be able to explain and justify their actions (Stenning, 1995; Jones, 2008; Walker and Archbold, 2020). This is particularly important vis-à-vis the far-reaching competences that police organizations 
have, including the use of force and the deprivation of liberty (Skolnick and Fyfe, 1993; Punch, 2011). Holding the police to account comes with its own set of problems, including the role of discretion in police practice (Walker, 1993), recalcitrance to external control in police culture (Punch, 2009), and because managerial approaches to accountability might not be well suited for police organizations (Chan, 1999).

The introduction of algorithmic analysis tools considerably complicates questions of accountability (Neyland, 2016; Zarsky, 2016). Giving an account of one's actions requires awareness of how one's decisions and actions came about in the first place. An ideal-typical human decision-making process would involve the collection of data about the issue to be addressed, an evaluation of the data, the weighing of different options, and potential deliberation with other persons and/or institutions, eventually culminating in a decision that can be rationalized and justified based on that process.

Decisions made with the help of algorithmic support systems differ quite radically from this sequence. Here, it is the machine that collects and processes the data by itself, in the end only presenting a menu of predefined outputs that the human user can choose from. Picking one of these options might not necessarily result in better or worse results compared to a human decision-making process, but it largely removes the capacity to explain how the decision was taken. Retracing how an algorithm came up with a decision recommendation might be impossible for several reasons. The data might involve information that is not accessible for human cognition (Matzner, 2016), the evaluation of the data might involve complex methods and techniques that are not easily understood by humans (Introna, 2013), and/or analytical processes might be black-boxed and inaccessible (Leese, 2014; Pasquale, 2015).

Little surprisingly, predictive policing has already been deemed “ 'black-box' policing" (Wilson, 2018: 112) on the grounds that it hides analytical processes and the production of risk more or less completely from the human user. As we discussed in Chapter 5, algorithmic analysis tools restructure the ways in which human officers and machines work together and split work tasks. The automation and speeding-up of complex statistical tasks is the primary rationale and sales pitch of predictive policing, and it inevitably comes with a degree of black-boxing that shuts out the human operator from at least parts of the analytical work. The operator is thus usually only presented with the system output (i.e., a risk estimate) and often has little opportunity to retrace how exactly this outcome came about.

This might only be a comparably minor problem with static, rule-based algorithms and a limited amount of processed data points, but it can quickly escalate when the amount of data and the complexity of the analytical processes increase (Bennett Moses and Chan, 2018: 818; Wilson, 2018: 120; Chavis, 2019: 466). Even in current predictive policing applications, there might be plenty of analytical functions that are not easily understandable for human analysts. When system outputs form the basis for decisions about where and how 
to patrol, full accountability for police action will thus effectively be undercut. In simple terms, when police departments cannot fully trace how the basis for their own decisions on where to patrol came into being, they will simply not be able to present an account of their choices.

Issues of transparency in algorithmic systems are additionally aggravated when applications are developed by private companies and procured by police departments as off-the-shelf solutions. Even though predictive policing and other crime analysis tools are usually customized for use within a particular organizational environment, their source code is considered a proprietary trade secret that will not be shared with the customer (Wexler, 2017). Private companies in fact have little interest in losing their competitive advantages in the marketplace by laying open the inner workings of their products. Even for tech-savvy and skilled crime analysts, it might therefore be impossible to understand and retrace how a specific system output was created (Joh, 2017: 118f; Bennett Moses and Chan, 2018: 818). For several German and Swiss police departments, this was in fact a major reason for their decision to rely on the in-house development of predictive policing tools rather than purchase software from an external vendor (I11; I16; I36; I48).

Last, but not least, the lack of transparency in predictive policing can have a chilling effect on the possibility of claiming an account from the police. Detailed knowledge about the technical details of predictive policing software is usually hard or even impossible to obtain for outsiders. Publicly available information about the software packages that police departments use and the data that feed them is in many cases sparse and superficial, and police departments are often reluctant to talk about their tools and operational measures. Without adequate documentation, however, questions about the responsibility and liability for police action are hard to formulate in the first place (Ferguson, 2017a: 1173ff).

In summary, predictive policing might be effectively removing decisionmaking processes with regard to crime prevention from democratic oversight and control. Algorithmic systems, by design, come with a tendency to hide analytical processes from the human eye and transform the decision-making processes that are so fundamental for the idea of accountability. Regardless of these difficulties, predictive policing should be a domain where, as Shapiro (2017: 460) puts it, "transparency is paramount". Finding ways to ensure transparency and accountability will be one of the major challenges in the further development, implementation, and regulation of algorithmic crime analysis tools.

\section{Conclusion}

In this chapter, we have discussed some of the most prevalent current concerns with regard to the societal impact of algorithmic crime analysis systems. The interface between the police and the public is where discrimination, violence, and injustice potentially manifest. It might not always be possible to neatly separate algorithmic risk production and "ordinary" police misconduct, 
but predictive policing comes with a number of caveats that must be carefully monitored in order to make sure that crime risk does not (further) undercut civil liberties and human rights. Predictive policing tends to rationalize police practices, and its alleged technical neutrality enables police departments to use algorithms as reference points to legitimize and tech-wash otherwise problematic practices and policing strategies. This tendency is reinforced by the scientific appeal of predictive policing tools that mobilize theories and methods. The technoscientific character of algorithmic crime analysis tools is often discursively used to create an overarching illusion of impartiality and to brush away a number of ethical and legal concerns.

The first concern affects the data processed by predictive policing tools. Crime data are likely to be biased, which means that certain features are over- or underrepresented in the dataset. Algorithmic systems might transform bias into less obvious shapes, but bias will inevitably persist and inform police action. Second, the creation of criminal futures is likely to affect how police officers perceive their environment and construct suspicion as a function of deviance between individuals and neighborhood characteristics. Predictive policing shows a tendency to reinforce already problematic practices of how patrol officers render individuals suspicious, and the alleged connection of space and risk might lead to more aggressive forms of policing. Third, predictive policing has demonstrated a tendency to favor the treatment of symptoms (i.e., crime) over the treatment of causes (i.e., the reasons why crimes are committed in the first place). It facilitates law enforcement strategies, rather than encouraging long-term and solutionoriented programs. Finally, predictive policing tends to remove transparency from knowledge production and decision-making processes, leading to a lack of accountability of police organizations for their actions.

This list could be continued. We have chosen to limit our discussion here to some of the most pertinent concerns over predictive policing and its societal impacts. They should, however, have sufficiently demonstrated that there are numerous pitfalls and caveats in the sociotechnical production of criminal futures that need to be closely monitored. In light of the themes that we have discussed, the tendency of algorithms to both conceal and rationalize potential civil liberties and human rights violations is a worrying one that might become even more pressing as predictive policing tools, as we will discuss in the final chapter of this book, can be expected to become more elaborate and pervasive in the future.

\section{References}

Albrecht H J (2020) Data, Data Banks and Security. European Journal for Security Research 5(1): 5-23.

Angwin J, Larson J, Mattu S and Kirchner L (2016) Machine Bias. ProPublica. 23 May. Available at www.propublica.org/article/machine-bias-risk-assessments-in-criminal-sentencing (accessed 30 April 2020). 
Assall M and Gericke C (2016) Zur Einhegung der Polizei: Rechtliche Interventionen gegen entgrenzte Kontrollpraktiken im öffentlichen Raum am Beispiel der Hamburger Gefahrengebiete. Kritische Justiz 49(1): 61-71.

Bakke E (2018) Predictive Policing: The Argument for Public Transparency. Annual Survey of American Law 74(1): 131-171.

Balabanian N (2006) On the Presumed Neutrality of Technology. IEEE Technology and Society Magazine 25(4): 15-25.

Barabas C, Dinakar K, Ito J, Viza M and Zittrain J (2018) Interventions over Predictions: Reframing the Ethical Debate for Actuarial Risk Assessment. In Friedler S A and Wilson C (eds.) Proceedings of Machine Learning Research Volume 81: Conference on Fairness, Accountability and Transparency. 23-24 February, New York. 1-15.

Barnett M (2016) Accountability and Global Governance: The View from Paternalism. Regulation \& Governance 10(2): 134-148.

Barocas S and Selbst A D (2016) Big Data's Disparate Impact. California Law Review 104(3): 671-732.

Barrett L (2017) Reasonably Suspicious Algorithms: Predictive Policing at the United States Border. New York University Review of Law \& Social Change 41(2): 327-347.

Bartsch T, Dreißigacker A, Blauert K and Baier D (2014) Phänomen Wohnungseinbruch: Taten, Täter, Opfer. Kriminalistik 68(8-9): 483-490.

Behr R (2018) Rassismus und Diskriminierung im Polizeidienst: Die Karriere zweier "Reizworte". SIAK-Journal - Zeitschrift für Polizeiwissenschaft und polizeiliche Praxis 13(2): 57-66.

Benbouzid B (2019) Values and Consequences in Predictive Machine Evaluation: A Sociology of Predictive Policing. Science \& Technology Studies 32(4): 119-136.

Bennett Moses L and Chan J (2014) Using Big Data for Legal and Law Enforcement Decisions: Testing the New Tools. University of New South Wales Law Journal 37(2): 643-678.

Bennett Moses L and Chan J (2018) Algorithmic Prediction in Policing: Assumptions, Evaluation, and Accountability. Policing and Society 28(7): 806-822.

Biderman A D and Reiss A J (1967) On Exploring the "Dark Figure" of Crime. The Annals of the American Academy of Political and Social Science 374(1): 1-15.

Bovens M (2005) Public Accountability. In Ferlie E, Lynn L E J and Pollitt C (eds.) The Oxford Handbook of Public Management. Oxford: Oxford University Press, 182-208.

Bowling B and Philipps C (2007) Disproportionate and Discriminatory: Reviewing the Evidence on Police Stop and Search. The Modern Law Review 70(6): 936-961.

boyd d and Crawford K (2012) Critical Questions for Big Data: Provocations for a Cultural, Technological, and Scholarly Phenomenon. Information, Communication \& Society 15(5): 662-679.

Brantingham P J, Valasik M and Mohler G O (2018) Does Predictive Policing Lead to Biased Arrests? Results from a Randomized Controlled Trial. Statistics and Public Policy 5(1): 1-6.

Burrington I (2015) What Amazon Taught the Cops: Predictive Policing Is Just Another Form of Supply-Chain Efficiency. The Nation. 27 May. Available at www.thenation.com/ article/archive/what-amazon-taught-cops/ (accessed 30 April 2020).

Casady T (2011) Police Legitimacy and Predictive Policing. Geography \& Public Safety 2(4): $1-2$.

Chan J (1999) Governing Police Practice: Limits of the New Accountability. The British Journal of Sociology 50(2): 251-270.

Chavis K (2019) The Pitfalls of Police Technology: A Minority Report. In Miller E J and Lave T R (eds.) The Cambridge Handbook of Policing in the United States. Cambridge: Cambridge University Press, 451-472. 
Collins H (1985) Changing Order: Replication and Induction in Scientific Practice. Chicago: University of Chicago Press.

Daston L and Galison P L (2007) Objectivity. New York: Zone Books.

Degeling M and Berendt B (2018) What Is Wrong about Robocops as Consultants? A Technology-Centric Critique of Predictive Policing. AI \& Society 33(3): 347-356.

Edwards E (2016) Predictive Policing Software Is More Accurate at Predicting Policing than Predicting Crime. American Civil Liberties Union. 31 August. Available at www.aclu. $\mathrm{org} / \mathrm{blog} / \mathrm{criminal}-\mathrm{law}-\mathrm{reform} /$ reforming-police/predictive-policing-software-moreaccurate-predicting (accessed 30 April 2020).

Egbert S (2018) About Discursive Storylines and Techno-Fixes: The Political Framing of the Implementation of Predictive Policing in Germany. European Journal for Security Research 3(2): 95-114.

Ellul J (1965) The Technological Society. London: Jonathan Cape.

Ensign D, Friedler S A, Neville S, Scheidegger C and Venkatasubramanian S (2018) Runaway Feedback Loops in Predictive Policing. In Friedler S A and Wilson C (eds.) Proceedings of Machine Learning Research Volume 81: Conference on Fairness, Accountability and Transparency. 23-24 February, New York. 1-12.

Ernst C (2014) Anlassunabhängige Personenkontrollen und Gefahrengebiete. Neue Zeitschrift für Verwaltungsrecht 33(10): 633-637.

Ferguson A G (2011) Crime Mapping and the Fourth Amendment: Redrawing "HighCrime Areas". Hastings Law Journal 63(1): 179-232.

Ferguson A G (2012) Predictive Policing and Reasonable Suspicion. Emory Law Journal 62(2): 261-325.

Ferguson A G (2015) Big Data and Predictive Reasonable Suspicion. University of Pennsylvania Law Review 163(2): 327-410.

Ferguson A G (2017a) Policing Predictive Policing. Washington University Law Review 94(5): 1115-1194.

Ferguson A G (2017b) The Rise of Big Data Policing: Surveillance, Race, and the Future of Law Enforcement. New York: New York University Press.

Ferguson A G (2019) Predictive Policing Theory. In Miller E J and Lave T R (eds.) The Cambridge Handbook of Policing in the United States. Cambridge: Cambridge University Press, 491-510.

Ferguson A G and Bernache D (2008) The "High-Crime Area" Question: Requiring Verifiable and Quantifiable Evidence for Fourth Amendment Reasonable Suspicion Analysis. American University Review 57: 1587-1644.

Friedman B and Nissenbaum H (1996) Bias in Computer Systems. ACM Transactions on Information Systems 14(3): 330-347.

Fuller S (2003) The University: A Social Technology for Producing Universal Knowledge. Technology in Society 25(2): 217-234.

Gandy O H (2010) Engaging Rational Discrimination: Exploring Reasons for Placing Regulatory Constraints on Decision Support Systems. Ethics and Information Technology 12(1): 29-42.

Gitelman L (ed.) 2013. "Raw Data” Is an Oxymoron. Cambridge: MIT Press.

Glover K S (2009) Racial Profiling. Lanham/Plymouth: Rowman \& Littlefield.

Gluba A and Pett A (2017) Das Potenzial von Polizeipräsenz für Maßnahmen im Sinne des Predictive Policing. Die Polizei 108(11): 323-330.

Godin B and Vinck D (eds.) 2017. Critical Studies of Innovation: Alternative Approaches to the Pro-Innovation Bias. Cheltenham/Northampton: Edward Elgar. 
Goode E (2011) Sending the Police Before There's a Crime. New York Times. 15 August. Available at www.nytimes.com/2011/08/16/us/16police.html (accessed 30 April 2020).

Hardyns W and Rummens A (2018) Predictive Policing as a New Tool for Law Enforcement? Recent Developments and Challenges. European Journal on Criminal Policy and Research 24(3): 201-218.

Herrnkind M (2014) "Filzen Sie die üblichen Verdächtigen!” oder: Racial Profiling in Deutschland. Polizei \& Wissenschaft 15(3): 35-58.

Introna L D (2013) Algorithms, Performativity and Governability. Paper presented at Governing Algorithms: A Conference on Computation, Automation, and Control, New York, 16-17 May. Available at http://governingalgorithms.org/wp-content/ uploads/2013/05/3-paper-introna.pdf (accessed 30 April 2020).

Jefferson B J (2018) Predictable Policing: Predictive Crime Mapping and Geographies of Policing and Race. Annals of the American Association of Geographers 108(1): 1-16.

Joh E E (2014) Policing by Numbers: Big Data and the Fourth Amendment. Washington Law Review 89(1): 35-68.

Joh E E (2017) The Undue Influence of Surveillance Technology Companies on Policing. New York University Law Review Online 92: 101-130.

Jones T (2008) The Accountability of Policing. In Newburn T (ed.) Handbook of Policing. Cullompton/Portland: Willan Publishing, 693-724.

Kaufmann M, Egbert S and Leese M (2019) Predictive Policing and the Politics of Patterns. British Journal of Criminology 59(3): 674-692.

Keitzel S (2020) Varianzen der Verselbstständigung der Polizei per Gesetz: "Gefährliche Orte" im bundesweiten Vergleich. Kriminologisches Journal 52(3): 191-209.

Keller N and Leifker M (2017) Gefahrengebiete. In Lemke M (ed.) Ausnahmezustand: Theoriegeschichte - Anwendungen - Perspektiven. Wiesbaden: Springer VS, 243-255.

Kitchin R (2014) Big Data, New Epistemologies and Paradigm Shifts. Big Data E Society 1(April-June): 1-12.

Kochel T R (2011) Constructing Hot Spots Policing: Unexamined Consequences for Disadvantaged Populations and for Police Legitimacy. Criminal Justice Policy Review 22(3): 350-374.

Koss K K (2015) Leveraging Predictive Policing Algorithms to Restore Fourth Amendment Protections in High-Crime Areas in a Post-Wardlow World. Chicago-Kent Law Review 90(1): 301-324.

Kroll J A, Huey J, Barocas S, Felten E D, Reidenberg J R, Robinson D G and Yu H (2017) Accountable Algorithms. University of Pennsylvania Law Review 165(3): 633-705.

Kurzweil R (1992) The Age of Intelligent Machines. Cambridge: MIT Press.

Latour B and Woolgar S (1986) Laboratory Life: The Construction of Scientific Facts. 2nd Edition. Princeton: Princeton University Press.

The Leadership Conference on Civil and Human Rights, 18 Million Rising, American Civil Liberties Union, Brennan Center for Justice, Center for Democracy \& Technology, Center for Media Justice, Color of Change, Data \& Society Research Institute, Demand Progress, Electronic Frontier Foundation, Free Press, Media Mobilizing Project, NAACP, National Hispanic Media Coalition, Open Media and Information Companies Initiative, Open Technology Institute at New America and Public Knowledge (2016) Predictive Policing Today: A Shared Statement of Civil Rights Concerns. 31 August. Available at http://civilrightsdocs.info/pdf/FINAL_JointStatementPredictivePolicing.pdf (accessed 30 April 2020).

Leese M (2014) The New Profiling: Algorithms, Black Boxes, and the Failure of AntiDiscriminatory Safeguards in the European Union. Security Dialogue 45(5): 494-511. 
Lum K and Isaac W (2016) To Predict and Serve? Significance 13(5): 14-19.

Mann M and Matzner T (2019) Challenging Algorithmic Profiling: The Limits of Data Protection and Anti-Discrimination in Responding to Emergent Discrimination. Big Data $\mathcal{E}$ Society 6(2): 1-11.

Matzner T (2016) The Model Gap: Cognitive Systems in Security Applications and Their Ethical Implications. AI \& Society 31(1): 95-102.

McCarthy M, Porter L, Townsley M and Alpert G P (2019) Influence of Community Characteristics on Serious Police Use of Force Events in an Australian Policing Jurisdiction: A Test of Minority Threat, Social Disorganisation, and Ecological Contamination Theories. Policing and Society 29(9): 1091-1108.

Meinicke D (2015) Big Data und Data-Mining: Automatisierte Strafverfolgung als neue Wunderwaffe der Verbrechensbekämpfung? Kommunikation \& Recht 18(6): 377-384.

Miller B (2020) Is Technology Value-Neutral? Science, Technology, \& Human Values. Online first. doi:10.1177/0162243919900965.

Miller K (2014) Total Surveillance, Big Data, and Predictive Crime Technology: Privacy's Perfect Storm. Journal of Technology, Law and Policy 19(1): 105-146.

Moravec H (1988) Mind Children: The Future of Robot and Human Intelligence. Cambridge: Harvard University Press.

Mulgan R (2003) Holding Power to Account: Accountability in Modern Democracies. Basingstoke: Palgrave Macmillan.

Neyland D (2016) Bearing Account-Able Witness to the Ethical Algorithmic System. Science, Technology \& Human Values 41(1): 50-76.

O’Donnell R M (2019) Challenging Racist Predictive Policing Algorithms Under Equal Protection Clause. New York University Law Review 94(3): 544-580.

Okon G (2015) Vorhersagen von Straftaten - Vision oder Wirklichkeit? arcAKTUELL 4: 22-23.

O’Neil C (2016) Weapons of Math Destruction. London: Penguin Books.

Parasuraman R and Wickens C D (2008) Humans: Still Vital after All These Years of Automation. Human Factors 50(3): 511-520.

Pasquale F (2015) The Black Box Society. Cambridge: Harvard University Press.

Philipps C and Bowling B (2017) Ethnicities, Racism, Crime, and Criminal Justice. In Liebling A, Maruna S and McAra L (eds.) The Oxford Handbook of Criminology. Oxford: Oxford University Press, 190-212.

Punch M (2009) Police Corruption: Deviance, Reform and Accountability in Policing. Cullompton: Willan Publishing.

Punch M (2011) Shoot to Kill: Police Accountability, Firearms, and Fatal Force. Bristol: The Policy Press.

Rademacher T (2017) Predictive Policing im deutschen Polizeirecht. Archiv des öffentlichen Rechts 142(3): 366-416.

Reiner R (2010) The Politics of the Police. Oxford: Oxford University Press.

Rey E (2014) PredPol Is Not Minority Report: It Doesn't Focus on Individuals. PredPol Blog. 15 August. Available at http://blog.predpol.com/predpol-is-not-minority-report (accessed 30 April 2020).

Richardson R, Schultz J and Crawford K (2019) Dirty Data, Bad Predictions: How Civil Rights Violations Impact Data, Predictive Policing Systems, and Justice. New York University Law Review Online 192: 1-30.

Robinson D G (2018) The Challenges of Prediction: Lessons from Criminal Justice. I/S: A Journal of Law and Policy for the Information Society 14(2): 151-186.

Rogers E M (2003) Diffusion of Innovations. 5th Edition. New York/London/Toronto/Sydney: Free Press. 
Rosenbaum D P (2019) Critic: The Limits of Hot Spots Policing. In Weisburd D and Braga A A (eds.) Police Innovation: Contrasting Perspectives. 2nd Edition. Cambridge: Cambridge University Press, 314-344.

Sanders C B and Sheptycki J (2017) Policing, Crime and "Big Data": Towards a Critique of the Moral Economy of Stochastic Governance. Crime, Law and Social Change 68(1): 1-15.

Schweer M and Schweer T (2015) Musterbasierte Prognosetechnik bei der Kriminalitätsbekämpfung: Die Methodik der Near Repeat Prediction. Polizeispiegel 49(5): 22-24.

Schweer T (2015) "Vor dem Täter am Tatort" - Musterbasierte Tatortvorhersagen am Beispiel des Wohnungseinbruchs. Die Kriminalpolizei 32(1): 13-16.

Schweer T (2018) Predictive Policing mit Precobs. In Institut für Versicherungswirtschaft der Universität St. Gallen (ed.) St. Gallen Trendmonitor für Risiko- und Finanzmärkte. Produkt- und Serviceinformationen 40(1). St. Gallen: Universität St. Gallen, 12-14.

Schweer T (2020) “Am Anfang war die Stecknadel”: Predictive Policing als Teil moderner Polizeiarbeit. In Bode F and Seidensticker K (eds.) Predictive Policing: Eine Bestandsaufnahme für den deutschsprachigen Raum. Frankfurt am Main: Verlag für Polizeiwissenschaft, 129-145.

Selbst A D (2017) Disparate Impact in Big Data Policing. Georgia Law Review 52(1): 109-195.

Shapiro A (2017) Reform Predictive Policing. Nature 541(7638): 458-460.

Shapiro A (2019) Predictive Policing for Reform? Indeterminacy and Intervention in Big Data Policing. Surveillance \& Society 17(3-4): 456-472.

Sheehey B (2019) Algorithmic Paranoia: The Temporal Governmentality of Predictive Policing. Ethics and Information Technology 21(1): 49-58.

Sheridan T B and Verplank W L (1978) Human and Computer Control of Undersea Teleoperators. Cambridge: Man-Machine Systems Laboratory/Department of Mechanical Engineering.

Singelnstein T (2018) Predictive Policing: Algorithmenbasierte Straftatprognosen zur vorausschauenden Kriminalintervention. Neue Zeitschrift für Strafrecht 37(1): 1-9.

Skolnick J H and Fyfe J J (1993) Above the Law: Police and the Excessive Use of Force. New York: The Free Press.

Smith D A (1986) The Neighborhood Context of Police Behavior. In Reiss A J and Tonry M (eds.) Communities and Crime. Chicago/London: University of Chicago Press, 313-342.

Stenning P C (ed.) 1995. Accountability for Criminal Justice: Selected Essays. Toronto: University of Toronto Press.

Susser D (forthcoming) Predictive Policing and the Ethics of Preemption. In Jones B and Mendieta E (eds.) The Ethics of Policing: Interdisciplinary Perspectives. New York: New York University Press.

Walker S E (1993) Taming the System: The Control of Discretion in Criminal Justice, 1950-1990. Oxford: Oxford University Press.

Walker S E and Archbold C A (2020) The New World of Police Accountability. Thousand Oaks/London/New Delhi/Singapore: Sage.

Weitzer R and Tuch S A (2006) Race and Policing in America: Conflict and Reform. Cambridge/New York: Cambridge University Press.

Wexler R (2017) Life, Liberty, and Trade Secrets: Intellectual Property in the Criminal Justice System. Stanford Law Review 70(5): 1343-1429.

Wilson D (2018) Algorithmic Patrol: The Futures of Predictive Policing. In Završnik A (ed.) Big Data, Crime and Social Control. London/New York: Routledge, 108-127.

Winter M (2015) Osteuropäische Einbrecherbanden auf Beutezug durch die Republik. Kriminalistik 69(10): 572-575.

Wolf G T (2010) The Data-Driven Life. New York Times. 28 April. Available at www.nytimes. com/2010/05/02/magazine/02self-measurement-t.html (accessed 30 April 2020). 
Zarsky T Z (2013) Transparent Predictions. University of Illinois Law Review 4: 1503-1569. Zarsky T Z (2016) The Trouble with Algorithmic Decisions: An Analytic Road Map to Examine Efficiency and Fairness in Automated and Opaque Decision Making. Science, Technology \& Human Values 41(1): 118-132.

Završnik A (2018) Big Data: What Is It and Why Does It Matter for Crime and Social Control? In Završnik A (ed.) Big Data, Crime and Social Control. London/New York: Routledge, 3-28.

Završnik A (2019) Algorithmic Justice: Algorithms and Big Data in Criminal Justice Settings. European Journal of Criminology. Online first. doi:10.1177/1477370819876762. 


\section{The future of (predictive) policing}

Throughout this book, we have unraveled the intricacies of predictive policing. We have demonstrated how sociotechnical practices of crime prediction and crime prevention include a multitude of human and nonhuman actors that all need to work together in order to produce and transmit knowledge and power. Without proper coordination between heterogeneous elements such as theories, algorithms, databases, maps, emails, and perceived deviance and suspicion, so our study has highlighted, insights about possible futures will fizzle out and targeted crime prevention will come to a grinding halt. An analysis of predictive policing, as we have argued, must thus pay careful attention to the diverse translation processes that continually happen between a multitude of social and technical components.

Translation sites are the critical junctions in the production and enactment of criminal futures. Without translation, insights about potential crime risk will not find their way from the back office to the patrol car. Analyzing criminal futures in terms of everyday police work then means to foreground the organizational, cultural, and epistemic gaps within the sociotechnical system that is predictive policing. We have seen that there are few instances of smooth transition from one stage to the next. Criminal futures must be actively enabled to speak to the lifeworlds of different, specialized stages of police work. This renders crime prediction a labor-intensive process that needs to be continually repeated in order to stay ahead of - or at least keep up with - current criminal events.

When introduced into police organizations, predictive policing realigns things and humans so that they can work together in the production and prevention of criminal futures. This means that work routines become tweaked, job profiles redefined, internal and external communication processes restructured, and not least, that police officers on all levels need to be convinced to integrate algorithmically produced crime forecasts into their daily work practices.

However, predictive policing does not only trigger organizational change. As we have shown through the study of the everyday work practices of crime prediction and crime prevention, it reconfigures the ways in which the police produce knowledge about the occurrence and distribution of crime across time 
and space. It recalibrates how the police perceive and patrol danger and vulnerability, and it affects the relationships between the police and the public. In particular, it involves some concerning tendencies in terms of aggravating already problematic police practices with regard to the production of deviance and suspicion - while at the same time cloaking discrimination and profiling in alleged rationalization and algorithmic opacity.

In-depth empirical engagement with predictive policing in everyday police work, that much was obvious from the start, would inevitably debunk some of the grand claims that software companies, politicians, and police managers attribute to it. Going back to the opening paragraph of this book, we could at this point ask ourselves what IBM's predictive policing commercial might have looked like if it was not about a glorified techno-utopia where a patrol officer just needs to look at a screen in order to receive precise information about where and when crime is bound to happen, but was instead an honest account of crime prediction and crime prevention.

Rather than simply showing us the patrol officer and the high-tech equipment installed in his patrol car, the commercial could have started with how some of his colleagues produce data at a crime scene. Alternatively, it could have illustrated how data from external sources such as other public agencies or private companies become integrated into police databases. In any case, it would have needed to foreground how any dataset needs to undergo quality control processes and be carefully prepared for analysis before it can be algorithmically processed.

The commercial could have shown how analysts work with crime prediction software. Even though the division of workload between humans and machines is being reconfigured through automation of analytical processes, there remains a substantial manual element. For operational, legal, and not least, normative reasons, police organizations insist on meaningful control of algorithmic processes. Fully automated and continuous crime analysis as a background process is technically possible but, in fact, unlikely to manifest in security contexts where decisions based on faulty intelligence can have severe consequences and where public servants need to act - at least in principle - in accountable ways. The commercial could in this sense have highlighted how human analysts double-check machine recommendations and discuss the plausibility of crime risk among themselves before any risk estimates are made available to patrol units.

Equally, the commercial could have shown how analysts send emails, pick up their phones and call their colleagues, or even attend meetings and shift briefings in order to communicate their analytical insights. Likewise, it could have engaged with the work environment of patrol forces and shown how they often need to act as "fire brigades" that rush from one urgent incident to the next, having little time left to actually patrol the way one would imagine: by freely roaming space and watching out for danger, en route deterring criminals by rendering the police visible and changing the cost-benefit ratio of crime. 
Last, but not least, if nothing else, an honest commercial would have made it clear that precise predictions for individual behavior (i.e., a known criminal attempting to rob a specific convenience store on a particular day and at a particular time) are not something that can be achieved with statistical methods. Approaches to predictive policing can take diverse shapes. They can range from rule-based to dynamic models and might even include machine learning techniques. They can cover the distribution of crime across time and space or assess individual threat/vulnerability levels. And they can process a wide range of data. But even the most advanced algorithmic calculations remain precisely that - calculations, based on data input and theoretical assumptions. And any calculation might be easily rendered irrelevant by the sheer contingency of the future.

But, of course, a commercial is not interested in telling us that things are complicated and uncertain. It is not interested in explicating the formation of sociotechnical systems. It is not keen on showing how police organizations deal with change that is brought about by new technologies or how such new technologies might trigger resistance as they force officers out of their comfort zone and redefine job profiles. It is not interested in exploring how predictive policing might in theory be quick enough to operate in real time and provide ongoing situational awareness and the possibility for flexible intervention but, in practice, becomes considerably slowed down by the entrenched, rhythmic interplay of social life, crime, and police work.

A commercial is also not interested in an analysis of how algorithms and humans produce different kinds of knowledge, based on how they perceive and understand the world in fundamentally different ways. It is not interested in how police organizations struggle to maintain meaningful control over algorithmic systems and subject them to multiple layers of institutional and practical oversight. It is not interested in detailing the ways in which crime risk is visualized and placed on maps in order to make it intelligible, tangible, and actionable - while at the same time assuring the beholder of its existence in the first place. And it is certainly not interested in the power that is inherent in choices about how to visually represent criminal futures in specific ways.

Neither is a commercial interested in foregrounding how predictive policing undermines the occupational culture of the police patrol and clashes with the traditional ways in which officers exercise their craft. It is not interested in an assessment of whether algorithmically produced crime risk is actually acted upon in the streets - and if so, in what fashion. Likewise, it is not interested in the uncomfortable epistemic quandaries that significantly complicate the question of whether predictive policing actually works - that is, whether it prevents crime. Positive side effects such as improved data-handling capacities or streamlined communication channels between different police divisions might be long-term assets for police organizations, but they are less well suited as legitimation for the procurement of an expensive new technology.

Finally, a commercial is not interested in telling stories about how the turn toward data and digital methods not only renders the police potentially more 
effective and efficient, but at the same time, creates a number of deep-rooted ethical and legal concerns about how algorithms reproduce and transform bias and how such bias affects the behavior of humans in ways that add to already existing social tensions vis-à-vis policing.

Needless to say, a commercial would of course not be the adequate format to discuss these issues. That is what this book is for. We hope that our study has provided some of the depth that is needed to understand the characteristics of predictive policing, to grasp its embeddedness in larger political agendas as well as police culture, and to assess its transformative potential for police work. Through our empirical engagement with predictive policing not as an isolated technical artifact but as a sociotechnical practice that is placed within larger trajectories of police organizations, we have foregrounded the importance of translation processes that allow knowledge and power to travel through police organizations and make their way from the analyst's desk to the street level.

Rather than simply summarizing the main arguments we have presented throughout the book, this final chapter aims to place our study within larger trajectories of police reform and future trends of policing. As we have shown, current algorithmic crime prediction tools are on the one hand firmly rooted in established criminological theories and crime analysis methods, but on the other hand significantly move beyond them. By automating and speeding up complex analytical tasks, predictive policing has introduced unprecedented capabilities into police work. And while it might for many police departments have been the first concerted effort to venture into the possibilities of the digital, it will certainly not be the last. Police departments are in fact just scratching the surface of digital methods and data exploitation. The remainder of this chapter will explore how predictive policing has exposed a number of structural shortcomings and put them on the reform agenda and how future versions of predictive policing software are likely to further strengthen trends toward the datafication and platformization of police work.

Most importantly, however, we will use the empirical findings from our field research to draw up some insights about how data-driven analytics in police work could now and in the future be implemented and used in responsible ways. These practical recommendations will speak to the needs of police organizations as much as they will speak to the protection of civil liberties and human rights.

\section{From experiment to structural reform}

The implementation of predictive policing software was in many regards a litmus test for police departments' capabilities to process data in unprecedented quantity and with unprecedented speed and frequency. As we argued in Chapters 3 and 8 , the introduction of predictive policing was seen by police departments as a form of experiment, designed not only to respond to the need to bring burglary numbers down but also to explore their organizational readiness 
to incorporate cutting-edge digital tools. The frictions that the production, dissemination, and enactment of algorithmic crime predictions have caused in everyday work practices were in this sense at least partially to be expected. The incorporation of novel crime analysis tools is in this regard not much different from the first major wave of digitization of police work that took place in the late 1990s and early 2000s.

At the same time, as evaluation reports on predictive policing have shown, police departments have seized the opportunity of the implementation of a new technology to identify areas for future reform. Predictive policing has in fact revealed a number of possible breaking points that could undermine police organizations' ability to thrive on data-driven tools. If there was a major lesson that police departments learned from the implementation of predictive policing software, then this lesson was that they were not "ready" to fully embrace algorithmic means of crime analysis. In many cases, existing IT infrastructures were not able to meet the data-handling requirements needed for the seamless use of predictive policing software. In addition, predictive policing highlighted legal limitations that restricted systematic data exchange across jurisdictional boundaries. And not least, it became apparent that police departments tended to lack adequately trained personnel with a clear understanding of how to implement and operate advanced analytical tools.

Some of these issues were well known even before the advent of predictive policing. The procurement and/or development of predictive policing software, coupled with the public attention that was directed at the police, however, did provide a window of opportunity to put entrenched problems at the top of the reform agenda. Reform efforts must thereby be understood both as a remedy for predictive policing itself and as a broader investment in the future that might be paving the way for more systematically "datafied" ways of policing.

However, as our informants admitted, structural reform does not come easy vis-à-vis the idiosyncrasy and relative autonomy of regional and local police departments (I02; I18; I51). It is further complicated by federal structures that subject police organizations to varying political programs and levels of financing. In both Germany and Switzerland, there is a large degree of fragmentation between police departments when it comes to databases, software solutions, and network structures. Coordination between jurisdictions is often only loose and informal, and there might even be more or less open "rivalries" between police departments, leading to solo efforts in the fight against crime rather than cooperation (USIS, 2001b, 2001a, 2002; Schiess and Schneider, 2003; Leese, 2018; Heitmüller, 2019).

A pertinent effect of such fragmentation is that crime analysis by default stops at jurisdictional boundaries. Police departments can work with the data that they have available for their jurisdiction (i.e., city or state), but they have no real way of identifying larger patterns that extend beyond their digital field of vision (I19; I22; I46; I78; P49). In practical terms, this means that there is a 
risk of potential trigger incidents not being identified at the edges of a certain territory, thus undercutting the capacities of predictive policing software. At the same time, it means that criminals could, by regularly crossing jurisdictional boundaries, easily avoid the "patterning" of their activities and effectively shield themselves from targeted prevention measures. In other words, even when two police departments in neighboring jurisdictions are using compatible databases and the same software package for predictive policing, they may not be able to pool their analytical activities. Data exchange across jurisdictions is, of course, in principle possible, but due to data protection legislation, it cannot usually be done in an automated fashion. Rather, it must be justified individually on a case-by-case basis, thus eradicating the time-saving potential of algorithmic crime analysis and undercutting the idea of timely response (Leese, 2018).

In light of these limitations, several initiatives have now been launched that seek to address the legal foundations for data exchange between jurisdictions. In Switzerland, the high-level working group of cantonal police chiefs (Konferenz der Kantonalen Polizeikommandanten, KKPKS) in 2019 identified the need for cross-cantonal pattern recognition in crime analysis as a primary goal in order to keep up with criminal activity that is considered highly mobile and professionalized (D373). As a response, a project on "National Crime Analysis" (Nationale Kriminalanalyse) has been tasked with the identification of a common definition of crime analysis and corresponding processes, the definition of software standards, and the exploration of legal prerequisites for an automated exchange of crime data between all Swiss cantons (D373). As a model for national harmonization, the KKPKS has pointed to the regional police association of Northwestern Switzerland (Polizeikonkordat Nordwestschweiz), comprising the cantonal police departments of Aargau, Berne, Basel-Landschaft, Basel-Stadt, and Solothurn (D374), which has already put forward an initiative for formalized data exchange for crime analysis (D373).

Based on the assessment that the legal basis for the cross-cantonal exchange and processing of data that are relevant for crime analysis and larger situational assessment was weak, Northwestern Swiss police departments had in 2018 started to explore how coordination on crime analysis could be rendered more technologically up to date, more future oriented, faster, more efficient, more coherent, and less costly (D360). The initiative explicitly referred to predictive policing and other risk-oriented forms of crime analysis (PRECOBS as well as the police-internal analysis tool PICAR) as a main reason for the cross-cantonal harmonization requirement, arguing that analytical insights would otherwise be restricted by cantonal borders (D360). At the same time, the need for strict legal oversight of any form of automated data and intelligence exchange was highlighted, particularly given the uncertain and volatile nature of some of the data that would be shared (D361). Eventually, a formal arrangement for data exchange for use in digital crime analysis systems was agreed upon in September 2019 (D375). At the time of writing, parliamentary approval is still pending, but this is expected to materialize at some point in 2020 (D373). 
A similar agreement could, according to the plans of the KKPKS, in the future be established on a national scale.

However, not only are legal foundations currently being targeted but also the fragmented landscape of police departments and the variations in technical infrastructures. One of the most prominent initiatives for the harmonization of federal police structures is Police 2020 (Polizei 2020). Initiated by the German Federal Ministry of the Interior, one of the primary goals of the project is to improve the availability of crime data and to overhaul fragmented and outdated IT systems (Kaller, 2019; Bundeskriminalamt, n.d.). It explicitly foregrounds the goal of streamlining the digital databases of all relevant police agencies in Germany in order to facilitate data sharing and crime analysis between different police organizations (Bundesministerium des Innern, 2018: 8). In order to do so, it aims at establishing a centralized digital platform that can be accessed by any authorized officer (Lezgus, 2019: 26).

Framed as a milestone on the road to modern police organization and digital methods (Bundeskriminalamt, n.d.), Police 2020 is being promoted as the key innovation piece that will finally empower German police departments to exploit the analytical possibilities of large quantities of data in a systematic fashion. Police 2020 is not only set to facilitate the collaborative development of capabilities and tools between different police organizations but also supposed to provide both a development platform and a kind of app store for future crime analysis applications (Münch, 2019). Commentators expect that Police 2020 will indeed provide a stepping stone for the modernization of police work and fundamentally change how police departments will restructure their activities based on data analysis (Kaller, 2019).

Another pertinent example of structural reform is the Police Information and Analysis Network (Polizeilicher Informations- und Analyseverbund, PIAV), which partially went live in April 2016 (Deutscher Bundestag, 2016: 8) and has, after an initial stand-alone phase, been integrated into the larger project context of Police 2020 (Bundesministerium des Innern, 2018: 6f). Being part of the Information System of German Police Organizations (Informationssystem der Deutschen Polizei, INPOL), PIAV pools data from the process management and case management databases of all federal and state police organizations and makes them available for strategic and operational crime analysis. One of the primary goals of PIAV is to enable police departments to identify regional and supra-regional crime series and trends more quickly and empower a systematic response (Bundeskriminalamt, 2017a; Bundesministerium des Innern, 2018). PIAV thus corresponds closely with the main rationale of predictive policing (i.e., the identification of patterns in criminal activity) but widens the analytical scope from localized phenomena to, at least in theory, the entire country.

At the same time, PIAV directly speaks to questions of the data basis for crime analysis. As we discussed in Chapter 4, the availability of data within police organizations is usually not a primary concern. The police produce large amounts of data on a regular basis as part of their daily activities. Moreover, 
additional data can be either obtained from other public service agencies or purchased from private companies. One of the main issues surrounding crime data is rather its accuracy and reliability. The rationale of PIAV is that combining data from a large number of police organizations will allow for the synchronization and verification of information and thus address persistent concerns about the quality of crime data. Through a centralized and vetted provision of high-quality crime data, PIAV is thus supposed to provide a structured hub for data collection and data exchange across different police organizations, thereby opening up novel and unprecedented forms of cooperation (Bundeskriminalamt, n.d.).

The desire for a reform of data infrastructures was also a common theme during our research. Our interviewees, particularly more senior officers and analysts, frequently put forward that traditional database architectures needed to be replaced by data warehouse structures that would enable police organizations to cross-search databases, use automated data exchange processes, and get rid of problems with poorly designed and nonstandardized user interfaces (I07; I26; I31; I36; I38; I45; I46; I50; I56; I78; I79; P49; P52; P70; P77). One senior officer described the current fragmented landscape of police databases and the resulting problems for crime analysis practices as follows:

We have a number of core systems: process management, case management, INPOL applications, telex, communication data, and so on. There are quite a few. ... The point is: all of them are silos, all of them are standalone systems. It is important to establish connections between these systems, so that we don't have to query 35 different databases when we want to know something about a person.

Finally, as we already briefly discussed in Chapter 5, the implementation of predictive policing has foregrounded the need for specialized personnel with professional training in computer science and statistics. In-depth understanding of how to translate theoretical assumptions into models and how to integrate data and run these models within an existing IT environment is not only important for the implementation of commercial off-the-shelf applications such as PRECOBS but is even more pertinent when it comes to the in-house development of analytical tools. Such expertise, however, is not usually a core competence for police officers, and even if individual officers are able to build such a skill set, traditional career paths are usually rather unsustainable in terms of institutional learning and knowledge management, as they prescribe the rotation of individuals between different divisions. In order to address these shortcomings, departments have started to explore how to systematize and professionalize crime analysis profiles as a distinct career path within police organizations, establish training programs, and to generally increase digital literacy among their staff (Bettermann-Jennes and Rabitz-Suhr, 2018; Hauber et al., 2019; Mahnken and Rabitz-Suhr, 2019). 
The initiatives we have outlined also correspond with a general professional framing of full-scale digitization as the most pertinent future direction in police work (Brückner, 2018). The agendas of large professional gatherings such as the European Police Congress or the "Police Days" (Polizeitage), for example, are currently overwhelmingly dominated by lectures and seminars on data analysis, artificial intelligence, digital work environments, and organizational readiness (Behörden Spiegel and Gewerkschaft der Polizei, 2019; Schmitz, 2019).

Against this backdrop, predictive policing must be understood as a symptom of larger trajectories of datafication of police work (i.e., the implementation of algorithmic systems for decision assistance and corresponding practices), just as it must be understood as a catalyst for structural reform (Egbert and Krasmann, 2019). The introduction and rapid diffusion of crime prediction software initially caused a hype in media coverage and public attention, but its long-term implications might be far more relevant for the future of policing. Predictive policing has put infrastructural, professional, and legal concerns around advanced data-driven forms of police work high on the reform agenda, where they resonate with the attention of politicians, police managers, and private industry.

\section{The expansion of predictive policing}

Structural reform projects are, however, only one side of the coin. Almost needless to say, predictive policing itself is not likely to stop its evolution at the current development level. As we have illustrated, existing predictive policing applications are in many regards still rather pedestrian. As with any technological tool that is still in the early stages of development, rollout, and institutional implementation and use, there is ample room for further development. This is true both for existing functionalities and for the incorporation of new features. In Germany and Switzerland, as we discussed in Chapter 3, trial runs were in fact deliberately kept open by both police departments and the software supplier so that practitioner feedback could be integrated into further development of the software. The general assumption was to start with a product that, while fully functional, was far from polished, and to jointly work out the kinks.

This principle of codevelopment has been extended into the regular use of predictive policing software. In the case of PRECOBS, in addition to being informally in touch with its clients on a regular basis, software manufacturer IfmPt organizes practitioner workshops where actors discuss their experiences and problems with the software - in this way providing valuable hints for future modifications (I02; I05; I09; I20; I44; I46; I50; I51; I80; P02; P52). Predictive policing must thus, just like any other software application, be considered a work in progress that will be subjected to changes over time and in accordance with its users' needs and preferences.

PRECOBS is in fact a pertinent example of how predictive policing software gradually expands in scope (the types of crime that are targeted, the 
underpinning theories, the concrete models that are used to detect patterns), data (more data, data from disparate sources), functionality (new analytical functions, visualization modes, improved interfaces with databases and other software tools), and technical architecture. The original version, launched in 2012 and now rebranded as PRECOBS Classic, was widely considered "too banal" (P77), as analysts felt that its narrow and static approach to the prediction of domestic burglary was limited with regard to both functionality and operational flexibility (I11; I41; I51; I62). These shortcomings were subsequently addressed through dialogue between users and developers. As one respondent detailed this process:

In the beginning, the functionalities were rather narrow. It was reliable, we could work with it. . . We were in dialogue with [police department A], [police department B] and [police department C] who were all also working with the software - and of course we figured out certain demands that we all had. Like "It would be nice if we could do this or that". And then we had a meeting with IfmPt and told them that we needed more functionalities and more flexibility. And they were like "Ok, we need to address that" - and this is how PRECOBS evolved over time.

Eventually, IfmPt decided to channel their clients' operational requirements into a radically overhauled new version of the software, PRECBOBS Enterprise, which was rolled out throughout 2019 and has, at the time of writing, been implemented by several German and Swiss police departments (I46; I50; I62; I66). There are several striking differences between PRECOBS Classic and PRECOBS Enterprise, including a completely new user interface, a revamped multilayer architecture based on a database connector/application server and multiplatform (browser, mobile devices) and web-based front-end applications for different user roles (i.e., analyst, operator, viewer), as well as remote maintenance and service functions (D002; D091; D287). While the new technical architecture is supposed to guarantee smooth import and processing of datasets from disparate sources and ensure flexible and adjustable interfaces with other software tools (D287), PRECOBS Enterprise also broadens the scope with regard to criminological theory and the statistical modeling of criminal patterns.

The new version includes (1) the possibility of using sociodemographic data in order to allow for a more fine-grained modeling and understanding of the relationship between crime and urban space, (2) the possibility of using weather data as a variable for criminal behavior, (3) the possibility of using data on mobility infrastructures such as highways or train stations in order to model offender movement, (4) "far-repeat" methodology to estimate risk spaces in rural areas where near-repeat theory cannot be applied, (5) a "journey-tocrime" approach that seeks to identify where anchor points for crime series 
could be located, (6) a "delta hot spots" function that indicates long-term trends in crime clusters, and (7) semantic analysis of free text reports (I77; D091; D288; D301).

These new analytical functionalities go hand in hand with the inclusion of other types of crime in addition to domestic burglary. PRECOBS Enterprise is now additionally supposed to be able to address shoplifting, robbery, pickpocketing, property damage, car theft, and theft from vehicles as well as sexual offenses (D288). It is not yet clear how some of these types of crime will be statistically captured and analyzed, as not all of them have yet been fully implemented (I50), but some police departments have, for instance, already started to use the journey-to-crime approach in order to pursue property damage caused by illegal graffiti. Starting from the assumption that sprayers tend to start working on objects close to their places of residence, the software thereby attempts to identify possible anchor points from the spatial distribution of graffiti (P49). Another key novelty in PRECOBS Enterprise is an early warning function that requires no active human intervention but is predicated upon the passive monitoring of predefined spaces, objects, persons, or events. Alerts will then be triggered automatically, based on manually configured thresholds for criminal activity or other variables (P49).

In light of these new features, it becomes quite clear that PRECOBS Enterprise, similar to recent developments in other applications such as PredPol (PredPol, 2019) or HunchLab (ShotSpotter, 2018), goes far beyond the initial scope of "merely" predicting criminal activity through an analysis of crime data. As a multifunctionality platform, it encourages analysts to tinker with available data and to carry out analyses based on intuition in a low-threshold, explorative fashion (I02; P49). Its stronger focus on a dynamic understanding of space and threats/vulnerabilities over time can be seen as an indicator of a gradual move toward risk terrain modeling. This conceptual move also corresponds with the incorporation of significantly more data and data sources. Moreover, in addition to analyses for operational use, PRECOBS Enterprise now enables a supplementary focus on the identification of long-term trends and support for strategic decision-making. Finally, the inclusion of several other types of "high-volume" crime is supposed to ascribe a larger role to its application in everyday police work.

From an economic perspective, such a reconfiguration of predictive policing certainly makes a lot of sense. There is a limited market for algorithmic crime analysis tools, and several German and Swiss police departments have already decided to pursue in-house software development strategies rather than rely on commercial products. Commercial predictive policing tools must thus, as one software developer put it, offer substantial added analytical value for police work that goes beyond the algorithmic production of risk estimates for specific types of crime: "PRECOBS must be more than just a tool for prognostics. . . We need to provide a tool for criminological analysis, and that includes geoprofiling, landmarks, sensors, and so on" (I01). 
The evolution of PRECOBS from a specialized tool for domestic burglary prevention toward a full-blown analytics suite was generally welcomed and appreciated by our interviewees. To a certain extent, of course, police departments had little choice but to be content with the direction of the development. After all, they were more or less closely involved in the process through their feedback. Moreover, having already procured the software, they needed to demonstrate that taxpayers' money was being well spent (I18; I50). Finally, the internal adjustments that police departments had made in order to accommodate predictive policing in their organizational structures and work routines presented additional sunk costs that made it difficult to pull the plug on PRECOBS and pursue a different strategy (although both the State Police Department of Baden-Württemberg and the Cantonal Police Department of Zurich decided in 2019 to withdraw from the use of PRECOBS and pursue in-house approaches to predictive policing instead). Overall, however, our interviewees did appreciate PRECOBS Enterprise and its new functionalities. As one police officer put it:

You have to admit that the PRECOBS software has come a long way. In the beginning it really was a niche application for predictive policing. But in the meantime, they have implemented a couple GIS functions and statistical tools. And they keep working on improving these features. ... PRECOBS Enterprise is a completely new version, with a new architecture, new user interface. .., its capacities now go way beyond predictive policing.

Similar expansion trends can also be witnessed in other predictive policing applications. The SKALA project, coordinated by the State Police Department of North Rhine-Westphalia, builds on supervised machine learning techniques for the further development of the SKALA | MAP software that targets several types of crime, including domestic burglary and burglary in commercial properties, car theft, and theft from vehicles (I35; D129; D142). Moreover, the project has started to hire computer scientists and data scientists whose task it is to model and integrate further types of crime into the software and to improve prediction quality and accuracy, for example through text mining techniques (I43; D129). In addition, SKALA now incorporates more finegrained topographical data (D142; Seidensticker, 2017), and the project team has experimented with different forms of visual representations and their effects on knowledge dissemination (Merbach and Stoffel, 2020). Similarly, continuous reform of the State Police Department of Lower Saxony's in-house predictive policing tool PreMAP is envisioned, including plans for broader prognostic functions and the inclusion of more types of crime (B57; Landeskriminalamt Niedersachsen, 2019).

However, the most radical version of "predictive policing and beyond" currently in use is arguably hessenDATA. Developed under the supervision of 
the State Police Department of Hesse, hessenDATA is based on the analytical platform Gotham by US software company Palantir Technologies and has been operational since 2018 (Hessischer Landtag, 2019b: 17). Palantir advertises Gotham on their website as a system that "integrates and transforms data, regardless of type or volume, into a single, coherent data asset" and facilitates intuitive, easy-to-use data mining methods. ${ }^{1}$ Gotham already had gotten some traction within US police departments (Brayne, 2017, 2021: 37ff), but Hesse is the first jurisdiction in Germany or Switzerland that has opted to pursue the use of a full-fledged cross-database analytical tool for policing and homeland security (Hessisches Ministerium für Inneres und Sport, 2018b: 59; Hessischer Landtag, 2019a: 1f).

The platform approach of hessenDATA speaks closely to the articulated need to modernize and harmonize IT infrastructures and databases in a proclaimed age of datafied police work. hessenDATA resembles the technical architecture of PRECOBS Enterprise, in that it establishes a virtual database layer that allows for the assembly and integration of data independent of its original location and format. In this fashion, analyses across multiple databases can be conducted through one centralized platform that can be accessed from anywhere - in theory resulting in unprecedented analytical volume and speed (Brayne, 2017: 994, 2021: 37ff; Hessischer Landtag, 2019b: 18). Not surprisingly, such an approach to data handling and crime analysis was praised by our interviewees and was at times even framed as a role model for other police departments (P52). One senior analyst described the advantages of hessenDATA as follows:

For future police work, from my perspective, it will be important to not just focus on data analysis but to use platforms and to recognize connections between our databases. That is our big challenge: not having to manually prepare data for analysis, but to fetch data from the source databases and integrate them in an automated fashion. Currently, our main task is to get the data ready for analysis. That's a lot of work, and it eats up time and resources that we would rather put into the actual analysis. That is what we must tackle: to have systems . . . to find possibilities to harmonize data from disparate sources in an automated fashion, and to make these data available for analysis. . . hessenDATA for instance does exactly that. I'm a big fan of hessenDATA, it's exactly what we need.

Other German states have already made plans to follow the example of hessenDATA. North Rhine-Westphalia has announced the development of a system for cross-database analysis and research that strongly resembles Palantir's Gotham software (Landeskriminalamt Nordrhein-Westfalen, 2019), and there are concrete plans for further collaboration with Palantir (Landeskriminalamt Nordrhein-Westfalen, 2020). The State Police Department of RhinelandPalatinate has launched a similar project to evaluate the added value of analysis 
platforms for police work, including the modernization of the department's database system and the development of a cross-cutting, comprehensive analytics platform (Schmidt-Wyk, 2019). And the State Police Department of Bavaria is currently conducting a research project on the potential of a research and analysis platform (Bayerisches Landeskriminalamt, 2019).

An aspect that warrants close monitoring in the future is the potential conflation of place-based and person-based approaches. hessenDATA and similar applications such as RADAR-iTE (an analytical tool for risk assessment geared towards terrorism and violent extremism developed by the German Federal Criminal Police Office) include functionalities for the identification and evaluation of individuals who are considered to pose a particular risk for public safety, particularly with regard to terrorism and organized crime (Bundeskriminalamt, 2017b; Hessisches Ministerium für Inneres und Sport, 2018a). Although such analyses are mostly still limited to a scoring system based on traditional questionnaires (I47; I72; D221), the functional integration of counterterrorism and transnational law enforcement into analytical platforms for police work could be an indication that the boundary between domestic policing and intelligence/national security might in the future become eroded.

Predictive policing, as these examples demonstrate, remains a dynamic field. After a brief consolidation phase, it appears that both software companies and police departments themselves are now aspiring to take the next step. New and updated versions of predictive policing tools include larger quantities of data from various sources, they incorporate additional criminological theories and model threats and vulnerabilities in a more dynamic fashion, and they are moving away from a narrow focus on domestic burglary by including other types of pertinent high-volume crimes and possibly individual risk profiling approaches. New analytical functions go beyond the initial idea of merely predicting crime, as predictive policing tools aspire to become more firmly anchored in analytical work through a number of explorative and investigative features. The most important trend, however, seems to be the move toward technical architectures that allow for the establishment of virtual, cloud-based analysis platforms that do away with the limitations of outdated databases and silo structures.

Such a "platformization" (Egbert, 2019; Gates, 2019; Wilson, 2019) of police work corresponds closely with datafication trends and structural reforms that are supposed to put police departments in a position where they can fully embrace the opportunities of digital environments. Taken together, these trends might in fact unfold a mutually reinforcing dynamic - the more police departments improve on infrastructures, professional skills, and legal initiatives, the more advanced analytical tools they will be able to use. And the more data-hungry platforms are incorporated into police work, the more likely will the increased production of crime data and integration of other data sources become.

It seems to be a safe bet to say that predictive policing is here to stay. There might be uncertainties regarding its look, scope, and capacities. After all, the 
outlined trends are once more based on the imaginaries of police organizations, politicians, and private companies - and there is no guarantee that they will materialize in the currently outlined forms. Nonetheless, our interlocutors unanimously agreed in their assessment that predictive policing will in the future be an integral part of police work (I02; I03; I05; I07; I10; I17; I18; I27; I31; I36; I42; I43; I46; I50; I51; I57; I76; I80). As one respondent concisely summarized the general expectations:

Ten years from now . . . I mean I have no idea where we will be technologically by then, but the major difference to today will be that predictive policing will be an inherent part of our toolkit and how we police. Independent of how software develops and which domains it will cover, it will be widely accepted as a standard tool. Just like today we work with tools that would have been inconceivable ten years ago.

The idea of predictive policing, as we have shown in this book, speaks closely to a number of pertinent long-term trends in police work, including futureorientation, scientification, rationalization, managerialism, and not least a certain techno-fetishism. Moreover, it picks up and reinforces current trends toward digitization and datafication in policing. And at the same time, it can be considered a stepping stone toward structural reform and the large-scale integration of data and analytical tools in multipurpose platforms. Predictive policing can thus be seen as emblematic for a multiplicity of larger trajectories in police work, and insights about how predictive policing reconfigures police organization and police practices can provide valuable indications of broader societal questions that emerge from the combination of data, algorithms, and security.

Although our study has been empirically limited to predictive policing in localized contexts, we believe that some general pointers for the future of datadriven security practices can be derived. The final section of this book outlines a number of takeaways that will be relevant both for academics and practitioners and decision-makers.

\section{Closing remarks: some words of caution}

As we have demonstrated throughout this book, predictive policing, even in narrow and straightforward variants, is an inherently complex practice that involves a multiplicity of human and nonhuman elements working together in intricate ways. Independent of possible future scenarios of data abundancy and all-encompassing, cross-cutting analysis platforms, data-driven analytics have profound implications for the police and their relations with society. The algorithmic production of criminal futures is already reconfiguring the ways in which the police as an organization perceive the world and act within it. It is 
already striking at basic principles of nondiscrimination and the just distribution of public services. And it already has the potential to cloak intelligence production, decision-making, and institutional accountability within complex and opaque systems.

Some words of caution are thus in order. Not without good reason, algorithmic systems for crime analysis and crime prevention have sparked concerns among civil liberties groups and critical scholars. While some critiques might be overblown and/or based on science-fiction narratives or hypothetical future scenarios rather than on actual analyses of existing tools and practices, debates about the societal impact of predictive policing are highly important. The way in which society is policed directly concerns one of the most fundamental societal challenges: the creation and maintenance of social order and justice. Predictive policing calls for close and critical attention, both now and in the future.

Rather than perpetuating a presumed conflict between the police and society where the former seek to exploit data and technology for purposes of surveillance and coercion and the latter tries to defend its freedom, our research calls for a more nuanced perspective. At least some of our interlocutors demonstrated a refined understanding of the problems that algorithmic crime analysis can bring into police work. Senior officers and analysts, in particular, were well aware of both the opportunities and the potential drawbacks that are inherent in technoscientific advances. And although the police are certainly no advocates of rigorous privacy and data protection legislation, we found throughout our research that police departments demonstrated an awareness of the need to act in accountable ways. This was maybe most pertinently reflected in the ways in which departments were bent on maintaining control over automated analytical processes and on retaining authority in decision-making processes between humans and algorithms.

At the same time, scholars have already suggested ways in which data could possibly be used not just to support police work, but also to foster police accountability and improve police departments' relations with the public. Ferguson (2017: 143ff) has, for instance, introduced the idea of "blue data" that could be used to reduce police violence and racialized practices. Databases could, in this sense, be used to store and analyze complaints about individual officers or entire departments and to identify patterns of misconduct and their structural underpinnings. Similarly, Barabas et al. (2018) have suggested that data-driven tools could be geared toward the identification of root causes of crime, thus enabling more sustainable, long-term strategies for crime prevention. What these and other proposals have in common is the idea to turn analytics inward and to mobilize the capacities of algorithms and data to improve the quality of policing.

It remains to be seen how such promising approaches play out in the future. Organizational adaptation and learning, as earlier studies on the implementation of new technologies within police departments have demonstrated, take 
time. Just as actors and technological infrastructures need to be aligned with predictive policing software in order to ensure the translation of risk estimates into operational prevention measures, normative and legal considerations must also become aligned with new capacities of data processing and targeted action. The formation of a sociotechnical system, as we have shown throughout this book, is likely to generate a number of unforeseen consequences and curious side effects. For instance, questions of data production and classification systems all of a sudden gained renewed importance. Crime analysts found themselves arm-wrestling with algorithms. And there was a renaissance for crime maps that give a tangible form to complex calculations.

The police have, in many respects, arrived late to the digital party, but they are now trying to catch up with debates and best practices that have been prevalent in the private industry for quite some time. Ferguson (2017: 188) has, in his analysis of the discriminatory potential of the use of "Big Data" technologies in US police departments, foregrounded that police decision-makers should at any point in time be able to identify the risks that a technology is trying to address, defend the inputs and outputs of a system, test a technology, and ensure its respectful use. These are important points, and we fully endorse them. Complementing Ferguson's recommendations from an "inside perspective" based on more than three years of empirical research on predictive policing and the frictions and tensions we were able to witness in everyday police work, we would like to end this book with the following advice for practitioners - be they politicians, police chiefs, managers, analysts, shift supervisors, or patrol officers:

(1) Data must not be mistaken for a true representation of the world. They are always a partial account that has been constructed within a particular context and for a particular purpose. A healthy degree of skepticism toward data is appropriate, especially when they are acquired from external sources.

(2) Algorithmic crime analysis tools must always remain transparent and comprehensible, independent of whether they are commercial products or inhouse developments. Overly complex and/or black-boxed applications will undercut institutional accountability and potentially trigger resistance among police staff.

(3) Full automation of analytical processes should in principle be ruled out. Human analysts must always remain in the loop and have meaningful control over system functions. That means that algorithmic systems must not withhold information from the user or proceed at critical junctions without user approval.

(4) Decisions must always be made by humans. In light of possible automation bias, critical engagement with algorithmic recommendations should be encouraged and the right to override them should be facilitated and institutionally enshrined. 
(5) Communication of risk estimates should specifically indicate that risk must not be treated as evidence, but as a possibility. Criminal futures, even when convincingly presented, may not come into being after all.

(6) Risk estimates can have performative effects on individual behavior. Patrol officers, in particular, should be aware of how their perception might be affected by imaginaries of criminal futures and how this might impact their interactions with citizens.

(7) The capacities and limitations of predictive policing must be carefully assessed. It should remain a complementary tool and not replace long-term strategic programs that address the root causes of crime.

We hope that paying attention to these principles will speak to the requirements of civil society as much as to the requirements of police organizations. They apply to current forms of predictive policing, and they will apply equally to future versions of predictive policing and other conceivable analytical tools. In the end, no one should have a serious interest in either impeding the capacities of the police as a guarantor of social order or in curtailing civil liberties and human rights.

\section{Note}

1 Available at www.palantir.com/palantir-gotham (accessed 30 April 2020).

\section{References}

Barabas C, Dinakar K, Ito J, Viza M and Zittrain J (2018) Interventions over Predictions: Reframing the Ethical Debate for Actuarial Risk Assessment. In Friedler S A and Wilson C (eds.) Proceedings of Machine Learning Research Volume 81: Conference on Fairness, Accountability and Transparency. 23-24 February, New York. 1-15.

Bayerisches Landeskriminalamt (2019) Markterkundungsverfahren (Projekt: Verfahrensübergreifende Recherche- und Analyseplattform). Available at www.it-ausschreibung. de/ausschreibung/57891/markterkundungsverfahren-projekt-verfahrensuebergreifenderecherche-und-analyseplattform (accessed 30 April 2020).

Behörden Spiegel and Gewerkschaft der Polizei (2019) Polizeitage 2019: Veranstaltungsübersicht. Available at www.polizeitage.de/wp-content/uploads/2019/03/Polizeitage_ Erfurt.pdf (accessed 30 April 2020).

Bettermann-Jennes U and Rabitz-Suhr S (2018) Informationsmanagement bei der Polizei: Digitalisierung als Herausforderung und Chance - Ergebnisse einer Sachbearbeiterbefragung der Polizei Hamburg. SIAK-Journal - Zeitschrift für Polizeiwissenschaft und polizeiliche Praxis 15(1): 13-26.

Brayne S (2017) Big Data Surveillance: The Case of Policing. American Sociological Review 82(5): 977-1008.

Brayne S (2021) Predict and Surveil: Data, Discretion, and the Future of Policing. Oxford: Oxford University Press.

Brückner A (2018) Der Megatrend in der TECHNIK der Inneren Sicherheit. Available at https://cives.de/tag/inpol-polas-competence-center-ipcc (accessed 30 April 2020). 
Bundeskriminalamt (2017a) Der Polizeiliche Informations- und Analyseverbund (PIAV). Available at www.bka.de/SharedDocs/Kurzmeldungen/DE/Kurzmeldungen/170307_ PIAV.html (accessed 30 April 2020).

Bundeskriminalamt (2017b) Presseinformation: Neues Instrument zur Risikobewertung von potentiellen Gewaltstraftätern. Available at www.bka.de/DE/Presse/Listenseite_ Pressemitteilungen/2017/Presse2017/170202_Radar.html (accessed 30 April 2020).

Bundeskriminalamt (n.d.) Das Programm "Polizei 2020". Available at www.bka.de/DE/ UnsereAufgaben/Ermittlungsunterstuetzung/ElektronischeFahndungsInformationssysteme/Polizei2020/Polizei2020_node.html (accessed 30 April 2020).

Bundesministerium des Innern (2018) Polizei 2020. White Paper. Available at www.bmi. bund.de/SharedDocs/downloads/DE/veroeffentlichungen/2018/polizei-2020-whitepaper.pdf?_blob=publicationFile\&v=1 (accessed 30 April 2020).

Deutscher Bundestag (2016) Drucksache 18/8533: Funktionsweise des Informationsaustauschs zwischen Polizeibehörden in Deutschland. Antwort der Bundesregierung auf die Kleine Anfrage der Abgeordneten Ulla Jelpke, Frank Tempel, Dr. André Hahn, weiterer Abgeordneter und der Fraktion DIE LINKE. Available at https://dipbt.bundestag.de/ dip21/btd/18/085/1808533.pdf (accessed 30 April 2020).

Egbert S (2019) Predictive Policing and the Platformization of Police Work. Surveillance \& Society 17(1-2): 83-88.

Egbert S and Krasmann S (2019) Predictive Policing: Not Yet, but Soon Preemptive? Policing and Society. Online first. doi:10.1080/10439463.2019.1611821.

Ferguson A G (2017) The Rise of Big Data Policing: Surveillance, Race, and the Future of Law Enforcement. New York: New York University Press.

Gates K (2019) Policing as Digital Platform. Surveillance \& Society 17(1-2): 63-68.

Hauber J, Jarchow E and Rabitz-Suhr S (2019) Prädiktionspotenzial schwere Einbruchskriminalität - Ergebnisse einer wissenschaftlichen Befassung mit Predictive Policing. Hamburg: Landeskriminalamt Hamburg.

Heitmüller U (2019) Missing Link: "Polizei 2020" - "Polizei 2030"? Heise Online. 25 August. Available at www.heise.de/newsticker/meldung/Missing-Link-Polizei-2020Polizei-2030-4504042.html (accessed 30 April 2020).

Hessischer Landtag (2019a) Drucksache 19/6864: Zwischenbericht des Untersuchungsausschusses 19/3zuDrucksache19/6574.3January. Availableathttps://www.bundesgesundheits ministerium.de/fileadmin/Dateien/3_Downloads/Gesetze_und_Verordnungen/ $\mathrm{GuV} / \mathrm{K} /$ Konversionstherapienverbot_bf_Beschlussempfehlung_GE_AfGesundh.pdf (accessed 30 April).

Hessischer Landtag (2019b) Drucksache 20/660: Kleine Anfrage Torsten Felstehausen (DIE LINKE) vom 20.05.2019: Hessendata - Teil 1 und Antwort Minister des Innern und für Sport. 22 July. Available at https://www.linksfraktion-hessen.de/fraktion/abgeordnete/ torsten-felstehausen/ (accessed 30 April 2020).

Hessisches Ministerium für Inneres und Sport (2018a) Innenminister besucht hessenDATA. Available at https://innen.hessen.de/pressearchiv/pressemitteilung/innenminister-besuchthessendata (accessed 30 April 2020).

Hessisches Ministerium für Inneres und Sport (2018b) Jahresbilanz 2018. Available at https://innen.hessen.de/sites/default/files/media/hmdis/jahresbilanz_2018_160119_ web.pdf (accessed 30 April 2020).

Kaller S (2019) Das Zukunftsprogramm der Polizei in Deutschland - Polizei 2020. Polizei Verkehr + Technik 64(1): 6-9.

Landeskriminalamt Niedersachsen (2019) Predictive Policing in Niedersachsen - Das Projekt PreMAP. Available at www.lka.polizei-nds.de/startseite/kriminalitaet/forschung/ 
premap/predictive-policing-in-niedersachsen - das-projekt-premap-114083.html (accessed 30 April 2020).

Landeskriminalamt Nordrhein-Westfalen (2019) Beschaffung eines Systems zur Datenbankübergreifende Analyse und Recherche (DAR) für die Polizei des Landes NordrheinWestfalen. Available at https://ausschreibungen-deutschland.de/550095_Beschaffung_ eines_Systems_zur_Datenbankuebergreifende_Analyse_und_Recherche_DAR_fuer_ die_2019_Duesseldorf (accessed 30 April 2020).

Landeskriminalamt Nordrhein-Westfalen (2020) LKA-NRW: Polizei NRW setzt bei Verbrechensbekämpfung und Gefahrenabwehr zukünftig neue Analysetechniken ein. Press Statement. 13 January. Available at www.presseportal.de/blaulicht/pm/58451/4490593 (accessed 30 April 2020).

Leese M (2018) Predictive Policing in der Schweiz: Chancen, Herausforderungen, Risiken. In Nünlist C and Thränert $\mathrm{O}$ (eds.) Bulletin zur schweizerischen Sicherheitspolitik. Zürich: Center for Security Studies, 57-72.

Lezgus A (2019) Ein gemeinsames Datenhaus entsteht. Moderne Polizei 1: 26-27.

Mahnken J and Rabitz-Suhr S (2019) Auswertung und Analyse 4.0: Das Projekt "Entwicklung Berufsbild Kriminalitätsanalytik”. Der Kriminalist 51(12): 21-26.

Merbach L and Stoffel F (2020) Bedarfsgerechte Visualisierung von Kriminalität. In Bode F and Seidensticker K (eds.) Predictive Policing: Eine Bestandsaufnahme für den deutschsprachigen Raum. Frankfurt am Main: Verlag für Polizeiwissenschaft, 289-310.

Münch H (2019) Kriminalitätsbekämpfung weiterdenken. Kriminalistik 73(1): 11-16.

PredPol (2019) Happy Birthday to PredPol! Predictive Policing Blog. 14 January. Available at https://blog.predpol.com/happy-birthday-to-predpol (accessed 30 April 2020).

Schiess E and Schneider M (2003) Föderalismus als Sicherheitsrisiko? Das kleinräumig organisierte Polizeiwesen der Schweiz stösst an seine Grenzen. Zürich: Avenir Suisse.

Schmidt-Wyk F (2019) Rheinland-Pfalz: Mit künstlicher Intelligenz auf Verbrecherjagd. Allgemeine Zeitung. 1 February. Available at www.allgemeine-zeitung.de/politik/rheinlandpfalz/rheinland-pfalz-mit-kunstlicher-intelligenz-auf-verbrecherjagd_19936052\# (accessed 30 April 2020).

Schmitz R (2019) Die Bedeutung von Daten für die Polizeiarbeit. eGovernment Computing. 21 February. Available at www.egovernment-computing.de/die-bedeutung-von-datenfuer-die-polizeiarbeit-a-802121/ (accessed 30 April 2020).

Seidensticker K (2017) Kriminalität in Mikrosegmenten. Forum Kriminalprävention 16(4): 26-31.

ShotSpotter (2018) Shotspotter Announces Acquisition of HunchLab to Springboard into AI-Driven Analysis and Predictive Policing. Press Release. 3 October. Available at www. shotspotter.com/press-releases/shotspotter-announces-acquisition-of-hunchlab-tospringboard-into-ai-driven-analysis-and-predictive-policing/ (accessed 30 April 2020).

USIS (2001a) Überprüfung des Systems der Inneren Sicherheit der Schweiz, Teil II: Grobe SollVarianten, Sofortmassnahmen. Bern: USIS.

USIS (2001b) Überprüfung des Systems der Inneren Sicherheit der Schweiz: Analyse des IstZustands mit Stärken-/Schwächenprofil. Bern: USIS.

USIS (2002) Überprüfung des Systems der Inneren Sicherheit der Schweiz, Teil III: Detailstudie. Bern: USIS.

Wilson D (2019) Platform Policing and the Real-Time Cop. Surveillance E Society 17(1-2): 69-75. 


\section{Index}

\section{9/11 176}

Aargau 6-7, 9, 136-137, 211

acceptability $21,62,82,107,109-110$, $128,153,155,178,189,220$

accountability 11, 15, 46, 51, 97, 103, 112,

152, 187-188, 196-199, 207, 221-222

actionability $4,8,14,20$

agenda 15, 23, 55, 90, 158, 165-167, 183, 209, 210, 214

amendment 9, 13, 62, 81, 82, 88-90, 99, 125-126, 145

analyst $9,13-15,34,49,61,77-82$,

84-87, 90, 94-95, 100-104, 106-108,

$110,116,124-125,128-130,142$,

152, 155, 172, 197-198, 207, 209, 213,

215-216, 218, 221-222

anti-trigger 33, 99-100, 109, 112, 175

app 136, 212

applied research 28

architecture 85, 172, 213, 215, 217-219

arrest $8,29,50,109,112,147,153,173$,

176, 182, 191, 194

artifact 3, 119, 209

artificial intelligence 3, 35, 52, 214

assemblage 9, 20, 44, 48, 55, 148, 189, 218

Atlanta 33

audience 14, 116, 120-121, 125, 130, 134, 136, 145

Austria 9

automation $2,8,13,52-53,88,94-100$, 104, 107-108, 112-113, 197, 207, 222 awareness 1, 3, 11, 26, 55, 69, 70, 76-77,

81, 85-87, 89-90, 95-96, 103, 108,

123-124, 135, 137-138, 141, 160, 173,

197, 208, 221, 223

Azavea 34

Baden-Württemberg 7, 164, 180, 182, 217 Basel-Land 6, 7
Bavaria 6, 7, 169, 219

Berlin 7

Beware (software) 30

bias 15, 27, 49, 97, 107-108, 172, 187-192, 199, 209, 222; algorithmic 50; automation 97, 107-108; selection 172

Big Data 3, 19, 21, 30, 34-35, 56, 74, 185, 222

black-boxed 13, 52, 97, 107, 113, 155, 187, 197, 222

Boston 28

Brandenburg 7

Bratton, William 28

budget 3, 6, 25-26, 96, 102, 105-106, 149, 167-168

Bulgaria 158

Bundesland 122

Bureau of Justice Assistance (BJA) 27-28, 37,56

business logic 27

career path 36, 48, 49, 154, 213

case file management database 83-84

CCTV 46

chain of command 145

chain of communication 121-123

chain of translation $4,45,61,63,178,181$

checklist 77, 110-112

Chicago 29

civil liberties 2, 11, 15, 29, 186-189, 199, 209, 221, 223

classification 13, 62, 72-73, 77-80, 82, 84, 101, 103, 109, 159, 190, 222

cognition 99, 113, 197

Coleman boat 12

collective liability 29; see also liability

commercial 1, 7, 35, 165, 168, 207-209, 213, 216, 217, 222

community engagement 135, 160, 173

companies 3, 19, 30, 47, 51, 57, 88, 105, 139-140, 198, 202, 207, 213, 219-220 
COMPSTAT 13, 24-25, 50, 151

contingency 120, 176-177, 183, 208

cost-benefit analysis 56

costs $8,56,96,167,175,177,207$,

211, 217

counterterrorism 28, 30, 97, 219

craft 14, 117, 120, 124-126, 128-129,

150-153, 160, 208

crime mapping 5, 19-20, 22-26, 66, 118, 125, 201-202

crime scene $1,2,4,13,70,75-82,84,89$, 190, 207

criminal justice 5, 21, 23, 27-29, 187

critical algorithm studies 189

critical data studies 73

crystal ball 170

\section{danger zone 159, 193}

data: creation 4, 70, 74, 90; crime 2, 4, 8 , $13,15,19,32,57,62,69-73,75-83$, 85, 87-90, 99-103, 118, 190-191, 199, 211-213, 216, 219; data-driven 1, 3, 11-12, 15, 20-21, 26-27, 34, 48, 187, 209-210, 214, 220-221; datafication 11, 15, 70, 209-210, 214, 218, 220; production $61,73,77-78,90,99,103$, $113,191,222$; quality $78,83,85,90,99$, 101, 103; raw 75; science 48

decision-making 13, 47, 70, 96-98, 103, 107, 110, 113, 149-151, 156, 160, 187-188, 192, 196-199, 216, 221 design $9,15,19,51,54-57,59,74,80,85$, 95, 97, 100, 117, 127, 130, 133, 138, 150, 173, 186, 189, 198, 209, 213

deterrence 2, 29, 147, 194

deviance 14, 146, 151, 158, 161, 192, 199, 206-207

discourse $5,6,30,55,73,120,166$

discretion 14, 16, 116, 122, 149-152, 160, 197, 223

discrimination 5, 14, 29-30, 50, 97, 112,

139, 159, 192, 198, 207, 221

displacement 174-175

dissemination 2, 14, 87, 103, 107, 116, 122-124, 130-131, 134, 178, 210, 217

DNA 44, 46-47, 153

domestic burglary 8, 70, 77, 166, 169, 190, 215-219

domestic violence 71

drilling 76

drug testing 47

Eastern Europe 158, 176, 194

ecological contamination 159, 193 effectiveness $8,12,22-27,32,35,51,70$, 73, 85, 96, 110, 117-118, 136-138, 147, 149, 151-152, 157, 165, 169, 173, 179, 181, 187-189, 194-195, 198, 209, 211

efficiency $8,25,27,46-47,50-51,56-57$, $70,102,113,147,150-152,157$

emergency call 75, 84, 148-149

environmental criminology 24,85

ethics $3,5,10,13,15,30,55,60,97,172$, 174, 186-187, 199

European Police Congress 214

European Union 40, 114, 174, 202

evaluation 9, 12, 14, 29-30, 49-50, 100-103, 106, 109, 122, 145, 150, 152, 164-165, 173, 178, 180-182, 186, 197, 210, 219

experiment $6,7,21,27,45,56-59,63$, $83,88,164-165,168,172,174,182$, 209, 217

extremism prevention 28,30

Facebook 137

facial recognition 46

failure $37,46,51,59,63,166,188$

false positive 30

fearmongering 138-139

fear of crime 118, 167

feedback loop 188, 190-191

financial crisis 27

fingerprinting 47

fixed-point system 148

forensics 44-49, 76, 82

France 158

freedom 29, 34, 130, 138, 145, 221

free text 79-80, 84, 216

functionality $44,58,121,182,214-219$

funding 55

GIS 8, 24, 118, 217

Gotham (software) 218

government 7, 75, 165-171, 178-179, 196 GPS 152

grand larceny 78-79

grounded theory 10

gut feeling 3, 109-110, 177; see also instinct

Hamburg 7

handout 123, 132-134, 137, 153, 155, 159

haul $8,33,76,79,81,83,129$

heat list 29; see also Strategic Subject List

(SSL)

hessenDATA 30, 217-219

hierarchy 53, 145 
hinge $3,45,63,99,157,160$

hot spot 12, 22-24, 31, 33, 139, 148-150, 165, 191, 193, 216

human-computer interaction (HCI) 94-99, 112-113

human control 95-98

human rights $3,11,15,29-30,186-189$, 195, 199, 209, 223

HunchLab 34, 36, 216

hype $168-170,214$

\section{IBM 1-2, 207}

IfmPt 6, 9, 69, 100, 102, 214-215

imaginary 5, 9, 47, 51-52, 56, 59, 69-70, $87,89,98,169,220,223$

impartiality 15, 22, 27, 97, 107, 188-189, 199

infrastructure $7,11,34,36,45,54-55$, $60,69,83,165-172,178,181-182$, $210-215,218-219,222$

injustice 187, 198

innovation 3, 12, 21, 23-24, 27, 35, 44, 46-47, 50, 52, 54-57, 63, 107, 112, 167-168, 188, 212; see also pressure

INPOL 212-213

inscription 62, 120, 124, 130-131, 134

instinct 100; see also gut feeling

interface $5,9,57,59,62,80,95,98,100$, 126, 147, 187, 198, 213, 215, 217

interpretive flexibility $120,125,131$, 134,142

interval 86-87, 103

intervening variable 14, 172-173, 183

Intrado 30

intranet 123-124

investigation 13, 20, 22, 30, 47, 73, 75, 81-84, 88, 90, 100, 192

job profile 77, 94, 100-102, 206, 208

Kanton 7, 122, 211

Kent 33

KKPKS 211-212

KLB-operativ 7

KrimPro 7, 179

legitimacy 49, 148

levels of automation (LOA) 94-98

levering 76, 79-80

liability 193-194, 198; see also collective liability

London 33 loop 98, 112, 192; see also feedback loop

Los Angeles 27-28, 33

Los Angeles Police Department (LAPD) 26

Lower Saxony 6-7, 180, 217

machine learning 19, 30, 34-35, 74, 94, 208, 217; see also artificial intelligence map 1, 14, 61-62, 116-120, 124-127, 129-134, 141, 155, 159, 206, 208, 222

marketing 55

MAXQDA 9

media $3,27,52,83,113,135-136$,

165-166, 169-171, 175-176, 214

memo 1, 88, 116-117, 122-133, 137

micromanagement 14, 152

Microsoft 125

Ministry of the Interior 155, 167, 182, 212

Minority Report 113, 170

misconduct 198, 221

misfit 77, 154, 158, 192

modus operandi 8, 33, 76, 79-80, 129, 175

multiplicity $3,25,44,53,104-105,160$,

$164,173,189,220$

municipality 32, 109, 122

narrative $3,21,30,34-35,52,74,96$, 100-102, 130, 177, 188-189, 194, 221

National Crime Analysis 221

National Institute of Justice (NIJ) 27-28, 56

near repeat $7,31-33,71-72,76,85-86$, 95, 100-101, 109, 126-127, 160, 174-175, 215

neutrality 55, 57, 188, 194, 199

New Orleans 33

New York 24, 28

nonhuman 4, 10, 13-14, 44-45, 206, 220

North Rhine-Westphalia 7, 180, 217-218

numbers 15, 26, 74, 95, 105, 112, 129, $139,148,153-156,160,163-168$, 171-172, 174-176, 178-183, 186, 190, 194, 209

objectivity 22, 48, 57, 107, 120, 188, 194 occupational culture see police culture ontology 53, 70-71, 74, 76, 78, 80, 103 operational circle 127,129

operator 13-14, 94-104, 106-113, 117, 122, 124, 126-129, 131, 134, 154, 178, 197, 215

organizational change $12,47,52,55$, 63, 206 
overpolicing 139, 147, 191

oversight 99-100, 103, 107, 113, 198, 208, 211

\section{Palantir Technologies 218}

patrol: car 1-4, 44, 6, 75, 144-149, 153, 156, 206-207; officer 4, 8, 11, 13-15, $20,45,61-62,75,77-80,82,84$, 87, 89-90, 105, 116-117, 120-124, 127-128, 131-134, 142, 145-161, 178, 181, 192-194, 199, 207, 222-223; patrolling 4, 7, 10, 12, 14-15, 19, 31, $58,61,70,87,89,105-106,121,123$, 128, 145-151, 156-158, 160-161, 172-173, 191, 193, 195; routes 133 , 149, 151, 155

pattern 2, 19, 24, 28, 31, 33-35, 56, 71, 96, 99-101, 104, 125, 127, 137, 141, 175, 190, 192, 195, 210-212, 215, 221

Peel, Robert 22

penal pessimism 22, 180

phenomenology 2

PIAV 212-213

pickpocketing 134, 216

pilot study $55,58,180$

plain-clothes 132

planning and operations 1, 14, 122-123, 129-130, 156

platformization 11, 15, 209, 219

police: culture $3,11,14,44,49,63,145$, 149, 151-153, 160, 181, 192, 197, 208-209; organization 3, 5-6, 10-12, $19,21,26,44-47,52-54,60,63,75$, 77, 87-90, 97, 116, 121, 130, 133, 141, 145-146, 149, 154, 181, 195-199, 206-210, 212-214, 220, 223; work 2-3, $5,9,11,19,21,23,25,35,46-48,50$, $60,63,70,73,75,89,116,120,133$, 141, 146, 149-151, 153-154, 160, 166, 181, 187, 194, 208-209, 216, 219, 222

policing: community $12,23,149,160$; disorder 149; evidence-based 48; fire brigade 107, 149, 156, 207; future of 11, 214-220; hot-spot 12, 22-23, 149; intelligence-led 12, 21, 23, 25, 149; problem-oriented 12, 23-24, 149 political climate 167

politicians $3,5-7,9-11,14-15,19$, 21-23, 26, 28, 35, 45-47, 51, 53-57, $60,73,105,118,136,139,165-169$, 171, 179, 182, 189, 207, 209-210, 214, 220, 222 possession of illegal substances 71

PRECOBS 1, 6-9, 33, 59, 76-77, 90, 95, 99, 100, 102, 108-110, 122, 126-129, 132, 153, 156, 164-165, 168, 173-174, 176, 179-180, 182, 187, 211, 213-218 predictive policing: as chain of translation 4, 45, 61-63; definition of 19, 25-26; future of 11, 214-220; history of 19-25; person-based 2, 28-30, 187, 219; place-based 2, 24, 30-35, 76, 113, $187,192,219$; rationale of 27 ; as sociotechnical practice $2-5,10-11$, 55-63, 88, 90

PredPol 27, 33, 69, 76, 90, 216

prejudice 14, 15, 161, 188, 189, 193, 194

PreMAP 7, 164, 180, 181, 217

pressure $19,26,28,35,69,78,99,104$, 149, 151, 165-169, 171, 182-183;

innovation 168; peer 169

prevention: operational $2,100,123,171,222$; situational crime 15, 24, 32, 135, 138, 140 , 160, 195; targeted 14, 19, 29, 180, 211 preventive turn 23

prioritization $11,14,22-23,45,60$, 105-106, 124, 139, 146, 149, 156, 160, $165-169,171,182$

privacy $3,11,19,29,47,51,57,72,76$, 135, 146, 152, 167, 186, 190, 198, 207. 213-214, 220-222

probability $28,59,108-109,177$

probable cause 159, 192

process management database $83-84$

procurement 46, 102, 139, 168, 178, 198, 208, 210, 217

profiling $2,5,6,22,28-30,76,86,161$, 170, 187, 193-194, 207, 216, 219

property damage 82,216

prosecution 191

prototype 59

public communication 135

quality control 70, 81-82, 85-88, 90, 99, 100, 103, 190, 207

quantification $20,26,46-48,50,73,75$, 110, 146, 154, 188, 196, 209, 212, 219

racial profiling 119, 158, 161

racism 14-15, 159, 161, 188, 193, 221

RADAR-iTE 30, 219

randomization 22, 24, 33, 95, 105, 146,

148-150, 158, 172-173, 188 rape 71 
rational choice 177,195

reasonable suspicion see suspicion

recommendation 1, 12, 15, 94, 96, 97, 99-101, 106-109, 117, 122, 129-131, 145, 165, 178, 180, 197, 207, 209, 222

reform 11, 15, 22, 36, 46, 49, 52, 90, 145, 149, 165, 182-183, 209-210, 212-214, 217, 219-220

reliability $61,70,76,81,83,88,99,120$, 131, 172, 190, 213, 215

repeat victimization 7, 24, 126; see also near repeat

reporting $9,52,62,70-73,75-83,87,88$, 102, 107, 109, 122, 129-130, 135-136, 138, 157, 165, 170, 175, 179-181, 190, 192, 210, 216

representation (visual) 6, 9, 13, 24, 75, $78,113,117,119,120-121,125-126$, 128-129, 131-134, 141, 148, 164, 190, 192, 217, 222

residential burglary $7,15,33,56,71-72,76$, 78-79, 86-88, 134, 136, 138-139, 157-158, 164-172, 175-176, 179-183, 190

resistance $13,46,51,63,146,152,171$, 181, 208, 222

rhythm 13, 32, 70-71, 85-90, 105, 208

Richmond 27

risk: production $31,160,188,198$; profiling 2, 6, 28-30, 187, 219 (see also predictive policing, person-based); terrain modeling 33,34

robbery 105, 134, 156, 216

robot 52

Romania 154, 158

routine activity 32,85

Santa Cruz 27

Schengen 176, 194

science $14,21,34,48-50,53-54$, 150-151, 153, 160, 180, 189, 213

Science and Technology Studies (STS) 44-45, 53-55, 57, 60-61, 63, 119

science fiction 2, 52, 170, 221

scientification 19, 21, 50, 151, 220

Second World War 22

self-fulfilling prophecy 192

Serbia 158

ShotSpotter 34, 216

Shreveport 164

situational awareness $26,70,87,208$

SKALA 7, 164, 180-181, 217

social media 135,136 social order 2, 12, 53, 195, 221, 223

sociotechnical 3, 5-6, 10-12, 15, 44-45, 53-57, 59-61, 63, 72, 88-90, 94, 97-98, 105-106, 113, 164, 181, 183, 189, 199, 206, 208-209, 222

speed $8,13,56,69-70,82-83,85,88-90$, 209, 218

speeding 71, 197, 209

SPSS 27

standard 22-23, 25, 48, 50, 55, 74-76, 80, $123,129,149,211,213,220$

standardization 76,79

state of emergency 159

statistics $14,21,25-26,50-51,73$,

78-79, 89, 95, 102, 108, 153, 158, 164, 170-172, 176-180, 183, 195, 197, 208, 213, 215-217

stereotype 119, 161, 193

stigmatization 140, 191-192

Strategic Subject List (SSL) 29; see also heat list success 10, 14-15, 26, 31-32, 51-52,

71, 90, 120, 121, 124-125, 133, 147, 153-154, 157, 165, 171, 173-183, 186, 194-195

supervisor $8,14,81,87,100,120$, $122-124,145,151,154,156$

surveillance 5, 22, 30, 32, 46, 50, 118, 146, 151-152, 170

suspicion $14-15,30,61,98,118,135-136$, 138, 146, 157-159, 161, 188, 192-194, 199, 206-207; generalized 98, 193; reasonable 192-193

Switzerland 1, 6, 7, 9, 15, 48, 56, 83, 139, 146, 152, 165-169, 170, 176, 194, 198, 210-211, 214-216, 218

target hardening 147, 160

technology 2, 10-13, 25-26, 44-47, 49-55, 57-58, 60, 63, 98, 150, 152, $155,166,188,189,208,210,221-222$

technoscience $15,22,47-48,56,89,166$, 168-169, 171, 187-188, 199, 221

temporality $7,11,13-14,31-33,58,69$, 70, 86-89, 112, 141, 145, 151, 164, 170-171, 175, 190, 195

topography 127, 129, 132-133, 194, 217

traceability 13, 22, 24, 27, 29, 46, 61, 63, 76, 94, 96-97, 117, 126, 146, 150, 152, 165, 196-198

trade-off $13,70,82,83,95,140$

transparency 50, 112-113, 140, 187-188, 196, 198-199, 222 
trigger $7,8,24,33,72,85,99-100,109$, $112,122,126-127,129,132-133,140$, 148, 156, 175, 181, 193, 206, 208, 211, 216,222

trust 23, 98-100, 102-103, 107-108, 139-140, 142, 147, 152, 156, 160 two-way radio $44,148-149$

UK 33

underpolicing 112, 147

uniform 129-130, 146-147, 151, 178, 189 upgrade 174,182

US 2, 6, 22-23, 27-28, 30, 33-34, 56, 137, 180, 218, 222

usability 58

value $30,51,69,71-72,75,78,80,82,84$, $87,89,100,139,168,186,189,190$,

192, 196, 216, 218 variable $14,30,32,44,47,63,72,76$, 79-80, 165, 172-173, 183, 193, 215-216; dependent 172; independent 172,183

violence $2,19,28-30,71,186,221$

visibility $2,32,35,96,125,146-148,153$, 160, 207

visualization 4, 14, 116, 122, 124-126, 128, 130, 131, 133, 145, 155, 181, 208, 215

weather 19, 34, 89, 177, 215

Western Europe 176, 194

window of opportunity 86, 166, 210

work culture see police culture

work schedule 63,87

Yorkshire 33

Zurich 6-7, 9, 169, 182, 217 


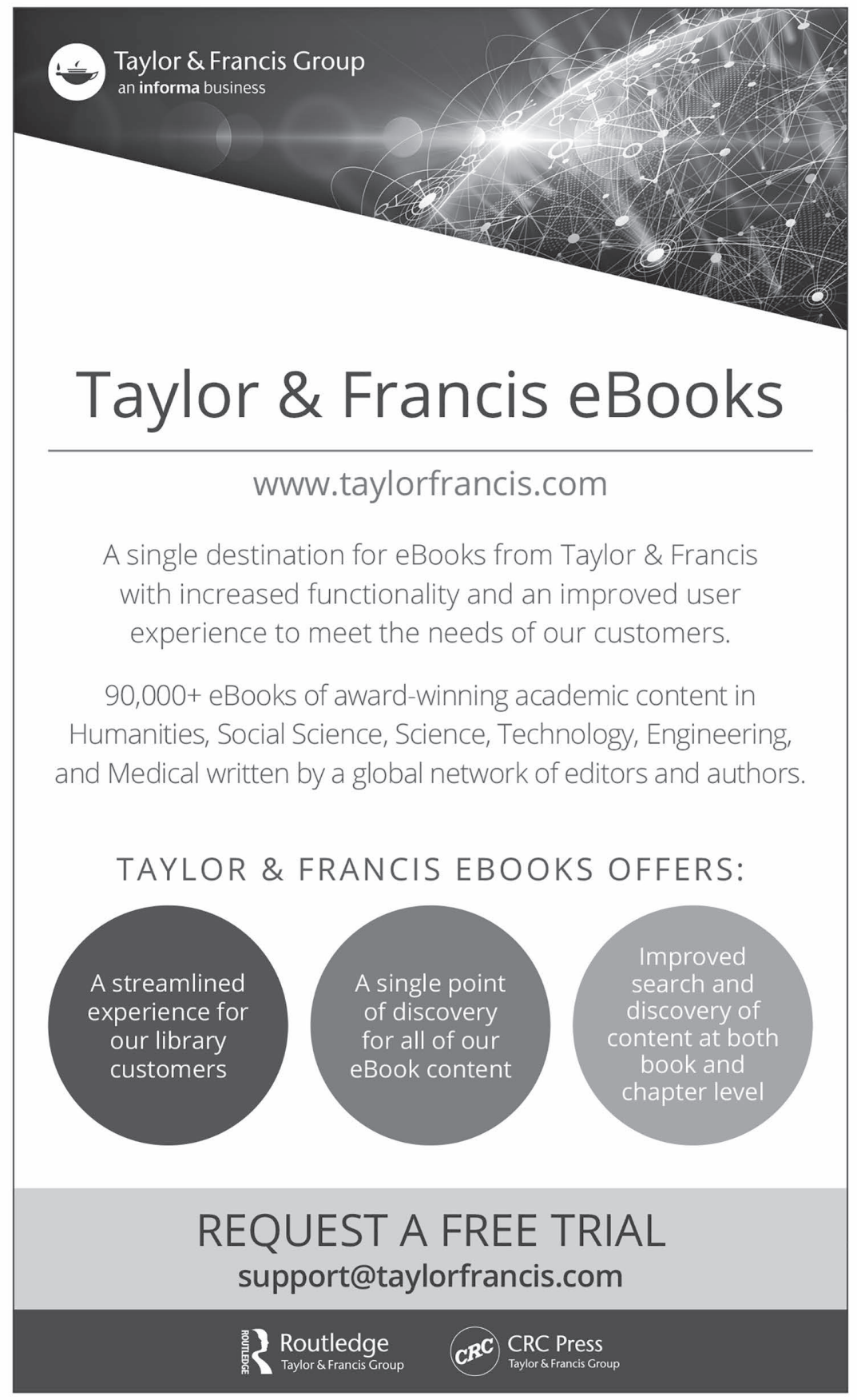

